April $1998 \bullet$ NREL/SR-540-24225 • UC Category: 1504

\title{
Development of a Dedicated Ethanol Ultra-Low-Emissions Vehicle (ULEV): Phase 3 Report
}

L. Dodge, T. Callahan, D. Leone, D. Naegeli, K. Shouse, L. Smith, and K. Whitney

Southwest Research Institute

NREL Technical Monitor: Bill Warnock

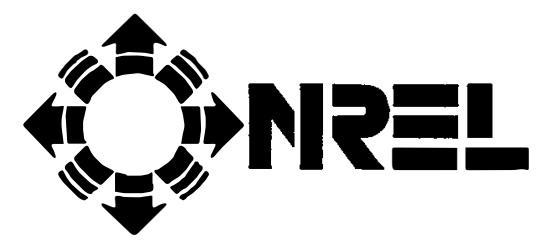

Alternative Fuels Hotline: 1-800-423-1DOE

Alternative Fuels Data Center World Wide Web Site: http://www.afdc.doe.gov

National Renewable Energy Laboratory

1617 Cole Boulevard

Golden, Colorado 80401-3393

A national laboratory of the

U.S. Department of Energy

Managed by the Midwest Research Institute

For the U.S. Department of Energy

Under Contract No. DE-AC36-83CH10093

Prepared under Subcontract Number YAW-3-12243-01

April 1998 
This publication was reproduced from the best available camera-ready copy submitted by the subcontractor and received no editorial review at NREL.

\section{NOTICE}

This report was prepared as an account of work sponsored by an agency of the United States government. Neither the United States government nor any agency thereof, nor any of their emplcyees, makes any warranty, express or implied, or assumes any legal liability or responsibility for the accuracy, completeness, or usefulness of any information, apparatus, product, or process disclosed, or represents that its use would not infringe privately owned rights. Reference herein to any specific commercial product, process, or service by trade name, trademark, manufacturer, or otherwise does not necessarily consitute or imply its endorsement, recommendation, or favoring by the United States govemment or any agency thereof. The views and opinions of authors expressed herein do not necessarily state or reflect those of the United States govemment or any agency thereof.

Available to DOE and DOE contractors from:

Office of Scientific and Technical Information (OSTI)

P.O. Box 62

Oak Ridge, TN 37831

Prices available by calling (423) $576-8401$

Available to the public from:

National Technical Information Service (NTIS)

U.S. Department of Commerce

5285 Port Royal Road

Springfield, VA 22161

(703) 487-4650 


\section{PREFACE}

This work was conducted by Southwest Research Institute (SwRI), San Antonio, Texas, under Subcontract No. YAW-3-12243-1, SwRI Project No. 03-5901 for the U.S. Department of Energy (DoE) in Washington, D.C. and the National Renewable Energy Laboratory (NREL) in Golden, Colorado. The contributions of technical monitors Christopher P. Colucci and Brent K. Bailey of NREL, John A. Russell and John Garbak of DoE, and subcontract administrator Brian Rieper of NREL are gratefully acknowledged. The expertise of Mrs. Susie Schliesing in preparing this report is also greatly appreciated.

The objective of this 3.5-year project is to develop a commercially competitive vehicle powered by ethanol (or an ethanol blend) that can meet Califomia's ultra-low emission vehicle (ULEV) standards and equivalent corporate average fuel economy (CAFE) energy efficiency for a light-duty passenger car application. The definition of commercially competitive is independent of fuel cost, but does include technical requirements for competitive power, performance, refueling times, vehicle range, driveability, fuel handling safety, and overall emissions performance.

This report summarizes the third phase of this project, which lasted 12 months. This report discusses emissions tests with advanced aftertreatment devices conducted on one of the two, nominally identical, test vehicles, a 1993 Ford Taurus flexible fuel vehicle. The report also discusses tests on the engine removed from the second Taurus vehicle. This engine was modified for an increased compression ratio, was fitted with air-assist injectors, and included an advanced engine control system with model-based control. 


\section{EXECUTIVE SUMMARY}

Automotive technology for reducing emissions to very low levels, including California's ultra-low emissions vehicles (ULEV) standards, has advanced significantly over the last few years. This project to develop a dedicated ethanol-blend-fueled vehicle has allowed the application of many of these state-of-the-art technologies on the demonstrator vehicle. These technologies have been developed and tested individually, but the integration of these technologies will be completed in Phase 4 of this project and will be reported later. However, the details of the individual technologies and test results are reported in this Phase 3 report.

SwRI obtained two 1993 Ford Taurus flexible fuel vehicles for supporting development and test work on this project. One vehicle was used for engine development, and the other for advanced aftertreatment development. The engine was removed from the first vehicle, and several modifications were accomplished. As reported previously, the compression ratio was increased from 9.25 to 11.0 by reducing material from the cylinder heads and block, and installing new pistons. Airassist injectors were developed and installed. These injectors were modified during this third phase of the project, to improve fuel delivery characteristics. An improved crank angle sensor based on one found in some GM vehicles was installed. Also, the standard idle air control (IAC) and exhaust gas recirculation (EGR) valves were replaced with valves that included pintle position sensors in order for valve position to be more accurately determined and controlled. A differential pressure sensor was installed across the throttle plate to estimate air flows into the intake manifold. Finally, these other modifications required that the standard engine controller be replaced with an SwRI developed full-authority engine controller, and that complete engine control algorithms be developed and implemented.

To control the Ford Taurus 3.0-liter engine, model-based controls for both air and fuel flow were developed. The air flow model estimates air flow into the intake manifold based on throttle position and pressure drop across the throttle, IAC position and pressure drop, air-assist injector pressure drop, PCV pressure drop, and the EGR valve position and pressure drop. Air flow out of the intake manifold is based on speed-density calculations. The difference in air flows is used to compute intake manifold absolute pressure (MAP) that is used along with the MAP sensor to estimate the true MAP accurately and quickly. Fuel flow into the cylinders includes a model for wall wetting that depends on engine temperature and engine operating conditions. Besides model-based control, a number of specialized algorithms were used to control certain parts of the engine cycle. For example, cylinder-event-based logic was used during cranking and startup to allow customized amounts of fuel injection and spark timing for each cylinder event. Closed-loop operation allows model-based control of switching frequency, and adjustable control bands for the air-fuel (A/F) ratio.

The engine-out exhaust emissions have been measured for the engine modified as described, and start-ups, steady-state operation, and transient operation including the transition from a cold to warm engine appear to be very good. Reinstalling the engine in the vehicle will be necessary before full U.S. Federal Test Procedure (FTP) emissions can be measured. 
The second 1993 Ford Taurus flexible fuel vehicle was used for tests of several advanced aftertreatment devices. These tests were conducted with the standard engine since engine tests were being conducted in parallel with the aftertreatment work. The aftertreatment devices included electrically heated catalysts (EHC), a hydrocarbon adsorber, and a combination adsorber/catalyst (adcat). Of these advanced aftertreatment systems, the EHC produced the lowest emissions. Without making any changes to the engine, the EHC system using a W.R. Grace catalyst followed by a Degussa main catalyst produced ULEV emissions for CO and $\mathrm{NO}_{\mathrm{x}}$, with close to ULEV emissions for nonmethane organic gases (NMOG). These results are summarized below.

\begin{tabular}{|c|c|c|c|}
\hline & NMOG* $^{*}(\mathrm{~g} / \mathrm{mi})$ & $\mathrm{CO}(\mathrm{g} / \mathrm{mi})$ & $\mathrm{NO}_{x}(\mathrm{~g} / \mathrm{mi})$ \\
\hline This project** & 0.052 & 0.8 & 0.068 \\
\hline ULEV*** & 0.04 & 1.7 & 0.2 \\
\hline \multicolumn{4}{|c|}{$\begin{array}{l}\text { * Estimated. Full speciation not performed. } \\
* * \text { Measured at } 4,000 \text { miles } \\
* * * \text { At } 50,000 \text { miles }\end{array}$} \\
\hline
\end{tabular}

Another approach for advanced aftertreatment, called rapid exhaust port oxidation (REPO), is to operate the engine rich after starting and to introduce air from an external pump into the exhaust ports to provide combustion in the exhaust manifolds. This results in both an addition of heat to bring the catalyst(s) up to operating temperature quickly, and to burn up some of the hydrocarbons and $\mathrm{CO}$ that would normally be present at the entrance of the catalyst. This can be combined with the original equipment manufacturer (OEM) catalysts that are located on each of the two exhaust manifolds of the V-6 engine just below the engine. This reduces heat losses that occur in the longer exhaust piping associated with an underfloor catalyst. The engine control system has been modified for control of the engine $\mathrm{A} / \mathrm{F}$ ratio and the air pump control valve to achieve efficient combustion in the exhaust. By combining the modified engine with one or more of the advanced aftertreatment devices, ULEV emissions should be demonstrated.

In a separate project with similar objectives (SwRI Project 08-6068, "Determination of Altemative Fuels Combustion Projects,"), SwRI tested the effectiveness of NREL's Vacuum Insulated Catalytic Converter. Operating on Ed85 in the baseline vehicle used on this project, emissions tests were performed after extended vehicle preconditioning for various soak periods. Compared to a similar but uninsulated catalyst, reductions of more than 90 percent were observed for $\mathrm{HC}$ and $\mathrm{CO}$ emissions, and 75 percent for $\mathrm{NO}_{\mathrm{x}}$ emissions for soak periods of 18 to 24 hours. These emissions would meet ULEV requirements, but the extended preconditioning is outside of the normal test procedure. The extended vehicle preconditioning was required to obtain complete conversion of the phase-change material used to help maintain heat in the catalyst.

Durability tests were conducted with both the fuel pump. and fuel injectors used in the demonstrator vehicle. Operating on neat ethanol (E-100), the injectors survived a 900-million injection cycle test as specified by the Society of Automotive Engineers (SAE) Recommended Practice J1832. At the end of this test, there was no measurable injector leakage in any of the six 
injectors, and the calibrations had not changed since the beginning of the test. It was assumed that E-100 would be at least as hard on the injectors and pump as Ed85, so tests were not conducted with Ed85. However, this may not always be an accurate assumption. Engines being operated by one U.S. OEM on Ed85 have suffered severe injector wear. That OEM suspects elevated fuel temperatures may be associated with the severe wear. The tests reported here were conducted with fuel maintained at $20^{\circ} \mathrm{C}$ as called for in Society of Automotive Engineers (SAE) J1832 specification. 


\title{
LIST OF ABBREVIATIONS
}

\author{
Abbreviation Description \\ adcat adsorber/catalyst \\ ADS adsorber \\ ASTM American Society for Testing and Materials \\ BMEP \\ CAD \\ brake mean effective pressure \\ cfm \\ crank angle degrees \\ cubic feet per minute \\ DSP \\ E100 \\ digital signal processor \\ Ed85 \\ ECT \\ EGR \\ $100 \%$ ethanol \\ EHC \\ $85 \%$ denatured ethanol, $15 \%$ gasoline, but denaturant was $5 \%$ gasoline \\ engine coolant temperature \\ exhaust gas recirculation \\ $\epsilon$ \\ electrically heated catalyst \\ epsilon (fraction of fuel that behaved like a vapor and entered the cylinder on the first \\ intake event following injection) \\ FID flame ionization detector (for hydrocarbons) \\ FFI fast flame ionization detector \\ FFV flexible fuel vehicle \\ FTP \\ GUI \\ U.S. Federal Test Procedure (light-duty, for emissions testing) \\ HEGO \\ IAC \\ graphical user interface \\ IMEP \\ heated exhaust gas oxygen \\ $\mathrm{kPa}$ \\ idle air control \\ $\mathrm{kPag}$ \\ LED \\ LEV \\ indicated mean effective pressure \\ kilopascal \\ kilopascal per gauge \\ light emitting diode \\ low-emission vehicle \\ LFE \\ MAF \\ laminar flow element \\ MAP \\ $\mu \mathrm{m}$ \\ mass air flow \\ manifold absolute pressure \\ MBT \\ $\mathrm{ms}$ \\ micrometer \\ minimum timing advance for best torque \\ milliseconds \\ NMOG \\ $\mathrm{NO}_{\mathrm{x}}$ \\ nonmethane organic gases \\ oxides of nitrogen \\ NREL \\ OEM \\ PC \\ National Renewable Energy Laboratory \\ original equipment manufacturer \\ ppmC \\ psia \\ PW \\ personal computer \\ parts per million carbon \\ absolute pounds per square inch \\ pulse width \\ PWM \\ pulse width modulated
}




\section{LIST OF ABBREVIATIONS (Cont'd)}

$\begin{array}{ll}\text { REPO } & \text { rapid exhaust port oxidation } \\ \text { RPECS } & \text { rapid prototyping engine control system } \\ \text { rpm } & \text { revolutions per minute } \\ \text { SAE } & \text { Society of Automotive Engineers } \\ \text { SI } & \text { spark ignition } \\ \text { SMD } & \text { Sauter mean diameter } \\ \text { SwRI } & \text { Southwest Research Institute } \\ \tau & \text { tau (time constant for the remaining fuel) } \\ \text { TDC } & \text { top-dead-center } \\ \text { TPS } & \text { throttle position sensor } \\ \text { UEGO } & \text { unheated exhaust gas oxygen } \\ \text { ULEV } & \text { ultra-low emission vehicle }\end{array}$




\section{TABLE OF CONTENTS}

Page

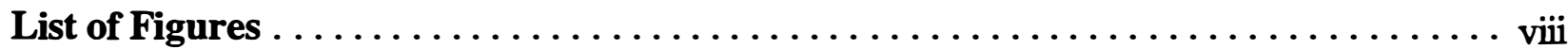

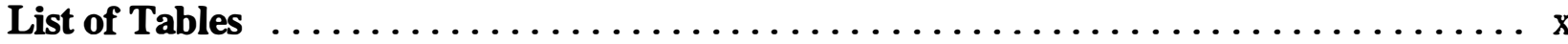

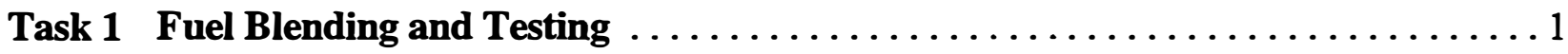

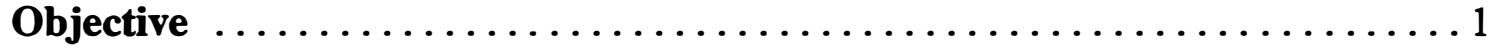

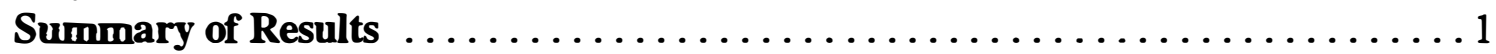

Task 2 Fuel Storage and Handling System Design $\ldots \ldots \ldots \ldots \ldots \ldots \ldots \ldots \ldots \ldots$

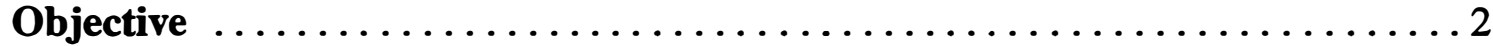

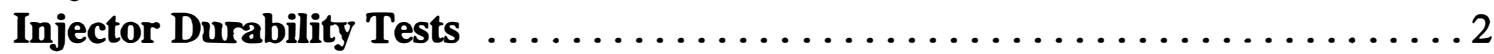

Task 3 Engine System Assembly and Testing $\ldots \ldots \ldots \ldots \ldots \ldots \ldots \ldots \ldots \ldots$

Task 5 Fuel/Engine/Vehicle System Integration $\ldots \ldots \ldots \ldots \ldots \ldots \ldots \ldots \ldots \ldots$

Task 6 Integrated Fuel/Engine System Optimization $\ldots \ldots \ldots \ldots \ldots \ldots \ldots \ldots \ldots$

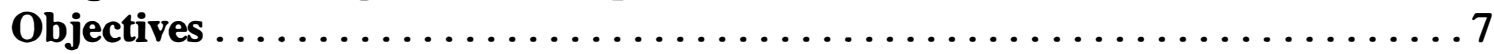

Improvement in Air-Assist Injectors $\ldots \ldots \ldots \ldots \ldots \ldots \ldots \ldots \ldots \ldots \ldots$

Installation of the Rapid Prototyping Engine Control System . . . . . . . . . 21

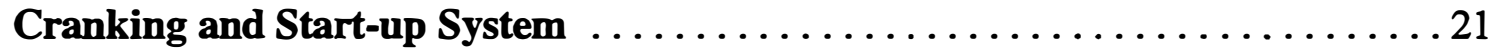

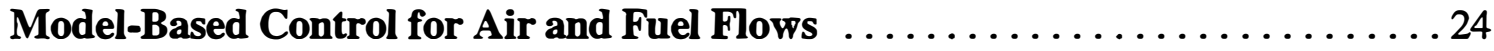

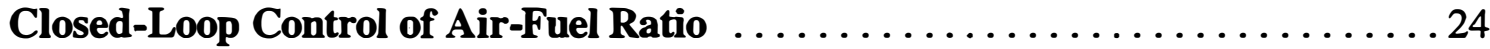

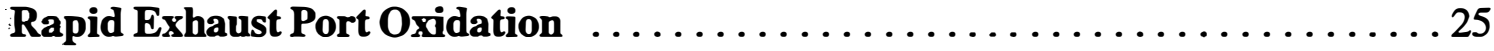

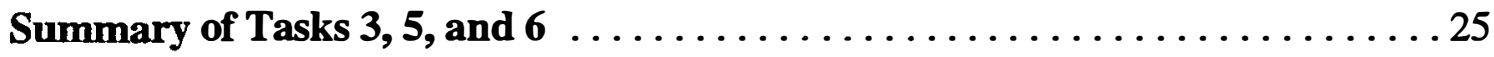

Task 4 Emissions Control System Development and Testing $\ldots \ldots \ldots \ldots \ldots \ldots \ldots \ldots$

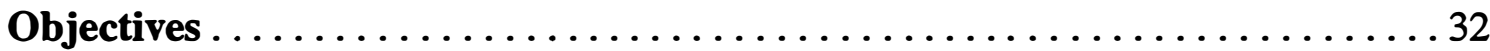

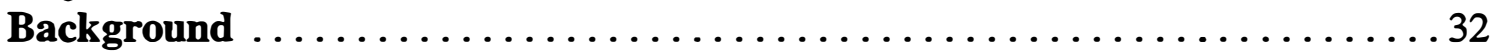

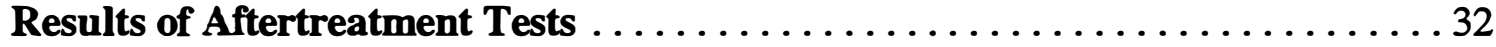

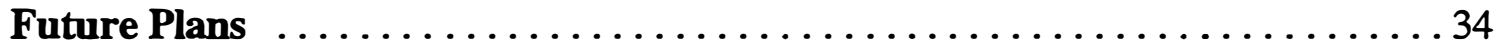

Task 7 High-Speed Data Acquisition and Control $\ldots \ldots \ldots \ldots \ldots \ldots \ldots \ldots \ldots$

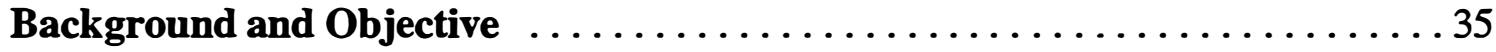

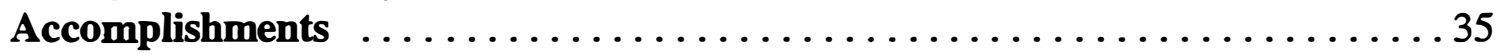

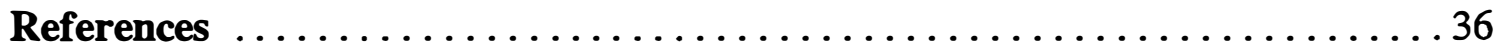

APPENDIX A: $\quad$ SAE PAPER, MODEL-BASED CONTROL AND

CYLINDER-EVENT-BASED LOGIC FOR A

LOW-EMISSIONS VEHICLE

APPENDIX B: $\quad$ TEST RESULTS 


\section{LIST OF FIGURES}

Figure

Page

2-1 SCHEMATIC OF INJECTOR DURABILITY TEST STAND . . . . . . . 3

2-2 SEAT LEAKAGE TEST APPARATUS $\ldots \ldots \ldots \ldots \ldots \ldots \ldots \ldots$

2-3 FUEL INJECTOR DURABILITY TEST RESULTS, E100 (NEAT ETHANOL) STATIC AND DYNAMIC FLOW RATES VERSUS

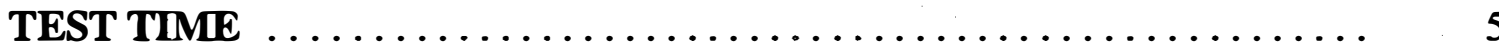

3-1a-b STEADY-STATE AF RATIO FOR TAURUS ENGINE, Air-Assist Injector, with Screens, $70 \mathrm{kPag}, \mathrm{ECT}=32^{\circ} \mathrm{C}$,

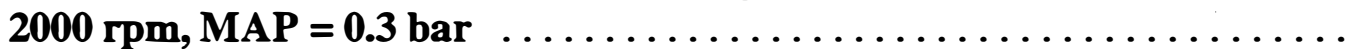

3-1c-d STEADY-STATE AF RATIO FOR TAURUS ENGINE, Air-Assist Injector, with Screens, $70 \mathrm{kPag}, \mathrm{ECT}=32^{\circ} \mathrm{C}$, 2000 rpm, MAP = 0.7 bar

3-1e-f STEADY-STATE AF RATIO FOR TAURUS ENGINE, Air-Assist Injector, with Screens, $70 \mathrm{kPag}, \mathrm{ECT}=82^{\circ} \mathrm{C}, 2000 \mathrm{rpm}$, MAP = 0.3 bar .

3-1g-h STEADY-STATE AF RATIO FOR TAURUS ENGINE, Air-Assist Injector, with Screens, $70 \mathrm{kPag}, \mathrm{ECT}=82^{\circ} \mathrm{C}$, 2000 rpm, MAP $=0.7$ bar

3-2a-b STEADY-STATE AF RATIO FOR TAURUS ENGINE, OEM Pintle Injectors, ECT $=32^{\circ} \mathrm{C}, 2000 \mathrm{rpm}, \mathrm{MAP}=0.3 \mathrm{bar}$

3-2c-d STEADY-STATE AF RATIO FOR TAURUS ENGINE, OEM Pintle Injectors, ECT $=32^{\circ} \mathrm{C}, 2000 \mathrm{rpm}, \mathrm{m}=0.7 \mathrm{bar}$

3-2e-f STEADY-STATE AF RATIO FOR TAURUS ENGINE, OEM Pintle Injectors, ECT $=82^{\circ} \mathrm{C}, 2000 \mathrm{rpm}, \mathrm{MAP}=0.3 \mathrm{bar}$

3-2g-h STEADY-STATE AF RATIO FOR TAURUS ENGINE, OEM Pintle Injectors ECT $=82^{\circ} \mathrm{C}, 2000 \mathrm{rpm}, \mathrm{MAP}=0.7$ bar $\ldots \ldots \ldots \ldots$

3-3a-b STEADY-STATE AF RATIO FOR TAURUS ENGINE,

Redesigned, Sleeved Air-Assist Injector, $70 \mathrm{kPag}, \mathrm{ECT}=32^{\circ} \mathrm{C}$, 2000 rpm, MAP = 0.3 bar 


\section{LIST OF FIGURES (Cont'd)}

Figure

Page

3-3c-d STEADY-STATE AF RATIO FOR TAURUS ENGINE,

Redesigned, Sleeved Air-Assist Injector, $70 \mathrm{kPag}, \mathrm{ECT}=32^{\circ} \mathrm{C}$,

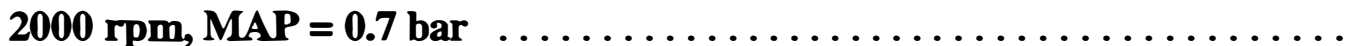

3-3e-f STEADY-STATE A/F RATIO FOR TAURUS ENGINE,

Redesigned, Sleeved Air-Assist Injector, $70 \mathrm{kPag}, \mathrm{ECT}=82^{\circ} \mathrm{C}$,

$2000 \mathrm{rpm}, \mathrm{MAP}=0.3 \mathrm{bar}$

3-3g-h STEADY-STATE AF RATIO FOR TAURUS ENGINE,

Re-Designed, Sleeved Air-Assist Injector, $70 \mathrm{kPag}, \mathrm{ECT}=82^{\circ} \mathrm{C}$,

2000 rpm, MAP = 0.7 bar

3-4 SMD VERSUS AIR PRESSURE SMALL VOLUME

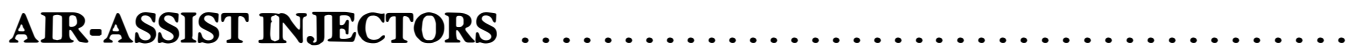

3-5 AMBIENT TEMPERATURE $27^{\circ} \mathrm{C}\left(80^{\circ} \mathrm{F}\right) \mathrm{COLD} \mathrm{START} \mathrm{SHOWING} \mathrm{NO}$ MISFIRES AND VERY LOW HYDROCARBON EMISSIONS.

(Two cycles of motoring preceding beginning of fuel injection.) . . . . . . .

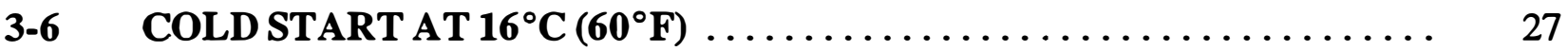

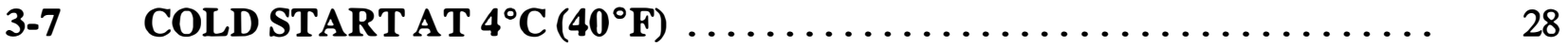

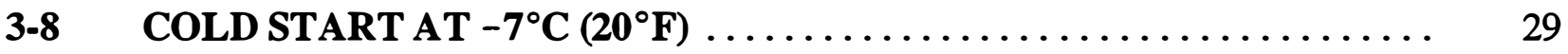

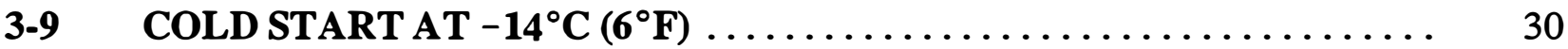

3-10 CATALYST FRONT-FACE TEMPERATURE RISE AND AFTERCATALYST HYDROCARBON EMISSIONS USING REPO

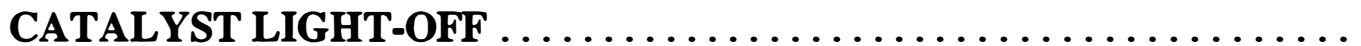




\section{LIST OF TABLES}

Table

Page

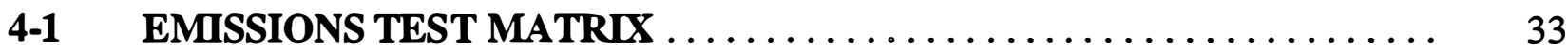

4-2 FTP EXHAUST EMISSIONS FROM FFV TAURUS ON Ed85 ........ 33

4-3 COMPARISON OF HYDROCARBON EMISSIONS WITH EHC . . . . . 33 


\section{TASK 1: FUEL BLENDING AND TESTING}

\section{Objective}

The objective of Task 1 was to determine the effects of ethanol fuel additives on fuel tank flammability, corrosion, wear, and lubricity.

\section{Summary of Results}

The work in Task 1 was completed in Phases 1 and 2 of this project. The only continuing work in this task is supplying fuel for other phases of the project. Highlights of the results of this phase that were previously reported are as follows.

- The octane number of the ethanol blend Ed85 (85\% denatured ethanol, $15 \%$ winter grade gasoline, and a denaturant of 5\% gasoline) was measured as 104.8 research, 99.3 motor, to give an $(\mathrm{R}+\mathrm{M}) / 2$ of 102.1 .

- Vapor pressures of the neat ethanol, the reference gasoline, and 12 ethanol blends containing two concentration levels of gasoline, butane, pentane, isopentane, C5-C6 isomerate, and diethyl ether, were measured at several temperatures in the $-14.4^{\circ} \mathrm{C}$ $\left(6^{\circ} \mathrm{F}\right)$ to $54.4 \mathrm{C}\left(130^{\circ} \mathrm{F}\right)$ range. The data were correlated according to the ClapeyronClausius equation to give a set of constants for each fuel, which could be applied to a general equation to calculate vapor pressure.

- $\quad$ Both upper and lower flammability limits were measured, and compared with flammability limits predicted from vapor pressure measurements. Except for the ethanol-diethyl ether blends, flammability limit data from the literature and flammability limits of the fuel blends predicted from the vapor pressure data appeared to be consistent. For the most part, flammability limits of the fuel blends could be predicted with reasonable accuracy from vapor pressure data and literature values of the flammability limits of the fuel components. 


\section{TASK 2: FUEL STORAGE AND HANDLING SYSTEM DESIGN}

\section{Objective}

The objective of this task was to evaluate material compatibility issues and specifically to examine ethanol-related wear in fuel injectors.

\section{Injector Durability Tests}

One area that has concerned U.S. original equipment manufacturers (OEM) with Ed85-fueled vehicles is injector wear problems. Field and engine tests have shown problems using some injector designs. For that reason, durability tests were conducted with six Nippon Denso injectors used as original equipment in the 1993 Ford flexible fuel vehicles. The fuel injectors were identified, injector no. F3DE-A2C, F3DZ-9F593-AFFV, CM-4753, 2561-272.

Evaluation of the fuel injector durability was performed in accordance with SAE J1832. The performance criteria to evaluate the injector performance are the nozzle flow rate and the seat leakage. A schematic of the durability test rig is shown in Figure 2-1. A Ford fuel rail was used to mount six injectors on a 5-gallon fuel container. A standard fuel pump used in the FFV was used to recirculate the fuel and to supply the fuel rail with $270 \mathrm{kPa}$ gauge fuel pressure. A heater and heat exchanger were used to control the temperature of the test fuel. An injector driver box was used to energize the injectors.

The seat leakage test was performed by using the following procedure. The injectors were cleaned by supplying the injectors with heptane at $270 \mathrm{kPa}$ gauge ( $39 \mathrm{psig})$ and running the injectors for 10,000 injections at a pulse width (PW) of $5 \mathrm{~ms}$ and a period of $10 \mathrm{~ms}$. The injectors were then dried with nitrogen in a similar manner for 6,000 injections with the tip pointed down and 6,000 injections with the tip pointed up. The seat leakage tests were then conducted by placing the injector in the apparatus shown schematically in Figure 2-2. Nitrogen was supplied to the nozzle at $270 \mathrm{kPa}$ gauge and any leakage was captured in the graduated cylinder filled with mineral oil. The leakage was recorded for a 5-minute period.

The static and dynamic flow rates were determined gravimetrically using injector calibration fluid and spraying into a container of known weight. For the static flow rate, the injector was energized continuously for a period of 30 seconds. After 30 seconds, the container was weighed to determine the mass of test fluid injected.

The dynamic flow rate measurement was also gravimetric using injector calibration fluid. The injector was supplied with $270 \mathrm{kPa}$ gauge fluid pressure and was energized intermittently using a pulse width of $5 \mathrm{~ms}$ and a period of $10 \mathrm{~ms}$ for a duration of 1,000 injections. The injected fluid was collected in a container and weighed to determine the mass injected.

A total of 1124 hours were accumulated on the injectors representing approximately 800 million injections. The results for the static and dynamic flow rates are shown as a function of test time in Figure 2-3. The plot shows the average of the six test injectors and a control injector with a error bar representing \pm one standard deviation. 


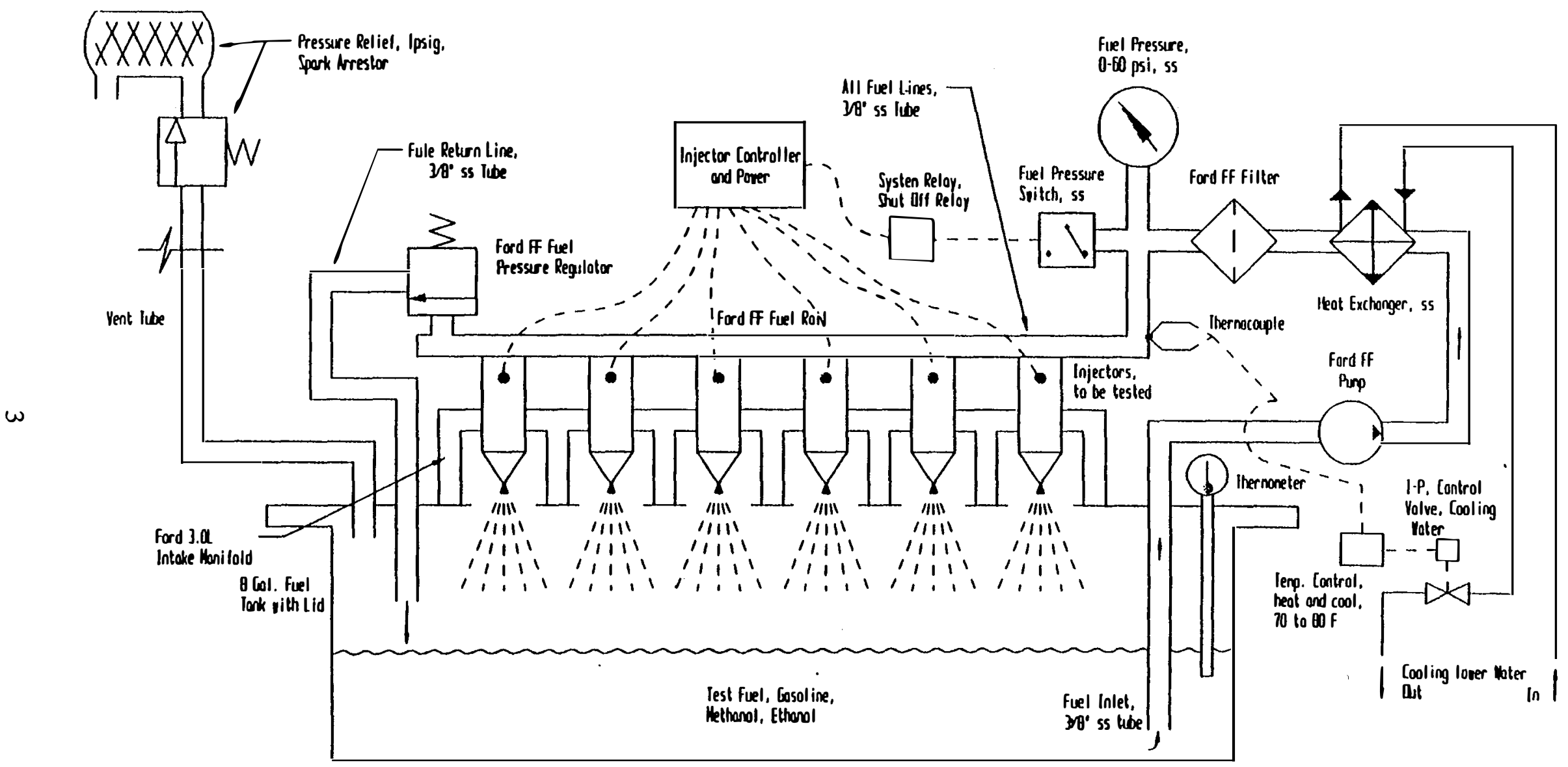

FIGURE 2-1. SCHEMATIC OF INJECTOR DURABILITY TEST STAND 


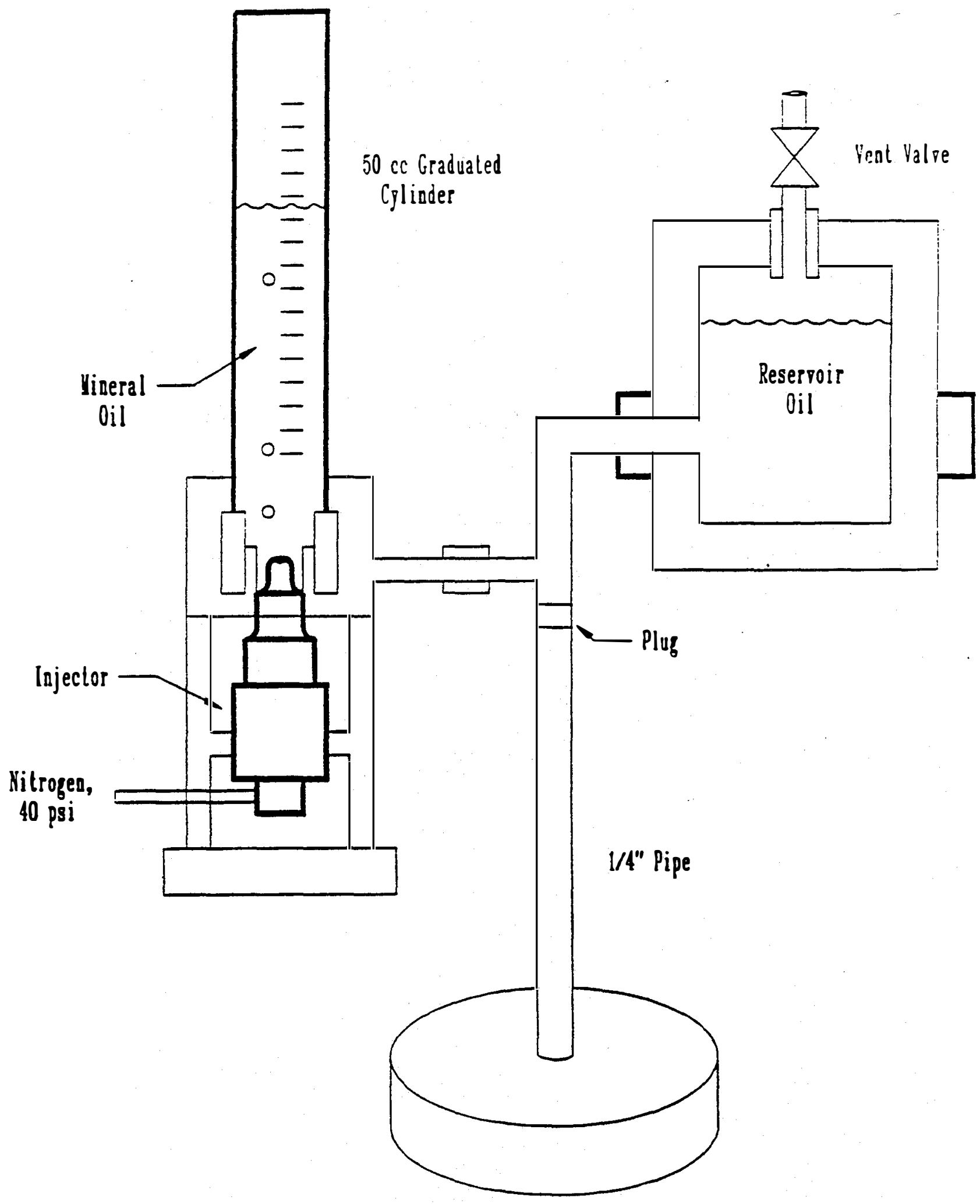

FIGURE 2-2. SEAT LEAKAGE TEST APPARATUS 


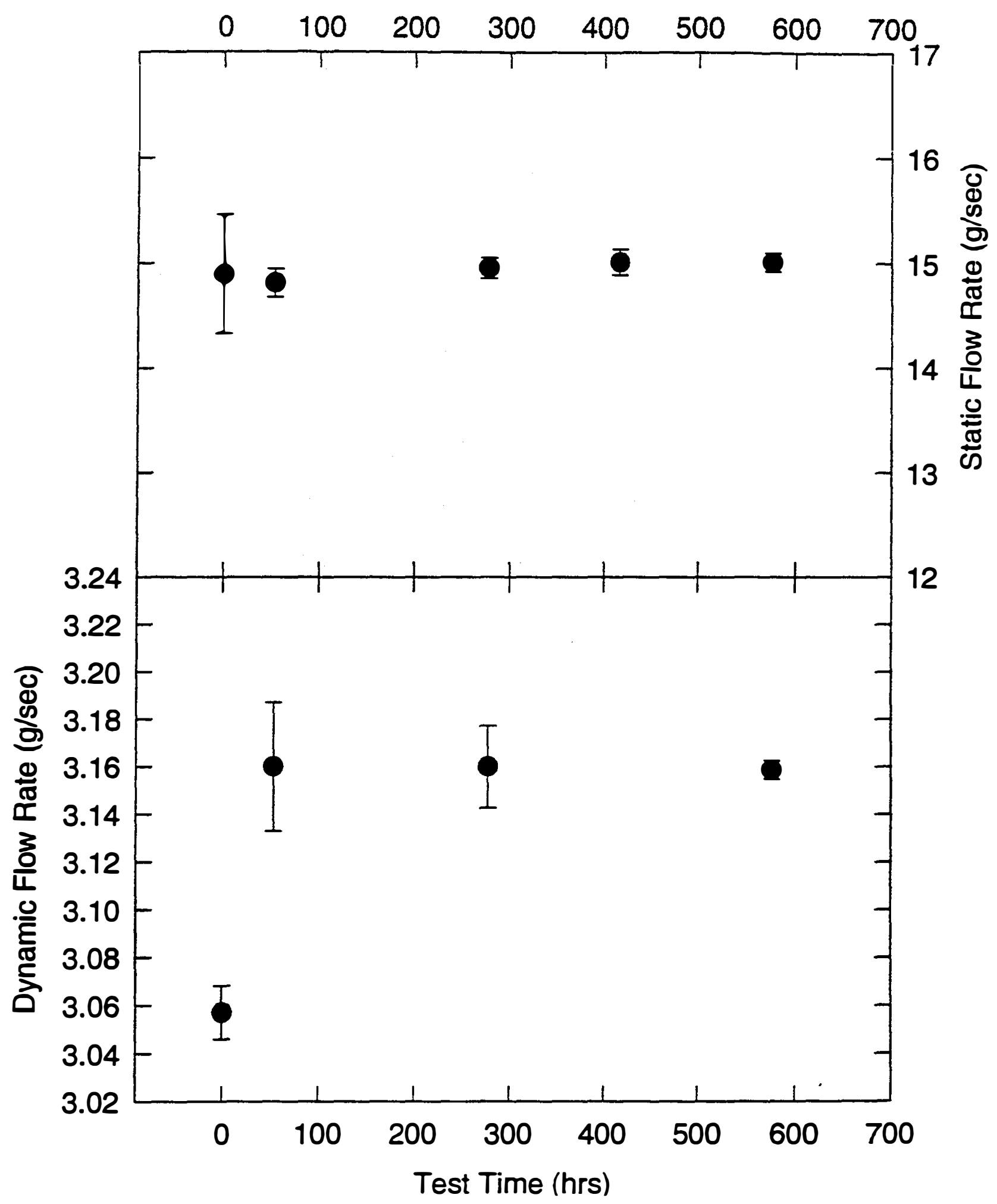

FIGURE 2-3. FUEL INJECTOR DURABILITY TEST RESULTS, E100 (NEAT ETHANOL) STATIC AND DYNAMIC FLOW RATES VERSUS TEST TIME 
For the static flow rate test, there was a shift in the measured values at the start of the testing (time 0 ) and the measured values after testing had begun (time $>0$ ). This shift is attributed to a modification of the test procedures. The initial test was performed with a hand held stop watch, while the remaining tests were performed with an automatic timer. The procedure requires the injectors to be flowed for a period of 30 seconds. A one second difference between the two timing methods would result in a 3-percent difference in fuel mass. The shift observed in the measured values was approximately 3 percent. With the exception of the initial shift in static flow, there did not appear to be significant changes in either the dynamic or the static flow of the injectors.

The seat leakage was also measured for all of the injectors throughout the test. The initial test indicated that two out of the six test injectors and the one control injector had measurable seat leakage levels. One injector had a seat leakage value of $1.0 \mathrm{cc} / \mathrm{min}$ and a second injector had a value of $0.5 \mathrm{cc} / \mathrm{min}$. Both of these injectors were within the acceptable leakage limit of $1.5 \mathrm{cc} / \mathrm{min}$. The remaining injectors had no measurable leakage. It was interesting to note that after 53.8 hours of testing (approximately 38 million injections), all injectors had a negligible level of seat leakage, indicating that a small amount of running improved the sealing capability of the injectors. None of the injectors developed seat leakage during the duration of the test.

Thus, although fuel injector wear and leakage has been a significant problem with the methanol-fueled vehicles in the past, the improved injector design and/or the use of ethanol fuels has resulted in no injector wear and no injector leakage. The E100 used for these tests was very low in water content. It may be that water is a crucial contaminant of the alcohol fuels that leads to wear. Discussions with others involved in testing ethanol injectors for wear have indicated that elevated fuel temperatures may also be critical in the alcohol wear problem. For the tests reported here, SAE $\mathrm{J} 1832$ recommendations were used to set the fuel temperature to $20^{\circ} \mathrm{C} \pm 1^{\circ} \mathrm{C}$. 


\title{
TASK 3: ENGINE SYSTEM ASSEMBLY AND TESTING
}

AND

\author{
TASK 5: FUEL/ENGINE/VEHICLE SYSTEM INTEGRATION \\ AND
}

TASK 6: INTEGRATED FUEL/ENGINE SYSTEM OPTIMIZATION

\section{Objectives}

During Phase 3 of this project, Task 3 for engine modifications, Task 5 for system integration, and Task 6 for the integration of the fuel/engine and system optimization overlapped heavily. For that reason, the progress made in these three tasks is reported in this one section. There were several objectives of these three tasks, but they were all directed at modifying engine hardware and then calibrating the engine for good performance and low emissions. These objectives included: (a) improving the air-assist injectors to improve $\mathrm{A} / \mathrm{F}$ ratio control under steady-state conditions; (b) replacing the OEM engine controller (Ford EEC-IV) with an SwRI rapid prototyping engine control system (RPECS) to provide flexibility to change control algorithms; (c) developing a cranking and start-up strategy that would provide rapid starts at any temperature, and in doing so, reduce hydrocarbon emissions associated with misfires; (d) implementing model-based control in the RPECS to compute air and fuel flow into the cylinders for optimum A/F ratio control under steadystate and transient conditions; (e) developing various other engine control strategies to take care of closed-loop engine control and specialized parts of the cycle; and (f) developing a rapid exhaust port oxidation (REPO) system and control algorithms to obtain rapid catalyst light-off with a minimum of added equipment. Details of how these objectives were met are provided below.

\section{Improvement in Air-Assist Injectors}

The main purpose of the air-assist injectors was to improve start-up and transient performance by improving fuel transport from the injectors to the cylinders. The air-assist injectors produce smaller drops that can follow the air stream through the port, past the intake valves, and into the cylinder. The finer spray also evaporates more quickly than the spray from a conventional injector. These processes reduce wall wetting, and reduced wall wetting improves engine performance during cranking and engine transients in speed and load, especially when the port walls and intake valves are cold. Good cranking and transient performance were observed with the firstgeneration air-assist injectors.

However, the performance of the first-generation air-assist injectors at steady-state conditions was found unacceptable for maintaining a very stable $A / F$ ratio. The $A / F$ ratio measured by a UEGO sensor for a constant commanded pulse width showed relatively high-frequency variations that were significantly larger for the first-generation air-assist injectors than for the OEM pintle injectors. As a result, the air-assist injector caps were redesigned to reduce the $\mathrm{A} / \mathrm{F}$ mixing volume, while maintaining a single $1-\mathrm{mm}$ exit hole diameter.

The performance of the OEM pintle injectors, the first generation air-assist injectors, and the redesigned or second-generation air-assist injectors are compared in Figures 3-1(a) through 3-1(h) for the first-generation air-assist injectors, Figures 3-2(a) through 3-2(h) for the OEM injectors, and in Figures 3-3(a) through 3-3(h) for the redesigned air-assist injectors. Figures (a) and (b) for each 
of the three cases compare performance at $32^{\circ} \mathrm{C}$ coolant temperature and $0.3 \mathrm{bar}(30 \mathrm{kPa})$ manifold air pressure (MAP). The A/F ratio control of the second-generation air-assist injectors is superior to the OEM pintle injectors at this condition, assuming the lean spike for the air-assist injectors was an instrument noise spike. The $\mathrm{A} / \mathrm{F}$ ratio control for the first-generation air-assist injectors shows high variability at this and most other conditions. At the same $32^{\circ} \mathrm{C}$ coolant temperature, but a highload condition of $0.7 \mathrm{bar}(70 \mathrm{kPa}) \mathrm{MAP}$, the comparisons are shown in Figures (c) and (d) for each case. Again, the redesigned air-assist injectors show superior performance when compared with the OEM pintle injectors. Compared with the $32^{\circ} \mathrm{C}$ results, at $82^{\circ} \mathrm{C}$ coolant temperature, the $\mathrm{A} / \mathrm{F}$ ratio control with the OEM pintle injectors improves dramatically, while the A/F ratio control with the redesigned air-assist injectors improves slightly, as shown in Figures (e) through (h) for all three cases. As a result, the redesigned air-assist injectors performed slightly better than the OEM pintle injectors at the $82^{\circ} \mathrm{C}$ condition.

Thus, the first-generation, air-assist injectors showed unacceptable $\mathrm{A} / \mathrm{F}$ ratio control at steady-state conditions compared with the OEM pintle injectors. However, the second-generation (or redesigned) air-assist injectors with a much smaller mixing chamber showed better $\mathrm{A} / \mathrm{F}$ ratio control at steady-state conditions than the OEM injectors. In addition, the second-generation, airassist injectors provided very good start-up and transient performance, although back-to-back comparisons of engine performance with the OEM pintle injectors were not made.

- The second-generation, air-assist injectors provided reasonably good atomization as shown in Figure 3-4. The 4-ms pulse widths correspond to an idle condition, and the 10-ms pulse width to a high power condition. With a manifold air pressure of $50 \mathrm{kPa}$ absolute corresponding to an idle condition with the automatic transmission in gear, the differential air pressure across the atomizer for the $70 \mathrm{kPa}$ gage air pump pressure is $220 \mathrm{kPa}$, and for the 4-ms idle pulse width the Sauter mean diameter (SMD) is about $14 \mu \mathrm{m}$. However, at wide-open throttle, the differential pressure of about $70 \mathrm{kPa}$ and 10-ms pulse widths result in an SMD of about $25 \mu \mathrm{m}$. At cranking, the pulse widths are even higher and the SMDs larger. These SMD's are much smaller than for the conventional pintle injectors that have SMDs of about $120 \mu \mathrm{m}$, but are somewhat larger than optimum. The optimum SMDs are about 10 or $15 \mu \mathrm{m}$ or smaller at all conditions. 


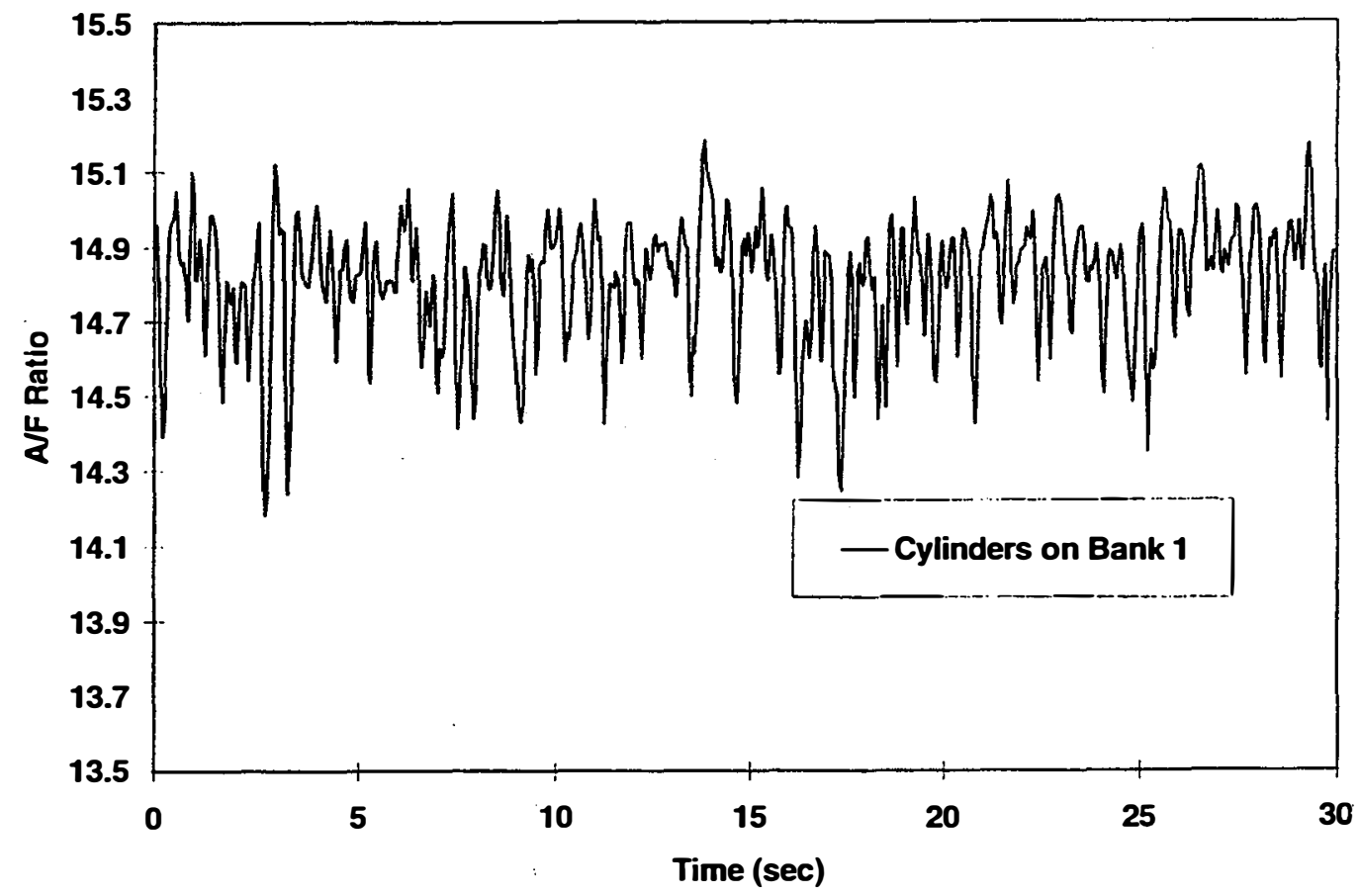

(a)

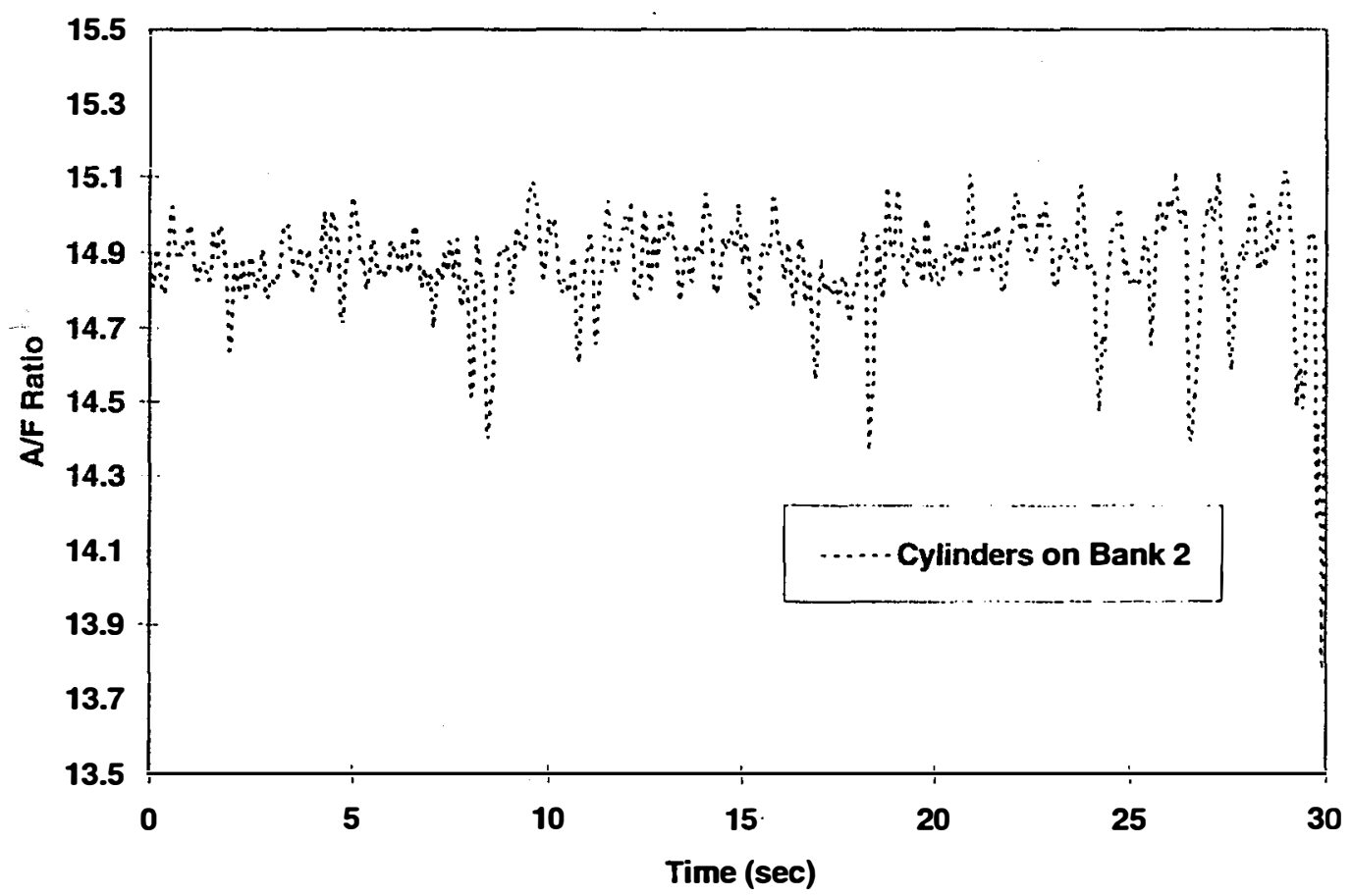

(b)

FIGURE 3-1. STEADY-STATE A/F RATIO FOR TAURUS ENGINE WITH CONSTANT COMMANDED PULSE WIDTH

Air-Assist Injector, with Screens, $70 \mathrm{kPag}, \mathrm{ECT}=32^{\circ} \mathrm{C}, 2000 \mathrm{rpm}, \mathrm{MAP}=0.3 \mathrm{bar}$ 


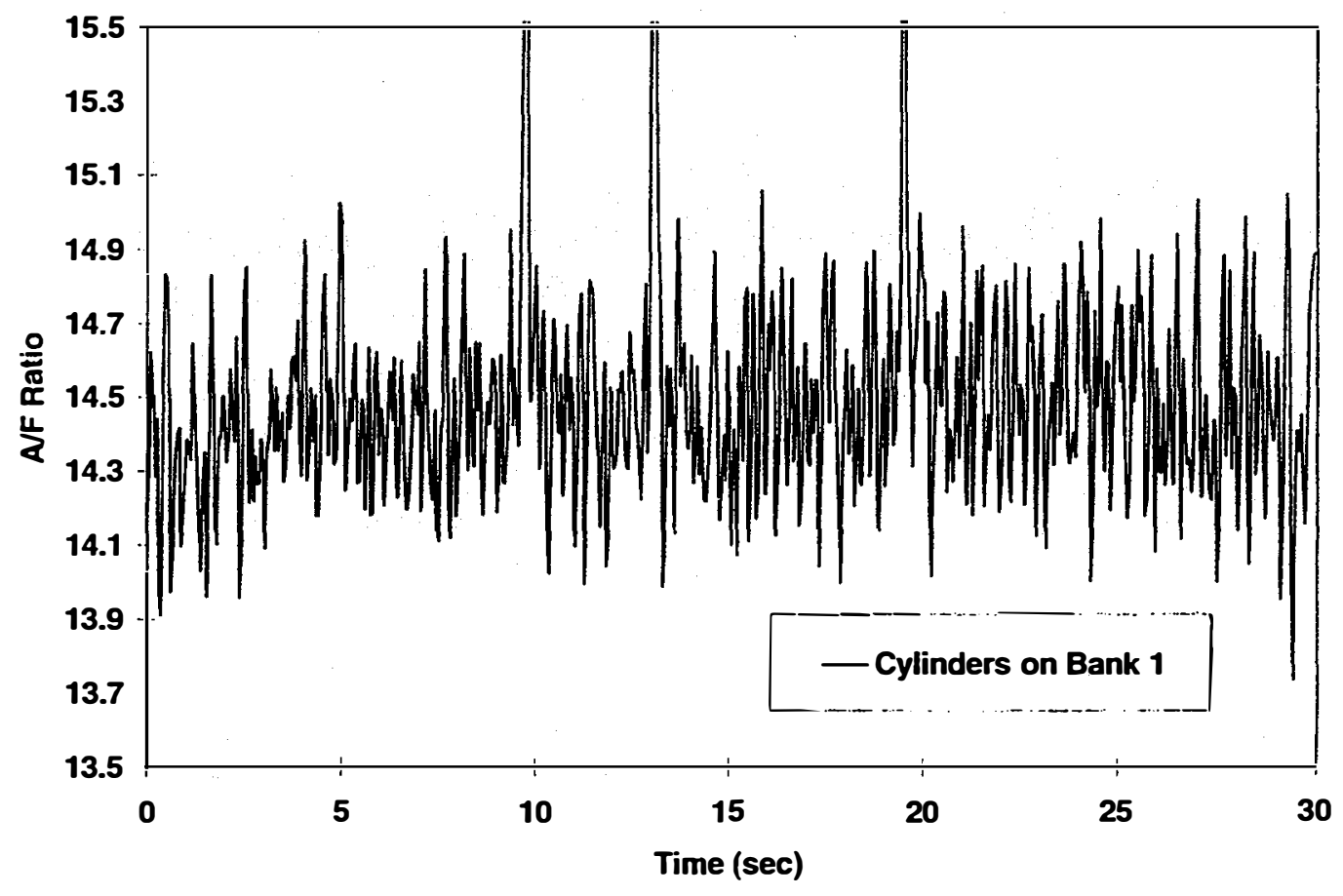

(c)

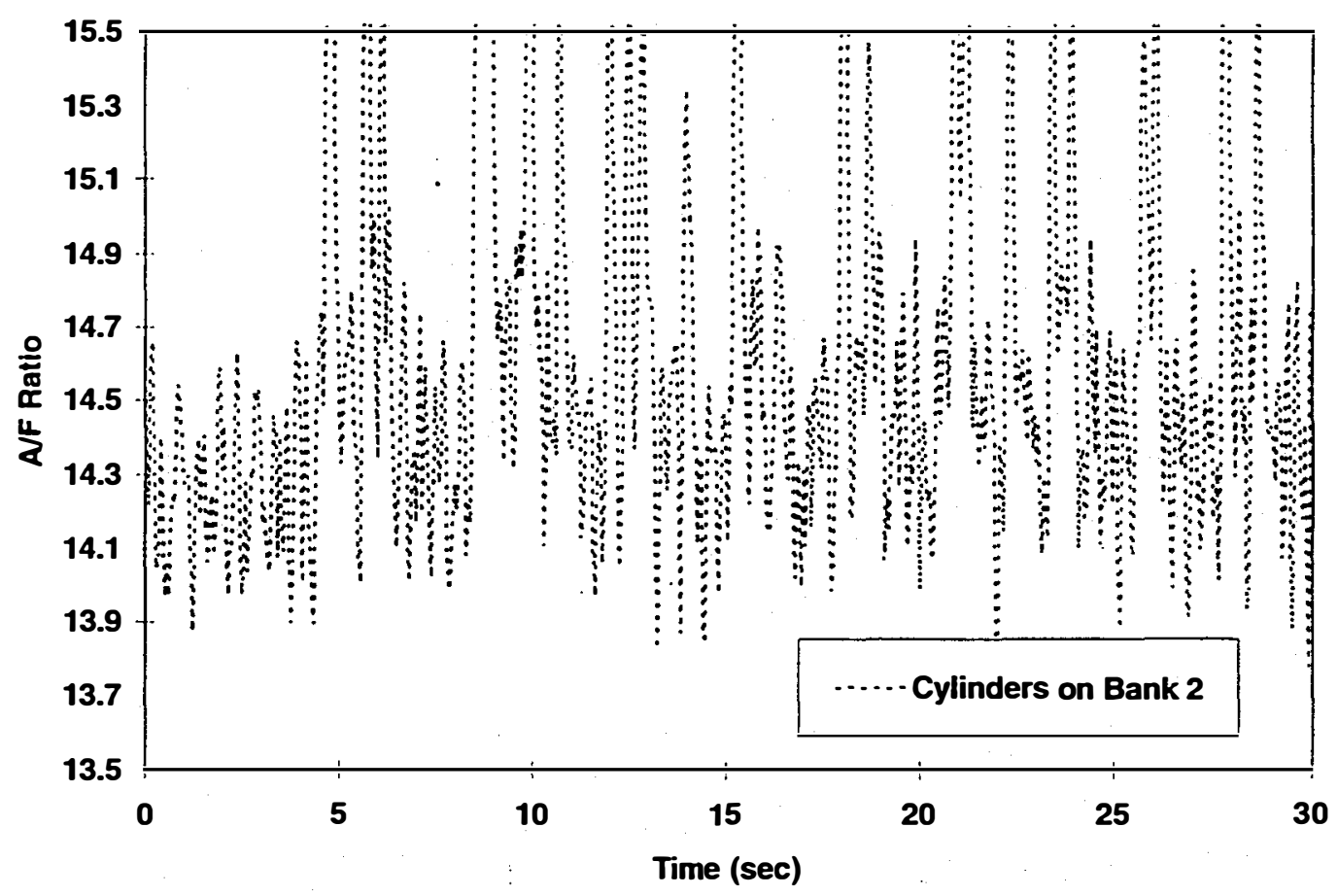

(d)

FIGURE 3-1. STEADY-STATE A/F RATIO FOR TAURUS ENGINE WITH CONSTANT COMMANDED PULSE WIDTH

Air-Assist Injector, with Screens, $70 \mathrm{kPag}, \mathrm{ECT}=32^{\circ} \mathrm{C}, 2000 \mathrm{rpm}, \mathrm{MAP}=0.7 \mathrm{bar}$ 


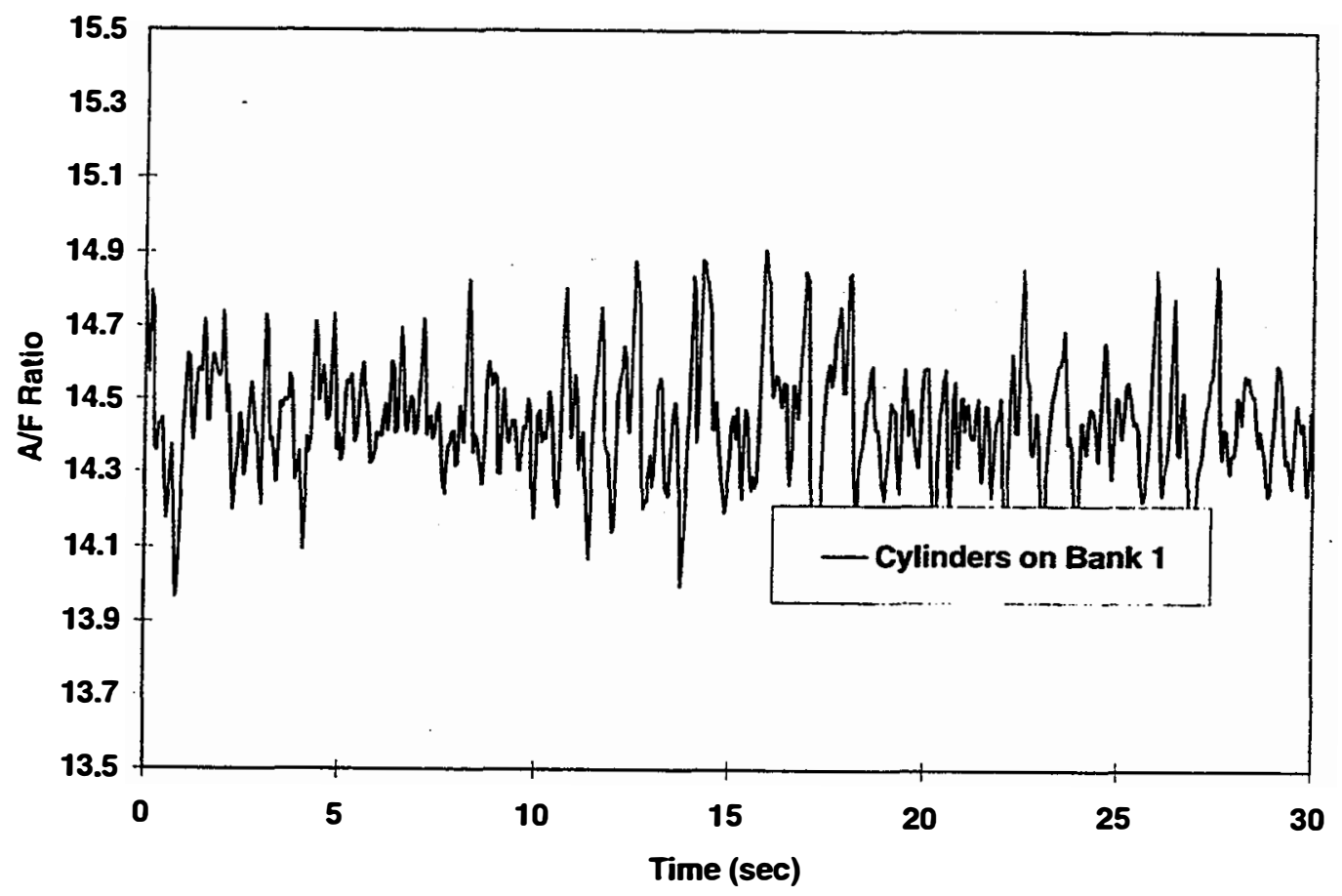

(e)

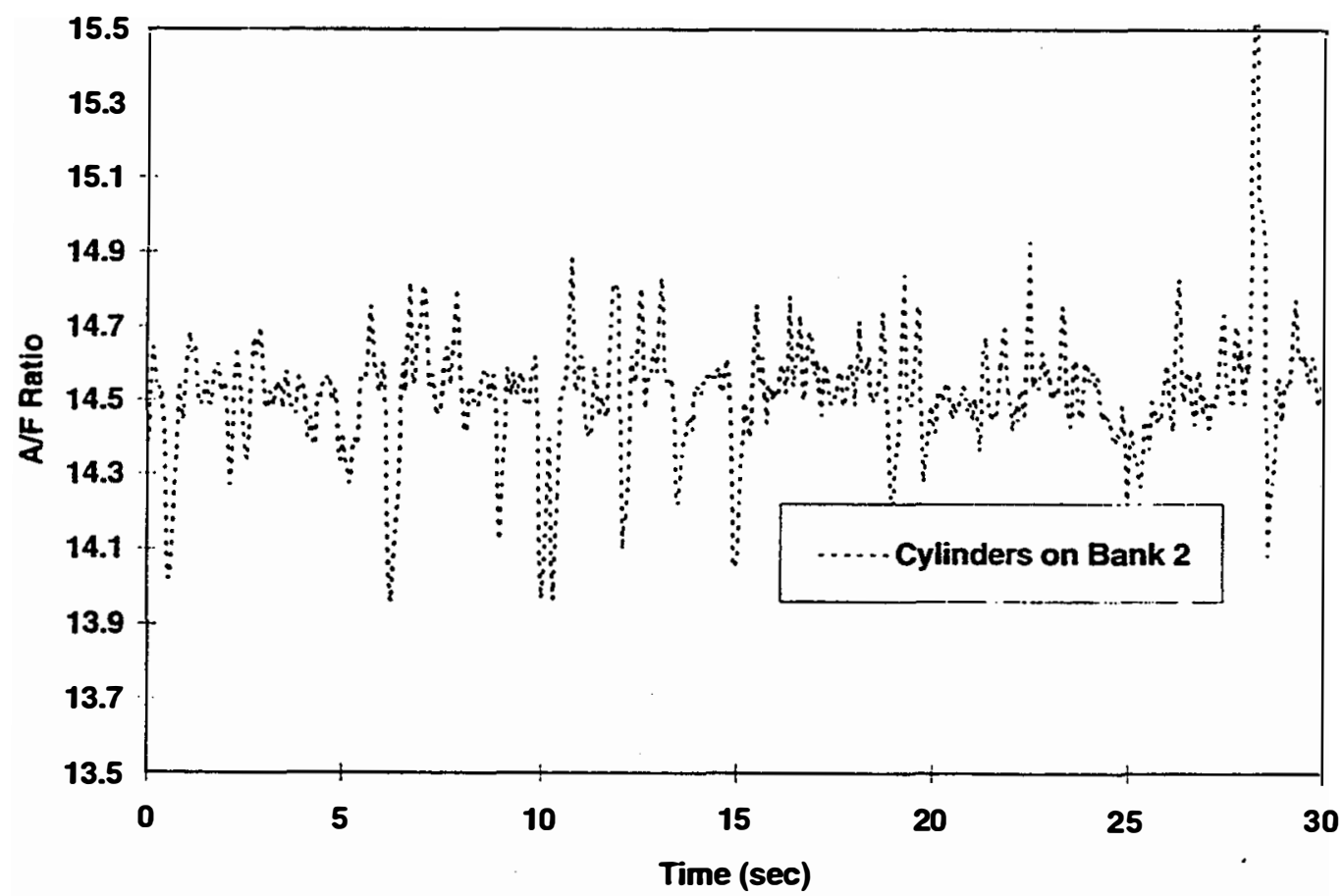

(f)

FIGURE 3-1. STEADY-STATE A/F RATIO FOR TAURUS ENGINE WITH CONSTANT COMMANDED PULSE WIDTH Air-Assist Injector, with Screens, $70 \mathrm{kPag}, \mathrm{ECT}=82^{\circ} \mathrm{C}, 2000 \mathrm{rpm}, \mathrm{MAP}=0.3 \mathrm{bar}$ 


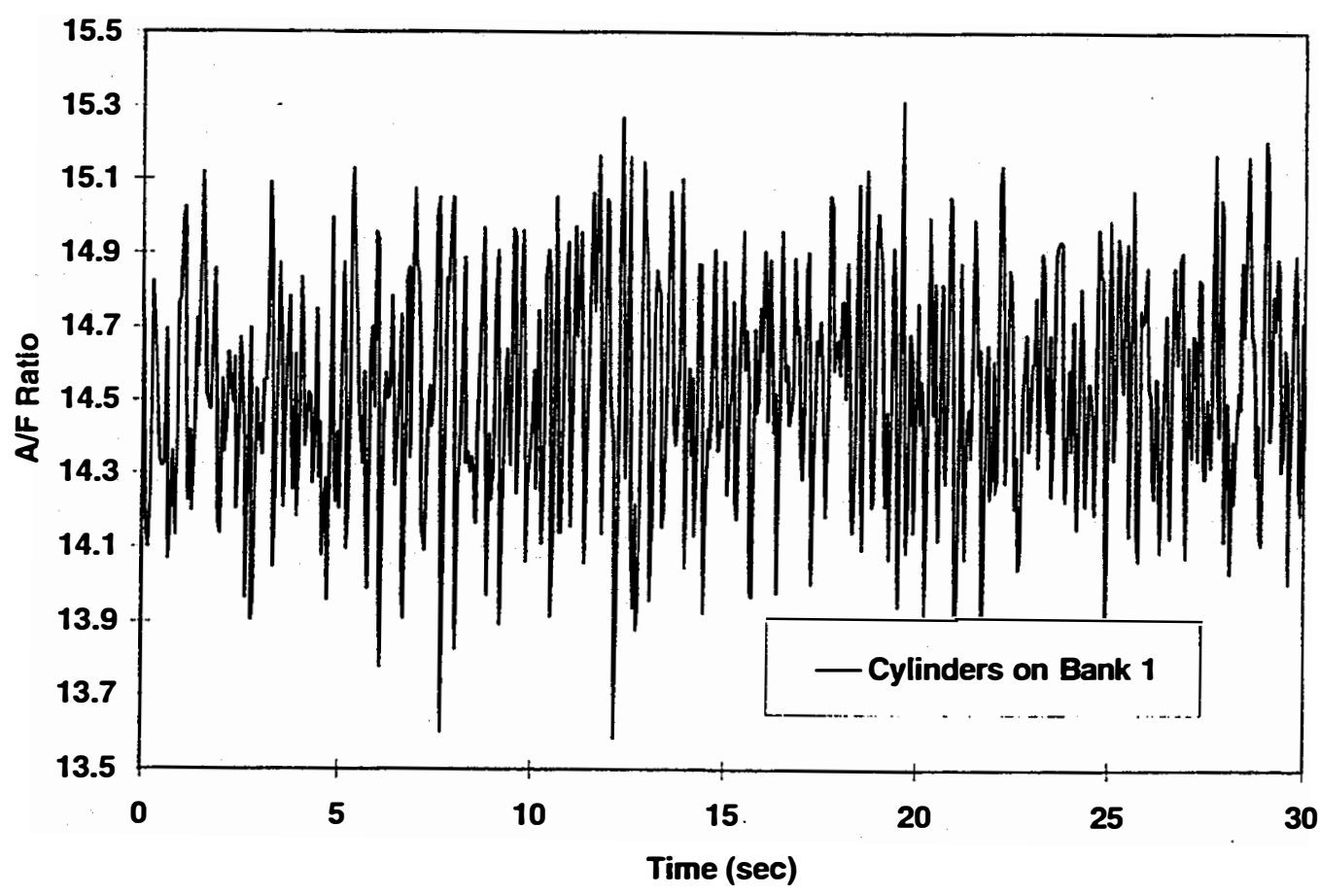

(g)

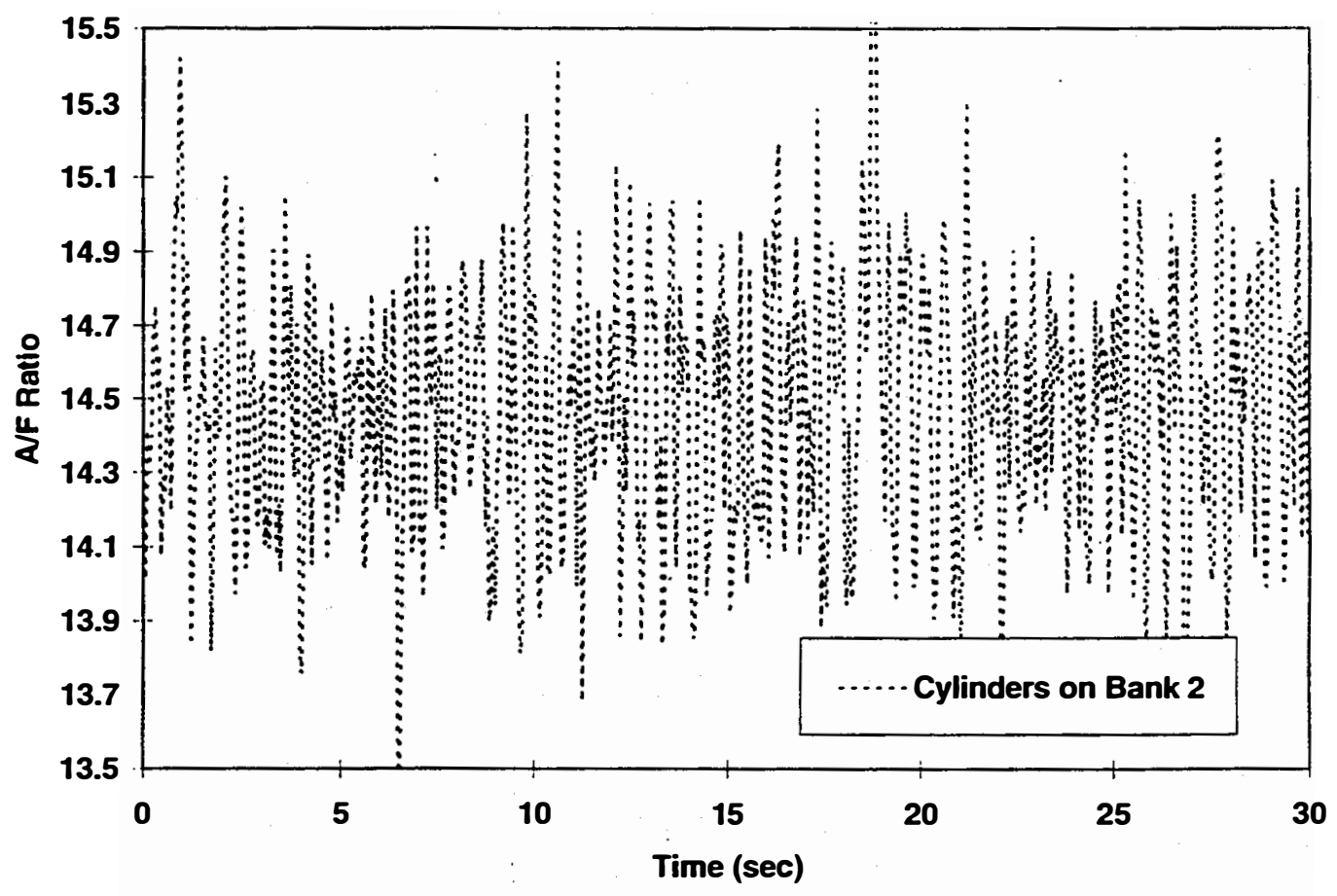

(h)

FIGURE 3-1. STEADY-STATE A/F RATIO FOR TAURUS ENGINE WITH CONSTANT COMMANDED PULSE WIDTH Air-Assist Injector, with Screens, $70 \mathrm{kPag}, \mathrm{ECT}=82^{\circ} \mathrm{C}, 2000 \mathrm{rpm}, \mathrm{MAP}=0.7 \mathrm{bar}$ 


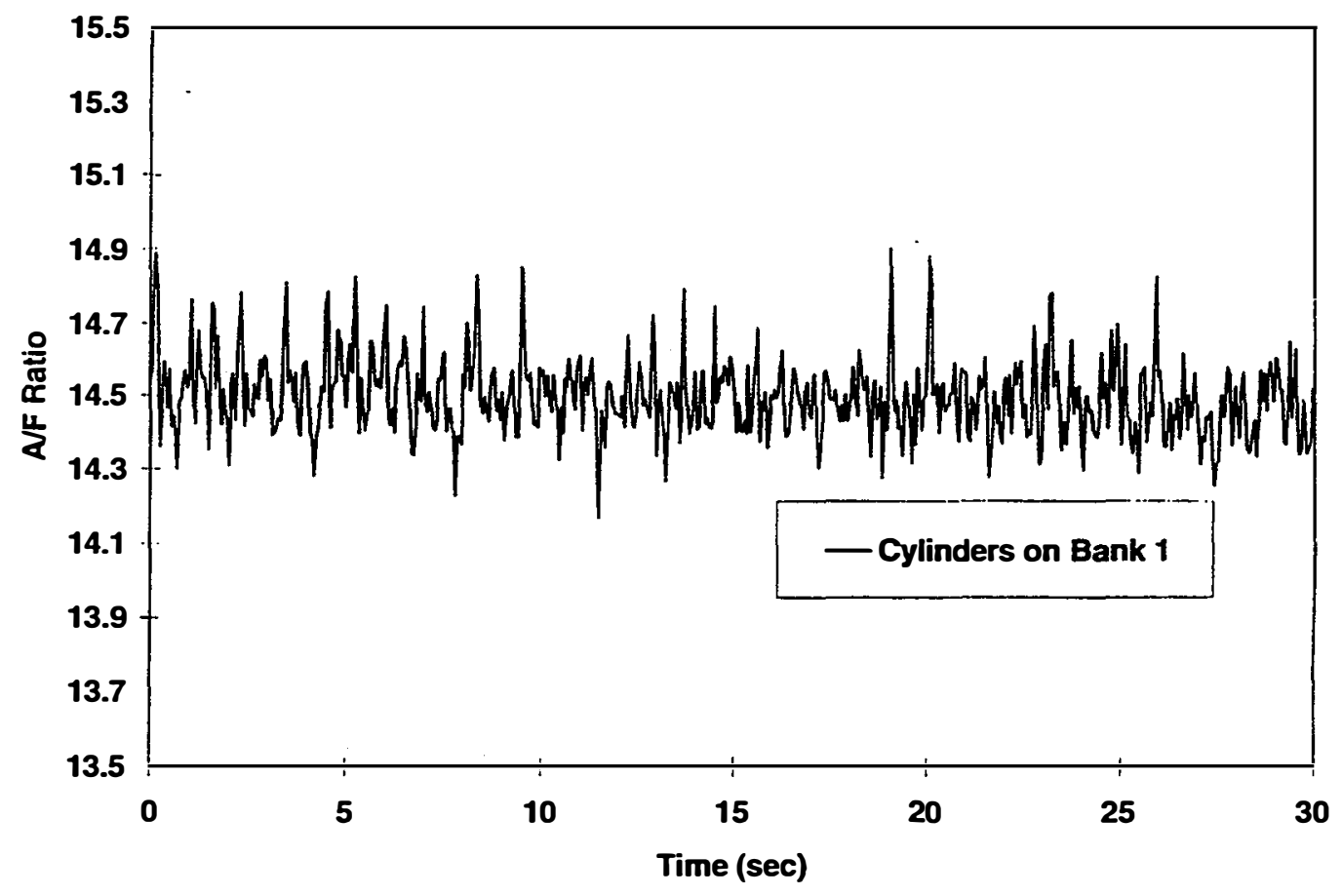

(a)

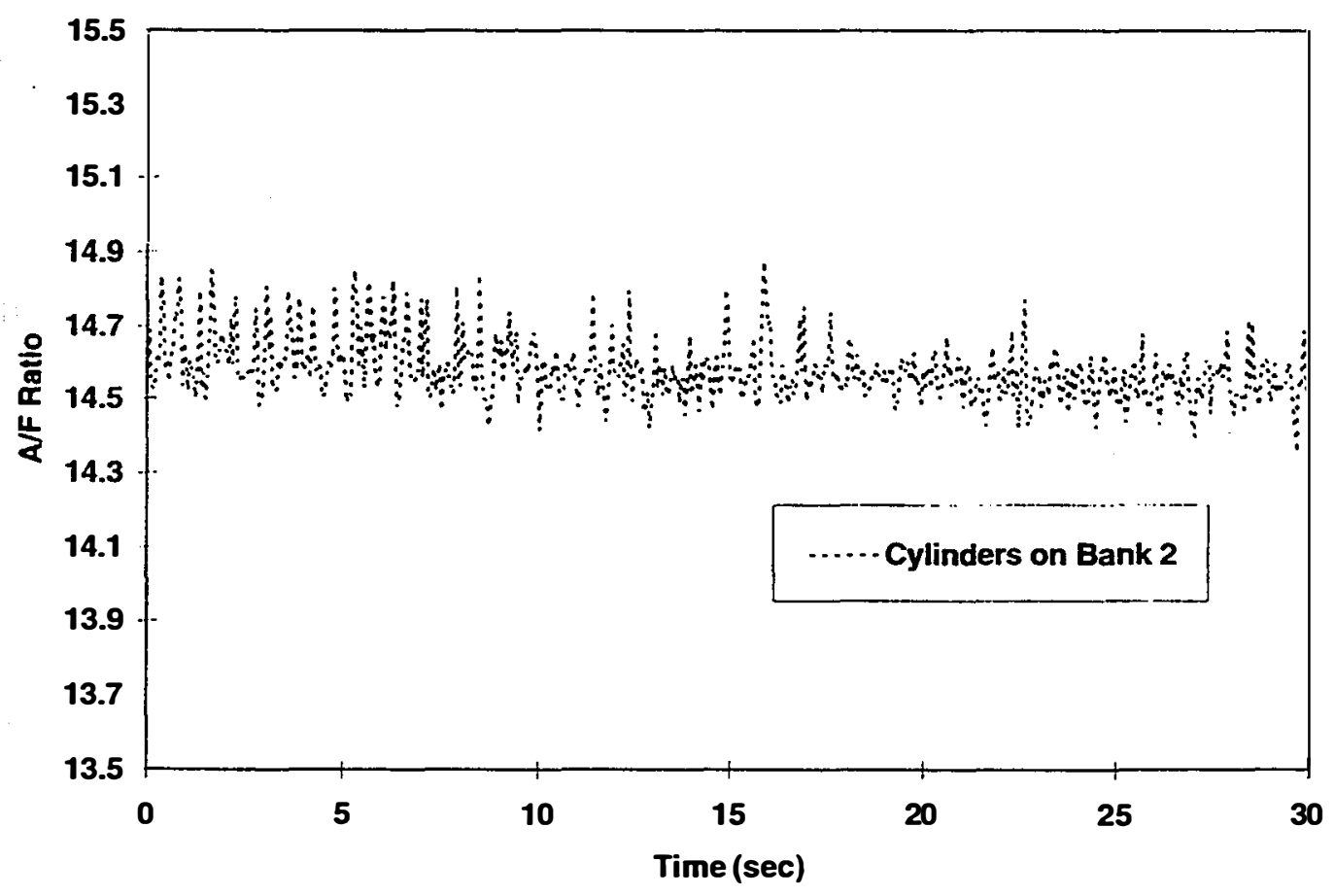

(b)

FIGURE 3-2. STEADY-STATE A/F RATIO FOR TAURUS ENGINE WITH CONSTANT COMMANDED PULSE WIDTH

OEM Pintle Injectors, ECT $=32^{\circ} \mathrm{C}, 2000 \mathrm{rpm}, \mathrm{MAP}=0.3 \mathrm{bar}$ 


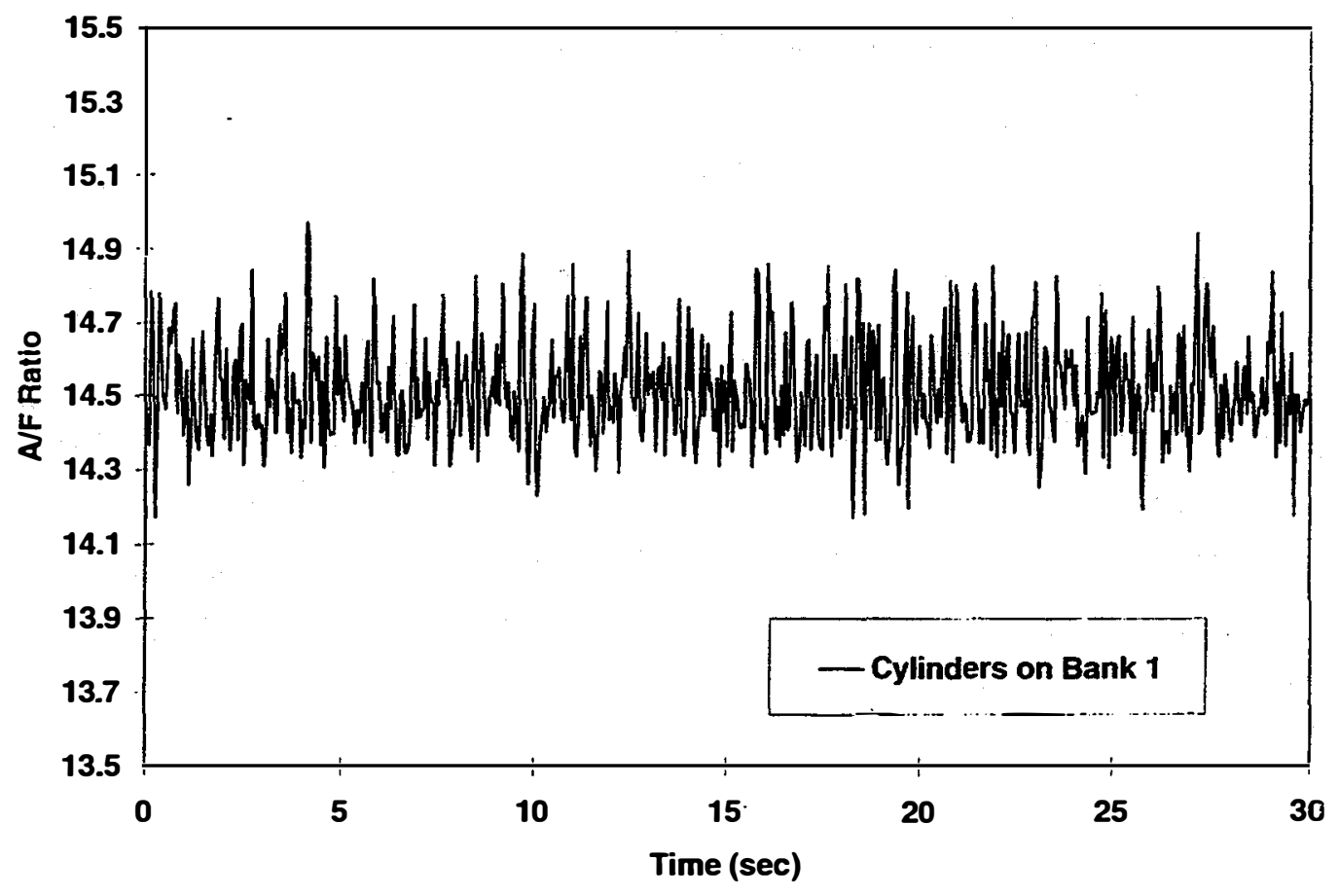

(c)

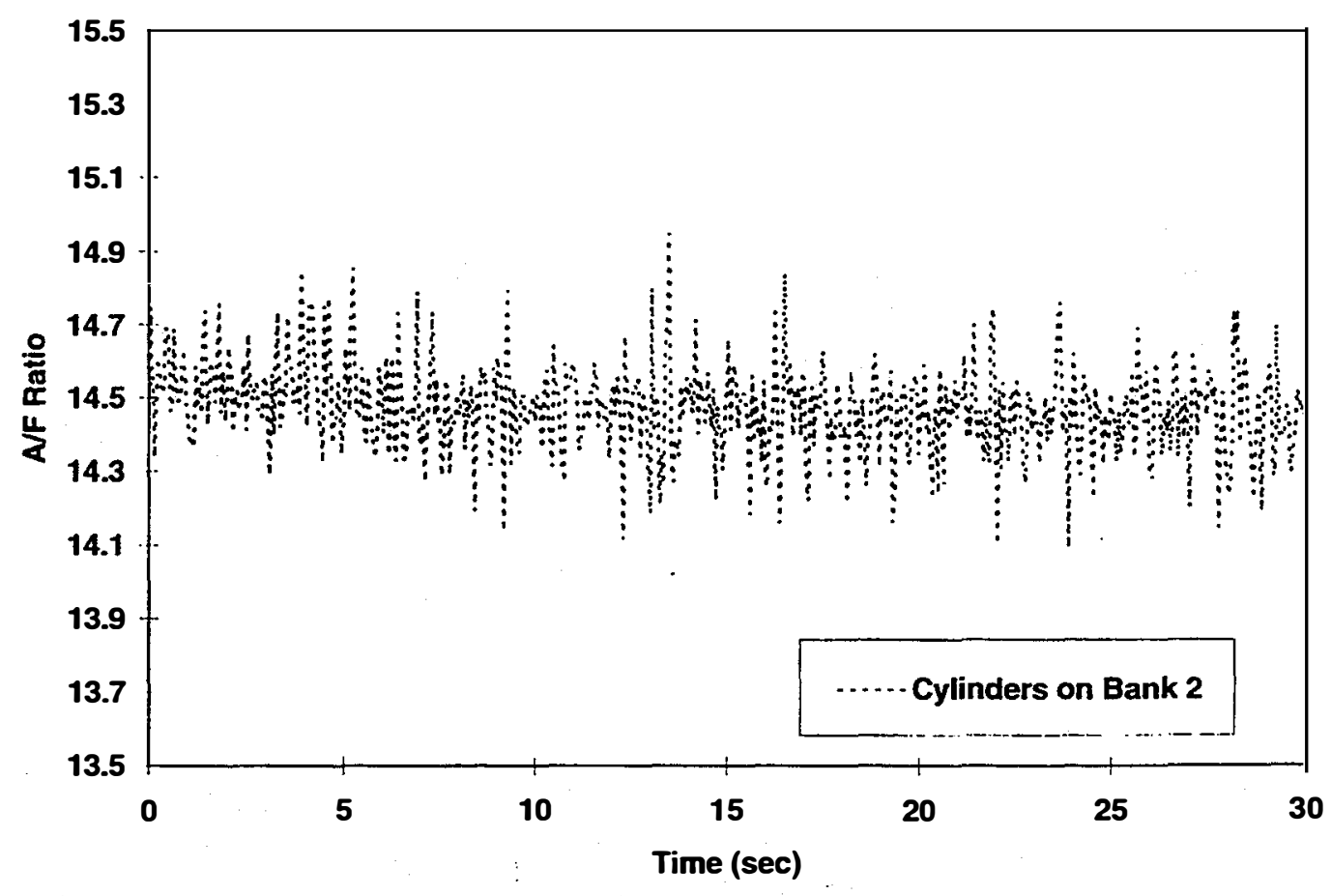

(d)

FIGURE 3-2. STEADY-STATE A/F RATIO FOR TAURUS ENGINE WITH CONSTANT COMMANDED PULSE WIDTH OEM Pintle Injectors, ECT $=32^{\circ} \mathrm{C}, 2000 \mathrm{rpm}, \mathrm{MAP}=0.7 \mathrm{bar}$ 


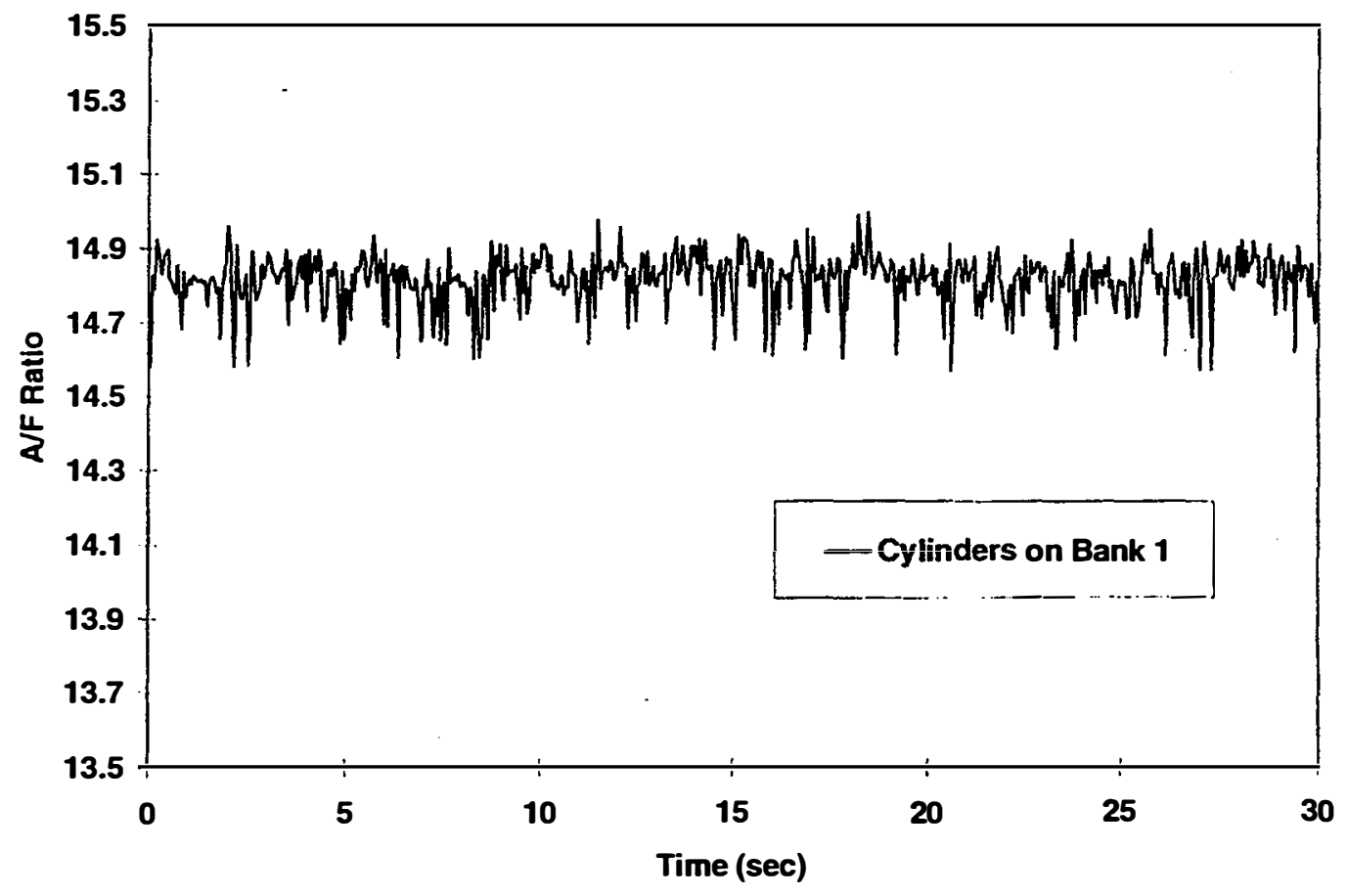

(e)

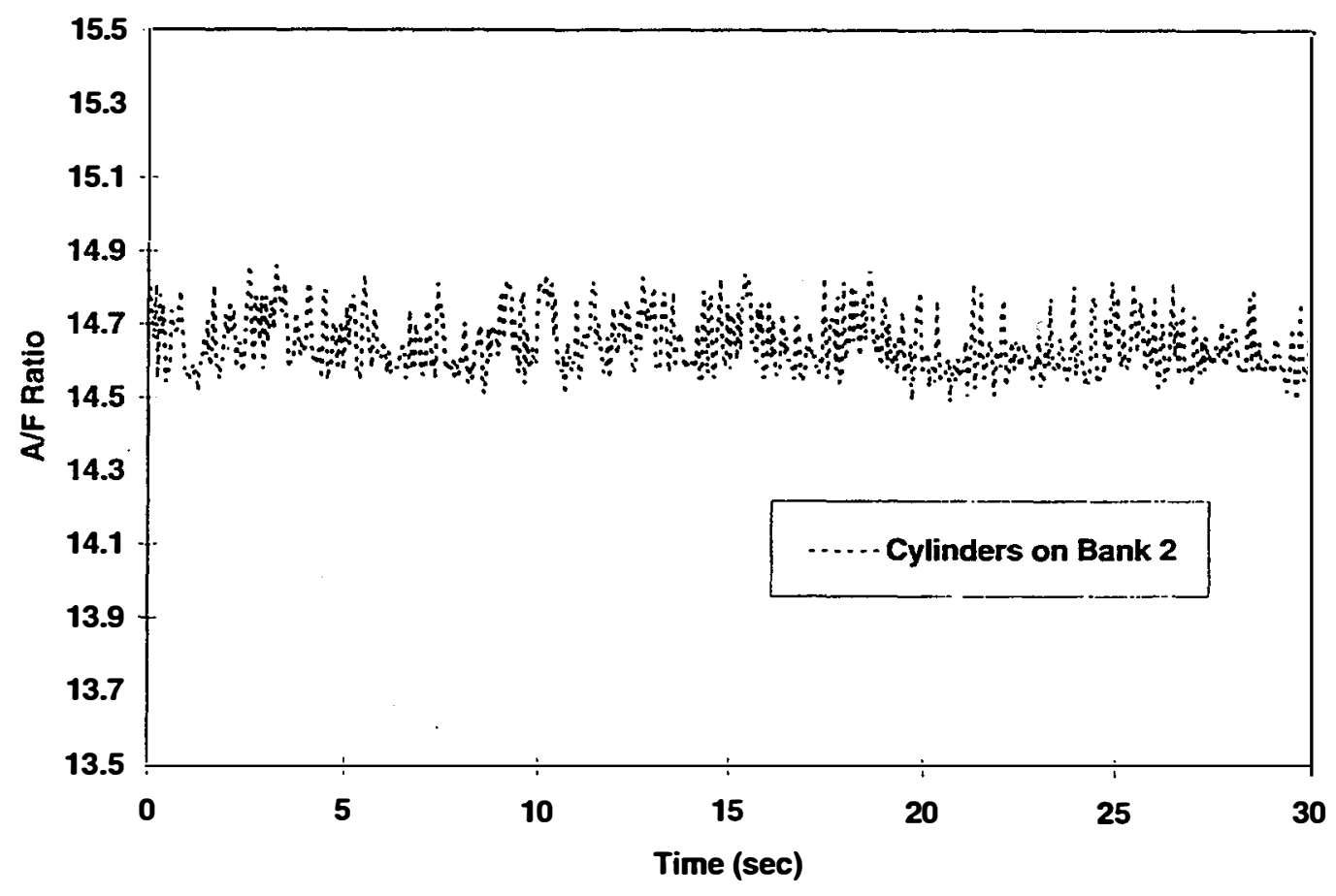

(f)

FIGURE 3-2. STEADY-STATE A/F RATIO FOR TAURUS ENGINE WITH CONSTANT COMMANDED PULSE WIDTH

OEM Pintle Injectors, ECT $=82^{\circ} \mathrm{C}, 2000 \mathrm{rpm}, \mathrm{MAP}=0.3 \mathrm{bar}$ 


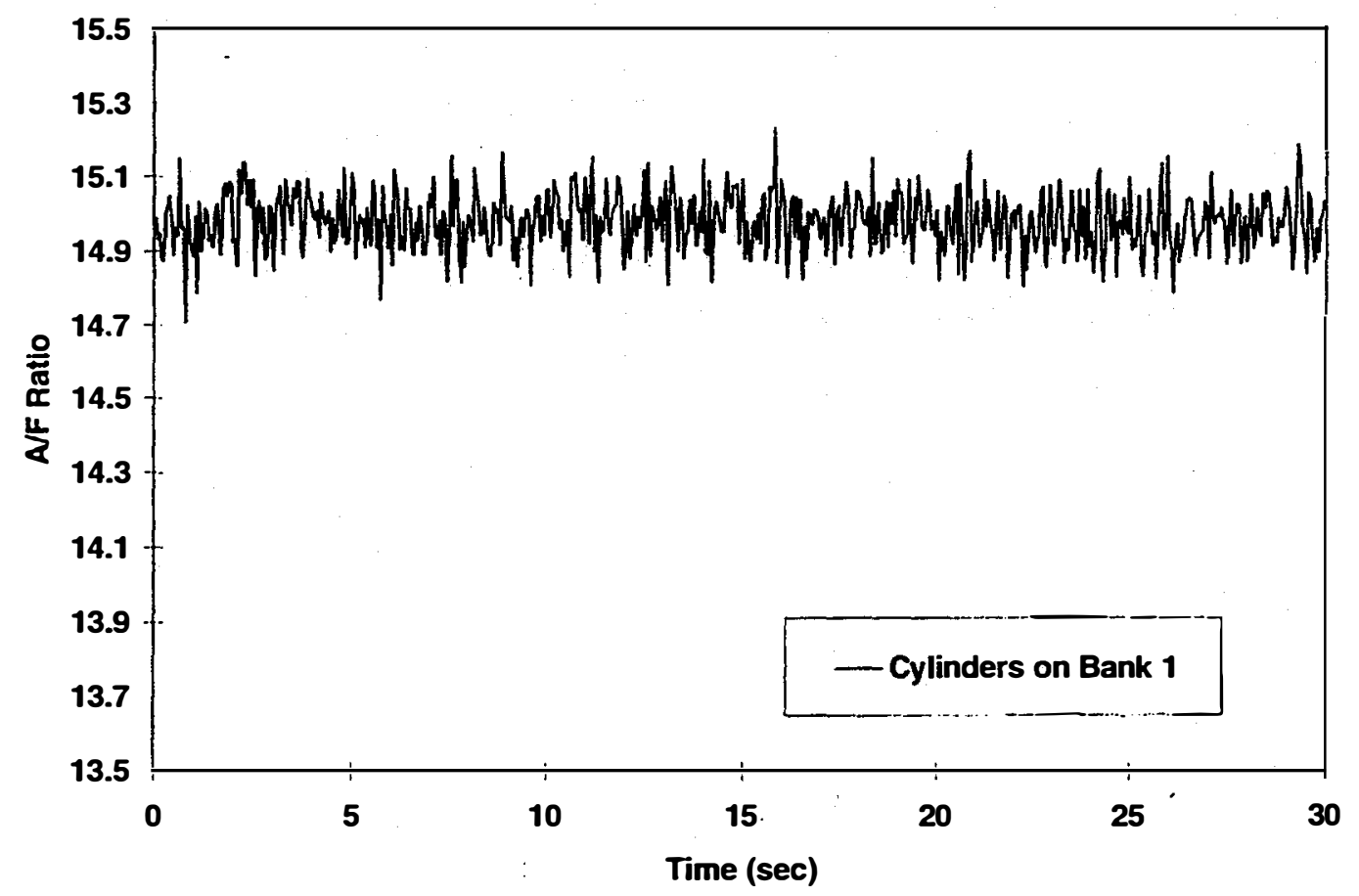

$(\mathrm{g})$

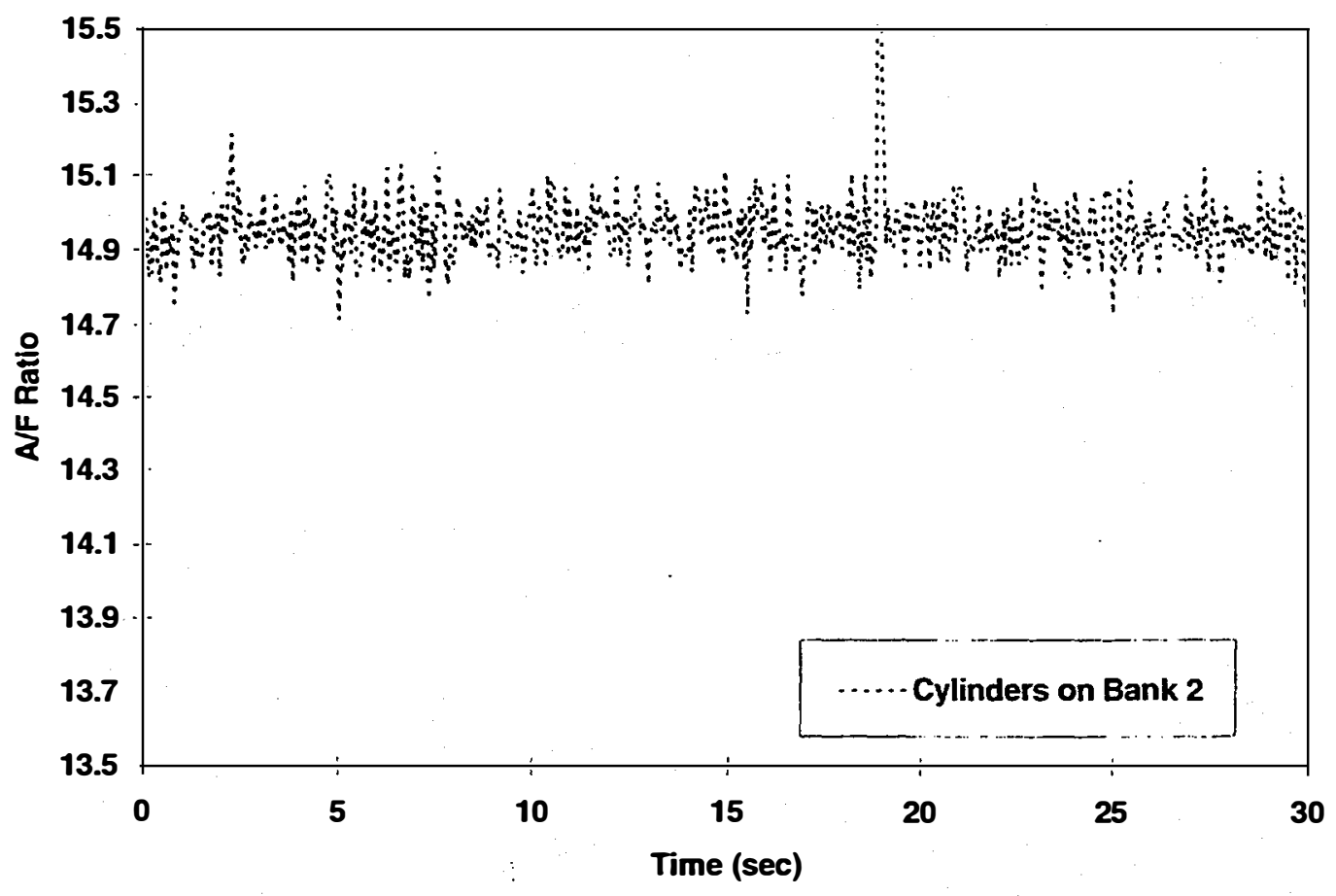

(h)

FIGURE 3-2. STEADY-STATE AVF RATIO FOR TAURUS ENGINE WITH CONSTANT COMMANDED PULSE WIDTH OEM Pintle Injectors, ECT $=82^{\circ} \mathrm{C}, 2000 \mathrm{rpm}, \mathrm{MAP}=0.7 \mathrm{bar}$ 


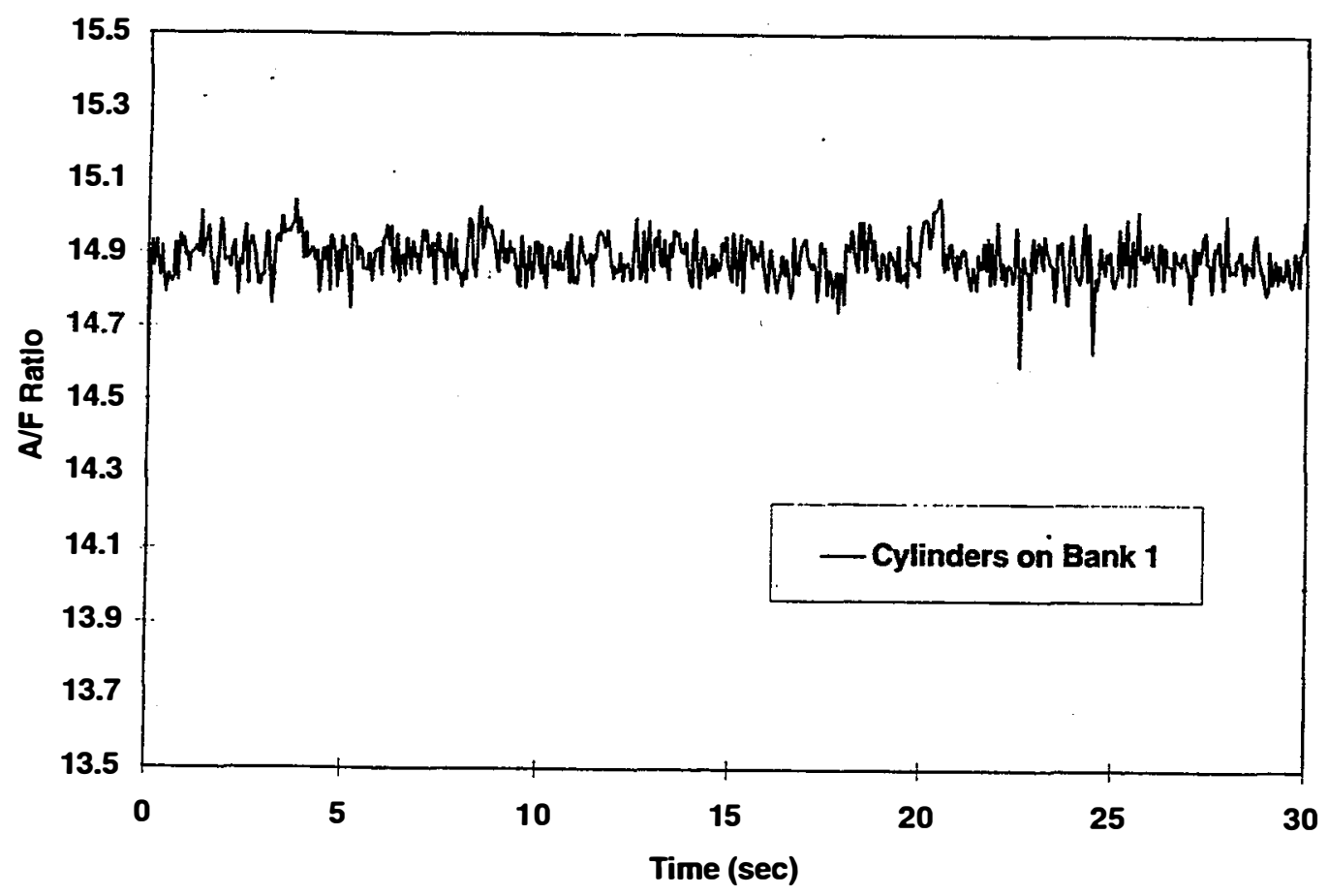

(a)

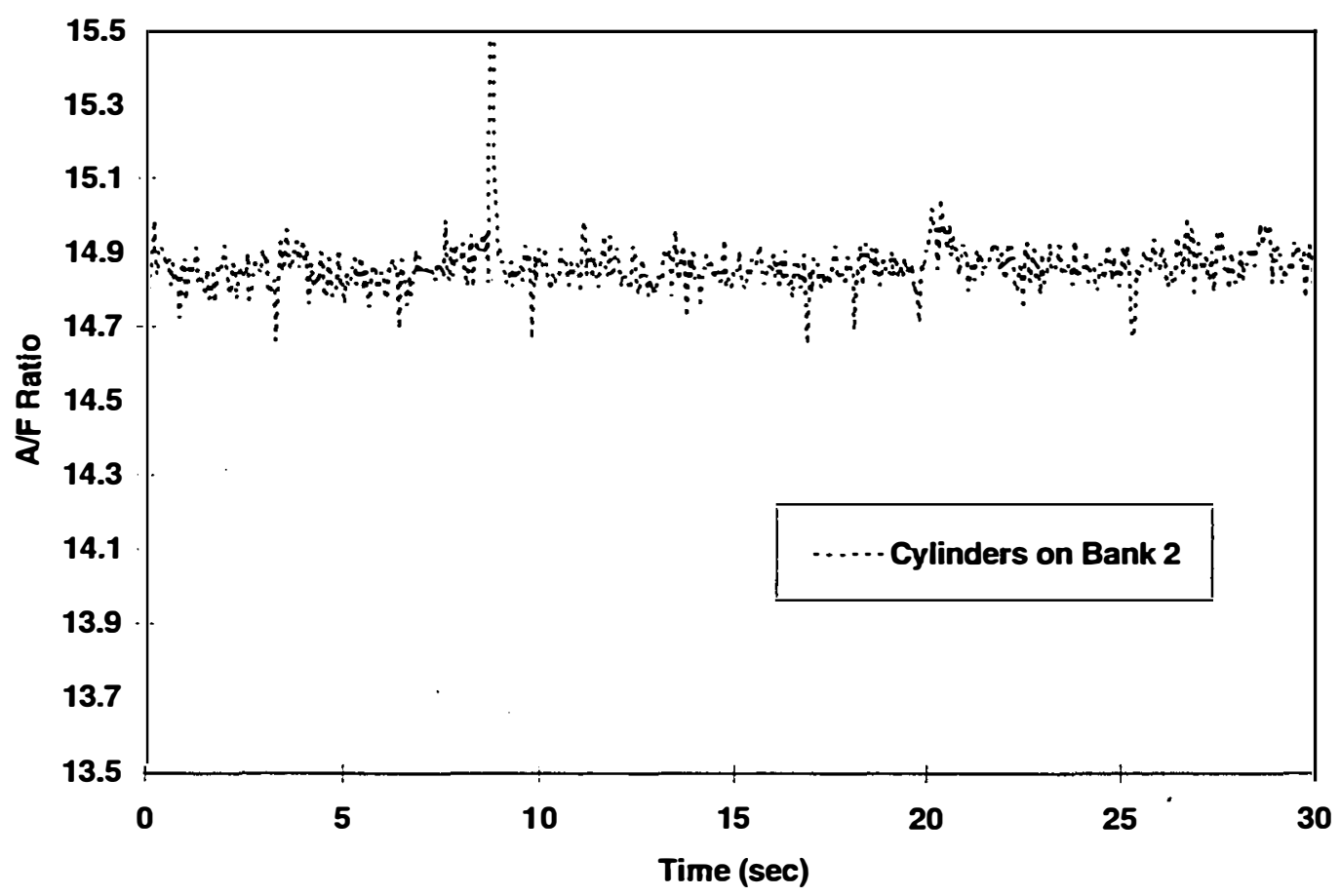

(b)

FIGURE 3-3. STEADY-STATE A/F RATIO FOR TAURUS ENGINE WITH CONSTANT COMMANDED PULSE WIDTH

Redesigned, Sleeved Air-Assist Injector, $70 \mathrm{kPag}, \mathrm{ECT}=32^{\circ} \mathrm{C}, 2000 \mathrm{rpm}, \mathrm{MAP}=0.3 \mathrm{bar}$ 


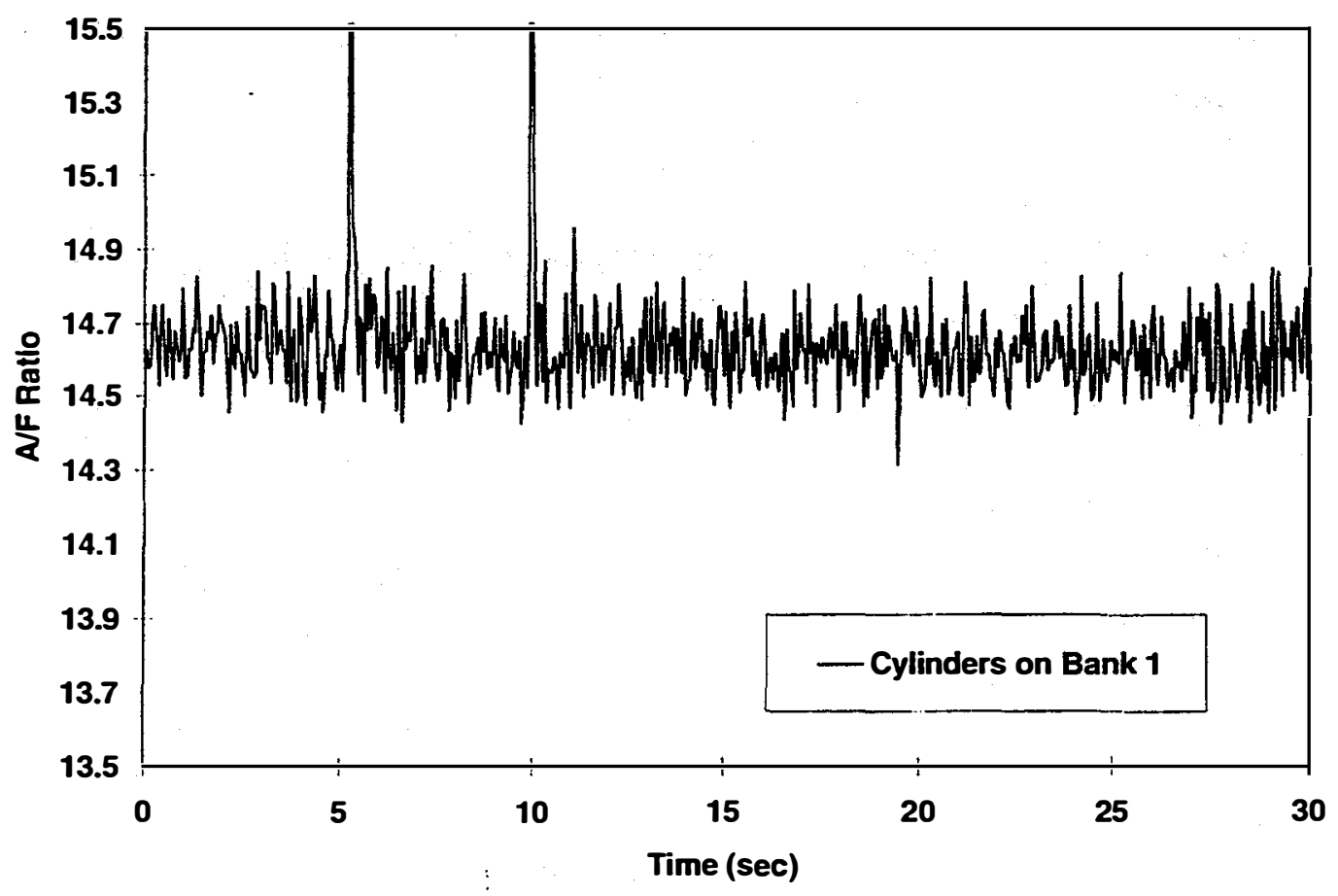

(c)

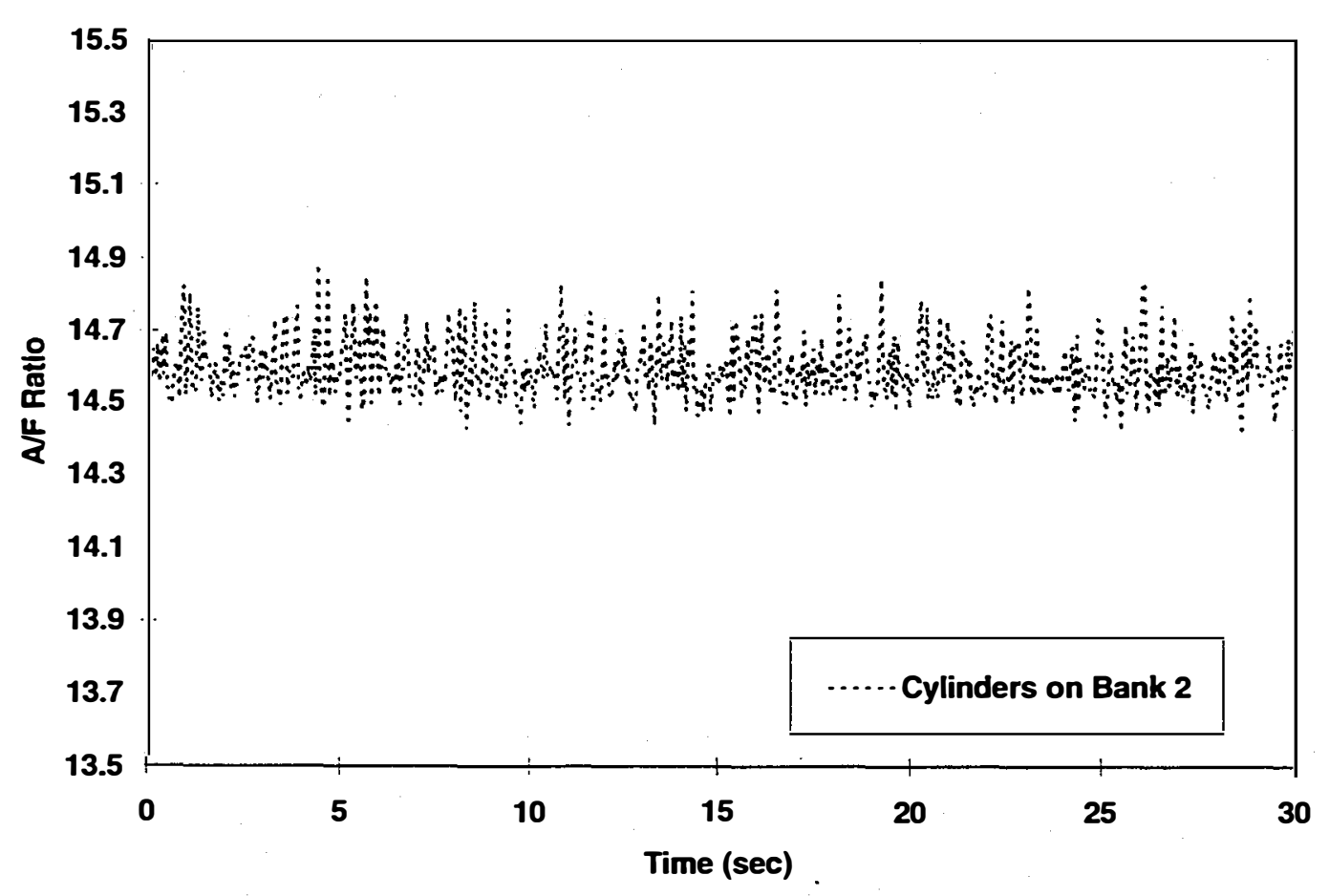

(d)

FIGURE 3-3. STEADY-STATE A/F RATIO FOR TAURUS ENGINE WITH CONSTANT COMMANDED PULSE WIDTH

Redesigned, Sleeved Air-Assist Injector, $70 \mathrm{kPag}, \mathrm{ECT}=32^{\circ} \mathrm{C}, 2000 \mathrm{rpm}, \mathrm{MAP}=0.7 \mathrm{bar}$ 


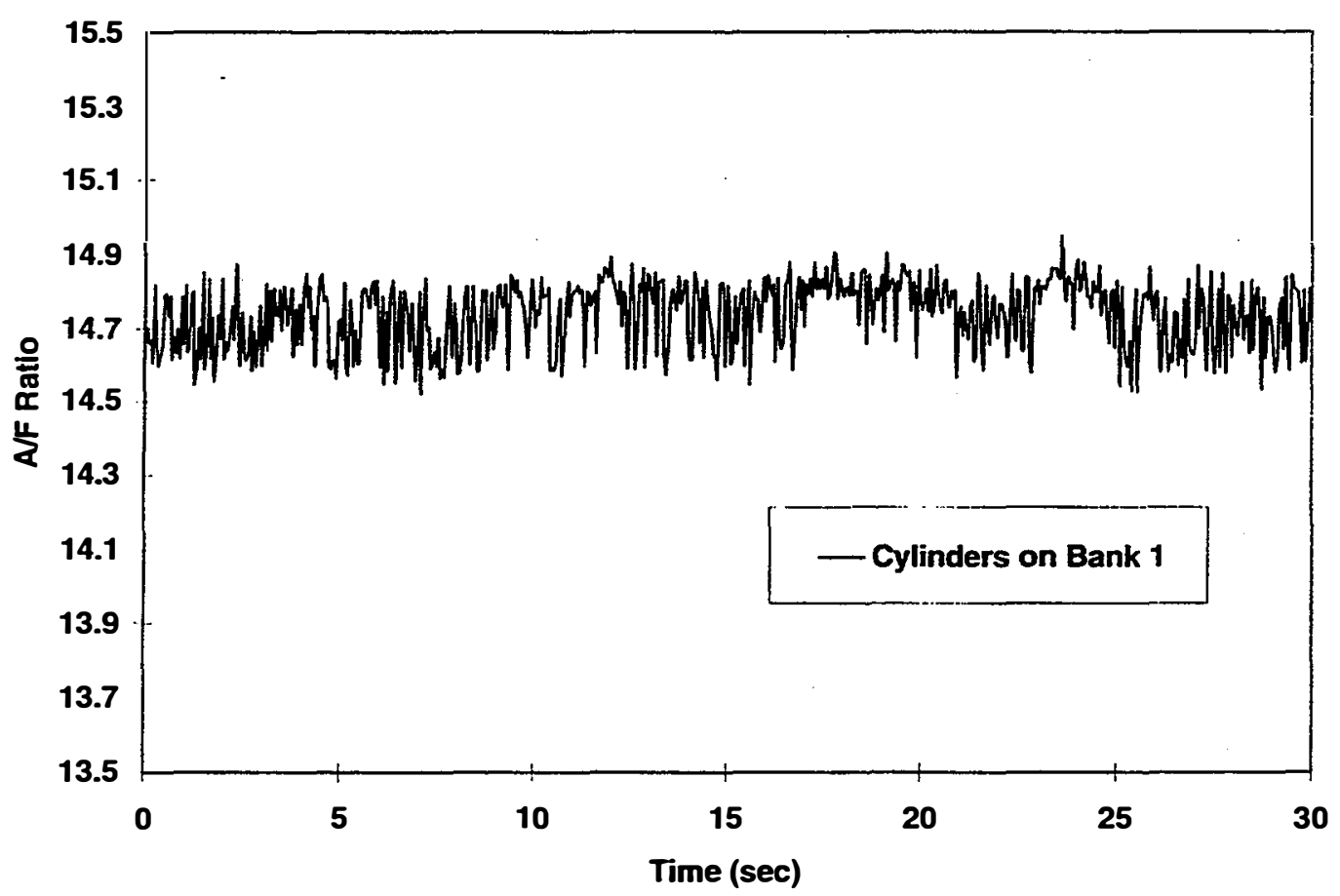

(e)

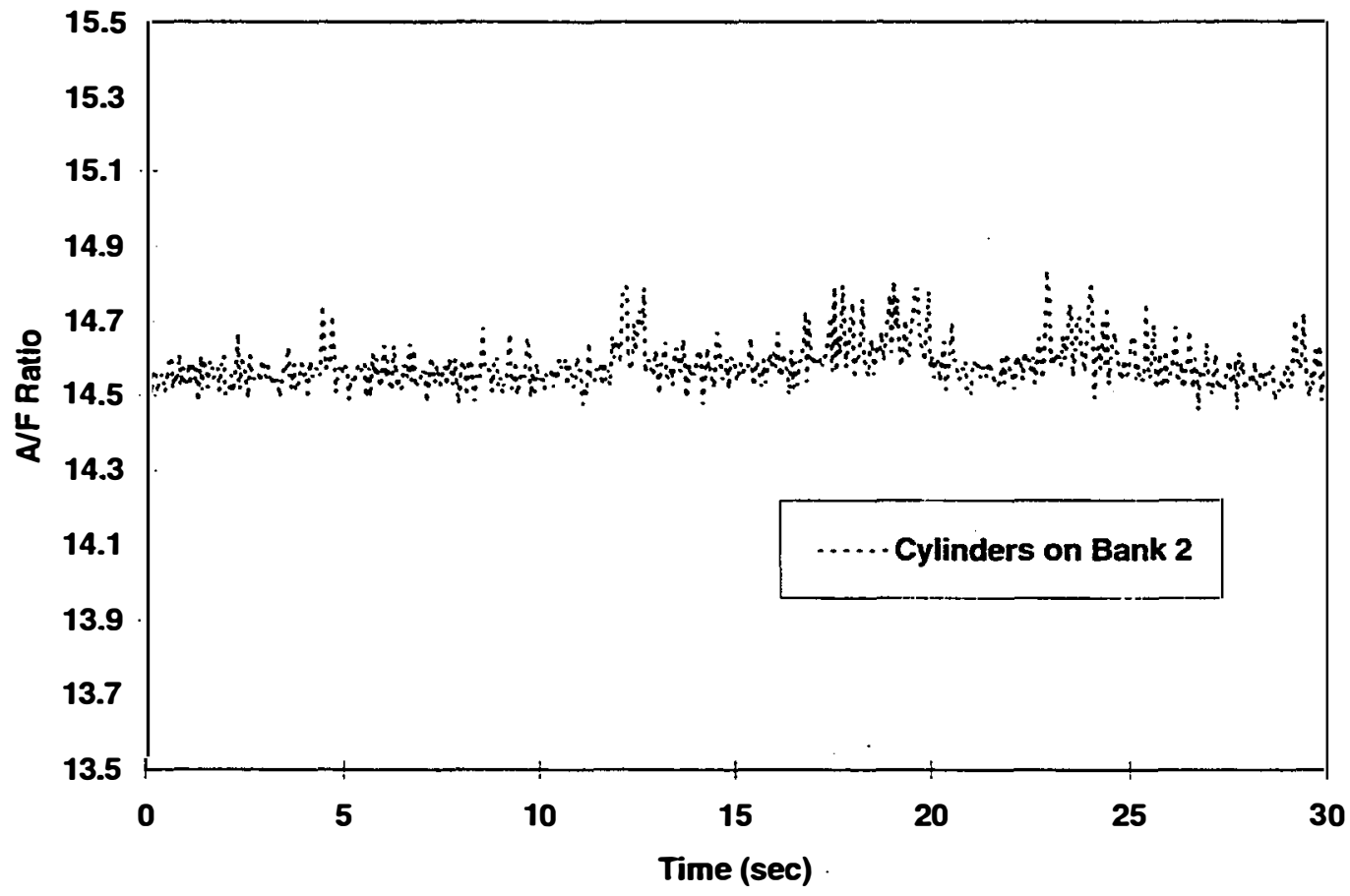

(f)

FIGURE 3-3. STEADY-STATE A/F RATIO FOR TAURUS ENGINE WITH CONSTANT COMMANDED PULSE WIDTH

Redesigned, Sleeved Air-Assist Injector, $70 \mathrm{kPag}, \mathrm{ECT}=82^{\circ} \mathrm{C}, 2000 \mathrm{rpm}, \mathrm{MAP}=0.3 \mathrm{bar}$ 


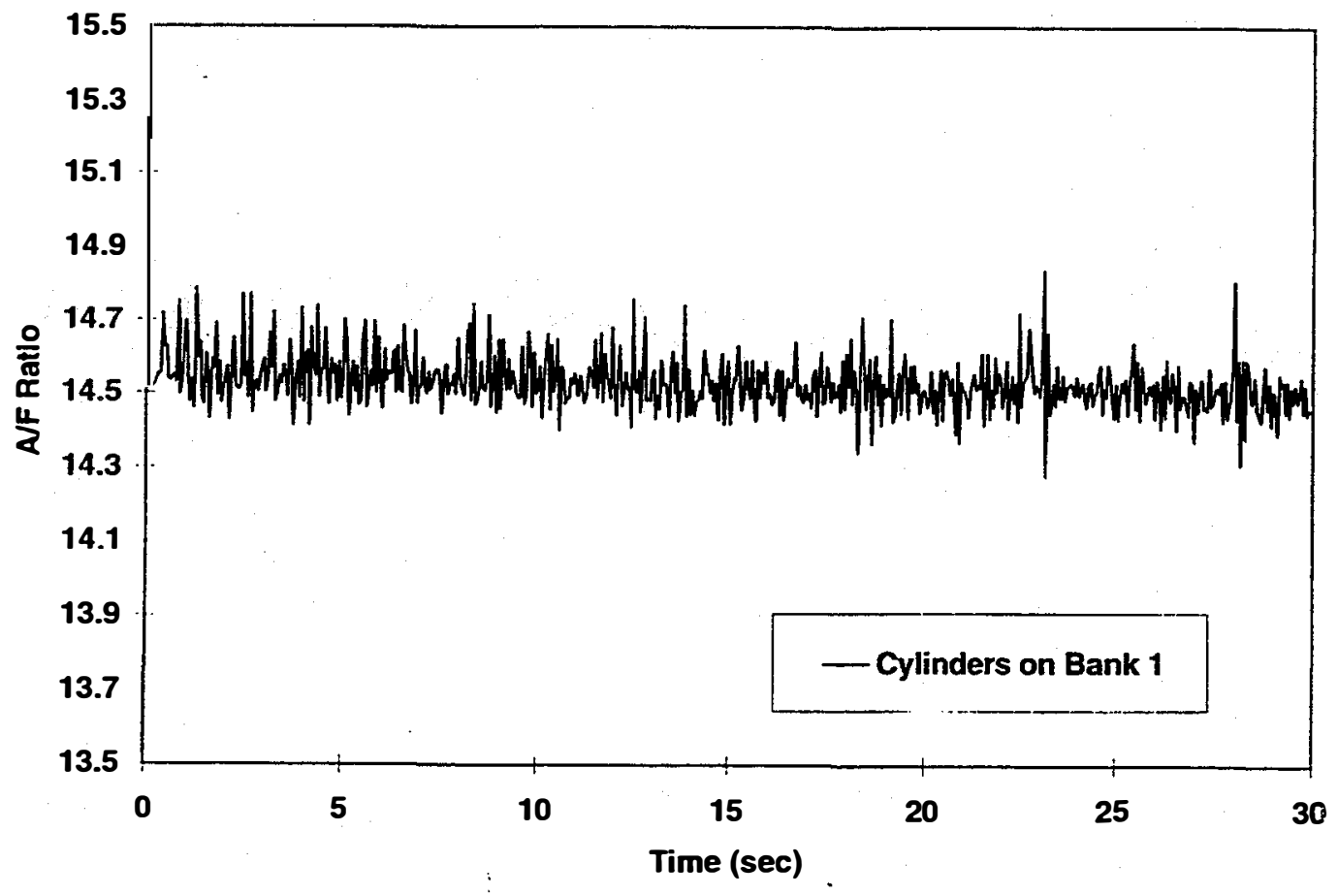

(g)

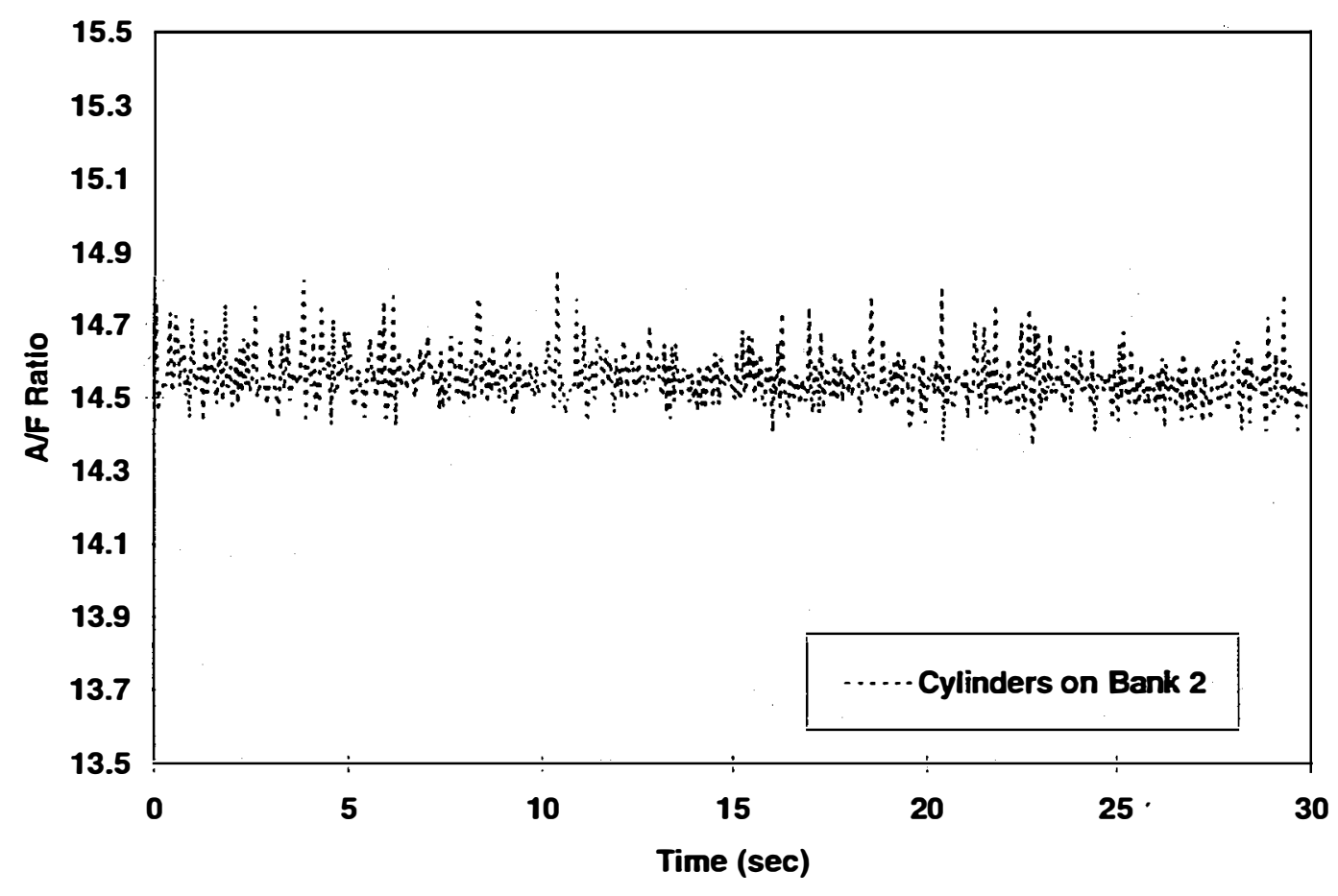

(h)

FIGURE 3-3. STEADY-STATE A/F RATIO FOR TAURUS ENGINE WITH CONSTANT COMMANDED PULSE WIDTH

Redesigned, Sleeved Air-Assist Injector, $70 \mathrm{kPag}, \mathrm{ECT}=82^{\circ} \mathrm{C}, 2000 \mathrm{rpm}, \mathrm{MAP}=0.7 \mathrm{bar}$ 


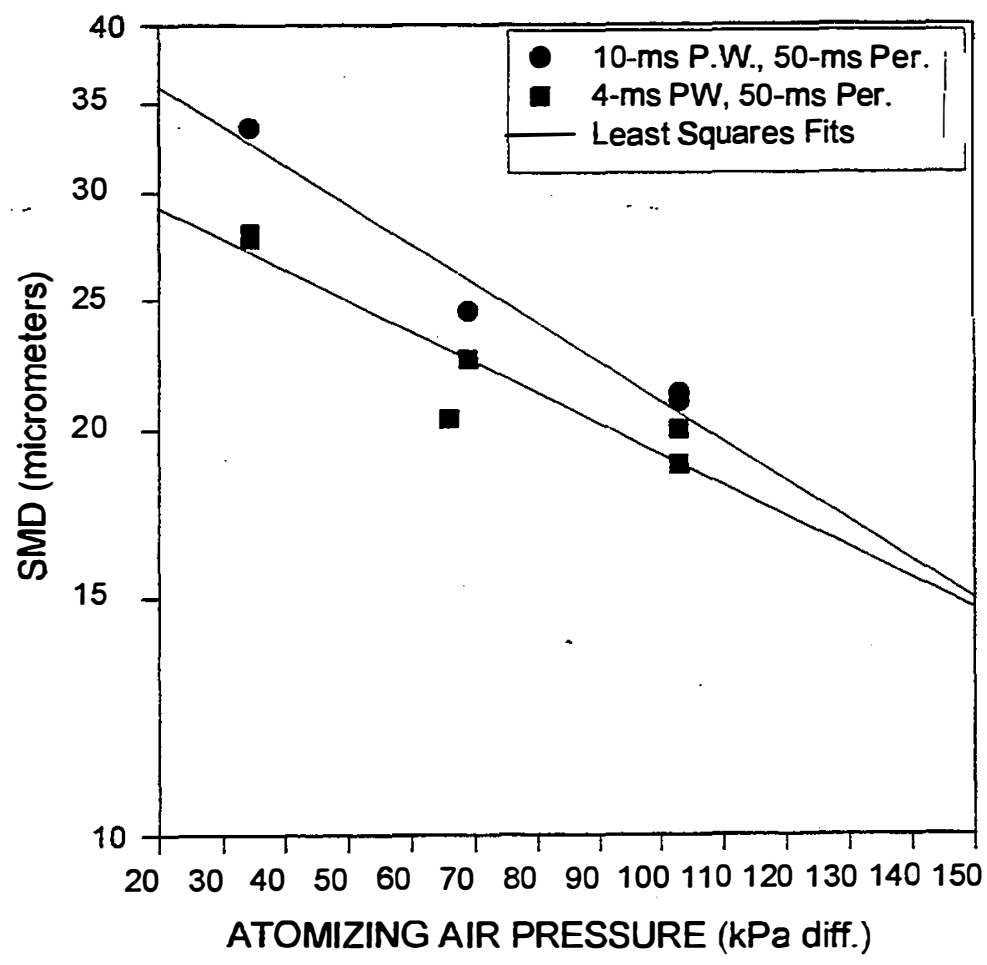

\section{FIGURE 3-4. SMD VERSUS AIR PRESSURE} SMALL VOL. AIR-ASSIST INJECTORS

\section{Installation of the Rapid Prototyping Engine Control System}

Ford, like all other OEMs, does not provide any support for adapting their engine controller for changes in engine hardware or for trying new control algorithms. Therefore, with the installation of the air-assist injectors, the rapid synchronization start-up system, the rapid exhaust gas oxidation system, and other changes, using the standard Ford EEC for control of the engine was not possible. Installing an SwRI-developed control system, a PC-based engine controller that could be programmed to handle all hardware changes and all engine control strategies, was necessary. This engine controller is called the SwRI RPECS. The details of the hardware for this system are described in the Phase 2 report on this project. The details of the algorithm development are provided in this section of the report.

\section{Cranking and Start-up System}

Many current production vehicles would fail the ULEV hydrocarbon emissions standards during the cranking portion of the U.S. Federal Test Procedure (FTP), before the engine ever started. Most vehicles in production do not synchronize spark and fuel injection until two or more engine revolutions. Before that time, fueling and spark timing are somewhat random relative to valve and piston movements. Therefore, only some cylinders of an engine are firing, while others are misfiring and producing high levels of hydrocarbons. This condition is unacceptable for a ULEV. It seems that an easy solution would be to wait to inject fuel until the controller is synchronized, there is enough fuel in the cylinders at shutdown that very high hydrocarbon emissions result from this approach. The high hydrocarbons result from cranking the engine and pumping the previously injected fuel through the engine without firing. It is necessary to fire as soon as possible. 
The first part of the approach adopted for clean starts in this project was to synchronize the engine controller with the engine hardware in $1 / 2$ or fewer rotations of the crankshaft. This was accomplished by replacing the standard synchronization system with a GM optical encoder used on the LT-1 engine (Kulkarni, 1992). The optical encoder was mounted in the distributor location on top of the 3.0-liter V-6 engine. This encoder has four, equally spaced, distinct marks, and 360 regularly spaced encoder marks used for higher-resolution position information. The four distinct encoder marks allow a unique indication of engine position within $1 / 4$ or fewer revolutions of the camshaft, or $1 / 2$ revolution or less of the crankshaft. Once one of these distinct marks passes the light emitting diode (LED) and detector, the control system is synchronized in about $5 \mathrm{~ms}$ ( $7.5 \mathrm{crank}$ angle degrees (CAD) at $250 \mathrm{rpm}$ cranking speed).

The encoder is connected to a Silicon Systems 67-F687 engine controller chip that keeps track of the engine position. The higher level control is accomplished on the Pentium PC, but the 67-F687 can compute the desired spark and fuel injection in time based on desired timings in CAD. This system allows rapid synchronization to begin the start-up process. No fuel or spark occurs until the engine controller is synchronized, but this occurs very rapidly. The first cylinder that has time to receive a full amount of fuel injection then receives the first fuel pulse. An exception to this occurs at low temperatures (below about $4^{\circ} \mathrm{C}$ or $40^{\circ} \mathrm{F}$ ) where prime pulses are used prior to cranking.

Cylinder-event-based logic is used to control fuel and spark through the first 500 or so (adjustable by user) cylinder events. This allows for a customized spark timing, and both amount and timing for fuel injection for every cylinder event. This starting calibration also depends on the engine temperature at start-up, with more fuel injected at lower temperatures for the first few cylinder events. Thus, there are three two-dimensional tables for start-up strategy, one each for spark timing, fuel injection timing, and fuel injection pulse-width multiplier. Each of the three tables has independent variables of engine coolant temperature at the start of cranking and cylinder event number. The pulse-width multiplier is a factor used to multiply the amount of fuel calculated to get a stoichiometric mixture in-cylinder if all of the injected fuel were transported in-cylinder on the first cylinder event following injection. In fact, much of the injected fuel collects on the port walls and intake valves during cold-start cranking.

The rapid synchronization and cylinder-event-based logic resulted in rapid starts at ambient temperatures. At low starting temperatures, the relatively non-volatile Ed85 is slow to vaporize, and large amounts of fuel must be injected for a sufficient fraction to vaporize to get a high probability for combustion on the first few cylinders to ingest $\mathrm{A} / \mathrm{F}$ mixtures. Below about $4^{\circ} \mathrm{C}\left(40^{\circ} \mathrm{F}\right)$ there was not sufficient time to inject all the fuel required to achieve combustion on the first few cylinder events (all in the first engine cycle). In addition, the Silicon System engine controller chip did not allow pulse widths long enough to obtain combustion as quickly as needed. Ford addressed these problems by using a very high flow rate starting injector that has an additional spray rod in the intake system to spray extra fuel for starting. Since SwRI was attempting to improve the spray quality using the air-assisted injectors and thereby improving the transport of fuel spray in-cylinder, this approach was not an acceptable solution. Therefore, SwRI modified the starting sequence at low temperatures, below about $4^{\circ} \mathrm{C}\left(40^{\circ} \mathrm{F}\right)$, to delay the starter motor until the "prime" pulses through the air-assist injectors were complete. If this approach is found to be unacceptable to vehicle operators, Ford's start-up injector could be used, but more fuel would be necessary for start-up, and hydrocarbon emissions would be increased. SwRI will also likely use a delay in the start-up 
sequence to allow the air pumps for the air-assist injectors to come up in speed before cranking the engine.

Using the rapid synchronization and cylinder-event-based logic combined with the prime pulse allowed very rapid starts over a wide range of temperatures. Hydrocarbon measurements were taken only at starts in the FTP range of $20^{\circ} \mathrm{C}$ to $30^{\circ} \mathrm{C}\left(68^{\circ} \mathrm{F}\right.$ to $\left.86^{\circ} \mathrm{F}\right)$ and it was verified that hydrocarbon emissions during the cranking period correlated very well with the number of misfires observed during cranking. Misfire information was obtained by instrumenting the engine with spark plug cylinder pressure transducers (Kistler 601B1) connected to a DSP Inc. Combustion Analyzer. Hydrocarbon emissions were measured with a Cambustion fast flame ionization detector (FFID). For most of the low-temperature starts, hydrocarbon emissions were not recorded, but it was assumed that a low misfire rate would correspond directly with low hydrocarbon emissions.

Starting calibrations have been developed for the temperature range from $27^{\circ} \mathrm{C}\left(80^{\circ} \mathrm{F}\right)$ down to $-18^{\circ} \mathrm{C}\left(0^{\circ} \mathrm{F}\right)$. For starts at the FTP emissions test temperature of about $25^{\circ} \mathrm{C}\left(77^{\circ} \mathrm{F}\right)$, the engine was first motored to clean out any fuel and hydrocarbon emissions from the engine. It was then started, but with no fueling on the first two engine cycles to allow the DSP Inc. Combustion Analyzer to synchronize with the engine. Figure 3-5 shows an ambient temperature start-up with no misfires, as shown in the top panel of indicated mean effective pressures (IMEP) that shows high values of IMEP for every cylinder event following the first two non-firing cycles. The hydrocarbon emissions shown in the bottom panel indicate a peak raw measured hydrocarbon level of 6000 ppmC, quickly dropping to about 2200 ppmC. This was essentially a perfect start.

As the temperature was lowered, the engine continued to start well, although the number of misfires increased as expected for low-temperature starts. For these tests, the two-cycle delay to allow the DSP engine analyzer to synchronize was not used, but instead a delay to wait until Cylinder No. 1 was available for fueling was used. This was probably not the best strategy since a prime pulse was already injected for each of the cylinders, and some of the cylinders fired during the first cycle on the prime pulse alone, while others were fueled with both a prime pulse and the pulse width commanded for the first firing event in the start-up sequence. This restriction to begin fueling with Cylinder No. 1 was later removed so that the first cylinder after synchronization of the 67-F687 controller chip with sufficient time for the fuel injection to occur will be the first cylinder fueled. However, this change was made after the test results reported here were obtained. In spite of the logic error in the start-up code, very strong starts were obtained.

At $16^{\circ} \mathrm{C}\left(60^{\circ} \mathrm{F}\right)$, the start-up results shown in Figure 3-6 were obtained. The top panel of Figure 3-6 shows the IMEPs, the second panel shows, on a much expanded scale, the actual cylinder pressure traces for the first few cycles, and the bottom panel shows the engine speed in rpm (dashed line), the manifold absolute air pressure in bar (solid line), and the wide range exhaust gas oxygen sensor (dotted line) in volts, where $3 \mathrm{~V}$ is stoichiometric, higher than $3 \mathrm{~V}$ is lean, and lower than 3 $\mathrm{V}$ is rich. The engine started with no misfires over the first 16 engine cycles, and then some misfires were observed when the MAP dropped to about 0.24 bar $(24 \mathrm{kPa})$, a pressure where the volumetric pumping efficiency of the engine is quite low. At this low MAP, the in-cylinder residual gases (burned gases from previous cycles) are high, so there is insufficient fresh air for good combustion. For this start, the idle air control (IAC) valve was used to set the air flow rate into the engine, and problems with the IAC are evident as shown in Figure 3-6. The speed oscillates to about $1800 \mathrm{rpm}$, and the MAP is so low during the speed oscillations, about $0.24 \mathrm{bar}(24 \mathrm{kPa})$, that the engine 
misfires. The IAC control problem was experienced during conditions other than start-up and, as a result, SwRI replaced the standard Ford IAC valve with a GM EGR valve that included a pintle position sensor. This pintle position sensor on the GM IAC valve allowed the position of the valve to be determined, and to be used for active feedback to the pulse-width-modulated (PWM) control for the valve.

At $4^{\circ} \mathrm{C}\left(40^{\circ} \mathrm{F}\right)$, the start-up results obtained are shown in Figure 3-7. At this condition, there were more misfires during the first 3 cylinder events, but the engine speed still increased quickly to $1800 \mathrm{rpm}$ in about 5 seconds after the beginning of cranking. Start-up results at $-7^{\circ} \mathrm{C}\left(20^{\circ} \mathrm{F}\right)$ are shown in Figure 3-8. As the air temperature was lowered, opening the throttle or IAC to progressively greater amounts was necessary so that the engine could overcome the greater loads due to more viscous oil. For this start-up, the throttle position was opened until the start-up speed exceeded $2000 \mathrm{rpm}$. This may be a higher speed than desirable, but note the very strong start with no misfires in spite of the low temperature. Figure 3-9 shows a start-up at $-14^{\circ} \mathrm{C}\left(6^{\circ} \mathrm{F}\right)$. At this temperature, the start-up was strong, but there were misfires on some cylinders during the first 8 cycles, and then no misfires after that.

Thus, the modifications to the engine and the strategy used in the control system are shown to provide very rapid, clean starts in the temperature range for FTP starts of $20^{\circ} \mathrm{C}$ to $30^{\circ} \mathrm{C}\left(68^{\circ} \mathrm{F}\right.$ to $86^{\circ} \mathrm{F}$ ). In addition, strong, rapid starts at low temperatures with Ed85 fuel have been demonstrated.

\section{Model-Based Control for Air and Fuel Flows}

The replacement of the OEM Ford EEC IV engine controller with the SwRI RPECS controller resulted in a loss of all the algorithms developed by Ford and used to control the standard engine functions. This allowed a clean-sheet approach to developing engine control. Consequently, a current state-of-the-art system was constructed. This system consisted of open-loop control to handle transients when closed-loop control based on the EGO sensor would be too slow, and closedloop control for the approximately steady-state conditions. Both open-loop and closed-loop control run continuously, with the open-loop doing the best estimates it can, and the closed-loop trimming out the errors.

The open-loop control system to control the A/F ratio tightly required a very extensive effort as part of this project. A paper describing the model-based control was presented at the $1997 \mathrm{SAE}$ Congress in Detroit. That paper provides a thorough description of the model-based control, and is included as Appendix A.

\section{Closed-Loop Control of Air-Fuel Ratio}

Beyond good fuel control during throttle transients, the low-emissions vehicle controller must provide the catalyst an exhaust feed gas that alternates rich and lean in a switching fashion. The catalyst efficiency for a particular species is dependent upon the A/F ratio switching point, amplitude, and frequency for the closed-loop controller. Dual, heated, switching exhaust gas oxygen (HEGO) sensors that were installed upstream of the catalysts provided the exhaust gas feedback. A model of the air and fuel transport was used to estimate transit times from the fuel injectors to the HEGO sensors to obtain the fastest switching frequency possible while maintaining control stability. The algorithm included jump-back logic. Jump-back increases the frequency of the switching rate. 
The rate of fuel ramp-up or ramp-down following the jump-back is computed based upon the desired biasing, switching amplitude, and computed transit time for fuel. Biasing of the switching point is obtained by using different fueling ramp-up and ramp-down rates. Biasing can be up to 1 percent rich or lean of stoichiometric. Desired biasing was a function of engine speed and manifold pressure. Desired switching amplitude depends on engine speed.

Adaptive feedback is used to improve the estimate of steady-state fueling requirements. The adaptive feedback correction factors are computed and stored in a two-dimensional table as a function of engine speed and manifold pressure. The adaptive update is driven by a standard steepest-descent adaptive update algorithm.

\section{Rapid Exhaust Port Oxidation}

The REPO is a method for rapidly heating the exhaust catalysts to a full catalytic activity temperature, about $400^{\circ} \mathrm{C}$, within about 20 seconds from the initiation of a cold-start on a U.S. FTP emissions cycle. The REPO accomplishes this by establishing a relatively low-temperature flame in the exhaust manifold of the engine. The flame is low temperature because it is diluted with burned gases from the primary combustion in the engine cylinders. The fuel for the REPO is supplied by running the engine rich. The air is supplied by an external air pump. The air pump to be used on the vehicle is supplied by Bosch for application to a Mercedes vehicle.

For the REPO system, the positions of the two catalysts (one for each bank) from the engine are the same as those found in the OEM vehicles. The front faces of the two catalysts are approximately 500 and $610 \mathrm{~mm}$ downstream from the exhaust port. Standard OEM catalysts were used for all tests, although they were aged the equivalent of roughly 4000 miles using a GM aging cycle.

Typical performance of the REPO system on the vehicle is shown in Figure 3-10. The front face of the front catalyst reaches $400^{\circ} \mathrm{C}$ in about $17 \mathrm{~s}$ following the cold start, and the hydrocarbons measured by a fast FID hydrocarbon analyzer show a reading of about $1000 \mathrm{ppmC}$ in about the same time. It is assumed that the catalyst conversion efficiency reaches $50 \%$ at roughly this time. By about $35 \mathrm{~s}$ following the cold start, the conversion efficiency is very high, with hydrocarbons levels of $50 \mathrm{ppmC}$ or less, except for a few excursions higher.

\section{Summary of Tasks 3, 5, and 6}

At the completion of these tasks, all modifications to the engine hardware and the addition of new sensors and replacement of control valves were complete. The RPECS engine control hardware was complete and operational. The algorithms necessary for all aspects of engine control were developed, and all calibrations possible in the engine test cell were complete. Further final calibration work will be required when the engine is installed in the vehicle under Phase 4 of this project. 


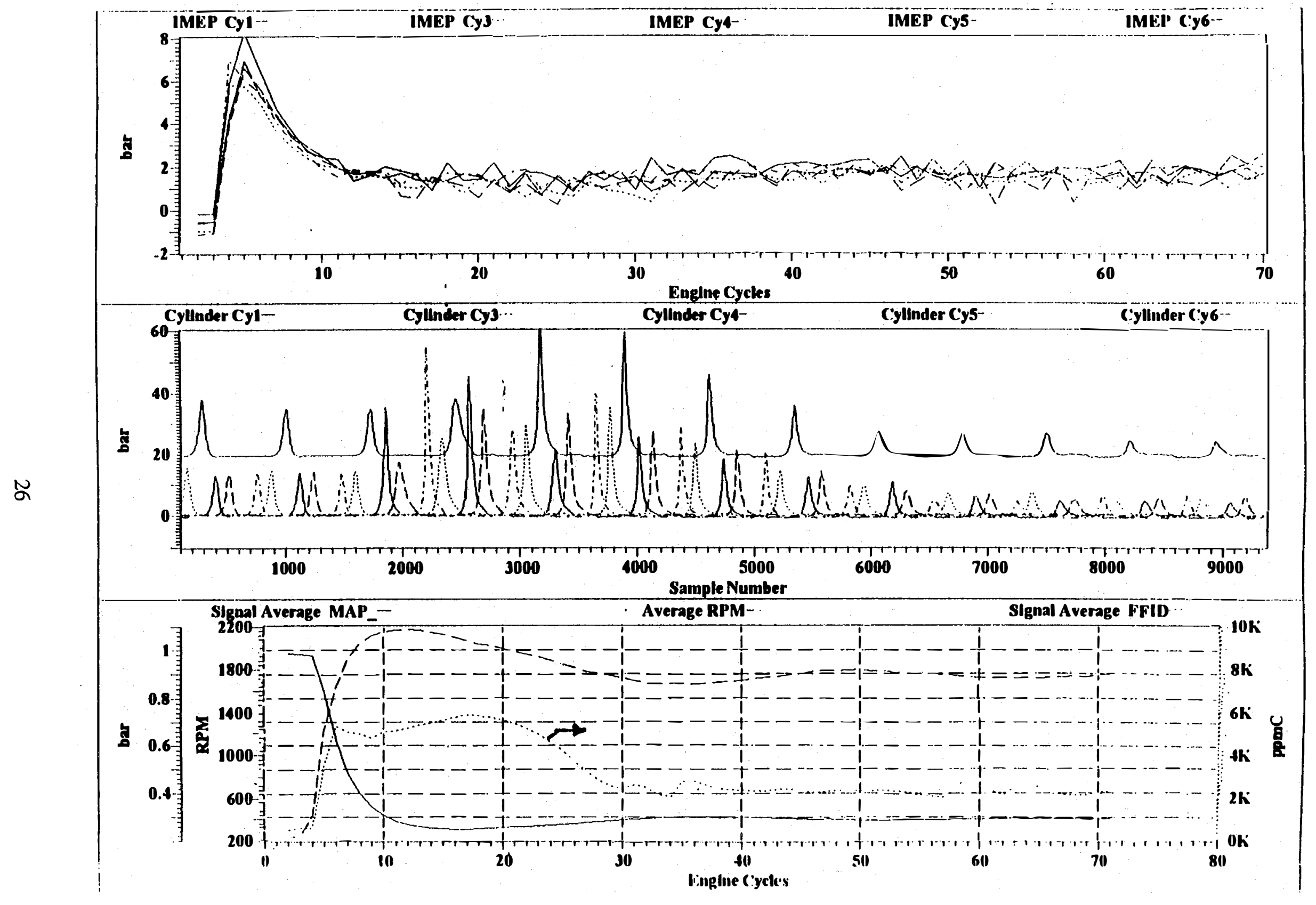

FIGURE 3-5. AMBIENT TEMPERATURE $27^{\circ} \mathrm{C}\left(80^{\circ} \mathrm{F}\right)$ COLD START SHOWING NO MISFIRES AND VERY LOW HYDROCARBON EMISSIONS. (Two cycles of motoring preceding beginning of fuel injection.) 


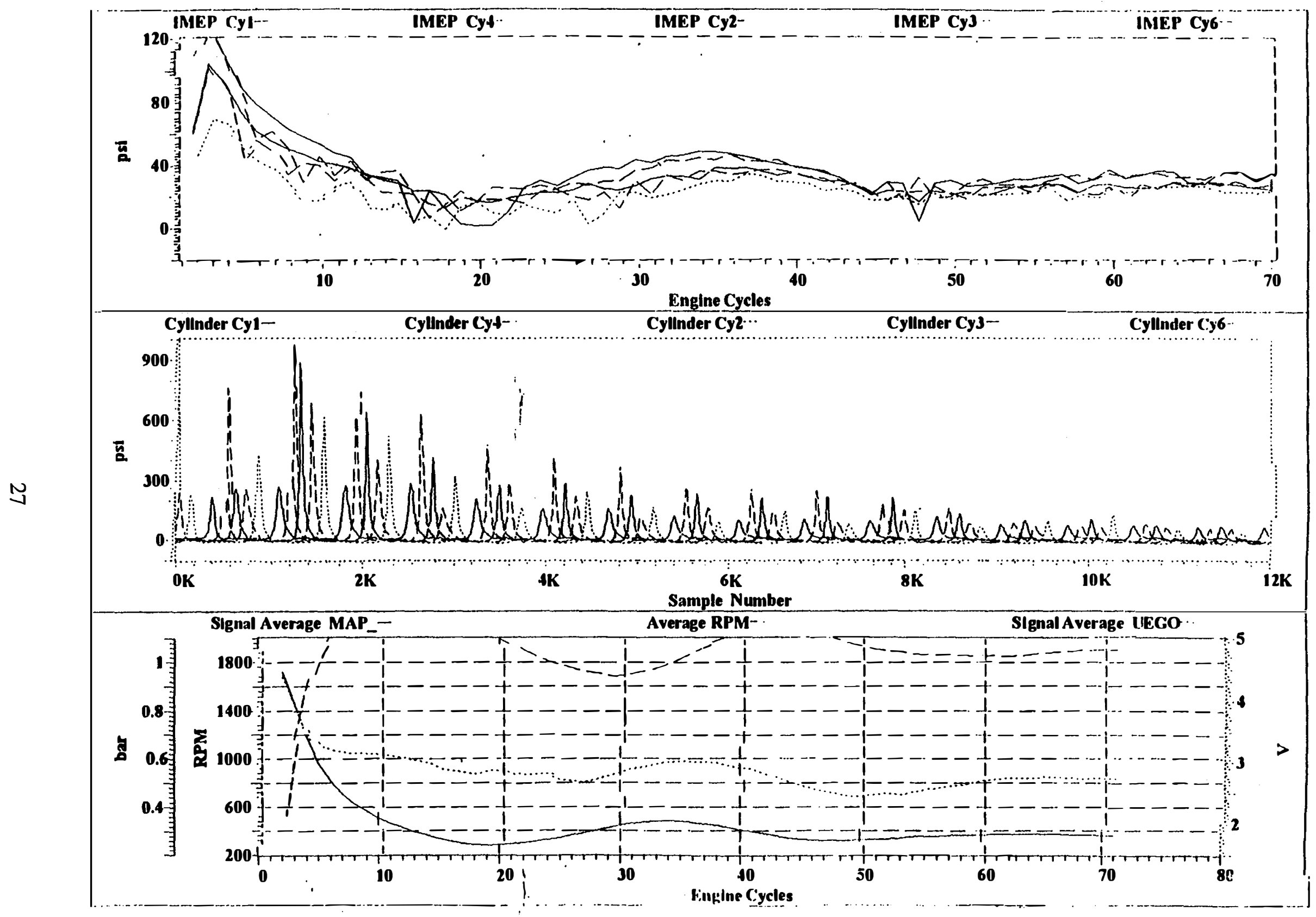

FIGURE 3-6. COLD START AT $16^{\circ} \mathrm{C}\left(60^{\circ} \mathrm{F}\right)$ 


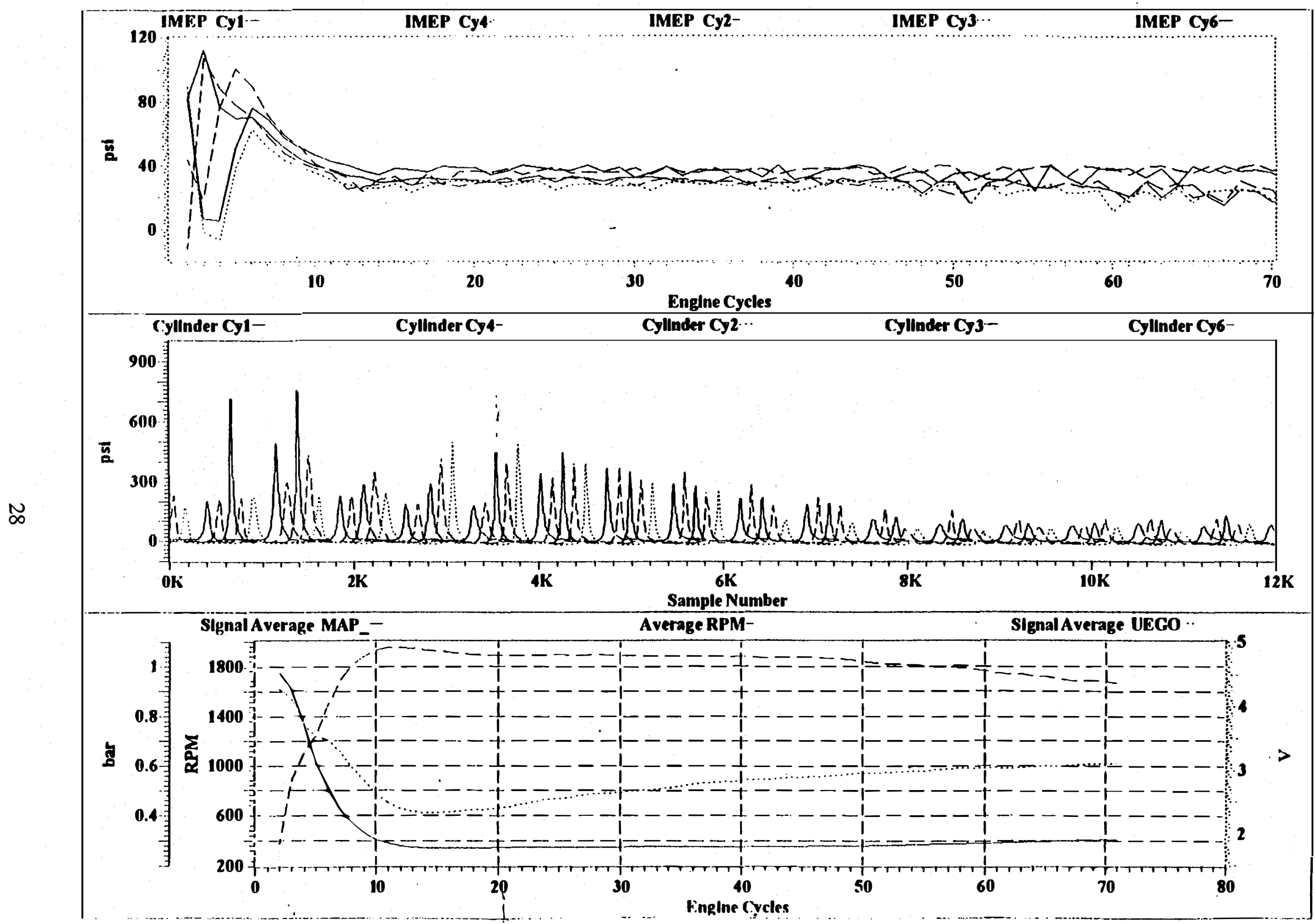

FIGURE 3-7. COLD START AT $4^{\circ} \mathrm{C}\left(40^{\circ} \mathrm{F}\right)$ 


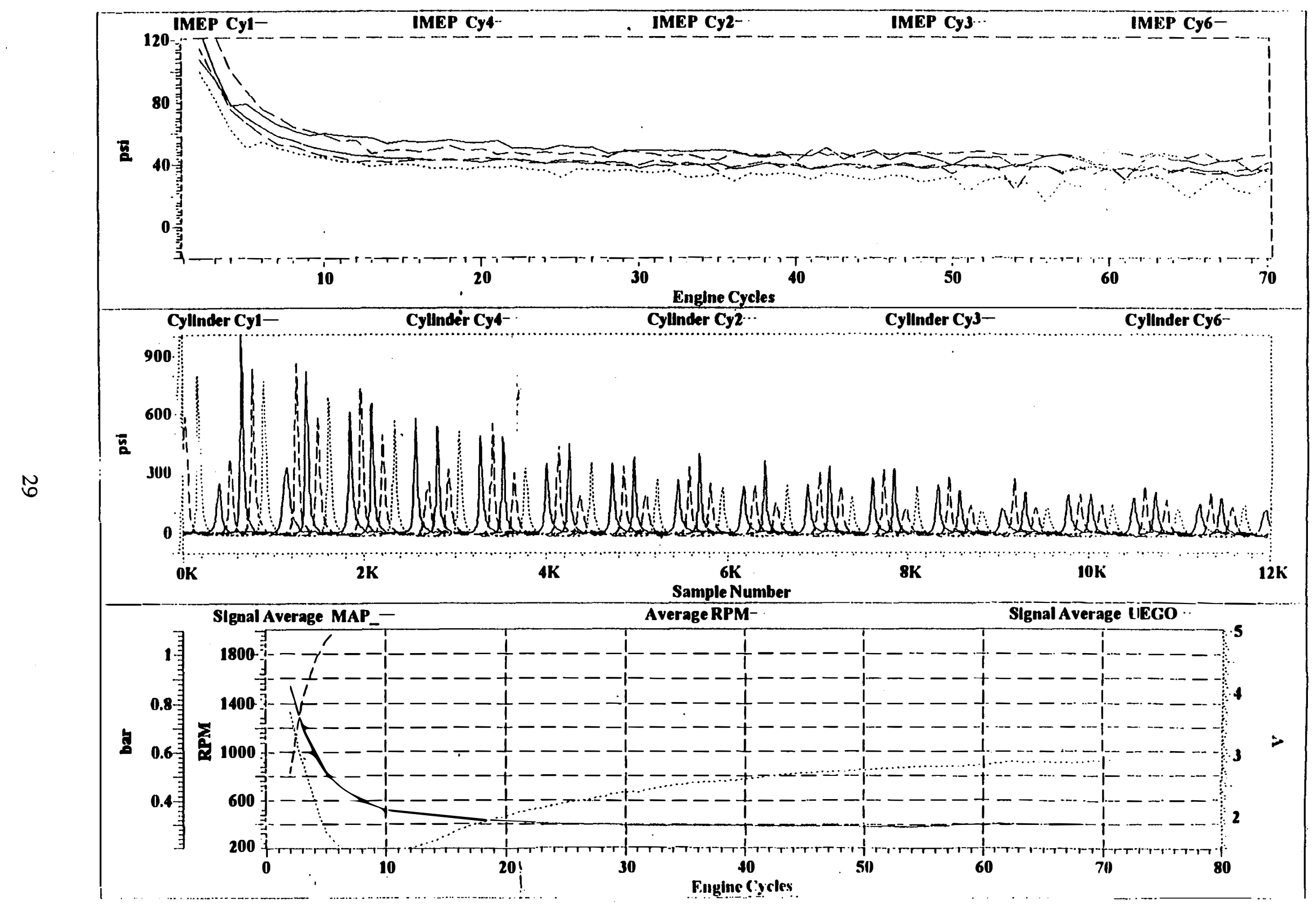

FIGURE 3-8. COLD START AT $-7^{\circ} \mathrm{C}\left(20^{\circ} \mathrm{F}\right)$ 


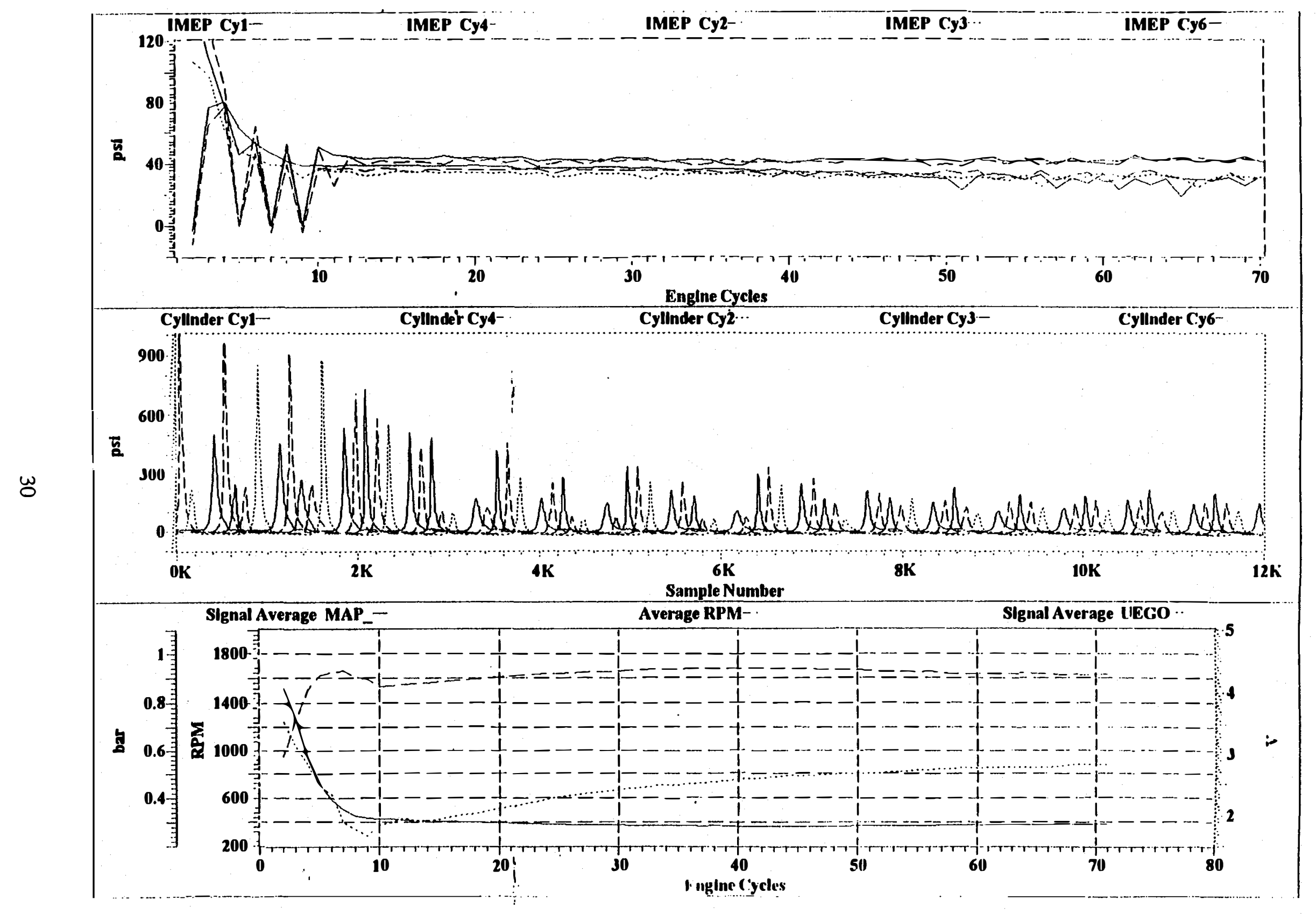

FIGURE 3-9. COLD START AT $-14^{\circ} \mathrm{C}\left(6^{\circ} \mathrm{F}\right)$ 


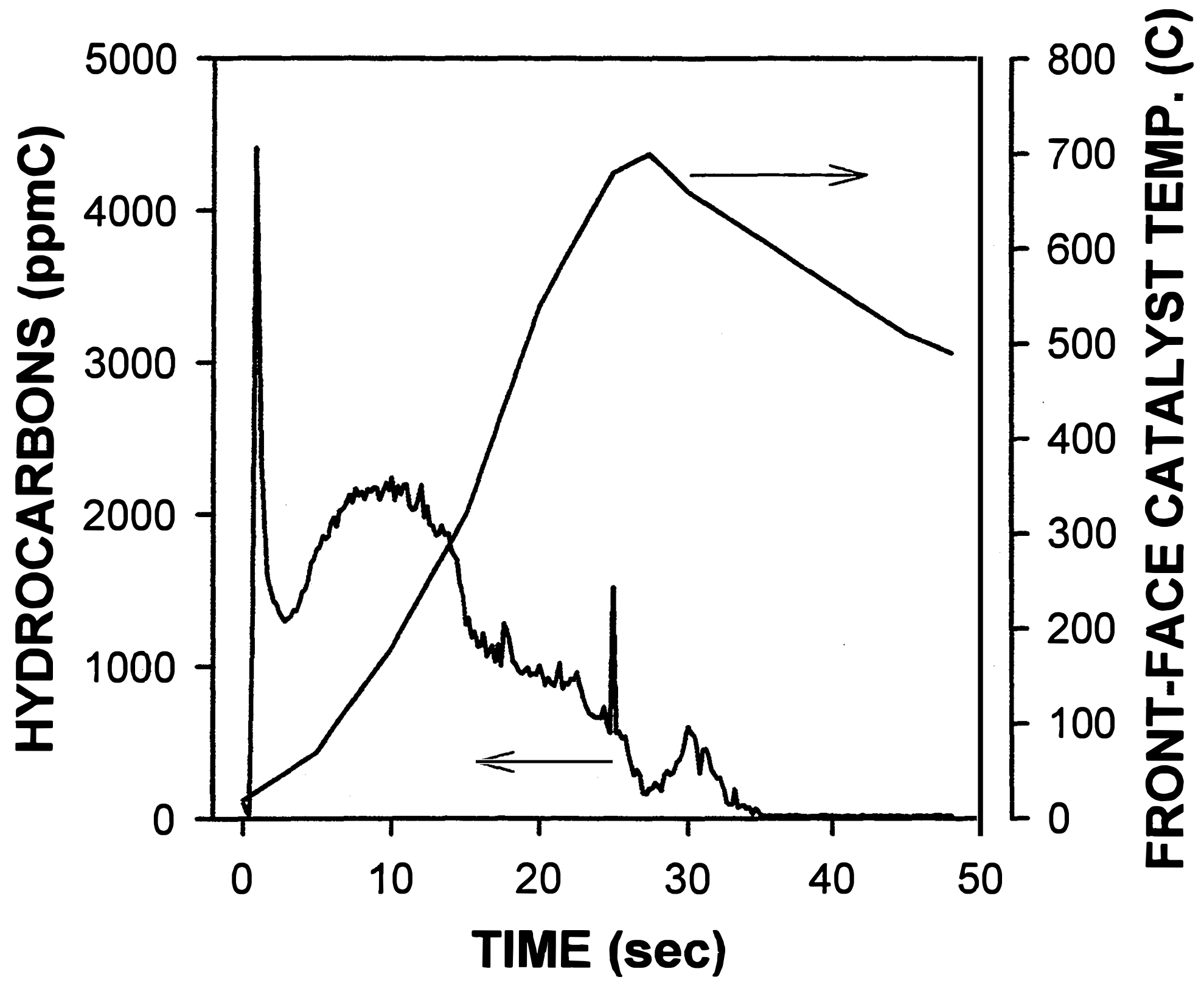

FIGURE 3-10. CATALYST FRONT-FACE TEMPERATURE RISE AND AFTER CATALYST HYDROCARBON EMISSIONS USING REPO CATALYST LIGHT-OFF 


\section{TASK 4 EMISSIONS CONTROL SYSTEM DEVELOPMENT AND TESTING}

\section{Objectives}

The objectives of tests during Phase 3 of this project were to evaluate two advanced aftertreatment technologies. The first was a hydrocarbon adsorber, and the second was a combination adsorber/catalyst built into one package. Also reported in Appendix B to this report are the results of tests of a vacuum insulated catalyst developed by NREL and tested on the baseline vehicle used in this project.

\section{Background}

Previous work on this project has included tests of electrically heated catalysts (EHC) at several different operating conditions (Dodge, et al. 1995). This work has shown that, for the EHCequipped vehicle, even without engine modifications, ULEV emissions can be achieved for both CO and $\mathrm{NO}_{x}$, but hydrocarbon emissions were slightly to significantly above the ULEV standards, depending on the individual test. These EHC tests were conducted on an unmodified OEM engine. It is likely that ULEV emissions for hydrocarbons would have been obtained using the modified engine as described in Task 3 and 5 of this project, but that work was being conducted concurrently, so it was not possible to use the modified engine. It should be noted that these emissions were achieved with a catalyst with 4,000 miles of aging, while ULEV standards must be met with catalysts with up to 50,000 miles of aging. Some of those EHC tests were repeated in the Phase 3 work, and the results are reported here.

\section{Results of Aftertreatment Tests}

The test vehicle was fitted with an exhaust system modified to accommodate experimental aftertreatment devices, including a hydrocarbon adsorber and a combination adsorber/catalyst (adcat). The hydrocarbon adsorber and the adsorber/catalyst were supplied as a 'black-box' by Degussa. SwRI was not permitted to analyze the materials or details of construction. The modifications to the exhaust system were conducted in preparation for a series of emissions evaluations utilizing the chassis dynamometer portion of the light-duty FTP.

After work on the exhaust system was completed, the vehicle was prepared for a series of FTP tests to determine the effect of the various aftertreatment systems on exhaust emissions. First, the previously tested EHC/reformulated catalyst system was installed on the vehicle to establish a current baseline for exhaust emissions. The system was operated with air injection at flow rates of $7 \mathrm{cfm}$ and $10 \mathrm{cfm}$. The vehicle was then tested with an adsorber in front of the EHC/reformulated main catalyst combination. Finally, the adcat system was tested on the vehicle in two configurations. The first configuration placed the adcat system where the OEM catalyst had been located and utilized the reformulated main catalyst located in an underbody position used for previous tests. In the second configuration, the reformulated main catalyst brick was cut in half perpendicular to the cylindrical axis, and each half was placed behind an adcat on each bank of the exhaust system where the OEM catalysts had been. A summary of the test matrix is given in Table 4-1. Results of the exhaust emissions tests conducted to date are given in Table 4-2. 
Comparing the current baseline EHC test (EHC-7CFM-B) with the previous baseline EHC test (E80-EHC-7CFM), exhaust emissions have increased slightly, especially hydrocarbon emissions. Examining the individual bag data (Table 4-3) reveals that hydrocarbon levels are elevated across the entire FTP. This vehicle sat idle for three months between tests, and it is believed that the higher HC emissions reflect a shift in the vehicle's emissions characteristics.

Comparing the EHC tests with $7 \mathrm{cfm}$ and $10 \mathrm{cfm}$ air injection flow rates, the lower flow rate yielded lower exhaust emissions. These differences are mostly found in Bag 1A - the first 140 seconds of the FTP. Apparently, the higher flow rate causes excessive cooling of the EHC during the idle immediately following cranking. This cooling leads to lower catalyst temperatures and poorer catalyst efficiency during the first few minutes of the test. Based on the above information, the EHC was operated with an air-injection flow rate of $7 \mathrm{cfm}$ for tests with the adsorber.

\section{TABLE 4-1. EMISSIONS TEST MATRIX}

\begin{tabular}{|c|c|c|c|c|c|c|}
\hline Test Number & Catalyst & $\begin{array}{l}\text { Catalyst } \\
\text { Position } \\
\end{array}$ & $\begin{array}{c}\text { Adsorber/ } \\
\text { adcat }\end{array}$ & EHC & $\begin{array}{c}\text { EHC } \\
\text { Heating } \\
\end{array}$ & Secondary Air injection \\
\hline EHC-7CFM-B & Degussa & underbody & no & yes & $\begin{array}{l}\text { Bag } 1-25 \mathrm{sec} \\
\text { Bag } 3-10 \mathrm{sec} \\
\end{array}$ & $\begin{array}{l}\text { Bag 1 - } 115 \mathrm{sec} @ 7 \mathrm{~cm} \\
\text { Bag 3 - } 10 \mathrm{sec} @ 7 \mathrm{cfm} \\
\end{array}$ \\
\hline EHC-10CFM & Degussa & underbody & no & yes & $\begin{array}{l}\text { Bag } 1-25 \mathrm{sec} \\
\text { Bag } 3-10 \mathrm{sec} \\
\end{array}$ & $\begin{array}{l}\text { Bag } 1 \text { - } 115 \mathrm{sec} @ 10 \mathrm{~cm} \\
\text { Bag 3 - 10 sec@10 cfm }\end{array}$ \\
\hline $\mathrm{ADS}+\mathrm{EHC}$ & Degussa & underbody & adsorber & yes & $\begin{array}{l}\text { Bag } 1-25 \mathrm{sec} \\
\text { Bag 3-10 sec } \\
\end{array}$ & $\begin{array}{l}\text { Bag 1 - } 115 \mathrm{sec} @ 7 \mathrm{~cm} \\
\text { Bag 3 - 10 sec @ } 7 \mathrm{cfm} \\
\end{array}$ \\
\hline $\mathrm{ADS}+\mathrm{EHC}-2$ & Degussa & underbody & adsorber & yes & $\begin{array}{l}\text { Bag } 1-45 \mathrm{sec} \\
\text { Bag } 3-10 \mathrm{sec} \\
\end{array}$ & $\begin{array}{l}\text { Bag 1 - } 115 \mathrm{sec} @ 7 \mathrm{~cm} \\
\text { Bag 3 - } 10 \mathrm{sec} @ 7 \mathrm{~cm} \\
\end{array}$ \\
\hline ADCAT+MAIN-A & Degussa & underbody & adcat & no & none & none \\
\hline ADCAT+MAIN-B & Degussa & close coupled & adcat & no & none & none \\
\hline
\end{tabular}

TABLE 4-2. FTP EXHAUST EMISSIONS FROM FFV TAURUS ON Ed85

\begin{tabular}{|c|c|c|c|}
\hline Test Number & FID HC & $\mathrm{CO}$ & $\mathrm{NO}_{\mathbf{r}}$ \\
\hline E80-EHC-7CFM, (previous baseline) & 0.139 & 0.795 & 0.068 \\
\hline EHC-7CFM-B & 0.178 & 0.831 & 0.073 \\
\hline EHC-10CFM & 0.202 & 0.878 & 0.093 \\
\hline $\mathrm{ADS}+\mathrm{EHC}$ & 0.407 & 1.935 & 0.201 \\
\hline $\mathrm{ADS}+\mathrm{EHC}-2$ & 0.340 & 1.750 & 0.177 \\
\hline ADCAT+MAIN-A & 0.254 & 1.456 & 0.066 \\
\hline ADCAT+MAIN-B & 0.276 & 1.670 & 0.092 \\
\hline
\end{tabular}

TABLE 4-3. COMPARISON OF HYDROCARBON EMISSIONS WITH EHC

\begin{tabular}{||c|c|c|c|c||}
\hline \multirow{2}{*}{ Test Number } & \multicolumn{4}{|c|}{ FID HC Exhaust Emissions (grams) } \\
\cline { 2 - 5 } & Bag 1A & Bag 1B & Bag 2 & Bag 3 \\
\hline EHC-7CFM & 1.244 & 0.532 & 0.098 & 0.311 \\
\hline EHC-7CFM-B & 1.588 & 0.723 & 0.156 & 0.325 \\
\hline
\end{tabular}


As shown in Table 4-2, test results with the adsorber are not as good as the EHC baseline (EHC-7CFM-B). Continuous data showed that catalyst temperatures dropped severely as soon as power to the EHC was turned off. It was thought that, at the time the EHC was turned off, the adsorber was still trapping exhaust emissions. Thus, the exhaust after the adsorber was too lean to maintain catalyst light-off temperatures. Therefore, a second test (ADS+EHC-2) was conducted with this configuration, but using a 45-second, post-crank heating time on the EHC rather than the previous 25 seconds. It was hoped that the adsorber would be releasing some of the trapped exhaust constituents by this time, providing an appropriate mixture in the exhaust stream to properly light-off the catalyst. Although this test showed some improvements in Bag $1 \mathrm{~A}$ emissions over the previous test, the temperature of the catalyst still dropped off quickly after the EHC was turned off. It is speculated that the adsorber was oversized for the system and that, even after 45 seconds of operation, the exhaust stream reaching the catalyst was too lean to maintain catalyst light-off. In addition, when the adsorber was installed, it acted as a heat sink in the exhaust stream. Thus, with the adsorber installed, the exhaust stream temperature at the face of the catalyst remained low for the first few minutes of the FTP, contributing to the rapid cooling of the catalyst after the EHC was turned off.

Results from tests with the adcat installed in conjunction with the main catalyst indicate this system also needs further development in order to achieve ULEV emissions levels. It is speculated that the adcat, like the adsorber, is oversized for this vehicle and that the catalyst was not provided with a sufficient amount of fuel to quickly reach light-off temperatures. In addition, the adcat system also acted as a heat sink ahead of the catalyst, causing longer times for the catalyst to reach light-off temperatures.

\section{Future Plans}

Based on the preliminary testing of advanced aftertreatment systems, the EHC will be developed further for this program. Once the engine modifications are complete, the aftertreatment effort will focus on improving the performance of the EHC. The scope of this program precludes further investigation of the adsorber or adcat system. Although this type of technology has been successfully proven on gasoline vehicles, most of these systems have used complex valving and routing of the exhaust and secondary air to achieve ULEV-level exhaust emissions. In addition, exhaust temperatures, when operating on gasoline, are higher than when operating on alcohols; thus, those systems are more tolerant to some heat loss to the adsorber. This is a new technology that needs to be further developed to properly operate on an ethanol-fueled vehicle. With further development, adsorbers aftertreatment technology may be capable of achieving ULEV exhaust emissions standards on alcohol-fueled vehicles. 


\section{TASK 7 HIGH-SPEED DATA ACQUISITION AND CONTROL}

\section{Background and Objective}

An important part of meeting ULEV standards is starting the engine with as few a number of misfires as possible. It is also necessary using the REPO strategy for catalyst light-off to operate the engine fuel-rich, but to avoid any misfires from operating too rich. Further, it is necessary to avoid misfires on vehicle decelerations when the engine is motored by the vehicle, and relatively low manifold air pressures are obtained. For peak efficiency, it is necessary to operate the engine near the minimum advance for best torque (MBT) ignition timing, but somewhat retarded from MBT for $\mathrm{NO}_{x}$ control. For all these reasons, it is desirable to have an ability to measure the power produced for each cylinder event, and this is usually specified by the IMEP, and to measure the peak cylinder pressure for each cylinder event. Misfires are easily identified by the zero IMEP produced, and MBT timing corresponds approximately to peak cylinder pressures occurring about 13 to $15 \mathrm{CAD}$ after top center. Therefore, it is very desirable to have built into the control system the capability of measuring cylinder pressures, and algorithms to compute from the cylinder pressures both the location of peak cylinder pressure and the IMEP.

The objective of this task was to develop a high-speed, cylinder-pressure data acquisition system that could be built into the RPECS engine control system. This system would provide rapid acquisition of cylinder pressure data for engine combustion analysis, or could be used in an active feedback to control knock, and could provide MBT or other engine performance criteria.

\section{Accomplishments}

The main pieces of hardware required for this phase were acquired with SwRI funds, and included:

- A 90 MHZ Pentium PC

- A copy of the QNX operating system

- $\quad$ A DAS58 High-Speed, Buffered, 8-channel, PC data acquisition board with external sample-and-hold circuitry

The concept is to build a stand-alone, PC-based, high-speed data acquisition and analysis system that includes a high-speed link to the RPECS engine controller. Both the high-speed data acquisition and analysis system and the RPECS engine controller are on PC platforms, but with QNX operating systems (a real-time UNIX-type system). The DAS58 card interfaces with the cylinder pressure transducer signals to digitize them for interfacing with the PC.

The interface code for the DAS58 high-speed data acquisition card has been completed. This code provides the low-level functions necessary to initialize and configure the DAS58 card, to initiate data acquisition to the DAS58 on-board memory buffer, and to retrieve the acquired data from the DAS58 on-board memory to the controlling PC's memory. Options supported include 
internal or external clocking; internal or external (either digital or analog) trigger; trace before, after, or around the trigger point; and fully software configurable trace length and number of channels.

Since no direct software support is provided by Keithley-Metrabyte for the QNX platform, and since very little technical documentation is included with the DAS58 card, the completion of these low level driver routines was perhaps the single greatest technical challenge in providing combustion analysis capabilities to the RPECS system using the DAS58 card. In fact, completion of the interface code required the disassembly of the Keithley-Metrabyte object format libraries, so that all details of the of the card configuration sequencing could be determined.

With the interface code complete, the next step required to develop an RPECS-integrated, high-speed combustion analysis system was to work toward integrating the new interface code into the existing library of RPECS real-time and user interface routines. This step will allow for use of the interface code within the RPECS libraries, and will provide the basic user interface (for both data acquisition control and plotting/logging of results). Once this step is complete, the incorporation of existing SwRI combustion analysis routines will be initiated.

With the low level interface routines to the Keithley-Metrabyte DAS58 high-speed analog-todigital card under QNX complete, work began on converting existing SwRI combustion analysis routines to the QNX platform. These routines are being organized in a library which will interface very tightly with the existing SwRI real-time and user interface capabilities of the RPECS. With these algorithms in hand, together with the existing real-time and GUI interface libraries, it will be a relatively simple matter to construct a high-speed analysis system---one that either stands alone, providing combustion analysis only, or one that tightly integrates with an RPECS, allowing for real-time feedback of combustion analysis results.

\section{References}

Kulkami, A.V. (1992). “New Generation Small Block V8 Engine,” SAE 920673.

Dodge, L.G., et al (1995). Development of a Dedicated Ethanol Ultra-Low Emission Vehicle (ULEV), Phase 2 Report. 


\section{APPENDIX A \\ SAE PAPER NO. 9070531 \\ 'MODEL-BASED CONTROL AND CYLINDER-EVENT-BASED \\ LOGIC FOR AN ULTRA-LOW EMISSIONS VEHICLE}




\section{Model-Based Control and Cylinder- Event-Based Logic for an Ultra-Low Emissions Vehicle}

D. M. Leone, L. G. Dodge, K. R. Shouse, and J. Grogan Southwest Research Institute

R. W. Weeks Modular Systems

Reprinted from: Electronic Engine Controls 1997

(SP-1236) 
Theappearance of the ISSNcodeat the bottom of thispageindicatesSAEs consent that copies of thepapermay bemadeforpersonal orintemal use of specificcients. Thisconsent is given on the condition however, that thecopierpay a\$7.00perarticlecopyfeethrough the Copyright Clearance Center, Inc. Operations Center, 222 Rosewood Drive, Darvers, MA 01923 forcopying beyond that permitted by Sections 107 or 108 of the U.S. Copyrigth Law. Thisconsentdoes notextend to otherkinds of copyingsuch ascopyingforgeneral distribution, foradvertisingorpromotional purposes, forcreating newcollectiveworks, or forresale.

SAE routinely stocks printed papers for a period of three years following date ofpublication. Directyourordersto SAE Customer Sales and Satisfaction Department.

Quantityreprintratescanbe obtained from the CustomerSalesand Satisfaction Department

To requestpermissionto reprintatectrical paperorpermissionto usecopyrightedSAE publications in otherworks, contact the SAEPublications Group.

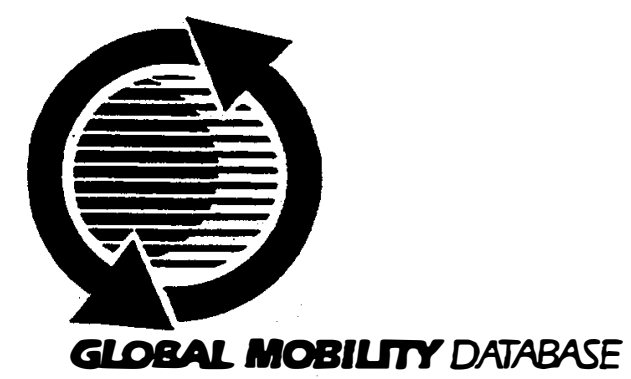

All SAE papers, standards, and selected booksareabstactedandindexedintheSAE GlobalMobility Database.

Nopart of this publicationmaybyreproducedinanyform, in an electronic retrieval system or otherwise, withourt the priorwsitten permission of the publisher.

\section{ISSN0148-7191}

Copyright 1997 Sociedy of Automotive Engineers, tha.

Positionsandopivionsadvancedinthis paperarethoseofthe author(s) and not necesanty those ofSAE Theauthorissolely responsibleforthecontent of the paper. A processis available by which discussions will be printed with the paper if it is published in SAE Transactions. For permission to publish this paper in full or in part, contact the SAE Publications Group.

Persons wishing tosubmitpaperstobeconsideredforpresentation or pubreation through SAEshould send the manuscript ora 300 word abstract of a proposed manuscriptto: Secretury, Engineering Meetings Board, SAE.

\section{Printed in USA}




\title{
Model-Based Control and Cylinder-Event-Based Logic for an Ultra-Low Emissions Vehicle
}

\author{
D. M. Leone*, L. G. Dodge, K. R. Shouse, and J. Grogan \\ Southwest Research Institute \\ R. W. Weeks \\ Modular Systems
}

Copyright 1997 Society of Automotive Engineers, Inc.

\section{ABSTRACT}

Improvements in several areas are required to convert current technology light-duty vehicles into low-emissions vehicles suitable for meeting California's Ultra-Low Emissions Vehicle (ULEV) standards. This paper discusses one of those areas, the engine and aftertreatment control system algorithms. The approach was to use model-based air and fuel flow calculations to maintain accurate air-fuel ratio control, and to interface the aftertreatment requirements with engine air-fuel ratio control during the cold- and hot-start parts of the cycle. This approach was applied to a 1993 Ford Taurus operating on Ed85 (85\% denatured alcohol, $15 \%$ gasoline).

Algorithms discussed in this paper include: a manifold airflow model for predicting airflow and exhaust gas recirculation (EGR) into and out of the intake manifold; a manifold absolute pressure (MAP) observer for predicting MAP with lead information compared with a MAP sensor; manifold air pressure control to reduce the likelihood of misfires during decelerations; a transient volumetric efficiency correction model; dual tau $(\tau)$, epsilon $(\varepsilon)$ type transient compensation models, cylinder-event-based control for starting, and an aftertreatment control system for rapid catalyst light-off.

\section{INTRODUCTION}

Current technology engines and vehicles need to be adapted to meet very low emissions standards, including California's Ultra-Low Emissions Vehicle (ULEV) standards, while maintaining good engine driveability and efficiency. Current technology vehicles suffer highest emissions during the cold-start portion (first 140 seconds of the first bag) of the U.S. Federal Test Procedure
(FTP) [1]t. Hydrocarbon and $\mathrm{CO}$ emissions are especially high during the cranking and transient portions of the cold start. In its original equipment manufacturers (OEM) configuration, the 1993 Ford Taurus used in this project emitted $93 \%$ of its FTP nonmethane organic gases (NMOG) in the first $140 \mathrm{~s}$. In addition to cold start, hot start and speed/load transients are also significant contributors to NMOG and CO FTP emissions. $\mathrm{NO}_{x}$ emissions are spread out through the cycle, but tend to be a problem during transients where air-fuel ratio control to the catalysts is not accurate and the air-fuel ratio is not switching across stoichiometric. Thus, the focus areas for improvements required for low emissions are in cold- and hot-starts, and transient fuel and air control.

Under funding from the National Renewable Energy Laboratory and the Department of Energy, the base Taurus was converted to dedicated Ed85 (85\% denatured ethanol, $15 \%$ gasoline) service, while its emissions were reduced to meet ULEV standards. Additional project goals included maintaining good driveability and using technologies that are cost competitive with gasoline.

Ethanol fuel is of interest because it: can be made from biomaterials and therefore is a renewable fuel, is higher in octane than regular grade gasolines [2], has a lower ozone forming potential than gasoline, has a potential for reducing greenhouse gases since it is made from biomaterial, and is nontoxic until toxins are added to prevent human consumption: However, ethanol's relatively low volatility makes it more challenging than gasoline for developing starting and transient compensation strategies. Further, the increased compression ratio (9.25 to 11.0) lowers the temperature at exhaust valve opening by a predicted $65^{\circ} \mathrm{C}$, and switching from gasoline to ethanol is predicted to further lower the temperature by $53^{\circ} \mathrm{C}$, making it more difficult to keep the catalyst active. (These calculations were made with the SwRI ALAMO_ENGINE cycle simulation [3].) Thus, this test

"Now with Woodward Governor Company, Ft. Collins, Colorado. tNumbers in brackets refer to References at end of paper. 
bed that includes both a high compression engine and an ethanol blend fuel represents a challenging vehicle for developing ULEV strategies.

\section{BACKGROUND - TYPICAL HARDWARE AND SOFT- WARE MODIFICATIONS FOR LOW-EMISSIONS VEHI- CLES}

At least seven improvements or refinements over current production vehicles can be made to reduce emissions in meeting ULEV or other very low emissions standards with minimal cost impact on the construction and operation of the vehicle. First, the cranking and engine start-up process must be improved to reduce hydrocarbon emissions resulting from misfires. Second, the engine-out emissions must be minimized while the catalyst is heating to operating temperature. Third, the catalyst must be heated up so that it is chemically active very quickly, and/or the hydrocarbons (and possibly $\mathrm{CO}$ ) must be stored until the catalyst is active. Fourth, accurate air-fuel ratio control must be maintained during transients, requiring accurate open-loop estimates of air and fuel flow into the cylinders. Fifth, misfires during engine decelerations must be avoided. Sixth, the air-to-fuel (AF) ratio switching point, amplitude, and frequency for the exhaust gas AVF closed-loop control must be optimized for best catalytic conversion of both $\mathrm{NO}_{x}$ and $\mathrm{CO}$. Seventh, exhaust gas recirculation (EGR) schedules must be adjusted to meet $\mathrm{NO}_{x}$ goals and fuel economy targets without increasing hydrocarbons beyond emissions goals.

Covering all aspects of these seven areas in one paper would be difficult. Therefore, this paper is limited to a discussion of the algorithms required for engine and aftertreatment control to achieve improvements in these seven areas. The hardware platform that allows the implementation of these algorithms, the Southwest Research Institute (SwRI) Rapid Prototyping Engine Control System (RPECS), is very briefly described in this paper, with a more thorough discussion planned in the future.

CRANKING-The first step in a low-emissions FTP test is cranking the engine with a minimum number of misfires. Most current production engine control systems take at least two crankshaft revolutions to synchronize fuel and spark accurately with engine position.

LOW EMISSIONS DURING CATALYST HEAT-UPThe second step in achieving very low emissions is maintaining low engine-out emissions during the period when the catalyst is reaching operating temperatures. Honda chose to operate their ULEV lean at 15.5 to 16.0 AVF ratio using their high-swirl VTEC engine that maintains stable combustion even at cold conditions [4].

RAPID CATALYST LIGHT-OFF-Obtaining rapid catalyst light-off is the third step to obtaining very low emissions. The OEM vehicle was delivered stock with two catalysts positioned approximately $356 \mathrm{~mm}$ downstream from the exhaust port. In this position with no catalyst heating technology, the FTP light-off times for the catalysts are approximately $80 \mathrm{sec}$, and the hydrocarbon tail-pipe emissions are 2 times ULEV levels. It is expected that to meet ULEV emissions the catalysts should light off in approximately $20 \mathrm{sec}$. Therefore, to decrease catalyst light-off time, some type of catalyst heating is required.

Electrically heated catalyst (EHC) equipped vehicles have demonstrated ULEV or close to ULEV standards [5-8]. However, some of these tests have been critcized for using brand-new "green" catalysts, in which case the catalyst efficiency is much higher than that seen after a few thousand kilometers of operation. Concern about EHCs include initial cost, durability, and added complexity of the electrical system.

Various burner concepts using fuel for heating have also been investigated. These include: a) burners outside the exhaust with their own fuel and air supply [8-10]; b) operating the engine rich, adding air with an external air pump, and then using an igniter and flame stabilizer in the exhaust near the catalyst $[9,11]$; and c) operating the engine rich, adding air in the port area, and using self-ignition in the exhaust port area [12]. The various burners have the advantage compared with EHCs of using the heat content of gasoline directly rather than using gasoline to generate electrical energy and then heat energy. External burners add significant expense, weight, and complexity to the vehicle. Ignition in the exhaust manifold is attractive from its simplicity and low cost. However, operating the engine rich to provide fuel for combustion near the catalyst or in the exhaust manifold might introduce spark plug fouling, oil dilution, and possibly soot in the exhaust.

ACCURATE AIR-FUEL RATIO CONTROL DURING TRANSIENTS-The fourth step in producing an economical low emissions vehicle is accurate air-fuel ratio control very close to stoichiometric during transient operation. This is required to avoid misfires for acceptable performance and good emissions, and for high catalyst efficiency $[13,14]$. During transients, feedback from the exhaust gas oxygen (EGO) sensor is too slow to correct errors in AF ratio. Using mass airflow sensors (MAF) or MAP sensors to estimate airflow rates in-cylinder has limitations related to sensor noise and sensor response time. Ideally the air and fuel flows into the cylinders should be predicted based on movement of the throttle plate and commanded pulse width of the fuel injection. Further, these predicted air and fuel flows should be relatively noise-free, and available within a few milliseconds of a throttle movement. Such predictions are available using model-based control.

For non drive-by-wire systems, the logical order is to predict airflow into the cylinders and then to predict the amount of fuel to be injected to arrive at the desired air-fuel ratio in-cylinder. Because of fuel wall wetting, the amount of fuel to be injected is, in general, different from the amount predicted to make it in-cylinder. The literature is rich with models developed to predict air and fuel flow into spark-ignition (SI) engines, and fairly lean with detailed results of applying models to engines over a wide range of operating conditions including cold-start conditions. Most engine applications are for warmed up engines operating over one type of transient. Successful implementation of an engine control system requires 
accurate control over the whole operating range, including cold-starts.

Hendricks and Sorenson [15-17] discuss a meanvalue engine model for both air and fuel flow and engine dynamics that can be used to simulate an engine for evaluating engine control algorithms. They also have shown application of the air and fuel flow models into engine controllers. Moskwa [18] provides a detailed analysis of the development and application of an airflow model to an engine.

Aquino [19] developed a two-parameter model to describe fuel flow into the engine, where the first parameter described the fraction of fuel that behaved like a vapor and entered the cylinder on the first intake event following injection, and the second parameter described the time constant for the remaining fuel.

CONTROL OF MAP DURING DECELERATIONSThe fifth step in developing a low-emissions vehicle is avoiding misfires during engine decelerations. When the vehicle motors the engine during decelerations with the throttle plate closed, the manifold pressure can drop below $20 \mathrm{kPa}$. Under these conditions, the volumetric efficiency becomes very low, the residual gases high, and the engine misfires. Hydrocarbon concentrations in the exhaust are very high under these conditions, although the mass flow is relatively low. The misfires can be eliminated by controlling the MAP with the idle air control (IAC) valve to avoid very low MAP values.

CLOSED-LOOP CONTROL SWITCHING POINTThe sixth step in low emissions vehicle development is the selection of the AF ratio switching point, amplitude, and frequency for the exhaust-gas AV ratio closed-loop controller. Operating slightly ( 0.25 percent) lean of stoichiometric usually reduces $\mathrm{CO}$ at the expense of $\mathrm{NO}_{x}$, while operating rich of stoichiometric reduces $\mathrm{NO}_{x}$ at the expense of $\mathrm{CO}$. The impact of the switching point on hydrocarbons is slight, with lean operation usually reducing hydrocarbons. Using practical control systems, the ANF ratio fluctuations are larger than desired for best conversion efficiency, but with fluctuating AVF ratio across stoichiometric at a frequency of about 0.5 to $1 \mathrm{~Hz}$, the band where the conversion efficiency is reasonably high (at least $80 \%$ ) can be broadened to about 1 AFF ratio [14]. Efficiencies typically increase with a reduction in the amplitude of the AVF fluctuations, and with an increase in frequency [13].

EGR TRANSIENT CONTROL-The seventh step in low-emissions vehicle development is the development of algorithms to control EGR to reduce $\mathrm{NO}_{x}$, while maintaining driveability and limiting hydrocarbon emission that increase with increasing EGR. EGR limits are typically determined by transient response rather than steadystate performance.

This paper is organized as follows. First the engine, vehicle, control system hardware, and fuel are briefly described. Then the specifics of the model-based engine control are described to show how the seven steps described above were accomplished. Preliminary emissions results are presented. These results are then discussed compared with other work described in the literature.
HARDWARE, SOFTWARE, AND FUEL

The descriptions of the modified vehicle hardware, engine control hardware and software, and fuel are as follows.

ENGINE AND VEHICLE-The demonstrator vehicle used for this project was a 1993 Ford Taurus flexible fuel vehicle with a 3.0-liter V-6 "Vulcan" engine. This vehicle was designed to operate on gasoline, M85, or any blend of these two fuels. However, in this project, the vehicle was converted to be a dedicated Ed85-fueled vehicle. Six significant hardware modifications were made to the vehicle for the conversion to Ed85 and to reduce exhaust emissions.

First the compression ratio was increased from 9.25 to 11.0. This was estimated to increase thermal efficiency about $6 \%$, and was possible due to the high octane number of Ed85 of about 102.1 [2]. This increase in the compression ratio is predicted to increase hydrocarbons about $26 \%$ to $41 \%$ [20-22], and $\mathrm{NO}_{x}$ about $11 \%$.

The second hardware modification was the use of internal-mix, air-assist injectors in place of the standard pintle injectors. The purpose of the air-assist injectors was to improve fuel atomization to reduce port wall-wetting to improve transient response and low-temperature cold-starting. These injectors were of a SwRI design, and required the use of two electrically operated air pumps supplying about $70 \mathrm{kPagauge}$ (10 psig) air pressure and a combined mass flow rate of about $1.6 \mathrm{~g} / \mathrm{s}$. The power required to operate the air pumps offset some of the thermal efficiency gains associated with the increased compression ratio.

Atomization quality for the air-assist injectors was measured using a Malvern Model 2600 laser-diffraction particle-sizing instrument. These measurements were cross-section averages of the spray at $75 \mathrm{~mm}$ from the spray tip, obtained by scanning the 9-mm diameter beam across the spray while recording the diffraction pattern. This sampling technique results in a number-densityweighted, cross-section average. Neat ethanol at $26^{\circ} \mathrm{C}$ rather than Ed85 was used for the spray tests, since the rapid evaporation of the gasoline results in measurement errors. Atomization quality with the conventional pintle injectors on ethanol is characterized by a Sauter mean diameter (SMD) of about $120 \mu \mathrm{m}$. The atomization quality for the air-assist injectors is strongly dependent upon the air pressure. For the air-assist injectors operating at $70 \mathrm{kPagauge}$ and a pulse-width and duty-cycle equivalent to an idle condition, the SMD is about $16 \mu \mathrm{m}$, while at a higher speed wide-open throttle condition, the SMD is about $25 \mu \mathrm{m}$.

The third modification was the addition of an opticalshaft encoder from a General Motors LT-1 engine to provide rapid synchronization of the engine control system [23]. The shaft encoder was interfaced with a Silicon Systems 67-F687 engine controller chip, which was part of the SwRI RPECS engine controller.

The fourth modification was the use of General Motors EGR valves with pintle position feedback in place of the OEM Ford IAC and EGR valves. The pintle position 
information makes these valves much easier to control than the standard OEM valves.

The fifth hardware modification was the addition of the rapid exhaust port oxidation (REPO) system [12]. REPO provides catalyst heating through exothermic reactions with rich exhaust and secondary air introduced in the exhaust stream. REPO does not require any additional ignition source. Ignition occurs spontaneously in this system. Secondary air is provided by an appropriately sized air pump [24] and metered with a General Motors EGR electronically-controlled valve with pintle position feedback.

Because of these modifications, making a sixth change to the vehicle hardware was necessary, the replacement of the Ford EEC controller with a SwRI RPECS controller. The details of the RPECS are given in the next section.

ENGINE CONTROLLER HARDWARE-RPECS is a commercially available PC-based vehicle controller for full-authority control of spark, fueling, EGR, idle-air, and aftertreatment [25]. The RPECS hardware components are shown in Figure 1. The base system consists of three main parts: (1) a Pentium PC, (2) a SwRI-designed custom engine controller ISA card and separate power electronics driver boards, and (3) an analog VO PC board. The Pentium PC.is responsible for all high-level computations and decisions. At this level the desired ignition timing, fuel control, and other high-level functions are determined. The PC determines this information with inputs from both the analog $1 / O$ and the engine controller boards. The PC then sends information to the engine controller and analog I/O boards, which are responsible for carrying out the desired actions at the proper timing.

The benefit of this system is that it provided good engine control, while offering the maximum flexibility in implementing and testing new control strategies and algorithms. The high-level computations and data-logging tasks performed by RPECS are implemented on the PC, running under QNX, a real-time UNIX operating system. The vehicle real-time, interrupt-based application code is written in the high-level $\mathrm{C}$ language. For this vehicle, the real-time vehicle application-specific code (approximately

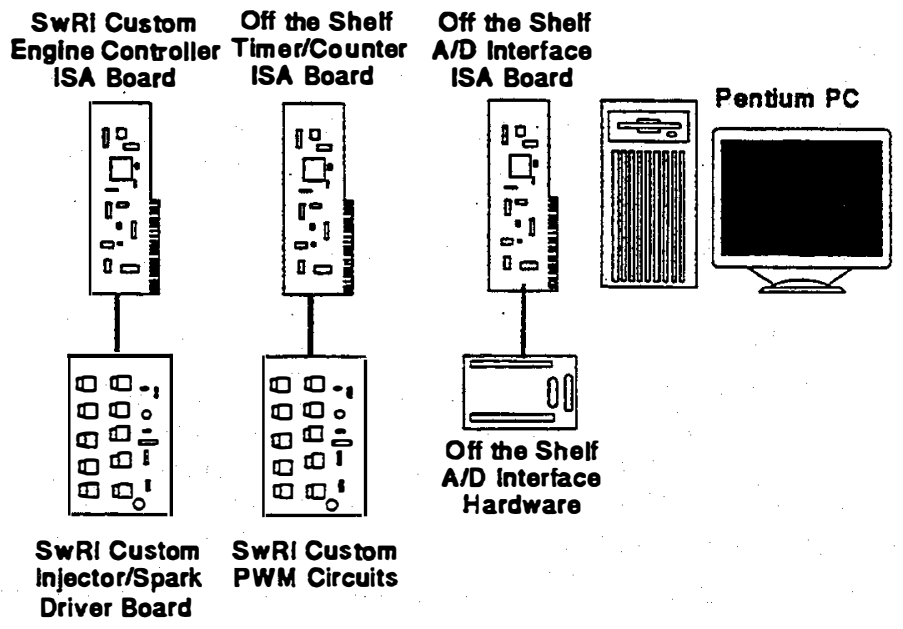

Figure 1. RPECS hardware.
2500 lines of vehicle-specific code) was run every 5 msec. The time-intensive job of actually achieving the desired ignition and fueling events was carried out by the engine controller board.

Interaction with the vehicle real-time control code is accomplished through two SwRI custom $X$-windows based programs. One program allows for displaying all desired application variables, constants, inputs, outputs, calibration tables, and modes. This program allows the user to both monitor and change calibration variables or tables at any time. A second program allows the user to log and plot in real-time all variables, inputs, and outputs in the application code. The plotting can sample at rates up to $500 \mathrm{~Hz}$, or as slowly as one $1 \mathrm{~Hz}$. Both programs can be run locally or across a network to a separate PC with X-Windows display capabilities. Therefore, RPECS provided a very flexible control system that allowed the user to perform rapid algorithm development, calibration, and testing online.

Sensor inputs were hardware (analog) filtered before being read by the analog-to-digital convertor board. A simple first-order low-pass R-C filter circuit was utilized for most of the sensors, except the MAF sensor. In addition to the hardware filter, a software filter was used with all inputs. The software filter can be either time or crankangle based. The amount of software filtering depended upon the input signal. For instance, the MAP sensor had a break frequency of 1 cycle per engine revolution.

FUEL-The fuel used for these tests was Ed85, made from 85 vol.\% denatured ethanol and 15 vol.\% winter-grade gasoline. About 5 vol.\% gasoline was used as a denaturant, so the blend was actually made from 80 vol. \% ethanol and 20 vol. \% gasoline. This ethanol content was within the range specified for a Class 1 fuel (Ed85) in a recent draft ASTM standard for fuel ethanol (Ed85Ed75) [26]. Some of the fuel specifications are given in Table 1, and compared with the draft ASTM standard. Also included in Table 1 are the vapor pressures of the blending components used to make the Ed85.

\section{ALGORITHM DEVELOPMENT}

The main purpose of this paper is to describe the development and use of cylinder-event-based logic and model-based control algorithms in a demonstrator lowemissions vehicle. As stated previously, it is well known that the vehicle emissions during the cold- and hot-start,

Table 1. Fuel Specifications for Ed85 and ASTM draft (2/28/95) Standards [26]

\begin{tabular}{|l|c|c|c|}
\hline \multicolumn{1}{|c|}{ Fuel } & $\begin{array}{c}\text { Vapor Pressure } \\
@ 37.7^{\circ} \mathrm{C}\left(100^{\circ} \mathrm{F}\right) \\
\mathrm{kPa}(\mathrm{psi})\end{array}$ & $\begin{array}{c}\text { Ethanol } \\
\text { Content } \\
\text { vol.\% }\end{array}$ & $\begin{array}{c}\text { Octane } \\
\text { Number } \\
{[(\mathrm{R}+\mathrm{M}) / 2]}\end{array}$ \\
\hline $\begin{array}{l}\text { ASTM Spec. } \\
\text { Ed85 }\end{array}$ & $38-59(5.5-8.5)$ & $79(\mathrm{~min})$ & - \\
\hline Ed85 & $50.8(7.38)$ & 80 & 102.1 \\
\hline E100 & $16.6(2.41)$ & 100 & - \\
\hline $\begin{array}{l}\text { Unleaded } \\
\text { gasoline }\end{array}$ & $89.8(13.0)$ & 0 & - \\
\hline
\end{tabular}


and emissions during throttle transients remain as the largest contributors to tailpipe emissions during the U.S. light-duty FTP cycle. Therefore, the focus of this work was in those areas. Cylinder-event-based logic was used to improve cranking and start-up performance. Modelbased control logic was used during engine transients to improve AF ratio control for improved catalyst efficiency. Descriptions of the vehicle control algorithms are provided below.

CYLINDER-EVENT-BASED START-UP CONTROLSpecial algorithms were implemented into RPECS to reduce the number of cylinder misfires during engine start-up. As a part of these algorithms, an advanced crank encoder (General Motors LT-1 optical crank encoder / distributor) was employed to reduce the time required for engine and controller synchronization. This optical encoder provides four distinct top-dead-center (TDC) pulses per cycle rather than the traditional one per cycle. Therefore, the controller can synchronize with the engine sooner and begin synchronized fueling rather than the initial random fueling more typical of today's production vehicles.

Once the engine and controller are synchronized, the specialized cylinder-event-based algorithms are activated. The fuel injection timing, fuel enrichment (compared with stoichiometric), and spark timing are all controlled on a cylinder by cylinder basis, and each of these three values are a function of engine coolant temperature (ECT) at the time of start and cylinder. event number since start. SwRI has determined that in the first few engine cycles, all three variables influence the startup hydrocarbon emissions. This approach was used for about the first 1200 engine cylinder events (200 cycles). This corresponds to about $18 \mathrm{sec}$. of operation.

MODEL-BASED TRANSIENT CONTROL-Warmedup vehicle tail-pipe emissions are strongly dependent upon the catalyst efficiency. For high catalyst efficiency, the engine-out $A F$ ratio needs to remain relatively close to stoichiometric and to switch across stoichiometric continually (see the closed-loop fueling algorithms covered later). As described in the background section, the Ed85 fuel film, and resultant fuel hang up in the intake system, result in poor AF ratio control during throttle transients if no compensation is included in the fuel control. Without compensation, the AVF ratio swings lean of stoichiometric on accelerations (tip-ins) since some of the increased fuel required for the higher engine power does not make it in-cylinder, but hangs up on the walls of the intake system. On decelerations (tip-outs) without compensation, the AF ratio swings rich of stoichiometric since the reduced fuel requirement is augmented by a wall film established at the higher power level. Both transients, if uncompensated, will result in reduced catalyst efficiency. For fast throttle tip-ins, the engine may have lean misfire, resulting in high engine-out hydrocarbons.

To control the engine-out AV ratio during transients accurately, the engine controller needs precise predictions or measurements of the amount of intake air, the amount of fuel injected that will go directly in-cylinder, and the amount of fuel from the wall film in the intake system that will go in-cylinder during the current cylinder event. The air intake process is modeled through the MAP observer model. The fuel hang up in the intake port is predicted with the transient fuel compensator model.

Airflow and MAP Observer Model-The fuel control used was a speed-density calculation that depends on the intake manifold absolute pressure (MAP). This MAP could be determined from a MAP sensor in the intake manifold. However, this MAP sensor suffers from both periodic noise associated with the filling events for each cylinder, and random noise from vibration and electrical noise. Adding analog or digital filtering to smooth out the noise is possible, but the response time is slowed, and fueling errors are then introduced. Ideally, the MAP signal should be relatively noise-free with no time delays, and preferably estimated into the future. The MAP observer, as described here, is a good approximation to such an ideal MAP signal.

The MAP observer model was based upon the mean-value manifold model $[18,27]$. A flowchart of this model is shown in Figure 2. All sources of mass flow into the intake manifold were summed based on the calibration of the effective areas of the throttle, the air-assist injectors, the IAC valve, the EGR valve, and the PCV valve, and the pressure differential across each element. For example, the mass flow through the throttle plate was computed from the throttle area determined from the throtthe angle, given by the throttle position sensor (TPS), the upstream air density determined by a barometric pressure sensor and thermistor, and the pressure difference across the throttle plate given by a differential pressure gauge on this engine. Each of these flow elements was calibrated on the engine to determine their effective discharge coefficients, except the air-assist injectors that were calibrated in separate experiments. The thesis by Moskwa [18] gives details and examples for these calculations.

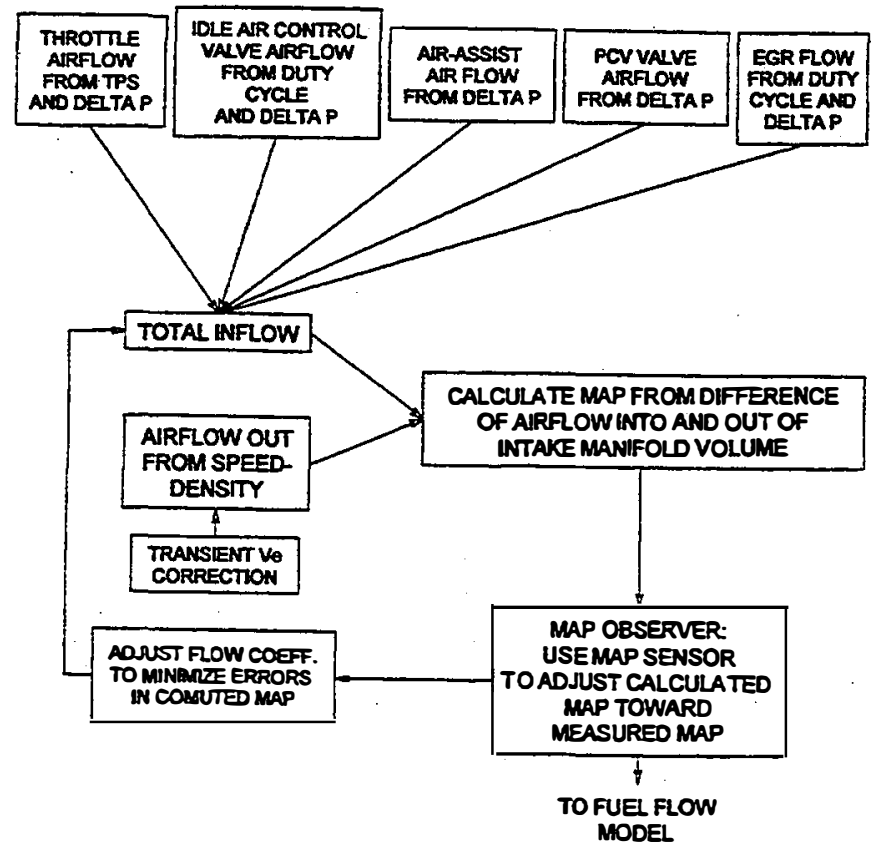

Figure 2. Flowchart representation of airflow model MAP observer model. 
The mass flow out of the manifold was computed from the traditional speed-density calculation [e.g., 18]. This computation is based on engine speed, displacement, volumetric efficiency, and manifold gas density. To estimate the aifflow out of the manifold, the EGR flow out of the manifold must be known. EGR flow out of the manifold is based upon a first order delay of the EGR flow into the manifold.

The difference between the mass flow into and out of the manifold, along with the manifold volume, was used to compute the MAP. This computed MAP was trimmed with the MAP sensor. This method of computing MAP with a sensor feedback term is known as a MAP observer. The question might be raised, "if the computed MAP is trimmed with the MAP sensor, why bother with the computed MAP and all the complexity involved?" The answer is that the computed MAP is available almost instantaneously from the TPS, IAC, etc. positions in the $5 \mathrm{~ms}$ computational loop, and is noise-free enough that the computed MAP may be extrapolated into the future to estimate the MAP near intake valve closing. The computed MAP alone is not accurate enough to use for precise fuel control. For that reason, it was trimmed by the MAP sensor, but this trimming is slow enough that the fast time response of the computed MAP is not degraded.

The computations to estimate the MAP are not accurate as the MAP approaches atmospheric pressure. The computed mass flows into the manifold under these conditions are not accurate due to the small pressure differential across the throttle plate, IAC, etc. Under these conditions the estimated MAP was replaced in a smooth fashion with the MAP sensor signal.

The estimated MAP is dependent on the calibrations for both intake manifold-in flows and manifold-out flows. At high loads the contribution of the throttle flow is quite large, but at light loads and idle the air-assist flow and the IAC valve flow may dominate. Inaccuracies in the flow calibrations for the air-assist injectors, IAC, and throttle can result in steady-state errors in the estimated MAP. The steady-state error was eliminated through integral feedback on the difference between the computed MAP and the MAP sensor, and the error was transferred to the integrator. Since the relative contribution from the air-assist injectors, IAC, and the throttle changes depending upon the engine operating condition, and the steady-state error varies depending upon the operating conditions, the value of the integrator changed as well. If the integral gain is high then the system response to changes in the steady-state error will be fast, but a high integral gain will result in a strong dependence between the estimated and measured MAP. Recall, that the goal of the MAP observer was to reduce dependence upon the slow response MAP sensor. To reduce this dependence two additions to the observer model were included: (1) trimming with the measured MAP was eliminated during fast transients, and (2) the integral term was adaptively leamed.

For estimating the manifold-out flows, the instantaneous volumetric efficiency should be known precisely. For a fixed engine configuration, the volumetric efficiency is a function of at least engine speed, MAP, intake wall temperature, intake valve temperature and manifold air temperature. All these dependencies need to be included to predict the volumetric efficiency during the engine warmup accurately and throughout the engine's operating range. A base volumetric efficiency calibration (a function of engine speed, MAP, and manifold air temperature) can predict the value during steady-state engine operation at fully warmed up conditions. Adaptive feedback, from the dual EGO sensors, for this base calibration was included and improved the prediction.

To account for the effect that the engine warmup process has on the volumetric efficiency, a simple function that accounts for time-from-start will not resolve the intake system heat up. Instead, the volumetric efficiency is considered a function of engine coolant temperature (ECT) at start-up and the amount of fuel burned since start, in addition to the base calibration. Thus, the volumetric efficiency during warmups was computed from the base calibration multiplied by a correction factor that depends on the amount of fuel bumed since start, with that function being determined empirically.

It was determined that the volumetric efficiency during and immediately following a transient, at any engine temperature, was not equal to the steady-state value. The transient volumetric efficiency was found to be as large as 10 percent different from the steady-state value. The volumetric efficiency is dependent upon instantaneous cylinder wall and valve temperatures. At light loads the intake wall and valve temperatures are less than those at high loads. The heat-up of the intake walls and valve is not instantaneous. During a fast throttle tip-in, initially the cooler cylinder walls result in a higher volumetric efficiency than that obtained once the cylinder wall temperatures equilibrate at the higher load. On tip-outs, the reverse trends are evident.

The details of the transient volumetric efficiency model are beyond the scope of this paper. Basically, the model predicts an instantaneous in-cylinder air temperature and a steady-state in-cylinder air temperature based upon engine experiments and cycle simulation results. The ratio of the instantaneous temperature to the steadystate temperature was then related to the ratio of the instantaneous volumetric efficiency and the steady-state volumetric efficiency.

The calculation for fuel injection quantity, ideally, would be based upon the air mass intake. Due to computation delays, sensor delays, and (mostly) advanced injection timing, the estimated air mass intake at the time of fuel injection is based upon parameters well before the end of the intake event. To improve the estimate of the intake flow at the intake event, the MAP estimated by the observer model was extrapolated into the future based upon the last two computed values. The amount of extrapolation depends upon the fuel injection timing and varies from 200 crank angle degrees (CAD) for open valve injection to $500 \mathrm{CAD}$ for closed valve injection.

Transient Fuel Compensator Model-Accurate AF ratio control requires that the fuel hang up in the intake system be accounted for. To model the fuel wall-wetting, a $\tau-\varepsilon$ model was used [19]. A pictorial description of the 


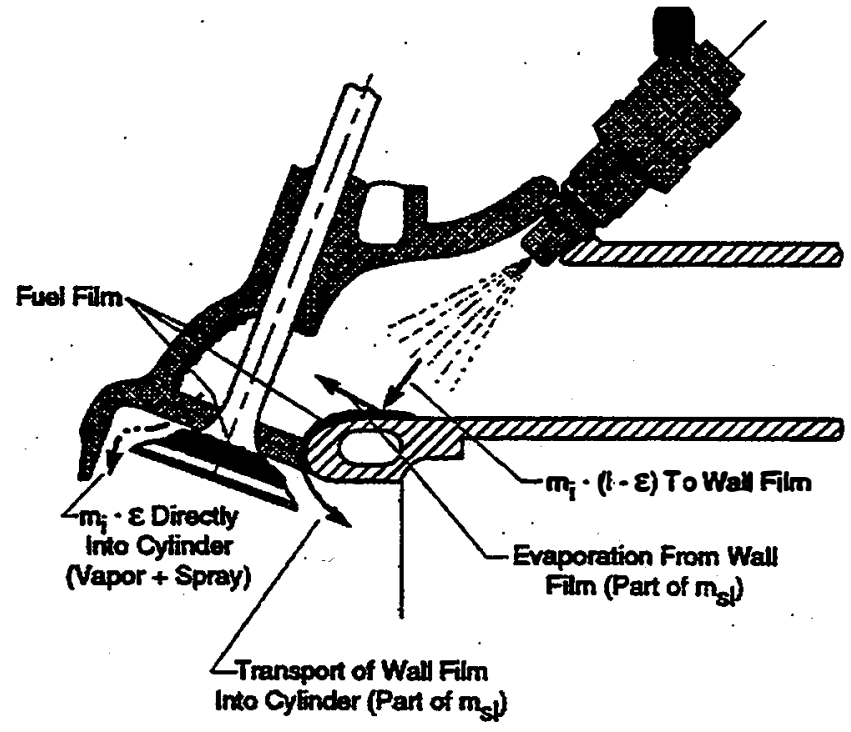

Figure 3. Pictorial representation of fuel wall-wetting.

wall-wetting is shown in Figure 3 . The variable $\varepsilon$ is the fraction of fuel injected that behaves like a vapor and goes directly in-cylinder. The value of $\varepsilon$ could potentially range from 1 (all fuel injected goes directly in-cylinder) to approaching zero (all fuel injected hangs up in the intake system). The variable $\tau$ is the time-constant for the fuel in the intake fuel puddle to be transported in-cylinder.

The amount of fuel hang up is dependent upon the intake port wall temperature, the intake valve temperature, the fuel volatility, the fuel atomization quality, and the fuel injection timing. When the engine is cold, the requirements for fuel compensation are much greater than for the warmed-up engine. Ethanol's volatility is much less than gasoline's, and therefore, the requirements for fuel compensation are increased compared with those for gasoline. The use of internal-mix, air-assist injectors improved fuel atomization and reduced the requirements for fuel compensation. Depending upon the intake valve temperature, closed-valve injection may increase or decrease required fueling compensation.

A flowchart of the fuel compensation model is shown in Figure 4. To provide fueling compensation during the engine warmup process adequately, two parallel $\tau-\varepsilon$ models were required. One model was active at all times, and was a short-time-based model. The other model was included only during the initial engine warmup period, and was a long-time-based model. The short-time-based model was a function of engine speed, MAP, ECT at engine start, and fuel burned since start. The long-timebased model was a function only of ECT at engine start and fuel burned since start. Although the $\tau$ and $\varepsilon$ values depended on speed and load, typical values for the short-time-based model at an intermediate-load, warmed-up condition were $0.10 \mathrm{~s}$, and 0.65 , respectively. The long-time-based model started with $\tau$ values of about $7 \mathrm{~s}$ at a $25^{\circ} \mathrm{C}$ start, with shorter times as the engine warmed up. These values would be different if air-assist injectors were not used (smaller $\varepsilon$ and larger $\tau$ for conventional injectors), or if gasoline were used in place of Ed85 (larger $\varepsilon$ and smaller $\tau$ for gasoline).

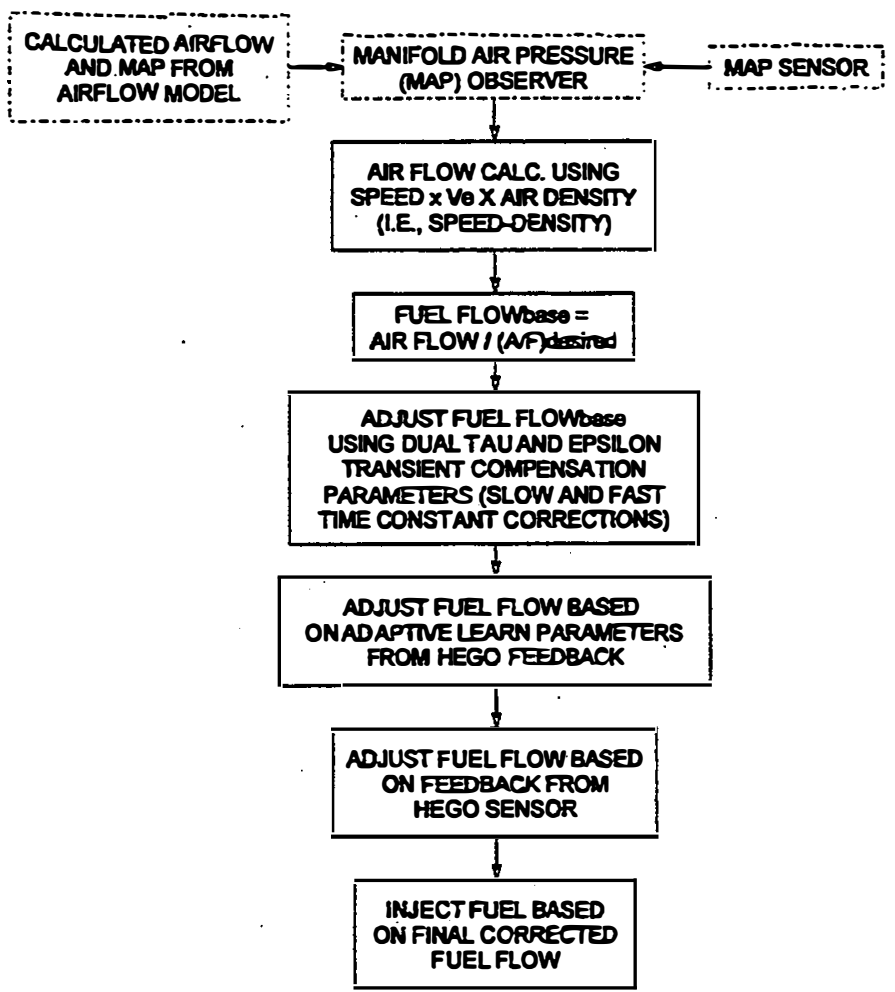

Figure 4. Flowchart representation of the fuel compensator model.

CLOSED-LOOP FUEL CONTROL-Beyond accurate fuel control during throttle transients, the low emissions vehicle controller must provide the catalyst an exhaust feed gas that alternates rich and lean in a switching fashion. The catalyst efficiency for a particular species is dependent upon the AF ratio switching point, amplitude, and frequency for the closed-loop controller. Dual heated switching exhaust gas oxygen (HEGO) sensors installed upstream of the catalysts provide the exhaust gas feedback. A model of the air and fuel transport was used to estimate transit times from the fuel injectors to the HEGO sensors to obtain the fastest switching frequency possible while maintaining control stability. The algorithm includes jump-back logic. Jump-back increases the frequency of the switching rate. The rate of fuel ramp-up or ramp-down following the jump-back is computed based upon the desired biasing, switching amplitude, and computed transit time for fuel. Biasing of the switching point was obtained by using different fueling ramp-up and ramp-down rates [28]. Biasing can be up to 1 percent or more rich or lean of stoichiometric. Desired biasing is a function of engine speed and MAP. The calibration of the biasing was based on steady-state and FIP results, and is not discussed further in this paper. Desired switching amplitude is a function of engine speed, and ranged from \pm 2 percent at low engine speeds to \pm 3 percent at higher engine speeds.

Adaptive feedback was used to improve the estimate of steady-state fueling requirements. The adaptive feedback is a function of engine speed and MAP. The adaptive update was driven by a standard steepest decent adaptive update algorithm [29]. 
BASE VEHICLE ALGORITHMS-In addition to the model-based control algorithms described earlier, several basic control algorithms required for engine control were included in the RPECS control code. These algorithms include:

- Spark timing and fuel injector timing and pulsewidth control

- EGR system control

- Idle control

- Transmission control

- Other vehicle systems control (engine cooling fan, etc.)

The details of these base algorithms are not included here, and are considered outside the scope of this paper.

\section{CALIBRATION PROCEDURES AND PRELIMINARY TEST RESULTS}

The calibration procedures and test results are described as follows: first, the cylinder-event-based start-up algorithms are investigated; second, the advanced aftertreatment technology is studied; and finally, the transient control algorithms are discussed.

CYLINDER EVENT BASED START-UP CALIBRATION-Typical FTP cold-start engine-out hydrocarbons from an OEM vehicle and controller are shown in Figure 5 , as measured by a flame ionization detector (FID). The engine-out hydrocarbons go off scale, above 10,000 ppmC, due to engine misfire during the first few cylinder events. One goal of this work was to reduce significantly or eliminate these initial cylinder misfires.

Engine cold-start tests were performed repeatedly to determine the proper calibration for the cylinder-eventbased spark timing, fuel injection timing, and fuel enrichment. The engine coolant and engine oil temperatures for all tests were held between $25^{\circ} \mathrm{C}$ and $28^{\circ} \mathrm{C}$. The cylinder head temperature was also monitored and was

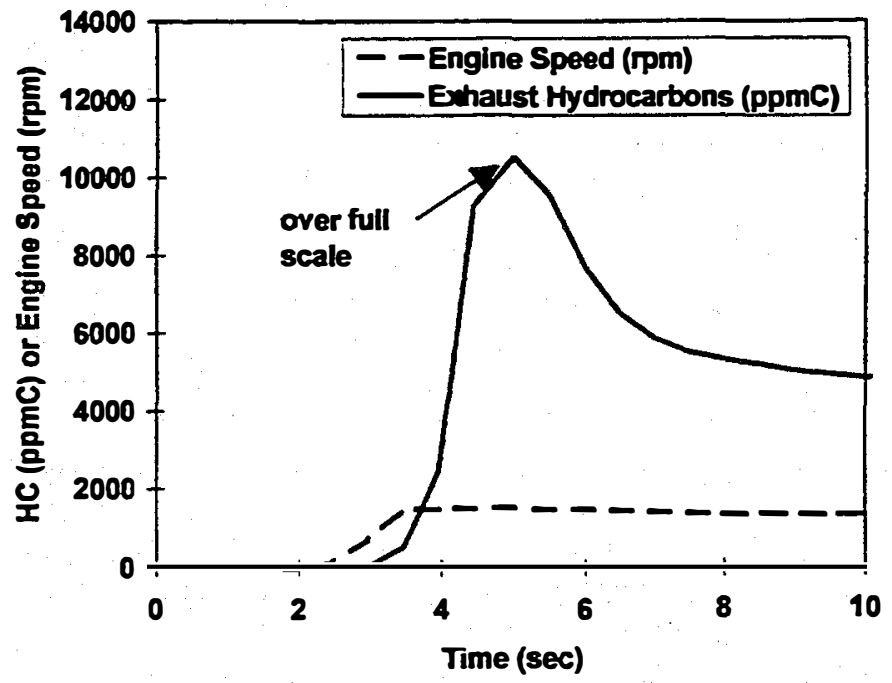

Figure 5. Pre-catalyst hydrocarbons (from one bank of cylinders) and engine speed measured from unmodified OEM vehicle during the cold-start of the U.S. FTP cycle. HC emissions are off-scale here, but typically are greater than 20,000 ppmC. kept below $30^{\circ} \mathrm{C}$. To eliminate the uncertainty of the engine shutdown position with respect to trapped unburned fuel, the engine was purged of fuel in the intake system and all the cylinders by motoring the engine between starts. Fueling was initiated only after the engine and controller were synchronized.

Cold-start measurement tools included a Cambustion HFR 400 fast flame ionization detector (fast FID), cylinder pressure transducers, and dual wide-range exhaust gas oxygen (UEGO) sensors. The fast FID, with a response time of a few milliseconds, provided engine-out hydrocarbon measurements, and can resolve and indicate individual cylinder misfires that a traditional FID can not. In addition, spark-plug mounted cylinder pressure transducers coupled to a DSP Inc. Redline high speed data acquisition system measured five of six cylinder pressures throughout the test. Dual UEGO sensors in the exhaust manifold measured the engine-out AF ratio.

After significant calibration effort, a calibration was adopted that significantly reduced the engine-out hydrocarbons from misfires compared with the OEM vehicle and controller. It was determined that the engine requires about 5 times calculated stoichiometric mixture injected into the intake port on the first cycle to achieve an approximately stoichiometric mixture in-cylinder at about $25^{\circ} \mathrm{C}$. This enrichment leaves a considerable fuel puddle in the intake system since the MAP for the first engine cycle is atmospheric and the effective volumetric efficiency is very high. This fuel puddle is transported into the cylinders in subsequent engine cycles to the point that commanded engine fueling is reduced below computed stoichiometric for several engine cycles.

The results from a typical start test are shown in Figure 6. The top graph shows the IMEP measured for five cylinders for the first 70 engine cycles. Initially, the IMEP is below zero (motoring) for all cylinders because fueling was not provided yet. However, once fueling was provided to the cylinder, it fires on the first cylinder event and all subsequent events. The second graph shows the

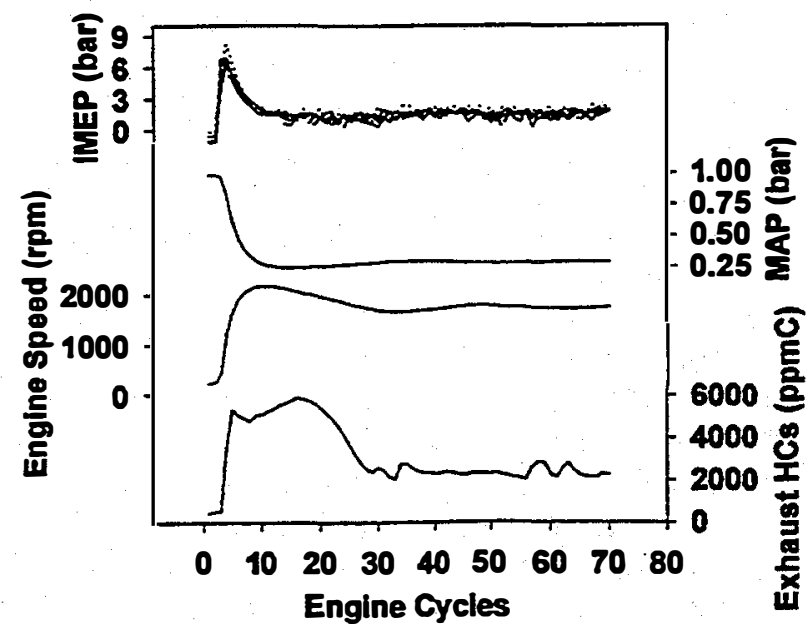

Figure 6. Results for first 70 engine cycles ( $6 \mathrm{sec})$ from a cold-start (ECT of $25-28{ }^{\circ} \mathrm{C}$ ) with calibrated cylinder-event-based algorithms. Top graph shows cylinder IMEPs; second graph, MAP; third graph, engine speed; fourth graph, exhaust HCs. 
MAP sensor signal and the third the engine speed. On these very rapid starts the MAP goes so low that avoiding misfires during the speed run-up is difficult. The fourth graph shows the very low hydrocarbons achieved with this starting approach, with a maximum value of about 6000 ppmC (or 2000 ppm propane).

ADVANCED AFTERTREATMENT CONTROL CALIBRATION-The rapid exhaust port oxidation (REPO) system is used to both heat the exhaust catalysts and reduce the unburned hydrocarbons and $\mathrm{CO}$ going into the catalysts during the cold and hot-starts of the U.S. FTP. The engine was started using the cylinder-eventbased logic as described above, but soon after starting the fuel-air equivalence ratio in the engine was increased to about 1.45. Secondary air was added to the exhaust so that the equivalence ratio in the exhaust was about stoichiometric (1.0). Spontaneous ignition was observed in the exhaust port and manifold [12].

The REPO system reduces $\mathrm{HC}$ and $\mathrm{CO}$ emissions in two ways, first by oxidizing some of gases before the catalyst, and secondly, by rapidly heating the catalyst to increase its chemical reactivity. This is illustrated in Figure 7 that compares a start without REPO maintaining an engine equivalence ratio of about 1.0 with a start where REPO is active. These starts were performed before a precise calibration of the cranking process was completed (as described above), and without purging the intake system of fuel, so the HC spike associated with cranking is quite high compared with Figure 6. However, following the startup, the before-catalyst $\mathrm{HC}$ emissions are reduced by a factor of about 4 for the REPO compared with the standard start. Also, the catalyst lights off more quickly with REPO, although these extended idle tests are not representative of the U.S. FTP.

TRANSIENT CONTROL-The calibration and testing of the MAP observer and the transient fueling compensation involve a several step process. First the airflow and MAP observer algorithms are fully calibrated and

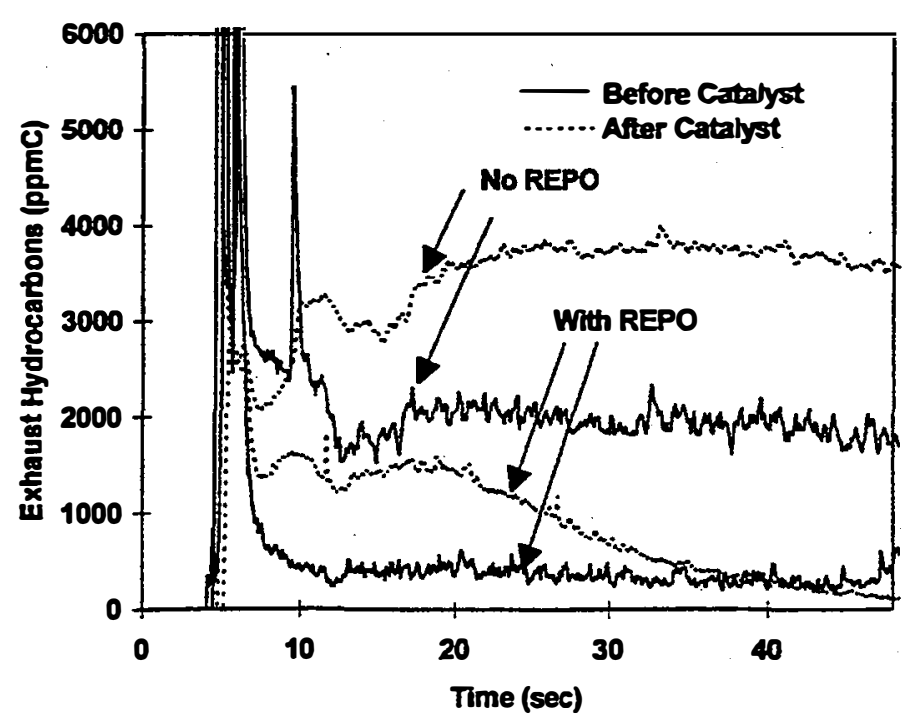

Figure 7. Exhaust hydrocarbon measurements for two cold-starts, one with the rapid exhaust port oxidation (REPO) system active, and the other a standard start. then the transient fueling compensation algorithms are calibrated.

Airflow and MAP Observer Calibration-The algorithms that compute manifold inflows (throttle, IAC, air-assist, PCV, and EGR) are calibrated independently as a function of valve position (if applicable) and pressure differential. The manifold outflow to the engine is computed based upon the volumetric efficiency. The engine volumetric efficiency is calibrated as a function of engine speed, MAP, manifold air temperature, engine coolant temperature at start, fuel burned since start, and manifold themal dynamics (for the transient volumetric efficiency).

The result is a model that accurately predicts the engine MAP with much less signal noise or lag than the MAP sensor. A comparison of the estimated MAP and that measured by the software-unfiltered MAP sensor for a throttle tip-in and tip-out is shown in Figure 8. The MAP observer tracks the measured MAP well, but removes the cyclic noise.

To demonstrate the fast response of the MAP observer, a comparison of the MAP observer against several engine sensors for a throttle tip-in is shown in Figure 9. As expected, the software-unfiltered throttle position sensor (TPS) is the first signal to respond. The extrapolated MAP observer and the software-unfiltered MAP sensor respond next, nearly simultaneously. The software-filtered MAP sensor responds last.

The software-unfiltered MAP sensor includes unacceptable cyclic noise during steady-state operation, and therefore engine fueling cannot be based upon this signal. The software-filtered MAP signal significantly lags the actual transient and, when utilized for fueling, would result in additional transient fueling errors.

A comparison of the exhaust AVF ratio was performed during a series of repeat throttle tip-ins and tipouts, with the engine fully warmed-up (ECT $\left.90^{\circ} \mathrm{C}\right)$. The fuel control was operated open-loop, with no feedback from the HEGO sensors. The test was repeated three

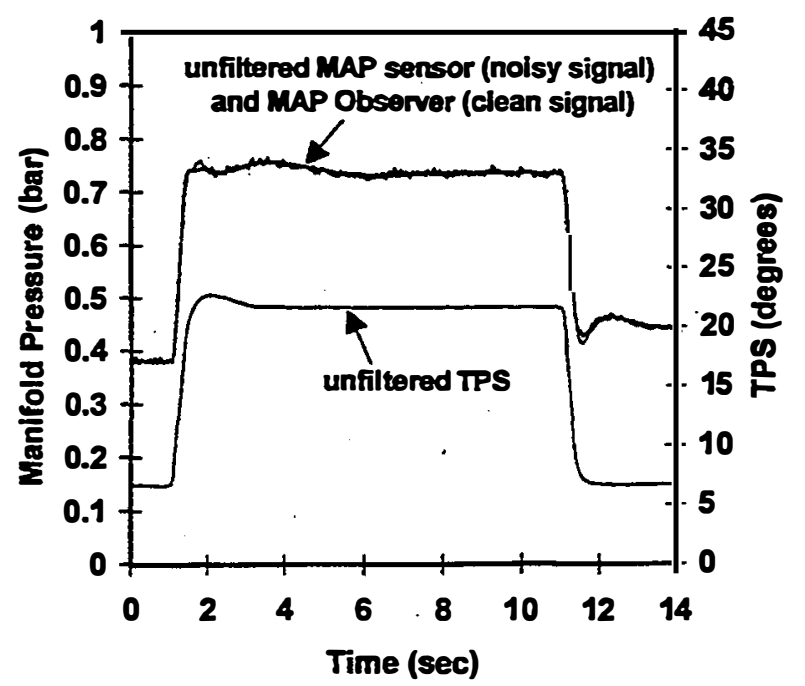

Figure 8. Comparison of the estimated MAP from the observer and the measured MAP from the softwareunfiltered sensor signal during a throttle tip-in and tipout. Engine speed varied from $1700 \mathrm{rpm}$ at light load to $2300 \mathrm{rpm}$ at high load. 


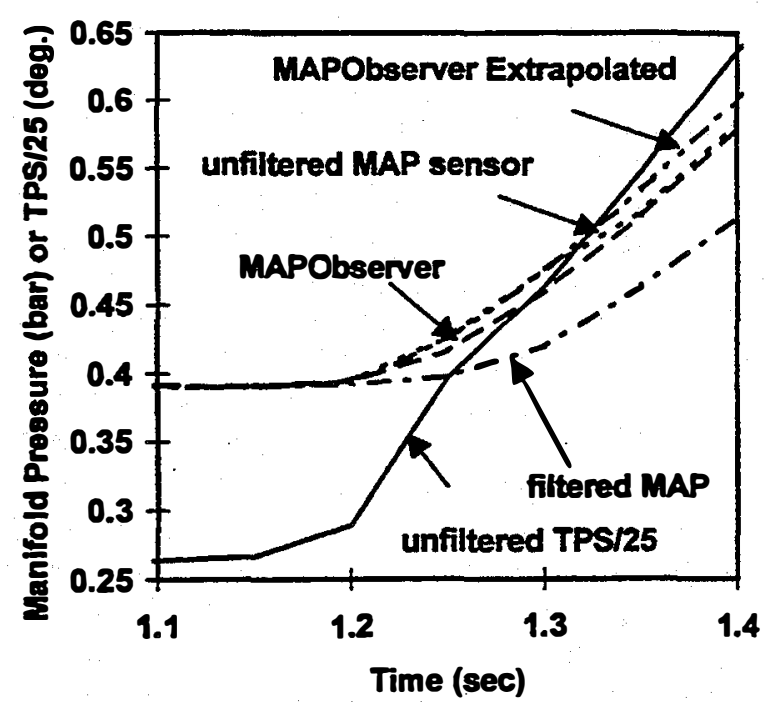

Figure 9. Comparison of the relative response of various signals (computed and measured) during the initial period of a throttle tip-in. Engine speed varied from $1700 \mathrm{rpm}$ at light load to $2300 \mathrm{rpm}$ at high load.

times with no transient fueling compensation for fueling based upon the extrapolated MAP observer, software-filtered MAP sensor, and the software-filtered MAF. The results are shown in Figures 10 and 11. As expected without fueling compensation, all three modes of airflow measurement or calculation result in the exhaust AVF ratio going lean during the throttle tip-in and rich during the tip-out. In both the throttle tip-in and tip-out, the exhaust AF ratio excursion during the transient is least with the MAP observer. The MAP observer best represents the throttle flow at the intake port with the least amount of

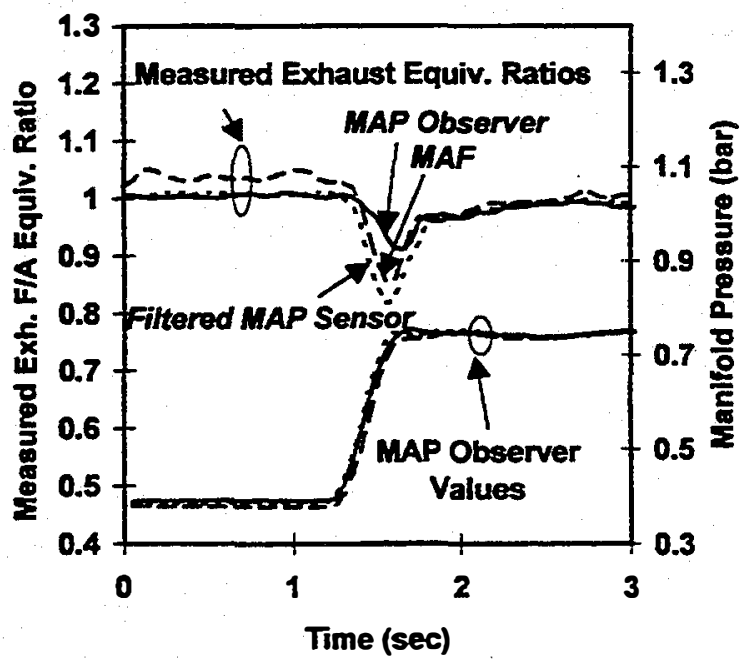

Figure 10. Measured exhaust F/A equivalence ratio during three repeated throttle tip-in transients for open-loop fueling without transient fueling compensation based upon the speed-density algorithm using the extrapolated MAP Observer value, speed-density algorithm using the software-filtered MAP sensor signal, and the airflow measurement obtained from the MAF sensor. Engine speed varied from $1700 \mathrm{rpm}$ at light load to $2300 \mathrm{rpm}$ at high load. Engine was fully warmed-up.

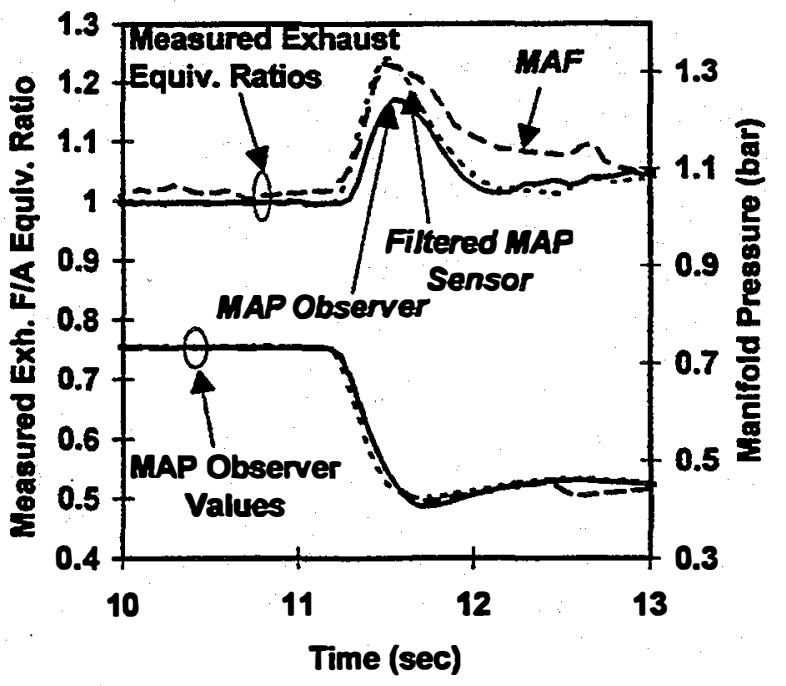

Figure 11. Measured exhaust F/A equivalence ratio during three repeated throttle tip-out transients for open-loop fueling without transient fueling compensation based upon the speed-density algorithm using the extrapolated MAP Observer value, speed-density algorithm using the software-filtered MAP sensor signal, and the airflow measurement obtained from the MAF sensor. Engine speed varied from $2300 \mathrm{rpm}$ at high load to $1700 \mathrm{rm}$ at light load. Engine was fully warmed-up.

signal lag. In all three cases, when the engine is fully warmed-up, the vehicle drives acceptably at most conditions, even with no transient fueling compensation. Under all but the most severe throttle tip-ins, the engine never stumbles. (This may be partly due to the air-assist injectors that provide excellent fuel transport into the cylinder, even for the relatively non-volatile Ed85.) The fueling compensation is, therefore, most important for driveability at cold engine conditions, and for improved exhaust AF ratio control for catalyst efficiency at both cold and warm engine conditions.

Transient Fuel Compensator Calibration-The first step in calibrating the transient fuel compensator was to determine the required parameters at warmed up engine conditions. Initially, a series of fast and slow throttle transients at various fixed engine speeds were run while the calibration parameters were varied for $\tau$ and $\varepsilon$. Once general calibrations were obtained, then the engine speed was allowed to vary as well. All this tuning was performed without closed-loop fuel control. Usually the compensators could be tuned so that the AFF ratio excursions for tip-ins were small enough, e.g., Figure 12, that they would essentially be lost in the noise when the closed-loop control was turned on. However, it was determined from these tests that the same values for $\tau$ and $\varepsilon$ could not compensate for both throttle tip-ins and tipouts. Example test results are shown in Figures 12 and 13. During the throttle tip-in, Figure 12, if there is no fueling compensation the exhaust AF ratio swings lean. With fueling compensation, the exhaust AVF ratio stays much closer to stoichiometric. Using the same $\tau$ and $\varepsilon$ parameters on the tip-out provides the results shown in 


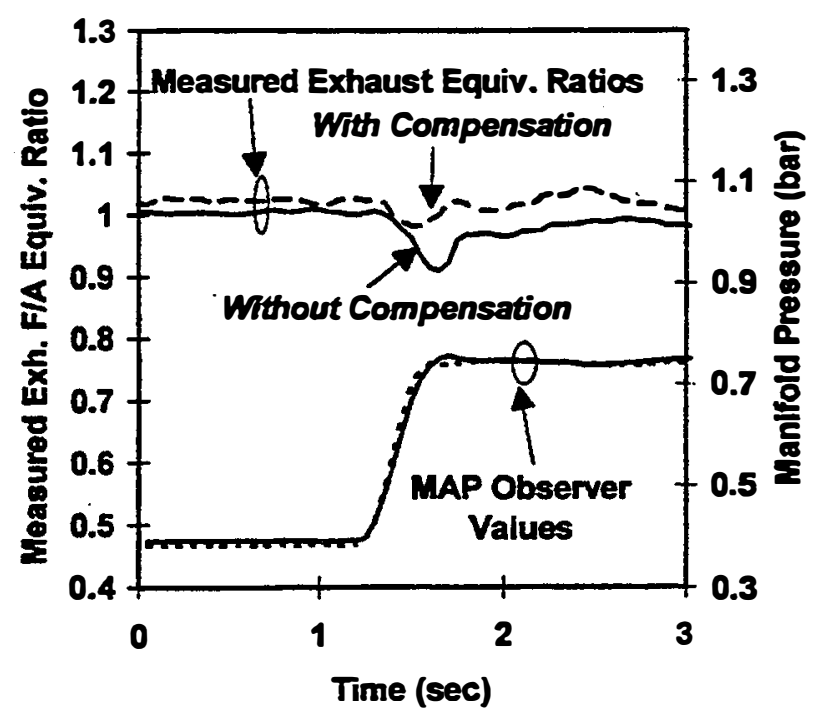

Figure 12. Measured exhaust F/A equivalence ratio during two repeated throttle tip-in transients for openloop fueling based upon the extrapolated MAP Observer algorithms with and without the $\tau-\varepsilon$ fueling compensation. Engine speed varied from $1700 \mathrm{rpm}$ at light load to $2300 \mathrm{rm}$ at high load. Engine was fully warmed-up.

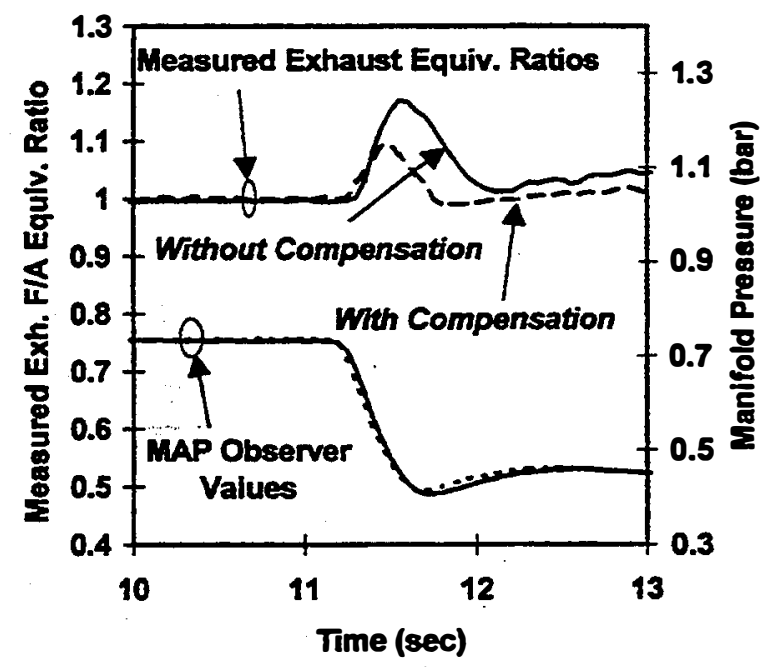

Figure 13. Measured exhaust F/A equivalence ratio during two repeated throttle tip-out transients for openloop fueling based upon the extrapolated MAP Observer algorithms with and without the $\tau-\varepsilon$ fueling compensation. Engine speed varied from $2300 \mathrm{rpm}$ at high load to $1700 \mathrm{rpm}$ at light load. Engine was fully warmed-up.

Figure 13. On the throttle tip-out, the exhaust AF ratio swings rich even with fueling compensation. It is apparent that on throttle tip-outs additional fueling compensation is required to control the $A / F$ ratio accurately. Modifications to the $\tau-\varepsilon$ model to accommodate for different parameters on throttle tip-in and tip-out are being investigated.

The next step in calibrating the transient fuel compensator is to determine the calibration necessary to describe the fueling compensation required throughout the engine warmup process. Under cold engine conditions, if the engine is run without any fueling compensation, then the vehicle drives unacceptably and has poor AFF ratio control. As shown in Figure 14 with no transient fueling compensation, the exhaust AF ratio swings excessively lean during throttle tip-ins. On throttle tip-outs the engine exhaust AF ratio swings excessively rich.

To calibrate the fuel compensators, repeated tests were run where the engine was started cold (ECT and oil temperature $\sim 28^{\circ} \mathrm{C}$ ), and run through a series of throttle transients while the engine warms-up. These tests were performed without the rapid exhaust port oxidation (REPO) system. Therefore, during the entire warmup, the desired engine exhaust equivalence ratio was stoichiometric (1.0). The values of $\tau$ and $\varepsilon$ were adjusted based on the temperature of the engine compared with warmed-up operating conditions. This was accomplished by setting up two-dimensional tables for both $\tau$ and $\varepsilon$ that were a function of the coolant temperature at the time of start, and the amount of fuel burned per cylinder since start. The engine was assumed to warm up in proportion to the amount of fuel burned per cylinder. The values in these tables were adjustment factors used to multiply the values in the warmed-up tables for $\tau$ and $\varepsilon$. These adjustment factors were less than 1.0 for $\varepsilon$, since in the cold engine the fraction of fuel behaving like a vapor is less than for a warmed-up engine. As the engine warmed up, these values eventually reached 1.0. The adjustment factors for $\tau$ were greater than 1.0 for the cold engine, and became smaller as the engine warmed up.

Using this approach, the rapid enleanment at tip-in and enrichment at tip-out could be eliminated. However, these tests also showed that in the cold engine there were some longer time constant excursions, of seconds rather than tenth's of a second, that could not be eliminated with the same approach. This is illustrated in Figure 15 that shows that even after the fast-time-response transient model has been calibrated to remove the rapid

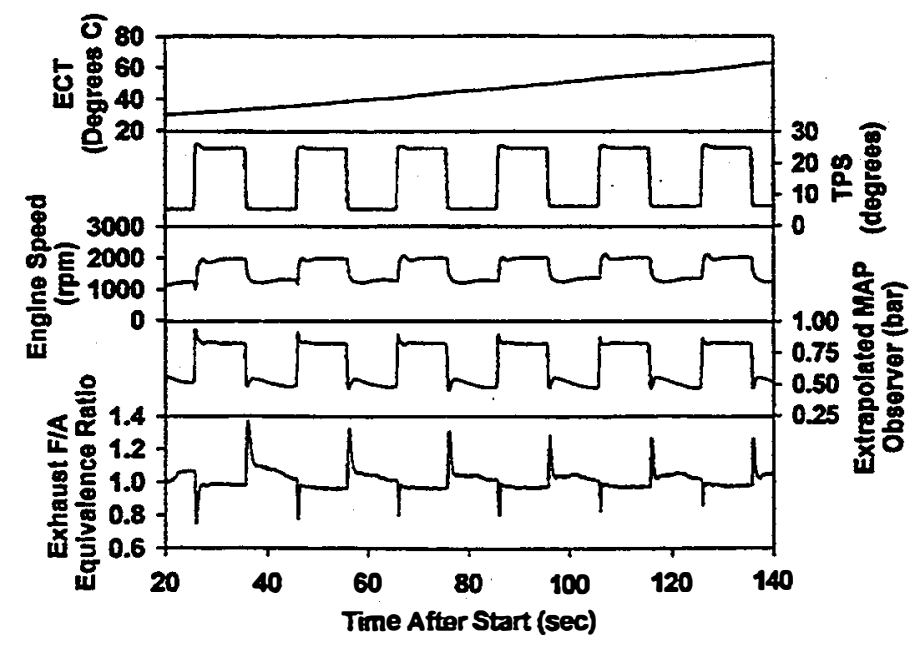

Figure 14. Measurements acquired from a series of throttle transient-performed for open-loop fueling based upon the extrapolated MAP Observer algorithms without the $\tau-\varepsilon$ fueling compensation. The transients started approximately $25 \mathrm{~s}$ after the engine was started. Initially the engine coolant and oil temperatures were approximately $28^{\circ} \mathrm{C}$. 


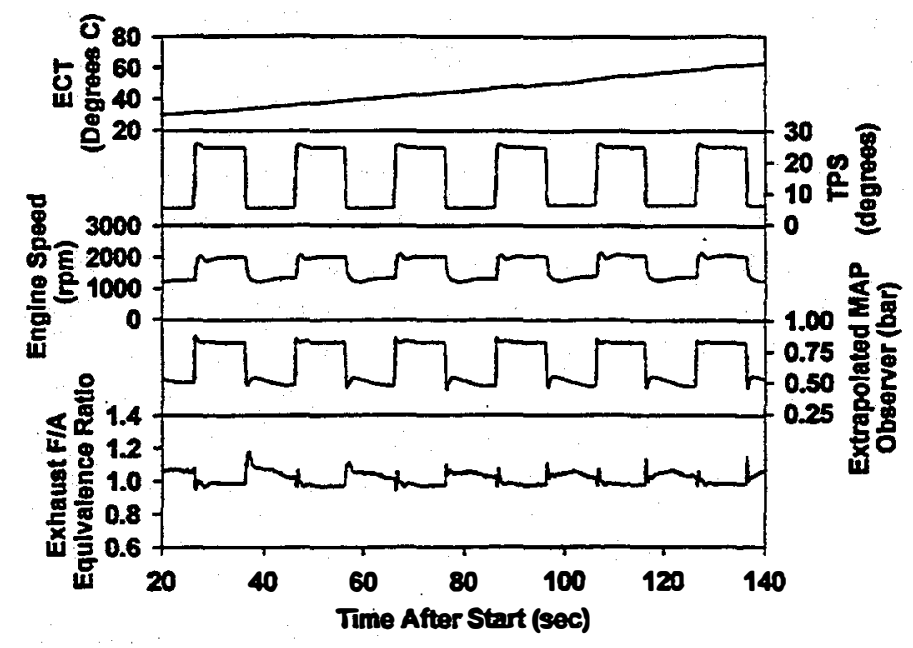

Figure 15. Measurements acquired from a series of throttle transients performed for open-loop fueling based upon the extrapolated MAP Observer algorithms with only the short time-constant $\tau-\varepsilon$ fueling compensation model. The transients started approximately $25 \mathrm{~s}$ after the engine was started. Initially the engine coolant and oil temperatures were approximately $28^{\circ} \mathrm{C}$.

AF excursions, there remain some longer time constant excursions. The short time constant $(\sim 0.2 \mathrm{sec})$ excursion is much higher in magnitude than the long time constant $(\sim 3 \mathrm{sec})$ excursion. As the engine warmed up, the magnitude of the long-time-constant excursion was reduced and eliminated at fully warmed-up conditions. The shorttime-constant excursion was also reduced in magnitude as the engine warmed up, but it was still observed under all operating conditions. To address these long-timebased excursions, a second $\tau-\varepsilon$ model in parallel with the first model was necessary. The second $\tau-\varepsilon$ model was only a function of ECT at start and fuel bumed per cylinder since start. After calibrating both $\tau-\varepsilon$ models, test results as shown in Figure 16 were obtained.

During the engine warmup, the heat-up of the intake valve, and the heat-up of the rest of the intake port area leads to faster evaporation and therefore less fuel hang up. As expected, the $\varepsilon$ value increases with engine warmup and $\tau$ decreases. However, the physical reason for the requirement of two $\tau-\varepsilon$ models can only be hypothesized. The slow-time-constant $\tau-\varepsilon$ may be related to the vaporization of the fuel off the intake valves. At cold temperatures the fuel sprayed onto the valves cannot evaporate in one engine cycle, while at fully warmed-up conditions, nearly all the fuel sprayed on the intake valve is evaporated [30].

Figure 16 represents the combination of all the models and factors described previously and applied under the worst and most important of the conditions encountered in the U.S. FTP test cycle. Transients immediately following cold-start cannot rely on any feedback from the dual HEGO sensors, since the sensors are not hot enough to operate for approximately $30 \mathrm{~s}$ following the cold start. Transient fueling compensation is most critical for driveability during this time to avoid lean misfires on

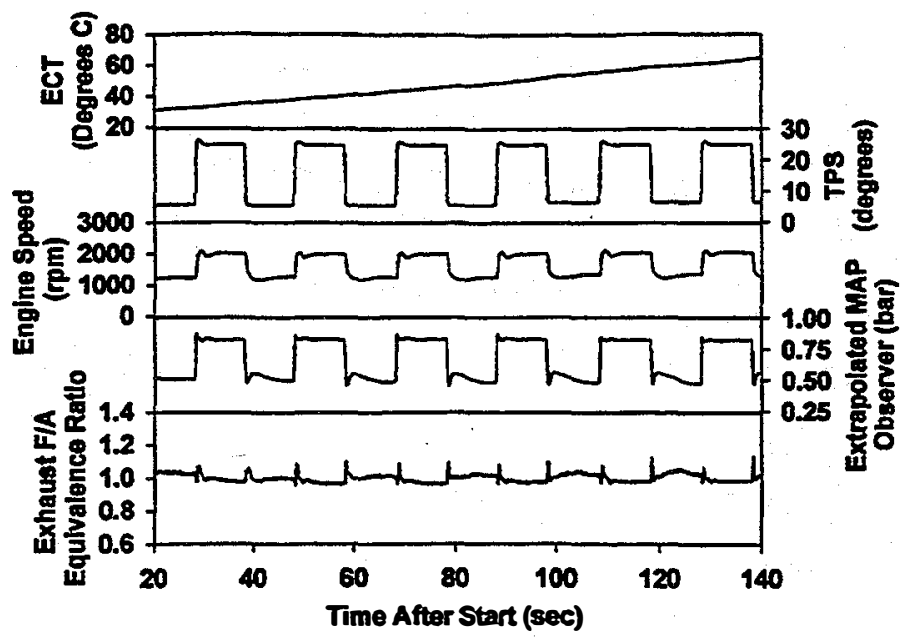

Figure 16. Measurements acquired from a series of throttle transient performed for open-loop fueling based upon the extrapolated MAP Observer algorithms with both the short and long time-constant $\tau-\varepsilon$ fueling compensation models. The transients started approximately $25 \mathrm{~s}$ after the engine was started. Initially the engine coolant and oil temperatures were approximately $28^{\circ} \mathrm{C}$.

tip-ins. The air-fuel ratio must be controlled accurately to minimize engine-out emissions and to provide the desired air-fuel ratio to the catalyst to both heat the catalyst to operating temperature, and then to maintain a stoichiometric mixture for maximum catalyst efficiency.

\section{EMISSIONS RESULTS FOR U.S. LIGHT-DUTY FTP}

Emissions testing of this vehicle using the U.S. lightduty FTP has not been completed. Preliminary results indicate $\mathrm{CO}$ and $\mathrm{NO} \times$ levels about $1 / 2$ of ULEV standards, and $\mathrm{HC}$ emissions slightly below ULEV standards. However, these results are for catalysts with about 4,000 miles $(6436 \mathrm{~km})$ of usage, and have not been adjusted for 50,000 miles $(80,450 \mathrm{~km})$ or 100,000 miles $(160,900$ $\mathrm{km}$ ) of vehicle and catalyst degradation. Further work is ongoing to improve these emissions results.

\section{DISCUSSION}

Various approaches are being used to meet ULEV emissions standards with gasoline-fueled vehicles. Ed85 is a cleaner fuel than gasoline in many ways, having a lower reactivity factor than gasoline, about 0.67 compared with 1.0 for standard gasoline [31]. However, because of its low volatility, Ed85 presents some special challenges for developing transient fueling compensation to maintain stoichiometric mixtures during cold transients. The air-assist injectors used on this vehicle helped to offset some of the low volatility effects on fuel transport in the intake manifold.

Low-temperature cold-starting is another limitation in the use of ethanol fuels. The combination of air-assist injectors and rapid synchronization of the engine controller and customized amounts of fuel injection on a cylinder-event basis provided very strong starts at the lowest 
temperatures tested $\left(-21^{\circ} \mathrm{C}\right.$ or $\left.-6^{\circ} \mathrm{F}\right)$, with few engine misfires. However, these results are beyond the scope of this paper.

Most of the algorithms discussed in this paper have been applied to SI engines previously. A possible exception is the combination of the cylinder-event-based logic and fuel injection hardware used for start-up. However, those algorithms have usually been presented as single algorithms applied to one type of transient for a fully warmed-up engine. This paper has demonstrated that for the algorithms chosen here, they can be integrated into a single package that covers the operation of a vehicle over the complete U.S. FTP cycle, including the cold-start and warmup period. Further, it has been demonstrated that the start-up techniques can be used to provide rapid startups with few misfires and low HC emissions.

The airflow model discussed does an excellent job of predicting air mass flow rates through the engine. The adaptive features for airflow into the manifold based on comparing the MAP observer with the MAP sensor, and on airflow out of the manifold based on feedback from the EGO sensor allow for the airflow model to tune itself to account for changes in calibration of the hardware. The transient fuel flow model is simplified compared with the complex processes involved, and could be improved upon. Adaptive transient compensation [32] and cylinderto-cylinder balancing should be added to the transient fueling model. However, it should be noted that these algorithms are usually demonstrated on fully warmed-up engines operating over one type of step transient. In practice, the most important part of the emissions cycle is the time when the engine and catalyst are not warmed up. Under these conditions, transient compensation is more difficult to make self-tuning since the critical component temperatures are more difficult to identify and model.

Further U.S. light-duty FTP tests will be conducted with this vehicle to help demonstrate the ability of these control algorithms and this system to better meet ULEV emissions standards. However, the performance of the control system to maintain tight fuel-air ratio control was demonstrated in this paper. The ability to obtain fast catalyst light-offs and low feed-gas HC has been demonstrated with the REPO system and controls described in this and previous work at SwRI [12].

As pointed out by Weeks and Moskwa [17], the use of a MAP observer as described here offers a number of opportunities for both on-board diagnostics (OBD) of problems in the engine, and correcting for problems such as air leaks in the intake manifold.

Considering the REPO system operating on Ed85 as compared with gasoline, some differences were observed. The engine misfires if it is run richer than a F/A equivalence ratio of about 1.45 on Ed85. Previous researchers have run cold engines on gasoline as rich as 1.7 to obtain suitable chemical energy in the exhaust stream [11]. Ethanol's rich flammability limit (while still producing a pressure rise) is 14.3 vol.\% [33], while $n$ heptane's, representing gasoline's, is 6.7 vol.\% [34]. Therefore, it appears curious that the richest practical equivalence ratio in the engine is lower for Ed85 than for gasoline. However, the 1.45 equivalence ratio for Ed85 corresponds to a fuel concentration by volume of about 8.3 vol. $\%$, or $58 \%$ of the rich limit. The 1.7 equivalence ratio for gasoline corresponds to about 3.1 vol. $\%$, or $46 \%$ of the rich limit. Therefore, the observed limits in the engine for Ed85 compared with gasoline are in correspondence with the rich limits observed in laboratory experiments for these fuels. Ed85 has an advantage compared with gasoline when the engine is operated rich in that it is less likely to form soot.

\section{CONCLUSIONS}

The following conclusions were reached as a part of this vehicle development effort:

1. Cylinder-event-based logic combined with an encoder that has four distinct 'TDC' indicators per revolution was shown to provide very rapid synchronization of the engine controller to the engine hardware, and rapid, clean, relatively misfire-free starts.

2. The model-based airflow model that includes both transient volumetric efficiency corrections and the manifold air pressure observer provides an accurate way of estimating airflow into the cylinders. The MAP observer provides a signal that is sufficiently noise-free that it can be extrapolated into the future to offset some of the errors associated with fuel injection before intake valve closure and computational and sensor delays.

3. The airflow model can be extended for use at cold engine temperatures and during the warmup process from a cold start by modifying the volumetric efficiency to include a dependence on cylinder wall temperatures, which are correlated with initial coolant temperature at start and the amount of fuel burned since starting.

4. At warmed up engine conditions, a single $\tau-\varepsilon$ transient fueling compensation model provided adequate air-fuel ratio control, but on this engine the compensation required for accelerations was different from decelerations.

5. Under cold engine conditions, a single $\tau-\varepsilon$-model for transient fueling compensation was not adequate for air-fuel ratio control. It was necessary to add a second $\tau-\varepsilon$ model with a time constant $(\tau)$ on the order of seconds, rather than the time constant on the order of tenths of seconds observed at warmed up conditions. It was also necessary to modify the values used in the fasttime-constant $\tau-\varepsilon$ model at cold conditions, with smaller $\varepsilon$ and larger $\tau$ values.

6. The REPO system relies on control of both the engine air-fuel ratio and the air-fuel ratio in the exhaust after air addition. This system appears to both reduce feed-gas $\mathrm{HC}$ and $\mathrm{CO}$, and adds significant heat to the catalysts for more rapid light-off. 


\section{ACKNOWLEDGMENTS}

The authors would like to acknowledge the financial support of the U.S. Department of Energy with technical monitors John Russell and John Garbak, and the National Renewable Energy Laboratories with technical monitors Chris Colucci and Brent Bailey. Further, Steve Schneider and Charles Nance provided much of the technician work required to achieve the results presented. Mike Crane and Kevin Whitney provided much of the work in the aftertreatment area. The authors would also like to acknowledge the efforts of Rob Thring as project manager. Dale Mayol of Ford provided the air pumps for the air-assist injectors, and his efforts and those of other Ford personnel are gratefully acknowledged. Discussions with Kennon Guglielmo of E-Controls are appreciated.

\section{REFERENCES}

1. Heimrich, M., Albu, S., Osborn, J. "ElectricallyHeated Catalysts System Conversion on Two Current-Technology Vehicles," SAE 910602, 1991.

2. Bourn, G.D., Callahan, T.J., Dodge, L.G., Mulik, J., Naegeli, D.W., Shouse, K.R., Smith, L.R., and Whitney, K.A., "Development of a Dedicated Ethanol UItra-Low Emission Vehicle (ULEV) - System Design," Southwest Research Report, SwRI Project No. 03-5901, U.S. DOE and NREL Subcontract No. YAW-3-12243-01, 1994.

3. Dodge, L.G., Leone, D.M., Naegeli, D.W., Dickey, D.W., and Swenson, K.R., "A PC-Based Model for Predicting NO$\times$ Reductions in Diesel Engines," SAE 962060, 1996.

4. Honda Press Release, January 6, 1995, "Honda First to Have Gasoline Engine Verified at ULEV Exhaust Levels."

5. Newkirk, M., Smith, L., Ahuja, M., Albu, S., Santoro, S., and Leonard, J., "Formaldehye Emissions Control Technology for Methanol-Fueled Vehicles: Catalyst Selection," SAE 920092, 1992.

6. Socha, L., Thompson, D., "Electrically Heated Extruded Metal Converters of Low Emissions Vehicles," SAE 920093, 1992.

7. Socha, L., Thompson, D., and Weber, P., "Reduced Energy and Power Consumption for ElectricallyHeated Extruded Metal Converters," SAE 930383, 1993.

8. Kollmann, K., Abthoff, J. and Zahn, W., "Concepts for Ultra Low Emission Vehicles," SAE 940469, 1994.

9. Langen, P., Theissen, M., Mallog, J., and Zielinski, R., "Heated Catalytic Converter: Competing Technologies to Meet LEV Emissions Standards," SAE 940470, 1994.

10. Oser, P., Mueller, E., Hartel, G.R., and Schurfeld, A.O., "Novel Emission Technologies with Emphasis on Catalyst Cold Start Improvements Status Report on VW-Pierburg Burner/Catalyst Systems," SAE 940474, 1994.

11. Ma, T., Collings, N., and Hands, T., "Exhaust Gas Ignition (EGI) - A New Concept for Rapid Light-Off of Automotive Exhaust Catalyst," SAE 920400, 1992.

12. Crane, M.E., Thring, R.H., Podnar, D.J., and Dodge, L.G., "Reduced Cold-Start Emissions Using Rapid Exhaust Port Oxidation (REPO) in a Spark-Ignition Engine," SAE 970264, 1997.

13. Heck, R.M., and Farrauto, R.J., Catalytic Air Pollution Control - Commercial Technology, van Nostran Reinhold, New York, p. 90, 1995.

14. Heywood, J.B., Internal Combustion Engine Fundamentals, McGraw-Hill Publishing Co., New York, p. 656, 1988.

15. Hendricks, E., and Sorenson, S., "Mean Value Modeling of Spark Ignition Engines," SAE 900616, 1990

16. Hendricks, E., and Sorenson, S., "Mean Value SI Engine Model for Control Studies," in Proceedings of the 1990 American Control Conference, pp. 1882-1887, 1990.

17. Hendricks, E., and Sorenson, S., "SI Engine Controls and Mean Value Engine Modeling," SAE 910258, 1991.

18. Moskwa, J.J., Automotive Engine Modeling for Real Time Control, PhD Thesis for Massachusetts Institute of Technology, 1988.

19. Aquino, C.F., "Transient AF Control Characteristics of the 5 Liter Central Fuel Injection Engine," SAE 810494, 1981.

20. Russ, S.G., Kaiser, E.W., Siegl, W.O., Podsiadlik, D.H., and Barrett, K.M., "Compression Ratio and Coolant Temperature Effects on HC Emissions from a Spark-Ignition Engine," SAE 950163, 1995.

21. Cook, P.D., Karlsson, S., Aspinall, E., and Sherwood, T., "Systems Enhanced by Software for LEV," SAE 940931, 1994.

22. Hamrin, D.A., and Heywood, J.B., "Modeling of Engine-Out Hydrocarbon Emissions for Prototype Production Engines," SAE 950984, 1995.

23. Kulkarni, A. V., New Generation Small Block V8 Engine," SAE920673, 1992.

24. Kollmann, K., Abthoff, J., Zahn, W., Bischof, H., Gohre, J., "Secondary Air Injection with a New Developed Electrical Blower for Reduced Exhaust Emissions," SAE 940472, 1994.

25. Rapid Prototyping Engine Control System (RPECS), commercially available from Southwest Research Institute, San Antonio, TX 78228.

26. Anon., "Standard Specification for Fuel Ethanol (Ed85-Ed75) for Automotive Spark-Ignition Engines," draft ASTM standard, 2/28/95. 
27. Weeks, R.W., and Moskwa, J.J., "Transient Air Flow Rate Estimation in a Natural Gas Engine Using a Nonlinear Observer," SAE 940759, 1994.

28. Camp, J., and Rachel, T., "Closed-Loop Electronic Fuel and Air Control of Internal Combustion Engines," SAE 750369, 1975.

29. Sastry, S., and Bodson, M.,

Prentice-Hall,

Inc., 1989.

30. Martins, J.J.G., and Finlay, I.C., "Fuel Preparation in Port-Injected Engines," SAE 920518, 1992.
31. Kroll, M., Decker, G., Hartung, A. Postulka, A., and Georgi, B., "Influence of Fuel Composition on NMOG-Emissions and Ozone Forming Potential," SAE 932676, 1993.

32. Ault, B.A., Jones, V.K., Powell, J.D., and Franklin, G.F., "Adaptive Air-Fuel Ratio Control of a SparkIgnition Engine," SAE 940373, 1994.

33. Naegeli, D.W., and Weatherford, W.D., Jr., "Practical Ignition Limits for Low Molecular Weight Alcohols," Fuel, Vol. 68, pp. 45-48, 1989.

34. Glassman, I. Combustion, Second Edition, Academic Press, Inc., Orlando, Florida, p. 469, 1987. 
APPENDIX B

TEST RESULTS 
Evaluation of a Vacuum-Insulated Catalyst in Reducing Cold-Start Exhaust Emissions

Excerpt from Project 08-6068

Phase II Report:

Determination of Alternative Fuels Combustion Products

Prepared by

Patrick M. Merritt

Kevin A. Whitney

Final Report

Prepared for the

National Renewable Energy Laboratory

1617 Cole Boulevard

Golden, CO 80401-3393 


\section{TABLE OF CONTENTS}

Page

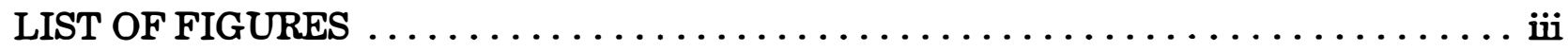

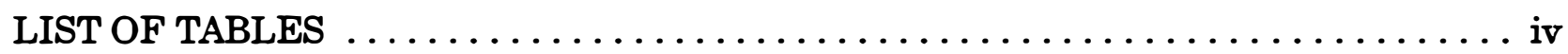

EXECUTIVE SUMMARY $\ldots \ldots \ldots \ldots \ldots \ldots \ldots \ldots \ldots \ldots \ldots \ldots \ldots \ldots \ldots$

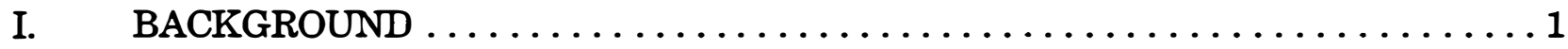

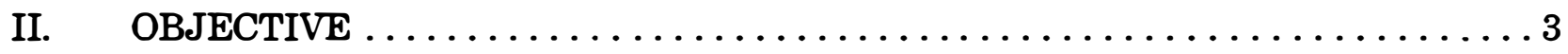

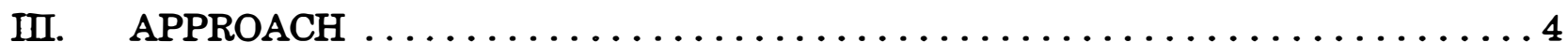

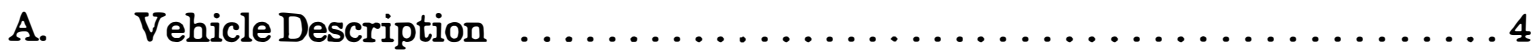

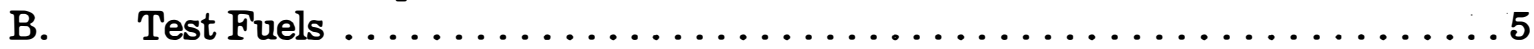

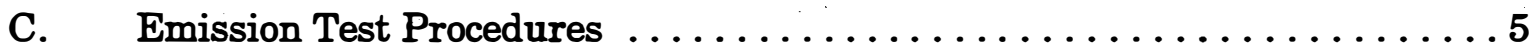

D. Emissions Sampling and Analysis Procedures $\ldots \ldots \ldots \ldots \ldots \ldots \ldots$

IV. TEST RESULTS AND DISCUSSION $\ldots \ldots \ldots \ldots \ldots \ldots \ldots \ldots \ldots \ldots \ldots \ldots \ldots \ldots \ldots$

A. Catalyst Break-In and Cool-Down $\ldots \ldots \ldots \ldots \ldots \ldots \ldots \ldots \ldots \ldots \ldots \ldots \ldots \ldots \ldots$

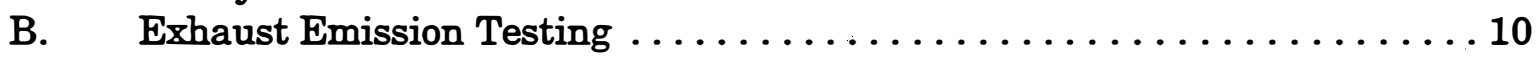

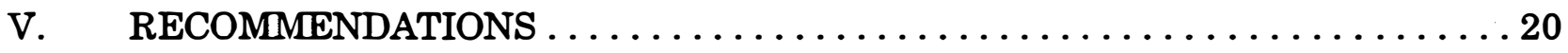

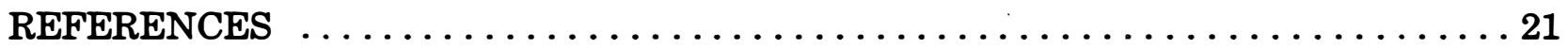

APPENDIX A - DETAILED COMPUTER PRINTOUTS OF THE FTP REGULATED EMISSION TESTS RESULTS FROM TASK 2 


\section{LIST OF FIGURES}

\section{Figure}

Page

1 Exhaust System Configuration $\ldots \ldots \ldots \ldots \ldots \ldots \ldots \ldots \ldots \ldots \ldots \ldots \ldots \ldots \ldots \ldots \ldots \ldots$

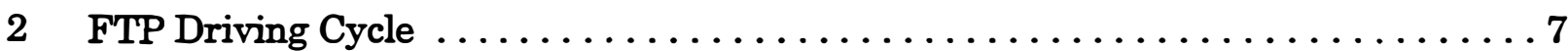

3 Insulated Catalyst Cooldown Temperature Profile $\ldots \ldots \ldots \ldots \ldots \ldots \ldots \ldots$

4 Taurus FFV With Insulated Catalyst, Summary of FTP Emissions $\ldots \ldots \ldots \ldots 12$

5 Comparison of Uninsulated and Insulated Catalyst Temperatures $\ldots \ldots \ldots \ldots 14$

6 Taurus FFV with Insulated Catalyst, FTP FID HC After Catalyst . . . . . . . 16

7 Taurus FFV with Insulated Catalyst, FTP CO After Catalyst $\ldots \ldots \ldots \ldots \ldots 17$

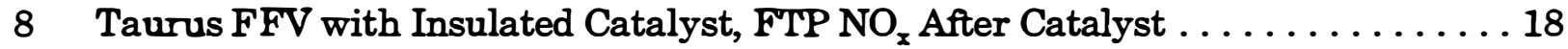

9 Temperature of TA-CC4 During Soak ....................... 19 


\section{LIST OF TABLES}

Table

Page

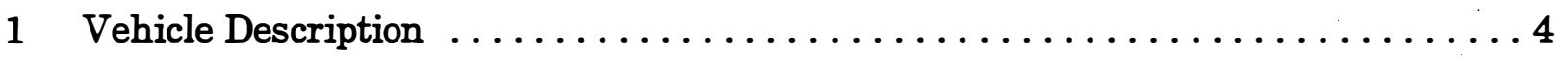

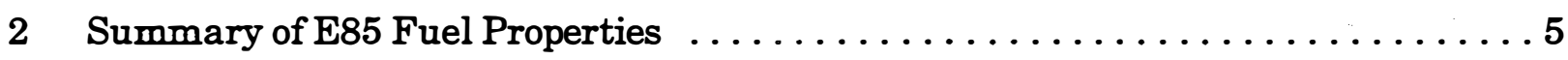

3 Summary of FTP Driving Schedule $\ldots \ldots \ldots \ldots \ldots \ldots \ldots \ldots \ldots \ldots$

4 FTP Exhaust Emissions from Ford FFV Equipped with TA-CC4 . . . . . . 13 


\section{EXECUTIVE SUMMARY}

Under SwRI Project 08-6068, "Determination of Alternative Fuels Combustion Products," the effectiveness of NREL's Vacuum Insulated Catalytic Converter (TA-CC4) in reducing cold-start FTP exhaust emissions after extended soak periods was evaluated. Regulated exhaust emissions and estimated NMOG emissions from a light-duty vehicle (operating on a blend of $85 \%$ denatured ethanol and 15\% gasoline and equipped with the TACC4 test article) were determined utilizing the chassis dynamometer portion of the FTP. Five different combinations of vehicle preconditioning type and soak period duration were evaluated. Some of the findings are summarized below.

- Compared to a similar but uninsulated catalyst, reductions of more than $90 \%$ were observed for $\mathrm{HC}$ and $\mathrm{CO}$ emissions, and $75 \%$ for $\mathrm{NO}_{\mathrm{x}}$ emissions for tests conducted following extended vehicle preconditioning and soak sequences (18and 24-hour soak periods).

- Results following an extended vehicle preconditioning sequence and a 36-hour soak showed reductions of more $70 \%$ from baseline levels for $\mathrm{HC}, \mathrm{CO}$, and $\mathrm{NO}_{\mathrm{x}}$ exhaust emissions.

- After conducting a standard vehicle prep and a 36-hour soak, exhaust emissions were found to be approximately $30 \%, 20 \%$, and $55 \%$ lower for the $\mathrm{HC}, \mathrm{CO}$, and $\mathrm{NO}_{\mathrm{x}}$ emissions, respectively, compared to baseline levels. In addition, THC and CO levels were approximately $20 \%$ less than those from testing with a similar, but uninsulated, catalyst configuration while $\mathrm{NO}_{x}$ levels were similar.

- As expected, most of the emission reductions were achieved in the first few minutes of the cold-start phase of the FTP.

- Compared with an uninsulated catalyst of similar configuration, baseline tests (no stored energy) with TA-CC4 show slightly higher THC and $\mathrm{NO}_{\mathrm{x}}$ exhaust emissions, with similar $\mathrm{CO}$ levels. These slightly higher exhaust emissions are likely due to heat being conducted away from the catalyst brick into the PCM.

The NREL technical monitors for this program were Mr. Brent Bailey and Mr. Chris Colucci of NREL's Center for Transportation Technologies and Systems in Golden, Colorado. The SwRI project manager was Dr. Lawrence R. Smith, and the project leader was Mr. Kevin A. Whitney. Individual task leader was Mr. Patrick M. Merritt. Mr. Danny Terrazas, laboratory supervisor, was responsible for emissions testing. 


\section{BACKGROUND}

Currently, $70 \%$ to $90 \%$ of the $\mathrm{HC}$ and $\mathrm{CO}$ emissions from the EPA certification test for light-duty vehicles are produced in the first few minutes of the vehicle cold-start. During this period, the engine is operating very rich to maintain driveability. However, during this period, the catalyst is not at its operating temperature and can not effectively control exhaust emissions. To achieve future emission standards, the catalytic converter must be immediately effective after the engine is started. When operating a vehicle on E85, catalyst light-off is a further problem because the heat of combustion for ethanol is much lower than that of gasoline. This leads to lower exhaust temperatures, which lengthens the time required for the catalyst to reach light-off temperature. Further, the lower volatility of E85 may dictate additional enrichment during the initial cold start.

Cold-start emissions can be reduced by several methods. One method is to electrically preheat the catalytic converter. This approach has been developed to the point where suppliers are introducing systems to the automotive industry. Great strides have also been made with other technologies, such as HC traps, gas-fired catalyst pre-heaters, and closecoupled catalysts, in reducing cold-start emissions. Of these, close-coupled catalysts are favored because they are not as mechanically complex as the other approaches. Yet, it is likely that even these catalysts will need a temperature boost to perform adequately in low ambient temperature conditions.

Beginning with 1996 production, $100 \%$ of OEM production vehicles must comply with the EPA cold $\left(20^{\circ} \mathrm{F}\right) \mathrm{CO}$ emissions standards. That standard requires all light-duty vehicles and light-duty trucks weighing less than $3750 \mathrm{lb}$ to emit less than $10.0 \mathrm{~g} / \mathrm{mile} \mathrm{CO}$ at $20^{\circ} \mathrm{F}$ (1) $^{(1)}$ In addition, California has specified 100\% compliance for all 1996 model year light-duty vehicles for standards issued for $\mathrm{CO}, \mathrm{NO}_{x}, \mathrm{NMOG}$, and formaldehyde measured at $50^{\circ} \mathrm{F}^{(2)}$.

The EPA has shown in the "Baltimore Study"(3) that average trip patterns in urban areas are quite short, 2.5 to 4.9 miles. Forty percent of all soak periods were between 10 min and $2 \mathrm{~h}$. In addition, the study indicated that only $30 \%$ of all in-use starts occur with the catalyst hot enough for prompt light-off. Thus, technology to effectively combat emissions from in-use vehicles should accommodate both short trips and frequent re-starts after soak periods longer than $10 \mathrm{~min}$.

The approach followed by researchers at NREL to answer these challenges was to store waste exhaust energy, and to use that energy to maintain the vehicle catalytic converter at elevated temperatures for future cold-engine starting. Of the various approaches to reducing cold-start emissions, storage of energy that would be otherwise wasted holds the most appeal. No additional energy input is required for such a system, and its operation is passive. To this end, NREL fabricated a Vacuum Insulated Catalytic Converter (TA-CC4) for evaluations over the chassis dynamometer portion of the FTP for light-duty vehicles. The testing of TA-CC4 complemented other work performed at SwRI under NREL Subcontract No. YAW-3-12243-01, "Development of a Dedicated Ethanol Ultra-Low Emission Vehicle (ULEV)."

Energy storage in TA-CC4 is accomplished with PCM and vacuum insulation. During the FTP vehicle emissions test, the catalyst bed temperature of the typical vehicle often 
exceeds $600^{\circ} \mathrm{C}$, well above the $350^{\circ} \mathrm{C}$ range required for catalyst light-off. This thermal energy can be stored and later used to provide nearly instantaneous catalyst light-off. PCMs absorb substantial amounts of thermal energy by virtue of their heat of fusion during the transition from a solid phase to a liquid phase. This stored energy is later released isothermally as the material solidifies. Harnessing this latent heat characteristic allows much greater energy storage density. Coupling this high-density heat storage medium with the efficiency of vacuum insulation yields a device that can maintain the catalyst bed at elevated temperatures for more than $36 \mathrm{~h}$.

Vacuum insulation coupled with PCM has been successfully demonstrated in an automotive application by Schatz, in a system to store heat that is subsequently dumped to the engine coolant. (4) $^{(1)}$ The system is currently being offered by Volkswagen in Germany as a dealer-installed option. Furthermore, Ivanov and co-workers reported using PCM heat storage for comfort heating in electric vehicles. ${ }^{(5)}$ Both of these applications operate at much lower temperatures than those found in automotive exhaust systems, however. 


\section{OBJECTIVE}

The objective of this task was to evaluate the effectiveness of NREL's Vacuum Insulated Catalytic Converter TA-CC4 in reducing cold-start exhaust emissions after extended soak periods when using ethanol-based fuel. In particular, evaluation of the effects of the test article in overcoming the inherently lower exhaust temperatures from ethanol was desired. TA-CC4 was evaluated over five FTPs with varying vehicle preconditioning sequences and soak periods. 


\section{APPROACH}

As received, the insulated catalyst had not been exposed to vehicle exhaust. Before emissions evaluations, it was installed in an engine dynamometer test cell for break-in. Following break-in, the catalyst was installed on a Ford FFV Taurus. To establish a baseline, an FTP was conducted with the catalyst at room temperature prior to testing. Complete melting of the internal PCM in TA-CC4 was desired, so an extended vehicle preconditioning sequence was devised. After the extended preconditioning sequence, the insulated catalyst was evaluated over the FTP following either an 18-, 24-, or 36-h soak period. An additional test was conducted following a standard vehicle preconditioning sequence and a $36-\mathrm{h}$ soak.

\section{A. Vehicle Description}

The vehicle used in this evaluation was a 1993 Ford FFV Taurus. This vehicle is designed to operate satisfactorily on gasoline and gasoline-methanol blends. A description of the vehicle is given in Table 1.

TABLE 1. VEHICLE DESCRIPTION

\begin{tabular}{|c|c|}
\hline Item & Configuration of Ford Taurus FFV \\
\hline Model year & 1993 \\
\hline Body style & 4-door sedan \\
\hline Transmission & Automatic-4 \\
\hline VIN & 1FALP5218P6281001 \\
\hline Tires & P205/65 R15 \\
\hline Accessories & $\begin{array}{l}\text { Power locks, windows, steering, brakes, } \\
\text { air conditioning }\end{array}$ \\
\hline Engine family & PFM3.0V5FFFC3 \\
\hline Engine displacement & 3.0L \\
\hline Number of cylinders & 6 \\
\hline Fuel system & SFI \\
\hline Ignition system & Electronic \\
\hline Emission control system & $\begin{array}{l}\text { Insulated underbody three-way catalyst, } \\
\text { TA-CC4, heated oxygen sensor, EGR }\end{array}$ \\
\hline $\begin{array}{l}\text { Chassis Dynamometer: } \\
\text { Inertia Setting } \\
\text { Road Load @ } 50 \mathrm{mph}\end{array}$ & $\begin{array}{l}3500 \mathrm{lb} \\
6.8 \mathrm{hp} \\
\end{array}$ \\
\hline
\end{tabular}


The test vehicle was fitted with an exhaust system modified to accommodate the insulated catalyst. Because of space constraints under the vehicle and the large diameter of the catalyst, it was installed much further downstream in the exhaust system than the OEM catalysts. Figure 1 shows the OEM and experimental exhaust system configurations. The twin OEM catalysts both reside approximately $14 \mathrm{in}$. downstream of the exhaust manifold flange. In the case of the experimental exhaust system, blank pipes were installed where the OEM catalysts were removed, and the insulated catalyst was installed at the termination of the Y-pipe. This placed the face of the insulated catalyst approximately $37 \mathrm{in}$. from the exhaust manifold flange on one side of the exhaust system, and 58 in. downstream of the manifold flange on the other side. In an effort to compensate for the heat loss, the exhaust system was wrapped with insulated fiber tape from the exhaust manifold flange to the termination of the Y-pipe.

\section{B. Test Fuels}

For these evaluations, the vehicle was operated on E85. A summary of properties for this fuel is given in Table 2.

TABLE 2. SUMMARY OF E85 FUEL PROPERTIES

\begin{tabular}{||l|c|}
\hline \multicolumn{1}{|c|}{ Fuel Property } & E85 \\
\hline RVP, psi & 6.76 \\
\hline Specific gravity & 0.7795 \\
\hline Carbon, wt. \% & 61.20 \\
Hydrogen, wt. \% & 13.21 \\
Oxygen, wt. \% & 25.59 \\
\hline
\end{tabular}

\section{Emission Test Procedures}

The insulated catalyst was evaluated using the chassis dynamometer portion of the FTP for light-duty vehicles. Complete melting of the internal PCM in TA-CC4 was desired, so an extended vehicle prep sequence was devised. This sequence consisted of the standard UDDS, followed by three highway fuel economy test schedules (HFETs). This extended prep sequence was used for each test except the baseline test and one of the 36-h soak tests, which used a standard preconditioning sequence. THC, methane, $\mathrm{CO}, \mathrm{NO}_{x}$, and $\mathrm{CO}_{2}$ emissions were collected as dilute exhaust in Tedlar gas sample bags. Aldehydes and ketones, and ethanol were sampled using wet adsorption techniques. All sampling was conducted in a manner consistent with EPA protocols for light-duty emissions testing. NMOG was estimated using NMHC from the gasoline portion of the fuel as measured by an FID rather than by HC speciation. Gasoline-derived NMIHC was determined by measuring HC with a FID calibrated on propane, then correcting the results for the removal of methane and ethanol. 

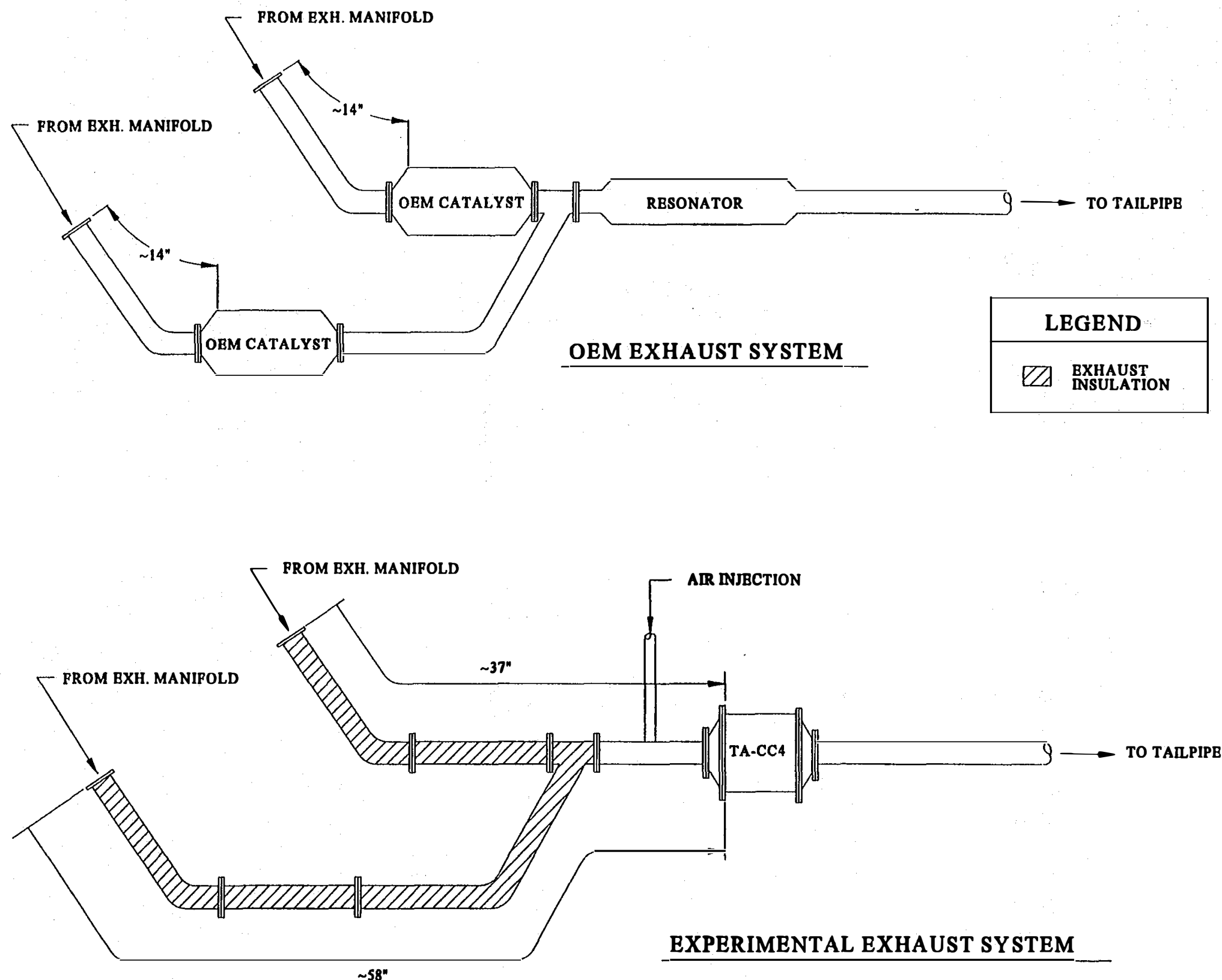

FIGURE 1. EXHAUST SYSTEM CONFIGURATION 


\section{Driving Cycle}

All exhaust emissions were evaluated using the chassis dynamometer portion of the FTP for light-duty vehicles as specified in the Code of Federal Regulations, Title 40, Part 86, Subpart B. The FTP utilizes the UDDS, which is 1372 seconds in duration. The UDDS is divided into a 505-second segment and an 867-second segment. An FTP is composed of a 505 cold-start transient portion (Bag 1) and an 867 cold stabilized portion (Bag 2), followed by a 10-min soak and then a 505 hot-start transient portion (Bag 3). A summary of the cycle duration, driving distance, and average speed is given in Table 3. The FTP driving schedule with the cold and hot test segments identified is given in Figure 2.

TABLE 3. SUMMARY OF FTP DRIVING SCHEDULE

\begin{tabular}{||l|c|c|c||}
\hline \multicolumn{1}{|c|}{ Segment } & $\begin{array}{c}\text { Duration, } \\
\text { seconds }\end{array}$ & $\begin{array}{c}\text { Distance, } \\
\text { miles }\end{array}$ & $\begin{array}{c}\text { Average Speed, } \\
\text { miles/hr }\end{array}$ \\
\hline \hline Transient phase & 505 & 3.60 & 25.7 \\
\hline Stabilized phase & 867 & 3.90 & 16.2 \\
\hline UDDS & 1372 & 7.50 & 19.7 \\
\hline
\end{tabular}

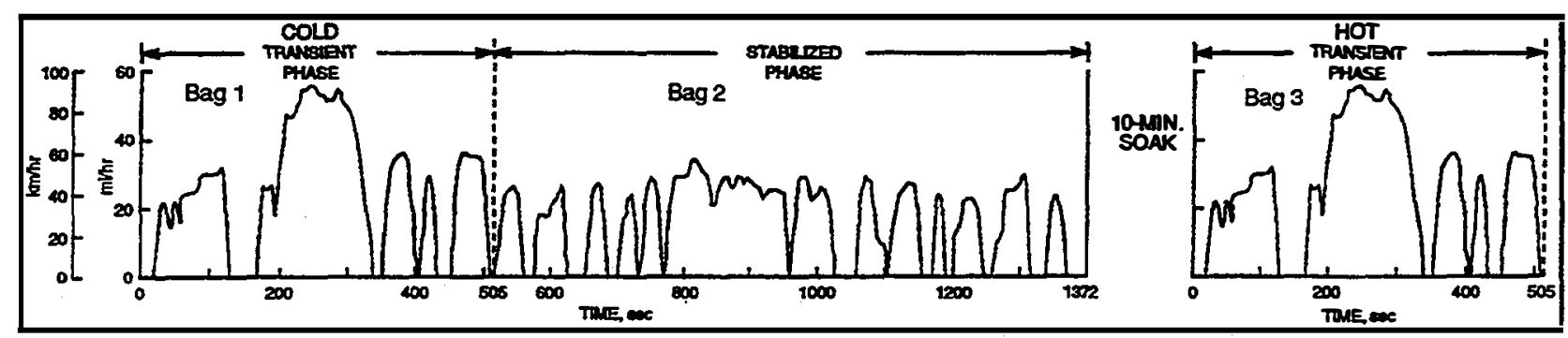

FIGURE 2. FTP DRIVING CYCLE

\section{Chassis Dynamometer and CVS}

A Clayton Model ECE-50 passenger car dynamometer with a direct drive variable inertia flywheel system was used for all testing. The inertia weight simulates equivalent weights of vehicles from $1,000 \mathrm{lb}$ to $4,875 \mathrm{lb}$ in 125-lb increments. A nominal 10inch diameter by 16-ft long full-flow exhaust dilution tunnel was used in conjunction with a CVS and a positive displacement pump. This unit has a nominal capacity of $325 \mathrm{scfm}$. The filter box at the entrance of the dilution tunnel was equipped with an MSA UltraTM filter to remove small particles, a charcoal filter to absorb background HC, and a MSA Dustfoe ${ }^{\mathrm{TM}}$ Space Filter as a backup filter to collect any particles that pass through the first two filters. The average temperature in the dilution tunnel at the particulate sampling zone was $110^{\circ} \mathrm{F}$, and did not exceed $125^{\circ} \mathrm{F}$ during testing. The vehicle hood was maintained fully open during all cycles and was closed during the soak periods. A cooling fan of 5,000 cfm capacity was used in front of the test vehicle to provide air flow during all tests. During soak periods, the fan was turned off. 


\section{Emissions Sampling and Analysis Procedures}

\section{Regulated Gaseous Emissions}

Total hydrocarbons (THC), or OMHCE, $\mathrm{CO}, \mathrm{NO}_{x}$, and $\mathrm{CO}_{2}$ emissions were quantified in a manner consistent with EPA protocols for light-duty emissions testing as given in the Code of Federal Regulations, Title 40, Part 86, Subpart B. Total hydrocarbons, CO, $\mathrm{NO}_{\mathrm{x}}$, and $\mathrm{CO}_{2}$ were sampled using proportional exhaust gas samples collected in Tedlar bags. Total hydrocarbons were measured using an $\mathrm{FD}$. Carbon monoxide and $\mathrm{CO}_{2}$ were determined using NDIR instruments. Oxides of nitrogen were measured using a chemiluminescent instrument. Wet absorption techniques were employed to collect methanol, ethanol, and aldehydes for the determination of OMHCE. These techniques are discussed in more detail below.

Methane levels were determined using proportional exhaust gas samples collected in Tedlar bags. A GC equipped with an FID was utilized in accordance with the SAE J1151 procedure to analyze the samples. The GC system was equipped with a packed column to resolve methane from other hydrocarbons in the sample. Samples were introduced into a 5 -mL sample loop via a diaphragm pump. For analysis, the valve was switched to the inject position and the helium carrier gas swept the sample from the loop toward the detector through a $61 \mathrm{~cm} \times 0.3 \mathrm{~cm}$ Porapak $\mathrm{N}$ column in series with a $122 \mathrm{~cm} \times 0.3 \mathrm{~cm}$ molecular sieve $13 \mathrm{X}$ column. As soon as the methane peak passed into the molecular sieve column, the helium flow was reversed through the Porapak $\mathrm{N}$ column to vent. Peak areas were compared to an external calibration standard.

\section{Particulate Emissions}

Total particulate mass was measured using a 47-mm fluorocarbon-coated glass fiber filter, which collected a proportional exhaust sample from the dilution tunnel. Filters were conditioned and weighed in accordance with the appropriate sections of the CFR for lightduty vehicles. ${ }^{(6)}$ Particle size distribution measurements were performed with a Sierra Series 220 In-Stack Cascade Impactor using a 0.375-in. internal-diameter isokinetic sampling nozzle. ${ }^{(7)}$ Stages 3 through 8 were used to collect particulate mass in equivalent aerodynamic diameter cut-off ranges from about $0.2 \mu \mathrm{m}$ to greater than $3 \mu \mathrm{m}$. The particles were collected on stainless steel substrates. This system uses a patented radial-slot impactor design with four radial rectangular slots $90^{\circ}$ apart. The slots between adjacent stages were $45^{\circ}$ apart. The last stage was followed by a fluorocarbon-coated glass fiber filter to collect particles below $0.2 \mu \mathrm{m}$.

\section{Aldehydes and Ketones}

An HPLC procedure was utilized for the analysis of aldehydes and ketones. Samples were collected by bubbling dilute exhaust at a nominal flowrate of $4 \mathrm{~L} / \mathrm{min}$ through chilled glass impingers containing an acetonitrile solution of 2,4-DNPH and perchloric acid. For analysis, a portion of the acetonitrile solution was injected into a liquid chromatograph equipped with a UV detector. External standards of the aldehyde and ketone DNPH derivatives were used to quantify the results. The aldehydes and ketones measured were: formaldehyde, acetaldehyde, acrolein, acetone, propionaldehyde, crotonaldehyde, isobutyraldehyde/methylethylketone (not resolved from each other during normal operating 
conditions, and so reported together), benzaldehyde, and hexanaldehyde. Detection limits for this procedure were on the order of $0.005 \mathrm{ppm}$ aldehyde or ketone in dilute exhaust.

\section{Alcohols}

The collection of methanol and ethanol in exhaust was accomplished by bubbling exhaust through glass impingers. Each impinger contained $25 \mathrm{~mL}$ of deionized water maintained at ice-bath temperature. Exhaust samples were collected continuously during test cycles at a nominal flow rate of $4 \mathrm{~L} / \mathrm{min}$ through a Teflon sample line held at $102^{\circ} \mathrm{C}\left(215^{\circ} \mathrm{F}\right)$. For analysis, a 1-pL portion of the sample was injected into the GC equipped with an FID and an analytical column. The analytical column was a $0.53-\mathrm{mm} \times 30-\mathrm{m}$ capillary column with a 1- $\mu m$ film of DB-WAX as the stationary phase. The GC carrier gas was helium at a column head pressure of approximately $4 \mathrm{psi}$. The column oven temperature was maintained at $70^{\circ} \mathrm{C}$ for $1 \mathrm{~min}$, then ramped to $110^{\circ} \mathrm{C}$ at $10^{\circ} / \mathrm{min}$, and held at $110^{\circ} \mathrm{C}$ for $5 \mathrm{~min}$. External standards in deionized water were used to quantify the results. Detection limits for this procedure were on the order of $0.06 \mathrm{ppm}$ in dilute exhaust. 


\section{TEST RESULTS AND DISCUSSION}

\section{A. Catalyst Break-In and Cool-Down}

Before emissions evaluations were conducted, TA-CC4 was installed in an engine dynamometer test cell for catalyst break-in. The catalyst was broken in for $24 \mathrm{~h}$ using a Ford 460 in. $^{3}$ V-8 engine running on gasoline. Engine parameters were set to achieve $500^{\circ} \pm 50^{\circ} \mathrm{C}$ at the thermocouple located between the intumescent mat and the steel wall which are positioned between the catalyst brick and the container for the PCM. As shown in Figure 3, temperature measurements recorded during the cool-down period after break-in correspond very closely to those temperatures observed by NREL during bench-testing at its facilities.

\section{B. Exhaust Emissions Testing}

Weighted exhaust emissions results from the five FTPs are given in Table 4 and Figure 4. Detailed computer printouts of these tests can be found in Appendix A. For these tests, supplemental air was injected into the exhaust system prior to the insulated catalyst during the first $100 \mathrm{~s}$ of the cold-start phase (Bag 1), and for $15 \mathrm{~s}$ at the beginning of hot-start phase (Bag 3). The nominal flow rate was $5 \mathrm{ft}^{3} / \mathrm{min}$. Supplemental air provided sufficient oxygen levels in the exhaust stream so unburned fuel and $\mathrm{CO}$ would be more effectively oxidized in the catalyst. Air injection is necessary because the catalyst is at operating temperatures when the engine is first started and is in open loop operation (running rich). Air injection is not effective in conventional vehicles because the catalyst has not reached light-off temperature while the engine is in open loop operation.

For comparison purposes, results from a previous test conducted on this vehicle (E80CATA\&INS) are also presented in Table 4. This test was conducted in September 1994, as part of Subcontract No. YAW-3-12243-01, "Development of a Dedicated Ethanol Ultra-Low Emission Vehicle (ULEV)." The catalytic converter used during this test was the same size, and had the same formulation as TA-CC4 but was insulated. Similar break-in procedures were conducted on both catalysts, and both catalysts were located in the same position under the vehicle.

Data from the baseline test with TA-CC4 (TA4-E85-BASE) show the performance of the system without the initial temperature assist from the vacuum insulation and heat storage via PCM. Following a standard vehicle preconditioning sequence and a soaking period of nearly $43 \mathrm{~h}$, the catalyst had not cooled to ambient temperature. Therefore, dry filtered shop air was blown through the exhaust system until the PCM and catalyst reached ambient temperature.

A comparison of exhaust emissions from the previously tested uninsulated catalyst (E80-CATA\&INS) and the baseline test with TA-CC4 (TA4-E85-BASE) shows slightly higher THC and $\mathrm{NO}_{x}$ exhaust emissions with the insulated catalyst. $\mathrm{CO}$ levels were similar between the two tests. These slightly higher exhaust emissions with TA-CC4 are likely due to heat being conducted away from the catalyst brick into the PCM, lengthening the time it takes for the catalyst to reach light-off temperature. Higher than normal emissions result from this 

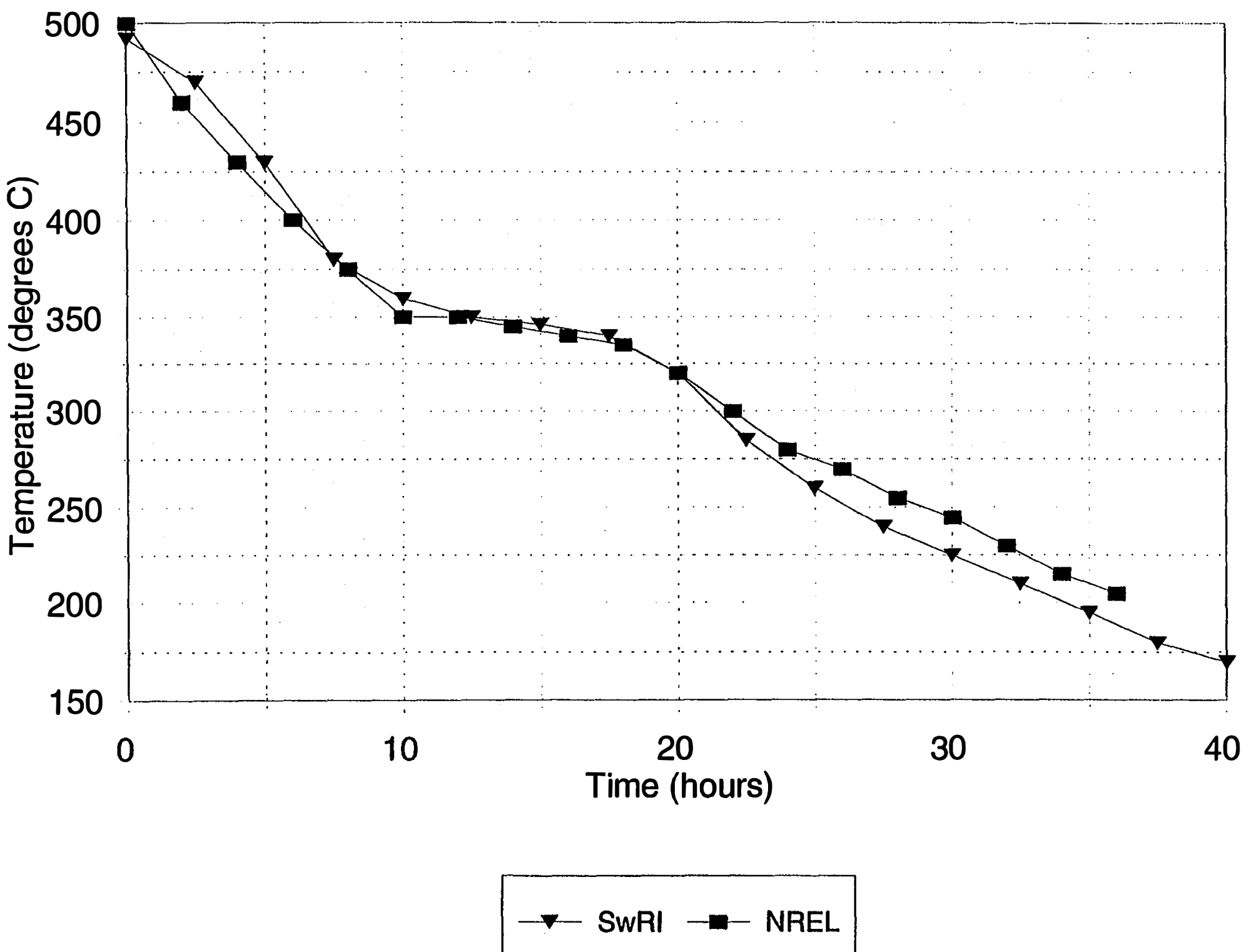

FIGURE 3. INSULATED CATALYST COOLDOWN TEMPERATURE PROFILE 


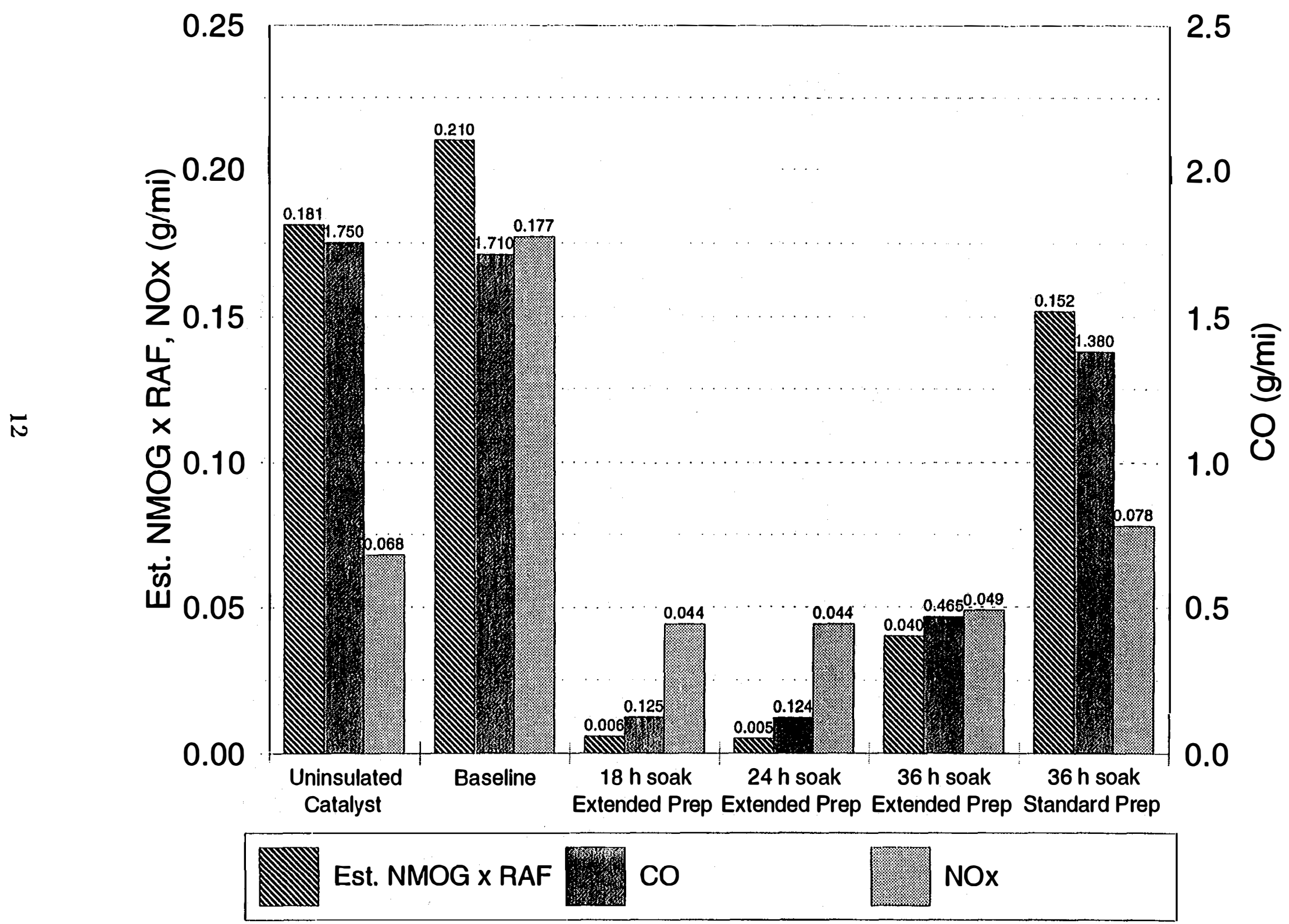

FIGURE 4. TAURUS FFV WITH INSULATED CATALYST, SUMMARY OF FTP EMISSIONS 
TABLE 4. FTP EXHAUST EMISSIONS FROM FORD FFV EQUIPPED WITH TA-CC4

\begin{tabular}{|c|c|c|c|c|c|c|}
\hline Test Condition & \begin{tabular}{|c|} 
Uninsulated \\
Catalyst \\
Baseline $^{\mathrm{g}}$
\end{tabular} & Baseline & $\begin{array}{l}\text { 18-h } \\
\text { Soak }\end{array}$ & $\begin{array}{l}\text { 24-h } \\
\text { Soak }\end{array}$ & $\begin{array}{l}\text { 36-h } \\
\text { Soak }\end{array}$ & $\begin{array}{c}36-h \\
\text { Soak }\end{array}$ \\
\hline $\begin{array}{c}\text { Vehicle Preconditioning } \\
\text { Sequence }\end{array}$ & UDDS & UDDS & $\begin{array}{l}\text { UDDS + } 3 \\
\text { HFETS }\end{array}$ & $\begin{array}{l}\text { UDDS + } 3 \\
\text { HFETs }\end{array}$ & $\begin{array}{l}\text { UDDS + } 3 \\
\text { HFETS }\end{array}$ & UDDS \\
\hline $\begin{array}{c}\text { Catalyst Temperature at } \\
\text { Start of Test }\left({ }^{\circ} \mathrm{C}\right)\end{array}$ & 22 & 25 & 290 & 234 & 175 & 118 \\
\hline Test Number & $\begin{array}{l}\text { E-80- } \\
\text { CATA\&INS }\end{array}$ & $\begin{array}{l}\text { TA4-E85- } \\
\text { BASE }\end{array}$ & $\begin{array}{l}\text { TA4E85- } \\
\text { 18HR }\end{array}$ & $\begin{array}{l}\text { TA4-E85- } \\
\text { 24HR }\end{array}$ & $\begin{array}{l}\text { TA4-E85- } \\
\text { 36HR }\end{array}$ & $\begin{array}{l}\text { TA4-E85- } \\
\text { 36HRC }\end{array}$ \\
\hline $\mathrm{THC}^{\mathrm{a}}(\mathrm{g} / \mathrm{mi})$ & 0.313 & 0.393 & 0.040 & 0.034 & 0.088 & 0.258 \\
\hline $\mathrm{CO}(\mathrm{g} / \mathrm{mi})$ & 1.75 & 1.71 & 0.125 & 0.124 & 0.465 & 1.38 \\
\hline $\mathrm{NO}_{x}(\mathrm{~g} / \mathrm{mi})$ & 0.068 & 0.177 & 0.044 & 0.044 & 0.049 & 0.078 \\
\hline $\mathrm{CH}_{4}(\mathrm{~g} / \mathrm{mi})$ & 0.043 & 0.080 & 0.032 & 0.026 & 0.029 & 0.031 \\
\hline $\mathrm{NMHC}^{\mathrm{b}}$ (g/mi) & 0.073 & 0.115 & 0.006 & 0.005 & 0.037 & 0.080 \\
\hline Total Carbonyls ${ }^{c}(\mathrm{~g} / \mathrm{mi})$ & 0.04 & 0.045 & 0.003 & 0.002 & 0.013 & 0.034 \\
\hline Alcohols $^{d}(\mathrm{~g} / \mathrm{mi})$ & 0.156 & 0.153 & ND & ND & 0.010 & 0.113 \\
\hline Estimated $\mathrm{NMOG}^{\ominus}(\mathrm{g} / \mathrm{mi})$ & 0.27 & 0.314 & 0.009 & 0.008 & 0.059 & 0.227 \\
\hline Est NMOG $\times$ RAF $(\mathrm{g} / \mathrm{mi})$ & 0.181 & 0.210 & 0.006 & 0.005 & 0.040 & 0.152 \\
\hline Formaldehyde (mg/mi) & 8.67 & 6.29 & 2.28 & 1.73 & 1.64 & 3.31 \\
\hline Acetaldehyde (mg/mi) & 30.4 & 37.8 & 0.159 & 0.214 & 10.1 & 28.8 \\
\hline \multicolumn{7}{|c|}{ 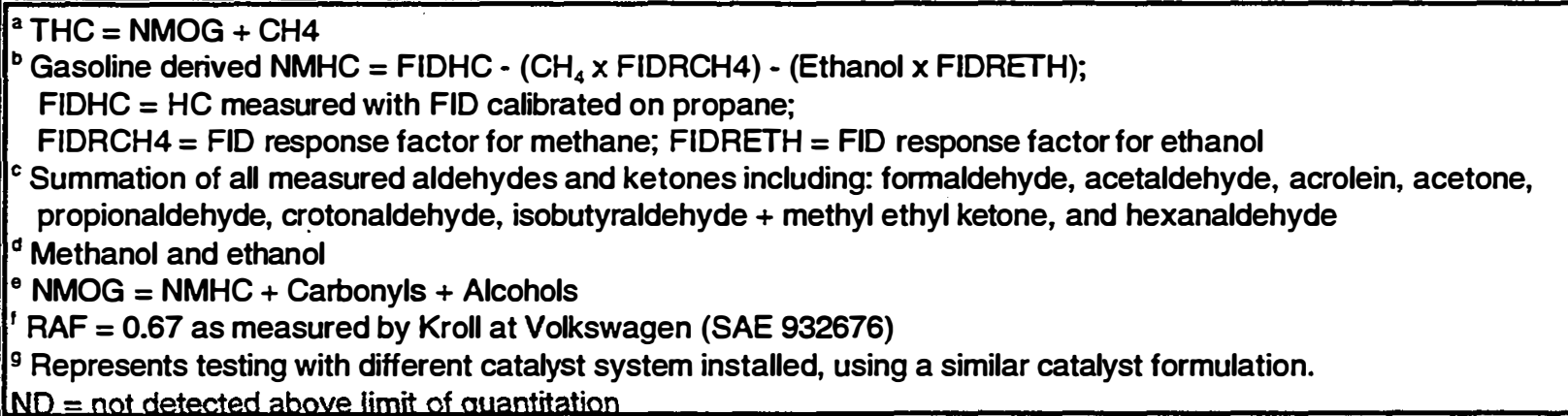 } \\
\hline
\end{tabular}

situation, which represents the case in which a vehicle would sit until all stored heat energy was depleted. This phenomenon is illustrated in Figure 5, which gives catalyst front brick temperature and exhaust outlet temperature for the uninsulated catalyst and the baseline test with the insulated catalyst (TA-CC4). Although the front face temperature of the catalyst is similar during both tests, the temperature of the exhaust exiting the insulated catalyst is substantially lower. However, EPA estimates that approximately $98 \%$ of all trips occur within $36 \mathrm{~h}$ of the previous trip. ${ }^{(8)}$ Therefore, most common driving patterns will result in the catalyst being at elevated temperatures at the next cold start, minimizing the heat sink effect. Careful analysis of both the effect that this cooling has on the exhaust emissions and the frequency with which this situation is likely to occur is necessary to determine whether use of such device will impart any net improvement in exhaust emissions from the vehicle under normal use. 


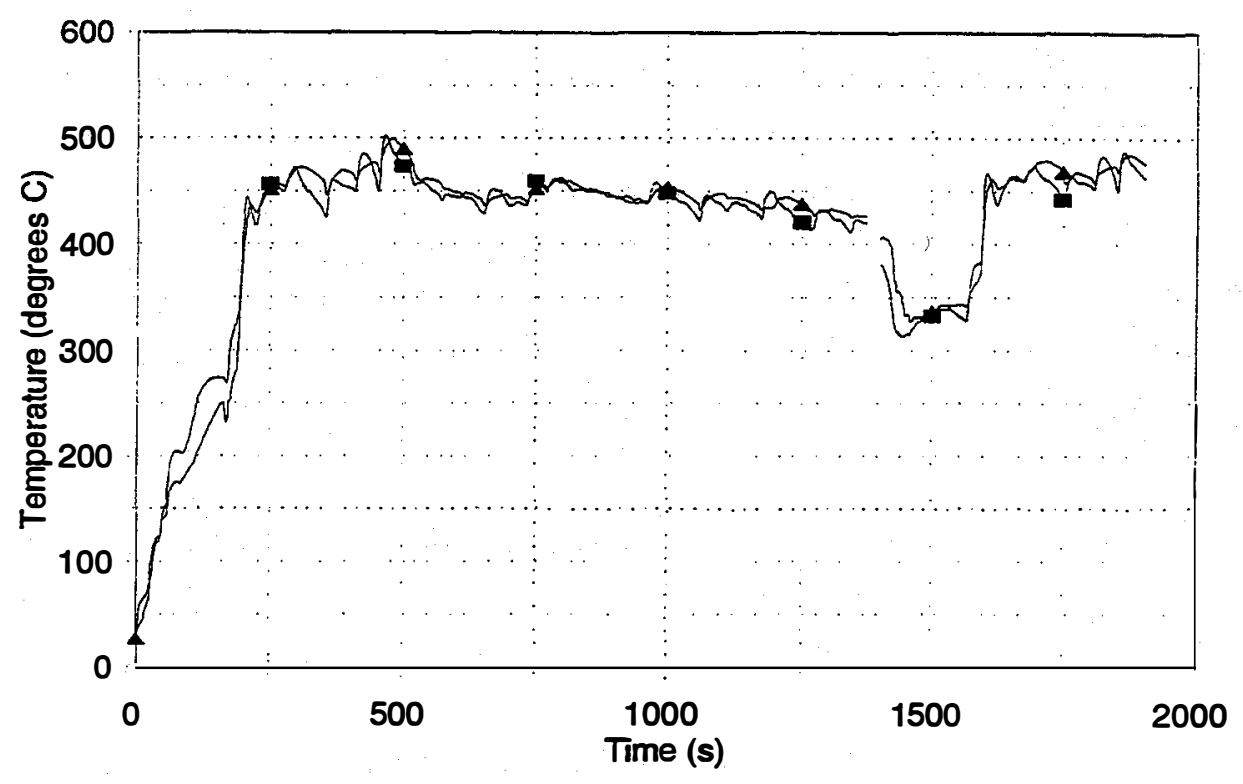

$\rightarrow-$ Uninsulated Catalyst $\longrightarrow$ Insulated Catalyst

a. Catalyst Front Face Temperatures

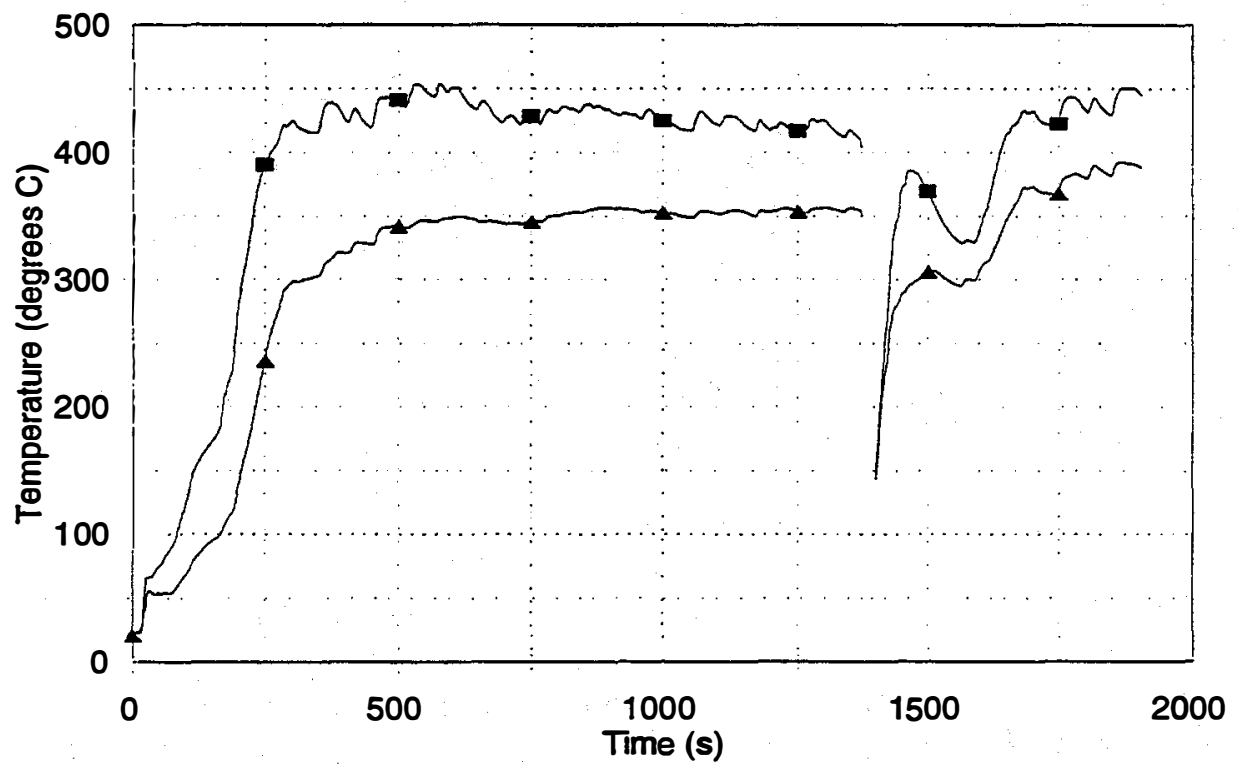

$\rightarrow-$ Uninsulated Catalyst $\multimap$ Insulated Catalyst

b. Catalyst Outlet Temperatures

FIGURE 5. COMPARISON OF UNINSULATED AND INSULATED CATALYST TEMPERATURES 
Tests conducted after 18- and 24-h soak periods produced similar results, and demonstrated the effectiveness of the insulated catalyst in reducing exhaust emissions after an overnight soak. Reductions of more than $90 \%$ were observed for $\mathrm{HC}$ and $\mathrm{CO}$ emissions, while $\mathrm{NO}_{\mathrm{x}}$ emissions were reduced approximately $75 \%$. Results following an extended vehicle preconditioning sequence and a $36-\mathrm{h}$ soak show reductions of more than $80 \%$ from baseline levels for $\mathrm{HC}, \mathrm{CO}$, and $\mathrm{NO}_{x}$ exhaust emissions. For emissions certification testing, a vehicle may soak up to $36 \mathrm{~h}$ following a single UDDS prep. Test TA4-E85-36HRC was to demonstrate the system performance at the maximum soak period following a standard prep with the PCM initially at ambient temperature (i.e., no extended prep sequence to ensure full melt of the PCM). This test showed reductions of approximately $30 \%, 20 \%$, and $55 \%$ in $\mathrm{HC}, \mathrm{CO}$, and $\mathrm{NO}_{\mathrm{x}}$ emissions, respectively, compared to baseline levels. In addition, THC and CO levels were approximately $20 \%$ less than those from testing with the uninsulated catalyst, while $\mathrm{NO}_{x}$ levels were similar.

Most of the emissions reductions were achieved in the first few minutes of the coldstart phase of the FTP. Figures 6 through 8 show continuous raw exhaust emissions concentrations measured after the insulated catalyst for the first $140 \mathrm{~s}$ of the FTP, for tests conducted following an extended vehicle preconditioning sequence and 24- and 36-h soaks, and for the test conducted following a standard prep and a 36-h soak. Exhaust emissions levels were similar for all tests following the first few minutes of operation.

Figure 9 shows representative temperature profiles of the front of the catalyst during soak following standard and extended vehicle preps. Other tests conducted with extended or standard preconditioning sequences showed similar results. Figure 9 illustrates the differences between starting with the PCM melted and with it only partially melted. The tests in which the PCM was fully melted clearly show the isothermal period in which the PCM was fusing between the 5- and 10-h marks, thus prolonging the time at elevated temperature. Figure 9 also shows the temperature gains made with the extended preconditioning sequence compared to the standard vehicle prep. Also note the rise in temperature during the first hour following a standard prep as heat from the catalyst brick is transferred to the PCM. 


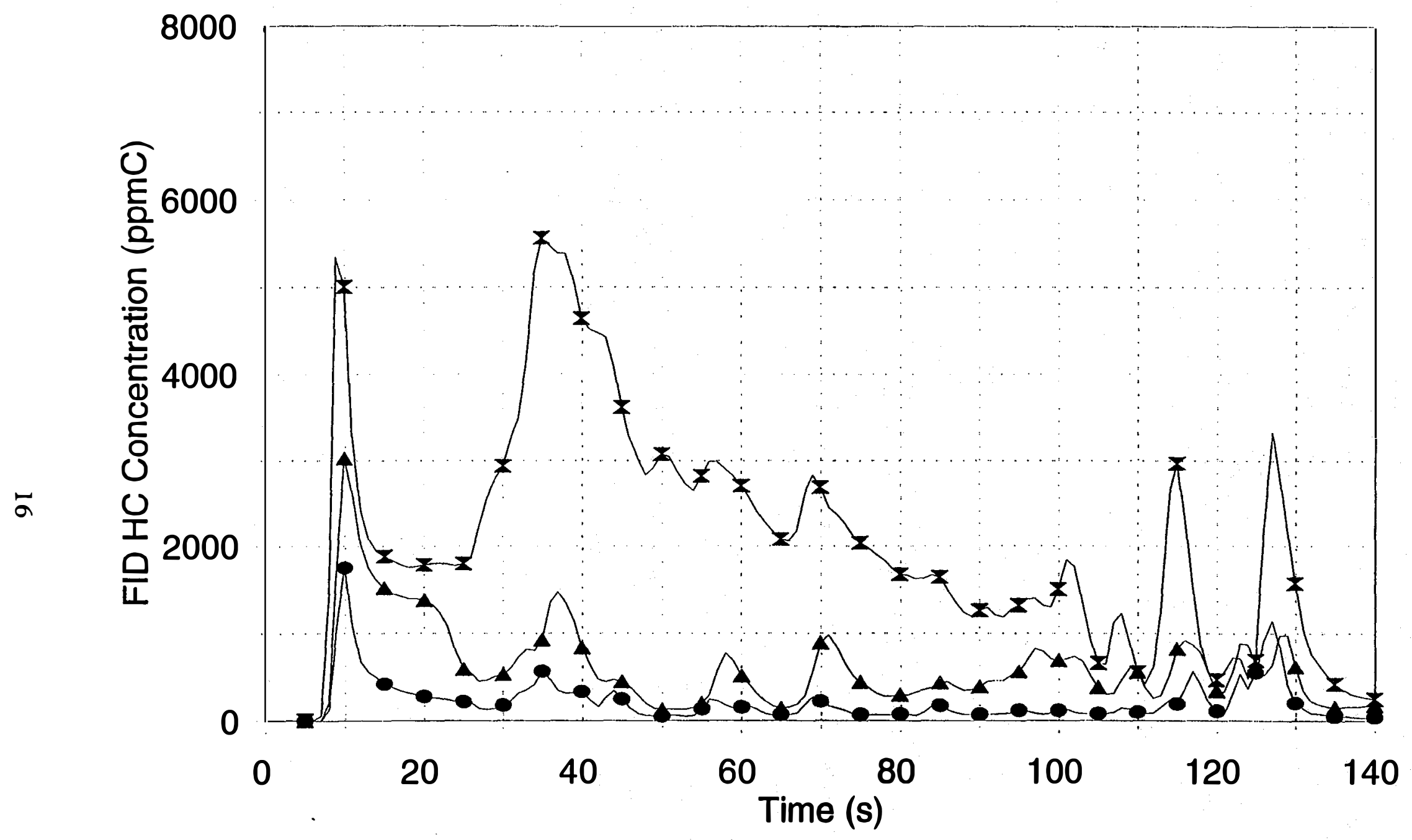

- 24-h Soak - Extended Prep $-\boldsymbol{\Lambda}-36-\mathrm{h}$ Soak - Extended Prep $\longrightarrow$ 36-h Soak - Standard Prep

FIGURE 6. TAURUS FFV WITH INSULATED CATALYST, FTP FID HC AFTER CATALYST 


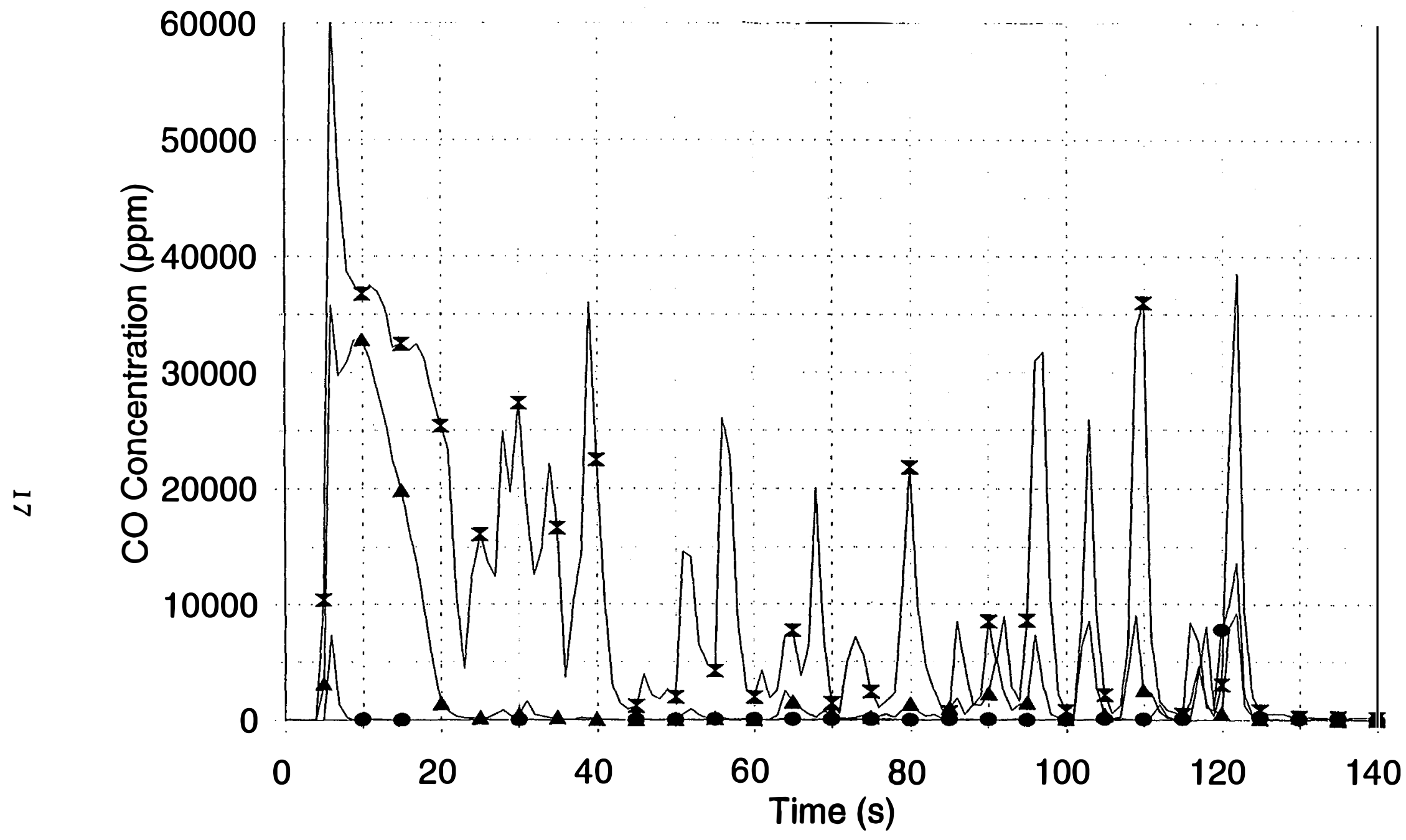

24-h Soak - Extended Prep $\longleftarrow$ 36-h Soak - Extended Prep $\longrightarrow$ 36-h Soak - Standard Prep 


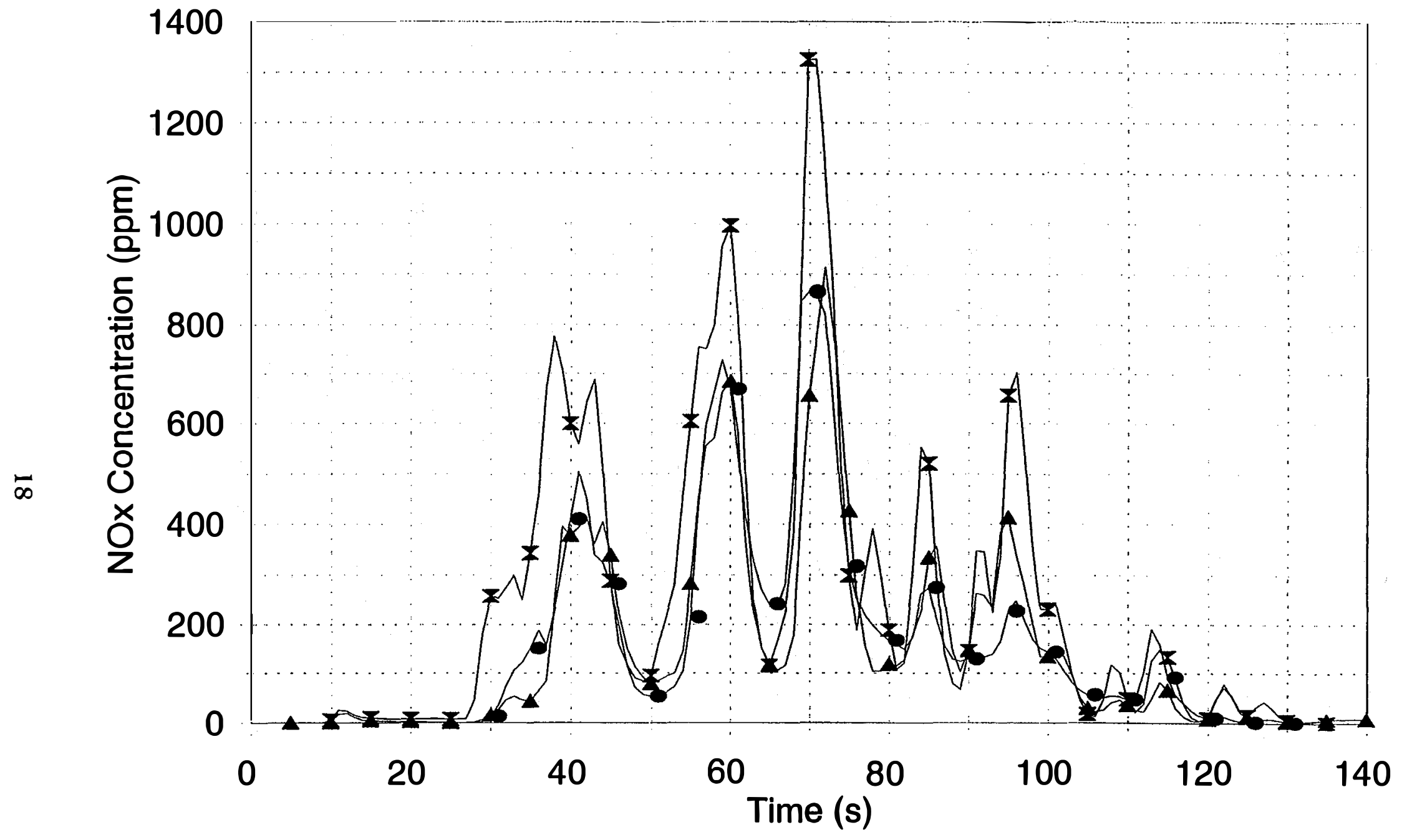

- - 24-h Soak - Extended Prep $\longrightarrow$ - 36-h Soak - Extended Prep $\longrightarrow$ 36-h Soak - Standard Prep

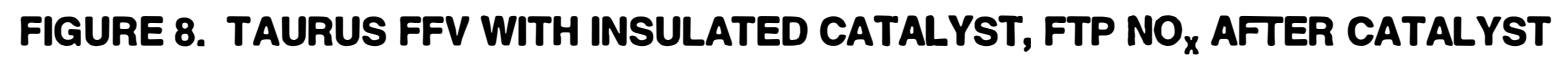




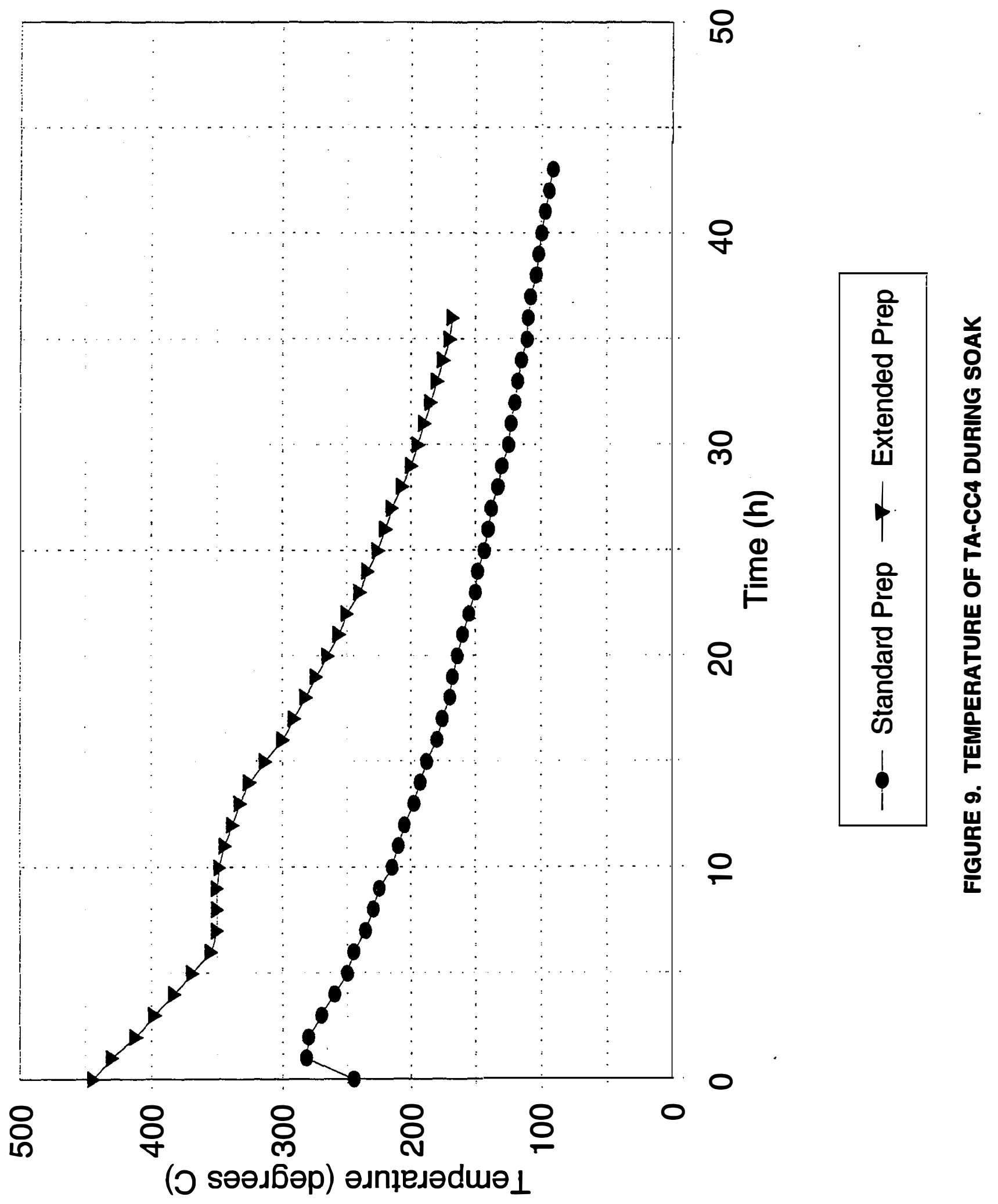




\section{RECOMMENDATIONS}

Further design improvements to hasten the full melt of the PCM would likely improve the net utility of the device, although the effects of the heat sink properties under certain circumstances can be detrimental. In its present state, a 38-mile extended prep sequence consisting of an UDDS followed by three HFETs was required to achieve full melt of the PCM. For the device to be fully effective, it would need to achieve full melt within the average in-use trip length, which was shown earlier to be on the order of 2.5 to 4.9 miles.

Heat storage capacity does not come without a weight penalty. Along with alternate configurations to accommodate the constricted space allotted to exhaust aftertreatment systems, weight is a big concern for automakers. As the system is refined, it would be expected that each of these design criteria would be further addressed.

Many studies of heat storage through PCM indicate that there is degradation of performance after a certain number of cycles, which varies with the particular PCM. Degradation of PCM performance can also be brought about by impurities, so not only will manufacturing practices need to be tightly controlled, but the PCM containment structure will have to exclude contamination as well as allow for expansion and contraction. Furthermore, material compatibility issues will have to be taken into account. Whether the PCM is a inorganic salt eutectic or a eutectic metal, interaction of the molten material with the container can be a daunting technical challenge. Failure of the PCM containment could lead to catastrophic results. Again, design for long-term durability will need to address these two concerns.

In selecting a PCM, not only will the above performance criteria need to be addressed, but the life cycle environmental impact of the selected material must be carefully evaluated. As with any new technology, environmental consequences of manufacture, use, and re-use or disposal must be studied and factored into the material selection process. 


\section{REFERENCES}

1. Code of Federal Regulations, Title 40, Part 86, Subpart C.

2. California Code of Regulations, Title 13.

3. Enns, P., German, J., and Markey, J., EPA's Survey of In-Use Patterns: "Implications for Mobile Source Emission Inventories," U.S. EPA Office of Mobile Sources, Certification Division, 2565 Plymouth Road, Ann Arbor, MI 48104.

4. Schatz, O., "Cold Start Improvements With a Heat Store," SAE 910305, SAE International Congress and Exposition, Detroit, Michigan, February 25 - March 1, 1991.

5. Ivanov, A.N., Vyboishikov, F.P., Misevich, B.S., and Tsvetkov, L.V., "Heat Accumulator for Electric Car Heating," Elektrotekhnika, Vol. 59, No. 11, 1988.

6. Code of Federal Regulations, Title 40, Part 86, Subpart B.

7. Series 220 Instruction Manual, Bulletin No. 12-78-220IM, Sierra Instruments, Inc.

8. Federal Test Procedure Review Project: Preliminary Technical Report, U.S. Environmental Protection Agency, EPA 4200-R-93-007, May 1993. 


\section{APPENDIX A}

\section{DETAILED COMPUTER PRINTOUTS OF THE FTP}

REGULATED EMISSION TEST RESULTS FROM TASK 2

\begin{tabular}{||c|c|c|c||}
\hline Test No. & $\begin{array}{c}\text { Soak Time, } \\
\text { hours }\end{array}$ & Vehicle Prep & Page No. \\
\hline \hline TA4-E85-BASE & 0 & Standard & A-1 \\
\hline TA4-E85-18HR & 18 & Extended & A-3 \\
\hline TA4-E85-24HR & 24 & Extended & A-5 \\
\hline TA4-E85-36HR & 36 & Extended & A-7 \\
\hline TA4-E85-36HRC & 36 & Standard & A-9 \\
\hline
\end{tabular}


SOUTBWEST RESEARCH INSTITOTE - DEPARTYIFNT OF EYISSIONS RESEARCH

COHPOTER PROGRAM LDT 1.5-R 4-BAG CARB FTP VEHICLE EMISSTON RESOLTS

PROJECT NO. 08-6068-200

VEHICLE NOEBER E85

VBRICLE MODEL 93 FORD TAOROS

ENGINE $\quad 3.0 \mathrm{~L}$ (183 CID)- 76

TRANSHISSION A4

ODOHETER $\quad 4671$ HILES ( 7515 KM)

BAROAETER 29.34 IN HG (745.2 IM HG)

RETLTIVE HOUIDITY 35.1 PCT.

BAG NOMBER

BAG DESCRIPTION

ROI TIRE SECONDS

DRY/WET CORRECTION FACTOR, SAMP/BACR

ITRASURED DISTANCE IILUES (RM)

BCONER FLON RATE SCPH (SONH)

GAS FETER FLON RATE SCPH (SCII)

TOTAL FLOW SCF (SCH)

HC SAYPLE KETEER/RANGE/PPH (BAG)

HC BCRERD LETER/RANGE/PPM

CO SAYPLE KLTERR/RAIGE/PPH

CO BCK GRD HETER/RABGE/PPH

CO2 SLYPLE HETERB/RABER/PCT

CO2 BCRGRD METER/RARGE/PCT

HOX SAMPLE KLTIER/RANGE/PPM (BAG) (D)

1OY BCRERD METER/RANGE/PPY

CH4 SAIPLE PPM (1.150)

CH4 BCRGRD PPH

DILOTION FACTOR

HC COICENTRATION PPM

CO CONCENITRATTON PPY

CO2 CONCENITRATTON PCT

NOX CONCENIRATION PPH

CH4 CONCENITRATTON PPY

NRTC CONCENTRATTON PPH

THC MASS GRAYS

CO MASS GRAHS

$\mathrm{CO} 2$ HASS GRAHS

NOX HASS GRAYS

CH4 MASS GRAYS

NRIBC MASS GRAYS (FID)

FURL HASS RG

PUEL ECONOMY MPG (L/100RM)
TEST TA4-E85-BASE

DATE $11 / 16 / 95$ RON

DYNO 2 BAG CART 2

ACTOAL ROAD LOAD $6.80 \mathrm{BP}$ ( $5.07 \mathrm{KN}$ )

TEST WEIGET 3500 LBS ( 1587 KG)

DRY BOLB TEYPERATORE $72.0^{\circ} \mathrm{F}\left(22.2^{\circ} \mathrm{C}\right)$

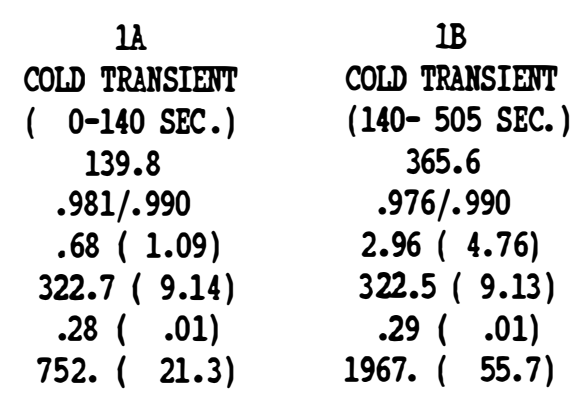
$22.9 / \quad 3 / 228.49 \quad 34.1 / \quad 2 / 34.08$
$.8 / 3 / \quad 7.98$
$88.8 / 1 / 914.16$
$1.5 / 1 / 10.57$
83.9/ 14/ .7306
$11.4 / 14 / \quad .0362$
$33.9 / 2 / 34.02$
$.5 / \quad 2 / \quad .50$
15.32
2.18
$7.6 / \quad 2 / \quad 7.60$
$59.4 / \quad 12 / \quad 58.54$
$1.5 / 12 / 1.45$
97.9/ 14/ 1.0918
$13.5 / 14 / .0441$
$10.3 / \quad 1 / 2.66$
$1.1 / \quad 1 / \quad .29$
10.31
2.12

\subsection{9}

221.04

878.62

.6968

33.55

13.29

114.38

\subsection{9}

21.798

271.87

1.183

.189

1.406

.144

$13.83(17.01)$
11.50

27.15

55.09

1.0516

2.40

8.37

13.04

1.248

3.573

1072.45

.221

.311

.419

.492
17.67 ( 13.31)
ETHARYL $85 \%$ ERY-2154-F

FUEL DENSITY $6.480 \mathrm{LB} / \mathrm{GAL}$

$\begin{array}{llllllll}\text { H } .132 & \mathrm{C} & .600 & 0 & .268 & \mathbb{8} .000\end{array}$

NOX HOKIDITY C.F. $\quad .865$

$\begin{array}{cc}2 & 3 \\ \text { STABILIZED } & \text { HOT TRANSIERT } \\ (505-1372 \text { SEC. }) & (-0-505 \text { SEC. }) \\ 866.7 & 506.0 \\ .981 / .990 & .979 / .990 \\ 3.84(6.18) & 3.64(5.86) \\ 326.8(9.25) & 325.6(9.22) \\ .28(.01) & .28(.01) \\ 4724 .(133.8) & 2748 .(77.8)\end{array}$

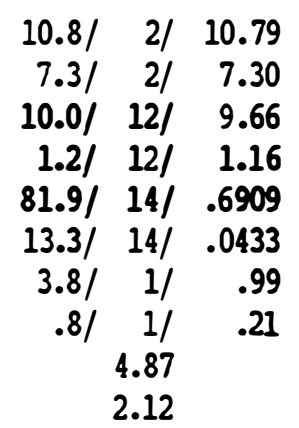

12.6/ 2/ 12.59

$\begin{array}{lll}7.1 / 2 / 2 & 7.10\end{array}$

$12.3 / 12 / 11.89$

$1.1 / 12 / 1.06$

91.7/ 14/ .9104

$13.4 / \quad 14 / \quad .0437$

$5.7 / \quad 1 / 1.48$

$.7 / 1 / \quad .18$

6.29

2.13

13.86

6.01

10.53

.8699

1.31

4.31

1.06

.290

.313

1.295

.954

1592.12

.175

1239.59

.169

.223

.255

.047

.726

.565

$15.56(15.12)$

$18.94(12.42)$

4-BAG COMPOSITE RESOLTS

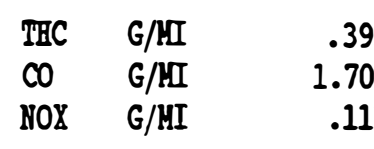

FUEL ECONOMY MPG (L/100K
.393
1.706
.117

117

$16.65(14.13)$

\begin{tabular}{|c|c|c|}
\hline $\mathrm{CH} 4$ & G/KII & .080 \\
\hline MNHC & G/MI & .115 \\
\hline CARBONYI & G/III & .045 \\
\hline ALCOHOL & G/MI & .153 \\
\hline NMOG & G/KI & $.314 \quad(\mathrm{RAF}=1.00)$ \\
\hline
\end{tabular}




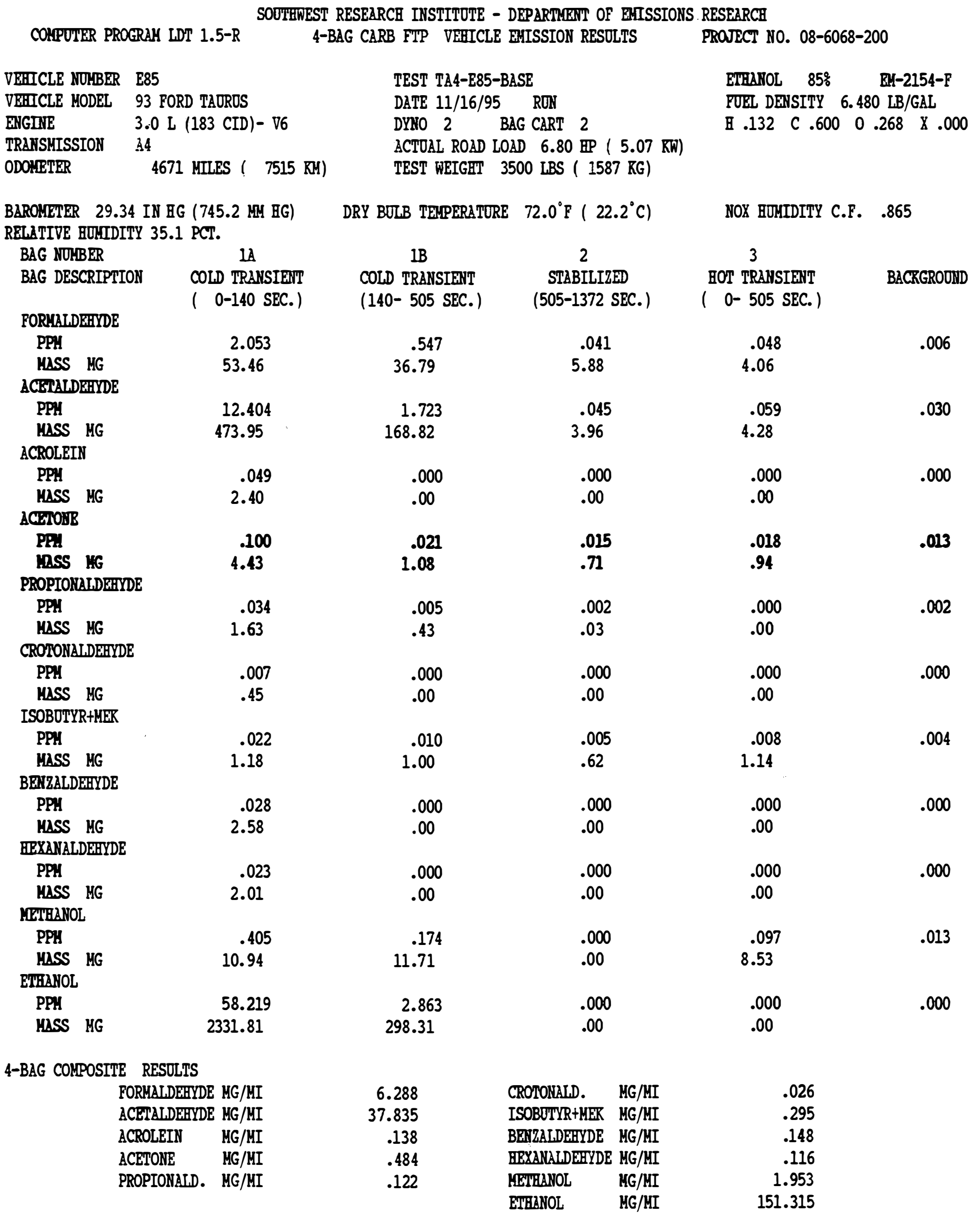


CONPUTER PROGRAH LDT 1.5-R

VEHICLE NOLBER E85

VEHICLE MODEL 93 FORD TAOROS

ENGINE $3.0 \mathrm{~L}$ (183 CID)- V6

TRAKSYISSION A4

ODONEL'ER

4711 KIILES ( 7579 KY)

BAROHETER 29.18 IN HG (741.2 IM HG) RRIATIVE HOHIDITY 53.8 PCT.

BAG NOMBER

BAG DESCRIPTION

RUI TLE SECONDS

DRY/WET CORRECTION FACTOR, SAYP/BACK

HFASURED DISTAHCE YILLRS (RM)

BLOMER FLON RATE SCPII (SCAM)

GAS HETIER FION RATE SCPII (SOA)

TOTAL FLON SCR (SCH)

BC SAYPLE AETER/RANGE/PPH (BAG)

HC BCRGRD HETER/RONGE/PPY

CO SAYPLE KISTER/RATGP/PPH

CO BCSERD VIFTER/RAIGE/PPI

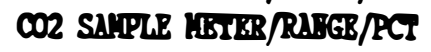

C2 BCRGRD KETER/RAFGE/PCT

NOX SAYPLE HETER/RAHGE/PPH (BAG) (D)

FOX BCR GRD METER/RANGE/PPY

CB4 SAYPLE PPH (1.160)

CB4 BCRGRD PPH

DILOTION FACTOR

HC CONCENTRATION PPH

CO CONCENTRATION PPH

$\mathrm{CO} 2$ CONCENTRATION PCT

NOX CONCENITRATION PPH

CH4 CONCENTRATION PPH

RIHC CONCENITRATION PPH

$\begin{array}{ll}\text { THC } & \text { HASS GRAYS } \\ \text { CO } & \text { MASS GRAYS } \\ \text { CO2 } & \text { MASS GRAYS } \\ \text { NOX } & \text { HASS GRAYS } \\ \text { CH4 } & \text { MASS GRAYS } \\ \text { LIHC } & \text { HASS GRAYS (FID) } \\ \text { FOEL } & \text { MASS KG }\end{array}$

FUEL ECONOHY IPG (L/10ORM)

4-BAG COMPOSITE RESOLTS
TRST TA4-E85-18ER

DATE 11/17/95 RON

DWNO 2 BAGCART 2

ACIOAL ROAD LOAD $6.80 \mathrm{HP}$ ( $5.07 \mathrm{KW}$ )

TEST WEIGET 3500 LBS ( 1587 RG)
DRY BOLB TERPERATORE $73.0^{\circ} \mathrm{F}\left(22.8^{\circ} \mathrm{C}\right)$

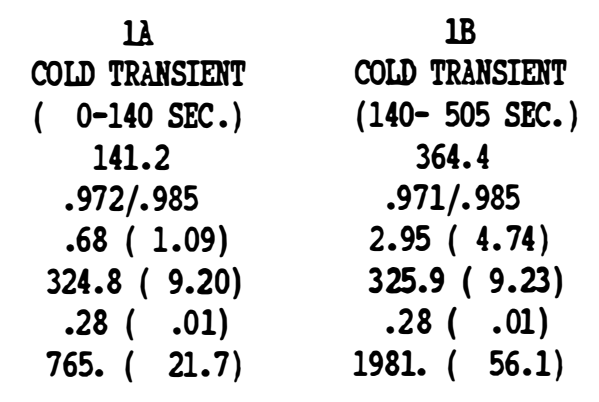

$20.6 / \quad 2 / \quad 20.59$

$4.5 / 2 / \quad 4.50$

$9.7 / \quad 12 / \quad 9.37$

$.8 / \quad 12 / \quad .77$

93.3/ $14 / \quad .9534$

$12.8 / 14 / \quad .0414$

$63.6 / 1 / 16.09$

$.3 / \quad 1 / \quad .08$

14.47

2.26

13.23

16.43

8.30

.9151

16.02

12.38

2.07

.212

.209

363.04

.640

.179

.026

.166

$12.01(19.58)$
$92.0 / \quad 1 / \quad 9.26$

42.6/ 1/ 4.29

12.2/ 12/ 11.79

$.7 / \quad 12 / \quad .68$

$58.8 / 1 / 1.0816$

2.6/ $1 / 2.0482$

$.5 / 1 / \quad .13$

$.4 / 1 / 10$

5.39

2.21

11.68

5.34

10.68

1.0375

.04

3.37

1.43

.182

.698

1065.53

.004

.126

.046

.485

$17.84(13.19)$
GASOLINE $85 \%$

FUEL DENSITY 6.480 LB/GAL

$\begin{array}{llllllllll}\text { H } .132 & \text { C } & .600 & 0 & .268 & \times & .000\end{array}$

NOX HOMIDITY C.F. .964

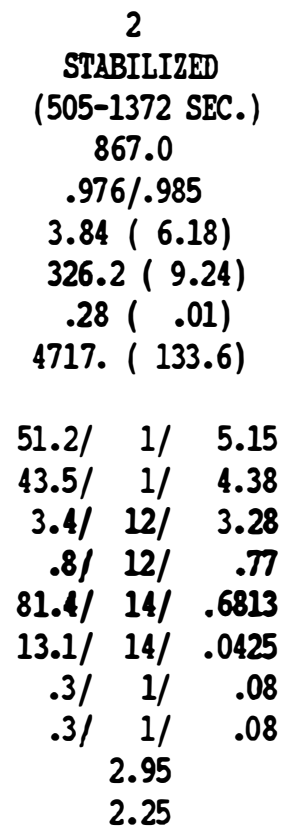

\subsection{5}

1.01

2.45

.6411

.00

.82

.05
.089
.382
1567.97
.001
.073
.004
.714

$15.81(14.88)$

$55.0 / \quad 1 / 5.54$

$43.5 / \quad 1 / 4.38$

$4.5 / 12 / \quad 4.34$

$1.2 / 12 / 1.16$

$91.5 / 14 / .9052$

$13.3 / \quad 14 / \quad .0433$

$2.5 / \quad 1 / \quad .65$

$.3 / \quad 1 / \quad .08$

3.15

2.25

13.96

1.47

3.12

.8651

.58

1.06

.25

.072

.281

1223.13

.082

.054

.011

.557

19.18 ( 12.27) $\begin{array}{lll}\text { THC } & \text { G/MI } & .040 \\ \text { CO } & \text { G/MI } & .125 \\ \text { NOX } & \text { G/MI } & .044\end{array}$

PUEL ECONOMY MPG (L/100KM) 16.76 (14.03)

$\begin{array}{lrl}\text { CH4 } & \text { G/MI } & .032 \\ \text { NHHC } & \text { G/MI } & .006 \\ \text { CARBONYL G/MI } & .003 \\ \text { ALCOHOL } & \text { G/MI } & .000 \\ \text { NMOG } & \text { G/MI } & .009 \quad(R A P=1.00)\end{array}$


SOUTHWEST RESEARCH INSTITOTE - DEPARTYETIT OF EMISSIONS RESEARCH

COSPOTER PROGRAY LDT 1.5-R 4-BAG CARB FTP VEHICLE EMISSION RESULTS

PROSECT NO. 08-6068-200

$\begin{array}{ll}\text { VEHICLE NOMBER } & \text { E85 } \\ \text { VERICLE MODEL } & 93 \text { PORD TAOROS } \\ \text { ENGINE } & 3.0 \text { L (183 CID)- V6 } \\ \text { TRAHSHISSION } & \text { A4 } \\ \text { ODONEIERR } & 4711 \text { HILES ( } 7579 \text { KM) }\end{array}$

BAROKETER 29.18 IN HG (741.2 WM BG) RRLATIVE HULIDITY 53.8 PCT.

BAG NOKBER

BAG DESCRIPTION

IA
COLD TRANSIENT
$(0-140$ SEC. $)$

PORLALDERYDE

PPH

HASS HG

ACETALDERYDE

PPII

HASS HG

ACROLEIN

PPI

HASS HG

ACEIOHE

PRI

IR.SS IIG

PROPIOLALDERYDE

PPH

HASS HG

CROTONALDEHYDE

PPII

HASS HG

ISOBUTYR+ KER

PPY

HASS HG

BERZALDERYDE

PPH

HASS MG

HEXANALLEEHYDE

PPY

HASS HG

METHANOL

PPY

HASS HG

ETHANOL

PPH $\quad .040$

HaSS MG

.192

5.05

.020

.55

.000

.00

.023

.97

.000

.00

.000

.00

.000

.00

.000

.00

.000

.00

.000

.00

.81
TEST TA4-E85-18RR

DATE $11 / 17 / 95$ RON

DWNO 2 BAG CART 2

ACTOAL ROAD LOAD $6.80 \mathrm{BP}$ ( $5.07 \mathrm{KW}$ )

TEST WEIGHT 3500 LBS ( 1587 KG)
DRY BULB TERPERATORE $73.0^{\circ} \mathrm{P}\left(22.8^{\circ} \mathrm{C}\right)$

GASOLINE 85\% BRI-2154-P

PUEL DENSITY $6.480 \mathrm{LB} / \mathrm{GAL}$

$\begin{array}{llllllll}\text { H } .132 & \mathrm{C} & .600 & 0 & .268 & \times & .000\end{array}$

NOX HOMIDITY C.P. .964

\begin{tabular}{|c|c|c|c|}
\hline $\begin{array}{c}\text { IB } \\
\text { COLD TRANSIENT } \\
(140-505 \text { SEC. })\end{array}$ & $\begin{array}{c}2 \\
\text { STABILIZED } \\
(505-1372 \text { SEC. })\end{array}$ & $\begin{array}{c}3 \\
\text { HOT TRANSIENTT } \\
(\quad 0-505 \text { SEC. })\end{array}$ & BACKGRODND \\
\hline $\begin{array}{l}.088 \\
6.01\end{array}$ & $\begin{array}{l}.056 \\
9.08\end{array}$ & $\begin{array}{l}.059 \\
5.58\end{array}$ & .000 \\
\hline .012 & .007 & .009 & .006 \\
\hline .62 & .41 & .48 & \\
\hline $\begin{array}{l}.000 \\
.00\end{array}$ & $\begin{array}{l}.000 \\
.00\end{array}$ & $\begin{array}{l}.000 \\
.00\end{array}$ & .000 \\
\hline $\begin{array}{l}.014 \\
1.33\end{array}$ & $\begin{array}{l}.003 \\
.00\end{array}$ & $\begin{array}{l}.005 \\
.36\end{array}$ & .004 \\
\hline $\begin{array}{l}.000 \\
.00\end{array}$ & $\begin{array}{l}.002 \\
.22\end{array}$ & $\begin{array}{l}.003 \\
.38\end{array}$ & .001 \\
\hline $\begin{array}{l}.000 \\
.00\end{array}$ & $\begin{array}{l}.000 \\
.00\end{array}$ & $\begin{array}{l}.000 \\
.00\end{array}$ & .000 \\
\hline $\begin{array}{l}.000 \\
.02\end{array}$ & $\begin{array}{l}.000 \\
.00\end{array}$ & $\begin{array}{l}.000 \\
.00\end{array}$ & .000 \\
\hline $\begin{array}{l}.000 \\
.00\end{array}$ & $\begin{array}{l}.000 \\
.00\end{array}$ & $\begin{array}{l}.000 \\
.00\end{array}$ & .000 \\
\hline $\begin{array}{l}.000 \\
.00\end{array}$ & $\begin{array}{l}.000 \\
.00\end{array}$ & $\begin{array}{l}.000 \\
.00\end{array}$ & .000 \\
\hline $\begin{array}{l}.000 \\
.00\end{array}$ & $\begin{array}{l}.026 \\
.90\end{array}$ & $\begin{array}{l}.000 \\
.00\end{array}$ & .022 \\
\hline $\begin{array}{c}.034 \\
1.47\end{array}$ & $\begin{array}{l}.021 \\
.28\end{array}$ & $\begin{array}{l}.014 \\
.00\end{array}$ & .021 \\
\hline
\end{tabular}

.034
1.47

4-BAG CONPOSITE RESOLTS

FORYALDEHYDE MG/MI

ACETALDEHYDE MG/MI

ACROLEIN MG/MI

2.279

.159

.000

.160

PROPIONALD. MG/MI

.058

$\begin{array}{lll}\text { CROTONALD. } & \text { HG/MI } & .000 \\ \text { ISOBUTYR+KER } & \text { MG/MI } & .001 \\ \text { BEMTALDEHYDE } & \text { HG/MI } & .000 \\ \text { HRXANALDEHYYDE HG/MI } & .000 \\ \text { METHANOL } & \text { HG/MI } & .120 \\ \text { ETHANOL } & \text { MG/MI } & .169\end{array}$




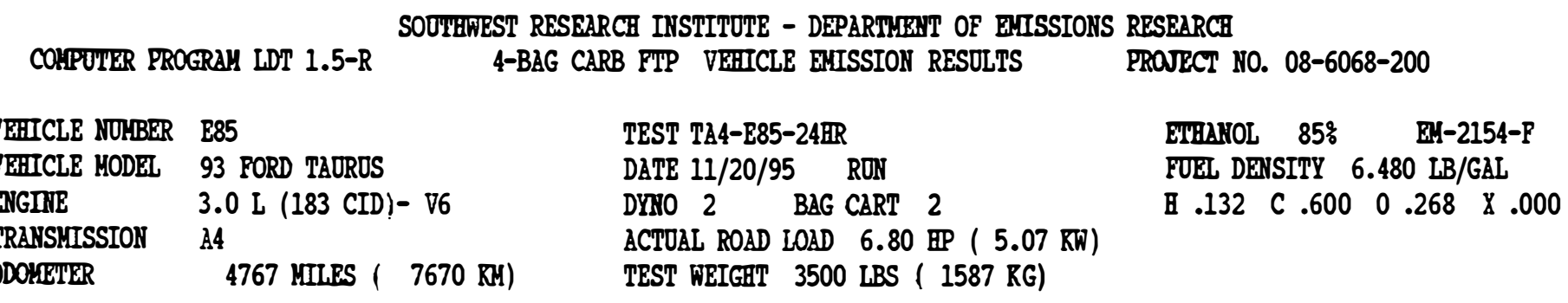

BARONEITER 29.35 IN HG (745.5 MM HG) DRY BOLB TEMPERATORE $74.0^{\circ} \mathrm{P}\left(23.3^{\circ} \mathrm{C}\right)$ RETLATIVE HUIIDITY 50.7 PCT.

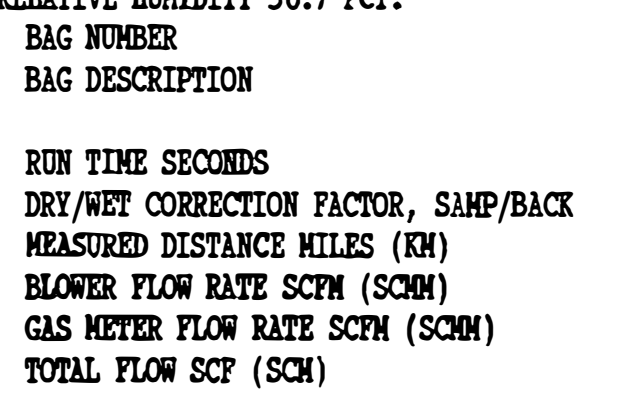

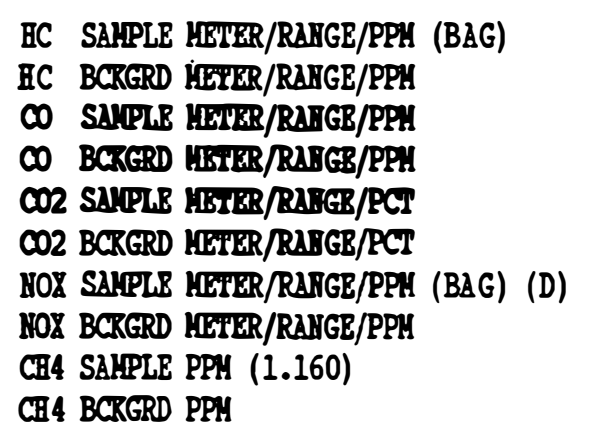

$\begin{array}{cc}\text { 1A } & \text { 1B } \\ \text { COLD TRANSIENT } & \text { COLD TRANSIENT } \\ (0-140 \text { SEC. }) & (140-505 \text { SEC. }) \\ 140.0 & 365.0 \\ .972 / .985 & .971 / .985 \\ .68(1.09) & 2.96(4.75) \\ 321.6(9.11) & 321.6(9.11) \\ .28(.01) & .29(.01) \\ 751 .(21.3) & 1958 .(55.5)\end{array}$

$\begin{array}{rrrrrr}24.5 / & 2 / & 24.49 & 9.9 / & 2 / & 9.89 \\ 6.4 / & 2 / & 6.40 & 6.0 / & 2 / & 6.00 \\ 27.2 / & 12 / & 26.41 & 6.5 / & 12 / & 6.28 \\ 2.2 / & 12 / & 2.12 & 1.4 / & 12 / & 1.35 \\ 54.4 / & 1 / & .9992 & 60.1 / & 1 / & 1.1060 \\ 2.8 / & 1 / & .0519 & 2.7 / & 1 / & .0500 \\ 63.7 / & 1 / & 16.12 & .7 / & 1 / & .18 \\ .6 / & 1 / & .16 & .5 / & 1 / & .13 \\ & 14.83 & & & 5.10 & \\ & 2.43 & & & 2.36 & \end{array}$

DILOTION FACTOR

BC CONCENTRATTON PPH

CO CONCENIRATION PPH

$\mathrm{CO2}$ CONCENTRATION PCT

NOX CONCENTRATTON PPM

CH4 CONCENTRATION PPH

NUIRC CONCENIRATION PPM

$\begin{array}{ll}\text { THC } & \text { MASS GRAHS } \\ \text { CO } & \text { MASS GRAMS } \\ \text { CO2 } & \text { MASS GRAHS } \\ \text { HOX } & \text { MASS GRAHS } \\ \text { CH4 } & \text { MASS GRAHS } \\ \text { NNHC } & \text { MASS GRAHS (FID) } \\ \text { FOEL } & \text { MASS RG } \\ \text { POEL ECONOHY MPG (L/100RM }\end{array}$

$\begin{array}{rr}12.60 & 11.42 \\ 18.60 & 4.42 \\ 23.44 & 4.80 \\ .9514 & 1.0603 \\ 15.97 & .06 \\ 12.59 & 2.95 \\ 4.02 & .99 \\ & \\ .233 & .148 \\ .581 & .310 \\ 370.48 & 1076.61 \\ .620 & .006 \\ .179 & .109 \\ .049 & .032 \\ .169 & .490 \\ 11.74(20.04) & 17.72(13.28)\end{array}$

NOX HOKIDITY C.F. .954

$\begin{array}{cc}2 & 3 \\ \text { STABILIZED } & \text { BOT TRANSIENT } \\ (505-1372 \text { SEC. }) & (0-505 \text { SEC. }) \\ 867.4 & 505.1 \\ .976 / .985 & .973 / .985 \\ 3.86(6.22) & 3.62(5.83) \\ 324.9(9.20) & 324.4(9.19) \\ .28(.01) & .28(.01) \\ 4701 .(133.1) & 2733 .(77.4)\end{array}$

4-BAG COIPOSITE RESOLTS

\begin{tabular}{|c|c|c|c|c|c|c|}
\hline THC & G/YI & .034 & & CH4 & G/HI & .026 \\
\hline $\mathrm{CO}$ & G/MI & .124 & & NMBC & G/MI & .005 \\
\hline NOX & G/HI & .044 & & $\begin{array}{l}\text { CARBONYL } \\
\text { ALCOBOL }\end{array}$ & $\begin{array}{l}\mathrm{G} / \mathrm{MI} \\
\mathrm{G} / \mathrm{HI}\end{array}$ & $\begin{array}{l}.002 \\
.000\end{array}$ \\
\hline FURा & Гону & 00RM) & $16.67(14.12)$ & NMEOG & G/HI & $.008 \quad(R A P=1.00)$ \\
\hline
\end{tabular}


SOUTHWEST RESEARCH INSTITOTE - DEPARTHEIT OF FISSTONS RESPARCH

COIPUITER PROGRAM LDT 1.5-R 4-BAG CARB FIP VEHICLE EMISSION RESOLTS PROSECT NO. 08-6068-200

\begin{tabular}{|c|c|c|}
\hline VEHICLE NOSBER & B85 & TEST TA4-E85-24HR \\
\hline VEHICLE MODEL & 93 FORD TAOROS & DATE $11 / 20 / 95$ \\
\hline ENGINE & $3.0 \mathrm{~L}(183 \mathrm{CID})-\mathrm{V6}$ & BAG CART 2 \\
\hline TRANSKISSION & A4 & ACTOAL ROAD LOAD $6.80 \mathrm{EP}$ ( $5.07 \mathrm{KW}$ ) \\
\hline ODONETER & 4767 KILES ( $7670 \mathrm{KM})$ & TEST WEIGHT 3500 LBS ( 1587 RG) \\
\hline
\end{tabular}

BAROMETER 29.35 IN HG (745.5 MM HG) DRY BOLB TERPERATORE $74.0^{\circ} \mathrm{F}\left(23.3^{\circ} \mathrm{C}\right)$ RELLTIVE HOIIDITY 50.7 PCT.

\begin{tabular}{|c|c|}
\hline RAG NTIRPP & \\
\hline 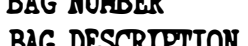 & IA \\
\hline BAG DESCKULIUN & ( 0-140 SEC.) \\
\hline PORYALDEHYDE & \\
\hline PPH & .157 \\
\hline MASS KG & 3.91 \\
\hline ACETATDEHYDE & \\
\hline PPI & .034 \\
\hline MASS MG & 1.02 \\
\hline ACROLETH & \\
\hline PPI & .000 \\
\hline MASS MG & .00 \\
\hline ACSTOIB & \\
\hline PP: & .000 \\
\hline DISS KG & .00 \\
\hline PROPIOKAIDEEIXDE & \\
\hline PPI & .000 \\
\hline MASS MG & .00 \\
\hline CROTONALDEEYDE & \\
\hline PPI & .000 \\
\hline MASS MG & .00 \\
\hline ISOBOTYR+MER & \\
\hline PPH & .000 \\
\hline MASS HG & .00 \\
\hline BERZALDEHYDE & \\
\hline PPH & .000 \\
\hline MASS MG & .00 \\
\hline HEXANALDEAYYDE & \\
\hline PPH & .000 \\
\hline MASS KG & .00 \\
\hline MELHANOL & \\
\hline PPH & .000 \\
\hline MASS HG & .00 \\
\hline ETHANOL & \\
\hline PPY & .000 \\
\hline MASS KG & .00 \\
\hline
\end{tabular}

4-BAG CORPOSITE RESOLTS

\begin{tabular}{|c|c|c|}
\hline FORYALDEHYDE & HG/MI & 1.727 \\
\hline ACETALDEHYDE & HG/MI & .214 \\
\hline ACROLEIN , & MG/MI & .024 \\
\hline ACETONE & MG/KI & .042 \\
\hline PROPIONALD. & MG/MI & .023 \\
\hline
\end{tabular}

ETHANOL 85\% ER-2154-P PUEL DENSITY $6.480 \mathrm{LB} / \mathrm{GAL}$

स $.132 \quad C .600 \quad 0 \quad .268 \quad \times \quad .000$

HOX HOMIDITY C.F. .954

\begin{tabular}{|c|c|c|c|}
\hline $\begin{array}{c}\text { 1B } \\
\text { COLD TRANSIENT } \\
\text { (140- 505 SEC.) }\end{array}$ & $\begin{array}{c}2 \\
\text { STABILIZED } \\
\text { (505-1372 SEC.) }\end{array}$ & $\begin{array}{c}3 \\
\text { HOT TRANSIENT } \\
(\quad 0-505 \text { SEC. })\end{array}$ & BACKGRODND \\
\hline $\begin{array}{c}.062 \\
3.79\end{array}$ & $\begin{array}{l}.050 \\
7.13\end{array}$ & $\begin{array}{l}.052 \\
4.37\end{array}$ & .006 \\
\hline .023 & .008 & .009 & .007 \\
\hline 1.58 & .31 & .32 & \\
\hline .003 & .000 & .000 & .000 \\
\hline .42 & .00 & .00 & \\
\hline .007 & .002 & .002 & .003 \\
\hline .67 & .03 & .00 & \\
\hline .000 & .001 & .000 & .000 \\
\hline .00 & .17 & .00 & \\
\hline .000 & .000 & .000 & .000 \\
\hline .00 & .00 & .00 & \\
\hline .002 & .000 & .000 & .000 \\
\hline .22 & .00 & .06 & \\
\hline .000 & .000 & .000 & .000 \\
\hline .00 & .00 & .00 & \\
\hline .000 & .000 & .000 & .000 \\
\hline .00 & .00 & .00 & \\
\hline .000 & .000 & .037 & .018 \\
\hline .00 & .00 & 1.96 & \\
\hline .025 & .015 & .032 & .018 \\
\hline .85 & .00 & 2.08 & \\
\hline
\end{tabular}




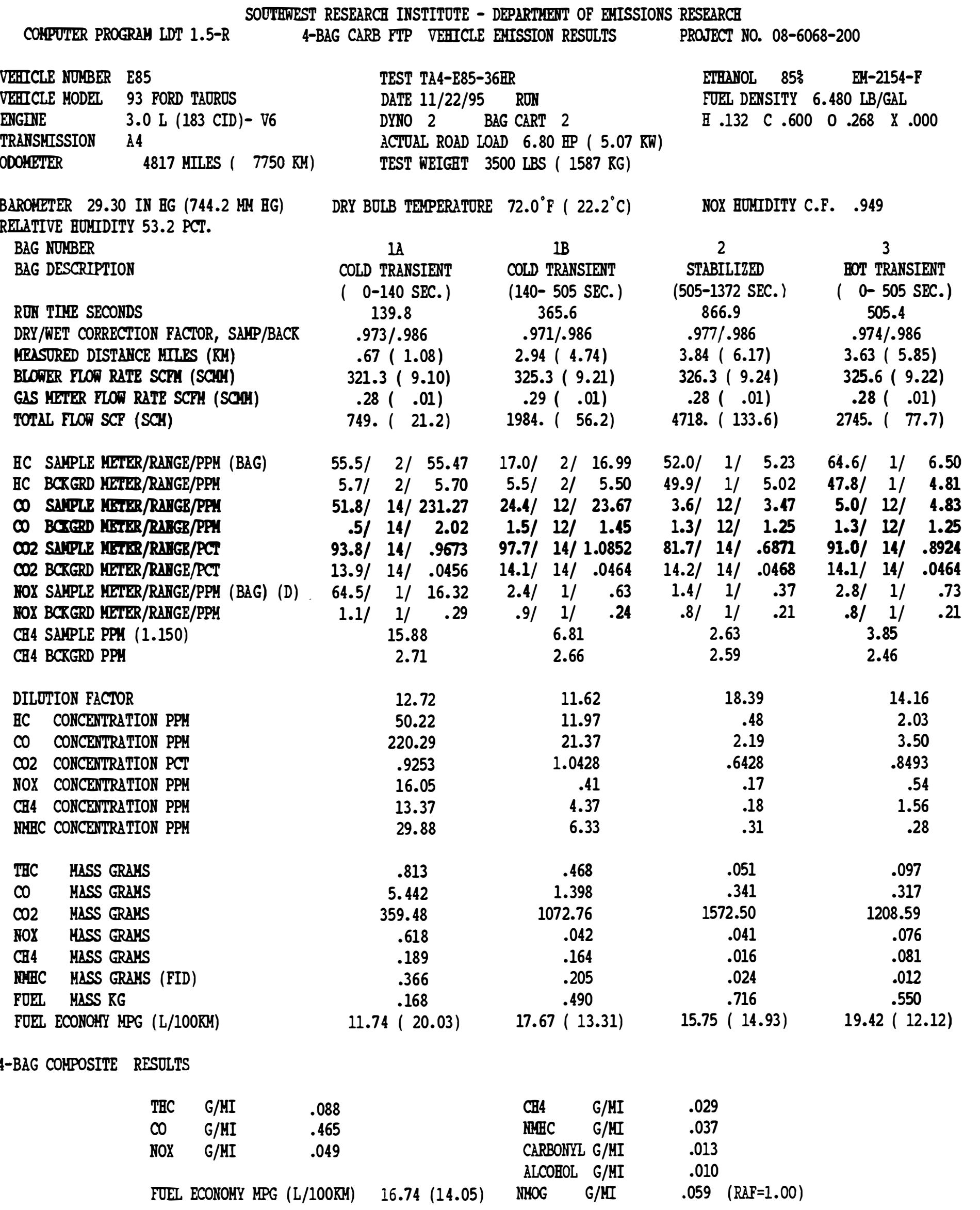


SOUTHWEST RESEARCH INSTITOTE - DEPARTMENT OF EMISSIONS RESEARCH

CONPUTER PROGRAY LDT 1.5-R 4-BAG CARB FTP VEHICLE EMISSION RESOLTS PROJECT NO. 08-6068-200

VEHICLE NOKBER E85

VBRICLE HODEL 93 FORD TAOROS

ENGINE $\quad 3.0 \mathrm{~L}(183 \mathrm{CID})-\mathrm{V} 6$

TRANSMSSSION A4

ODOIEIIER 4817 MILES ( 7750 KM)
TEST TA4-E85-36HR

DATE 11/22/95 RON

DWN 2 BAG CART 2

ACTOAL ROAD LOAD 6.80 HP ( 5.07 KW)

TEST NEIGHT 3500 LBS ( 1587 RG)

BARONETER 29.30 IN HG (744.2 IM BG) DRY BOLB TERPERATORE $72.0^{\circ} \mathrm{F}\left(22.2^{\circ} \mathrm{C}\right)$ RERLATIVE HOMIDITY 53.2 PCT.

\begin{tabular}{|c|c|c|c|c|}
\hline BAG NOIBER & $1 \mathrm{~A}$ & $1 B$ & 2 & 3 \\
\hline BAG DESCRIPTION & $\begin{array}{l}\text { COLD TRANSIENT } \\
(0-140 \text { SEC. })\end{array}$ & $\begin{array}{l}\text { COLD TRANSIERT } \\
(140 \text { - } 505 \text { SEC. })\end{array}$ & $\begin{array}{c}\text { STABILIZED } \\
(505-1372 \text { SEC.) }\end{array}$ & $\begin{array}{l}\text { HOT TRANSI } \\
\left(\begin{array}{c}0-505 \mathrm{~S}\end{array}\right.\end{array}$ \\
\hline \multicolumn{5}{|l|}{ FORYALDEHIDE } \\
\hline PPH & .220 & .079 & .038 & .030 \\
\hline MASS MG & 5.64 & 5.27 & 5.94 & 2.75 \\
\hline \multicolumn{5}{|l|}{ ACEIAIDERYDE } \\
\hline PPI & 3.146 & .536 & .009 & .009 \\
\hline MASS MG & 118.80 & 53.12 & 1.02 & .52 \\
\hline \multicolumn{5}{|l|}{ ACROLEDY } \\
\hline PPH & .000 & .000 & .000 & .000 \\
\hline MASS MG & .00 & .00 & .00 & .00 \\
\hline \multicolumn{5}{|l|}{ ACGIOIB } \\
\hline PPY. & .030 & .000 & .013 & .002 \\
\hline R.SS IIG & 1.39 & .00 & 3.36 & .03 \\
\hline \multicolumn{5}{|l|}{ PBOPIORAILDEHIDE } \\
\hline PPH & .000 & .000 & .000 & .000 \\
\hline NASS MG & .00 & .00 & .00 & .00 \\
\hline \multicolumn{5}{|l|}{ CROTONALDEHYDE } \\
\hline PPH & .000 & .000 & .000 & .000 \\
\hline MASS MG & .00 & .00 & .00 & .00 \\
\hline \multicolumn{5}{|l|}{ ISOBOTYR+MER } \\
\hline PPH & .000 & .000 & .000 & .000 \\
\hline MASS MG & .00 & .00 & .00 & .00 \\
\hline \multicolumn{5}{|l|}{ BEIIZALDEHYDE } \\
\hline PPI & .073 & .000 & .000 & .000 \\
\hline MASS MG & 6.64 & .00 & .00 & .00 \\
\hline \multicolumn{5}{|l|}{ EBXXNALLDEHIDE } \\
\hline PPH & .000 & .000 & .000 & .000 \\
\hline NASS MG & .00 & .00 & .00 & .00 \\
\hline \multicolumn{5}{|l|}{ ME'HAANOL } \\
\hline PPY & .000 & .000 & .000 & .000 \\
\hline MASS HG & .00 & .00 & .00 & .00 \\
\hline \multicolumn{5}{|l|}{ ETHANOL } \\
\hline PPH & 3.208 & .416 & .000 & .000 \\
\hline MASS MG & 125.92 & 40.94 & .00 & .00 \\
\hline
\end{tabular}

ELHANOL $85 \% \quad$ EM-2154-F

FUEL DENSITY $6.480 \mathrm{LB} / \mathrm{GAL}$

В .132 C .600 $0.268 \times .000$

NOX HOMIDITY C.F. $\quad .949$

3

505 SEC.)

.030

.001

.009

.005

.000

.00

.000

.002

.002

.000

.000

.000

.000

.000

.000

.000

.000

000

.000

.014

.00

.000

.027

4-BAG COMPOSITE RESOLTS

$\begin{array}{lrr}\text { FORULALDEHYDE } & \text { MG/MI } & 1.635 \\ \text { ACETALDEHYDE } & \text { MG/MI } & 10.096 \\ \text { ACROLEIN } & \text { MG/MI } & .000 \\ \text { ACETONE } & \text { MG/MI } & .533 \\ \text { PROPIONALD. } & \text { MG/MI } & .000\end{array}$

$\begin{array}{ll}\text { CROTONALD. } & \text { MG/MI } \\ \text { ISOBOTYR+LERR } & \text { MG/MI } \\ \text { BENZALDEHYDE } & \text { MG/MI } \\ \text { HEXANALDEHYYE } & \text { MG/MI } \\ \text { METHANOL } & \text { MG/MI } \\ \text { ETHANOL } & \text { MG/MI }\end{array}$ 
SOUTHINEST RESEARCH INSTITUTE - DEPARTHEYT OF EYISSIONS RESEARCH

COIPUTER PROGRAM LDT 1.5-R 4-BAG CARB FTP VEHICLE EMISSION RESOLTS

PROSRCT NO. 08-6068-200

VEHICLE NOIBER E85

VEHICLE HODEL 93 FORD TAOROS

ENGINE $3.0 \mathrm{~L}$ (183 CID)- 76

TRANSYISSTON A4

ODOHETER $\quad 4874$ MILES ( 7842 KM)

BAROHETER 29.17 IN HG (740.9 WM HG) RELATIVE HORIDITY 53.8 PCT.

BAG NOIBER

BAG DESCRIPTION

RON TIRE SECONDS

DRY/WET CORRECTION FACTOR, SAYP/BACR

LEASURED DISTANCE RILRS (KM)

BLOWIR FLON RATE SCPII (SOM)

GAS HETER FLON RATE SCPI (SCAM)

TOTAL FLOT SCP (SCH)

HC SAYPLE HETER/RANGE/PPM (BAG)

HC BCKGRD KETER/RANGE/PPM

CO SAIPLE IIEIER/RAIGB/PPI

CO BCKGRD IESTER/RABER/PPI

CO2 SAYPLE LENER/RNIEB/PCT

CO2 BCRGRD HETER/RAIGE/PCT

NOX SAYPLE KLTIER/RANGE/PPM (BAG) (D)

NOX BCKGRD HETER/RANGE/PPH

CH4 SAYPLE PPH (1.150)

CH4 BCRERD PPH

DILOTION FACTOR

BC CONCENTRATION PPH

CO COACENTRATION PPH

$\mathrm{CO} 2$ CONCENTRATTON PCT

NOX CONCENTRATTON PPM

CH4 CONCENTRATTON PPM

MNRC CONCENTRATTON PPM

THC MASS GRAYS

CO MASS GRAYS

CO2 MASS GRAYS

NOX MASS GRAYS

CH4 MASS GRAYS

MUAC MASS GRAYS (FID)

PUEL MASS RG

FUEL ECONOHY MPG (L/100KM)
TEST TA4-E85-36ERC

DATE 12/ 1/95 RON

DYNO 2 BAG CART 2

ACTOAL ROAD LOAD $6.80 \mathrm{EP}(5.07 \mathrm{KW})$

TEST WEIGHT 3500 LBS ( 1587 KG)
ETHAMOL 85\% EMI-2154-F

FUEL DENSITY 6.480 LB/GAL

$\begin{array}{lllllllll}\text { H } .132 & \text { C } & .600 & 0 & .268 & \times & .000\end{array}$

NOX HORIDITY C.F. .964

DRY BOLB TEYPERATORE $73.0^{\circ} \mathrm{F}\left(22.8^{\circ} \mathrm{C}\right)$

$$
\begin{array}{cc}
\text { IA } & \text { IB } \\
\text { COLD TRANSIENT } & \text { COLD TRAHSIENT } \\
(0-140 \text { SEC. }) & (140-505 \text { SEC. }) \\
140.2 & 365.4 \\
.973 / .985 & .970 / .985 \\
.68(1.09) & 2.95(4.75) \\
319.1(9.04) & 322.2(9.13) \\
.27(.01) & .29(.01) \\
746 .(21.1) & 1964 .(55.6)
\end{array}
$$

$\begin{array}{rrrrrr}19.9 / & 3 / & 198.56 & 18.0 / & 2 / & 17.99 \\ .8 / & 3 / & 7.98 & 7.2 / & 2 / & 7.20 \\ 89.1 / & 1 / & 918.32 & 19.8 / & 12 / & 19.18 \\ .3 / & 1 / & 2.10 & 1.4 / & 12 / & 1.35 \\ 91.2 / & 14 / & .8975 & 59.4 / & 1 / & 1.0928 \\ 13.7 / & 14 / & .0448 & 2.7 / & 1 / & .0500 \\ 29.5 / & 2 / & 29.60 & 3.4 / & 1 / & .89 \\ .4 / & 2 / & .40 & 1.1 / & 1 / & .29 \\ & 17.58 & & & 7.07 & \\ & 2.85 & & & 2.83 & \end{array}$

12.62

191.21

881.41

.8562

29.23

14.96

99.80

3.820

21.685

331.28

1.139

.211

1.216

.170

$11.73(20.05)$
11.54

11.42

17.15

1.0471

.62

4.49

5.31

$$
\begin{gathered}
2 \\
\text { STABILIZED } \\
(505-1372 \text { SEC. }) \\
866.8 \\
.976 / .985 \\
3.85(6.20) \\
323.9(9.17) \\
.28(.01) \\
4684 .(132.6)
\end{gathered}
$$

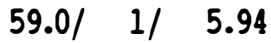

$58.21 \quad 1 / 5.86$

$3.4 / \quad 12 / 3.28$

$1.1 / 12 / 1.06$

81.6/ 14/ .6851

$14.0 / 14 / .0460$

.456

1.110

1066.38

.064

.166

.170

.486

17.85 ( 13.18)

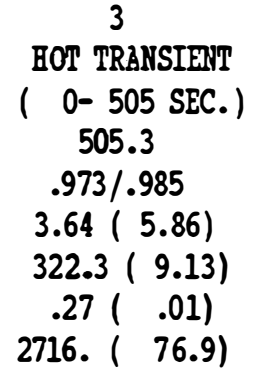

HOT TRANSIENT

( 0- 505 SEC.) 505.3

$.973 / .985$

$3.64(5.86)$

$322.3(9.13)$

.27 ( .01)

2716. ( 76.9)

$\begin{array}{lll}.9 / & 1 / & .24\end{array}$

$.9 / \quad 1 / \quad .24$

2.92

2.71

18.44

.40

2.19

.6416

.01

.35

$-.01$

$\begin{array}{lll}67.9 / \quad 1 / & 6.84\end{array}$

$55.2 / \quad 1 / 5.56$

$5.2 / \quad 12 / \quad 5.02$

$1.2 / 12 / 1.16$

91.5/ 14/ .9052

$14.1 / 14 / .0464$

$3.7 / \quad 1 / \quad .96$

$.8 / \quad 1 / \quad .21$

4.05

2.81

13.96

1.68

3.77

.8622

.77

1.44

$-.01$

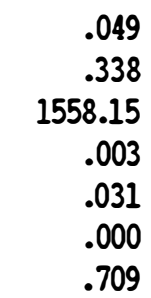

.080

.338

1214.25

.109

.074

.000

.553

$15.97(14.73)$

$19.36(12.15)$

4-BAG COMPOSITE RESULTS

$\begin{array}{llr}\text { THC } & \text { G/MI } & .258 \\ \text { CO } & \text { G/MI } & 1.380 \\ \text { NOX } & \text { G/MI } & .078\end{array}$

FUEL ECONOMY MPG (L/100RM) 16.88 (13.94)

$\begin{array}{lrl}\text { CH4 } & \text { G/MI } & .031 \\ \text { MIHC } & \text { G/NI } & .080 \\ \text { CARBONYL G/MI } & .034 \\ \text { ALCOHOL } & \text { G/HI } & .113 \\ \text { NMOG } & \text { G/MI } & .227 \quad(R A F=1.00)\end{array}$




\section{SOUTHWRST RESEARCH INSTITOTE - DEPARTMENTT OF EMISSTONS RESEARCH}

COIPUTER PROGRAH LDT 1.5-R 4-BAG CARB FTP VEHICLE EMISSION RESOLTS

PRQSECT NO. 08-6068-200

\begin{tabular}{ll} 
VEHICLE NOMBER & E85 \\
VEHICLE HODEL & 93 FORD TAOROS \\
ENGINE & $3.0 \mathrm{~L}$ (183 CID)- 66 \\
TRANSHISSION & A4 \\
ODONETER & \multicolumn{1}{c}{4874 MILES ( 7842 KM) }
\end{tabular}

BAROHE'IER 29.17 IN HG (740.9 WM HG) RELATIVE HORIDITY 53.8 PCT.

BAG NOIBER

BAG DESCRIPTION

FORHALDEHYDE

PPY

HASS MG

ACETALDERYYDE

PPYI

HASS HG

ACROLEIN

PPH

HASS HG

ACETOIIE

PFE

lass IIG

PROPIONALDEHYDE

PPII

HASS HG

CROTONALDEHYDE

PPH

MASS MG

ISOBOTYR+MER

PPH

HASS HG

BERZALDEHYDE

PPY
NASS HG

HEXANALDEHYDE

PPH

HASS HG

METERANOL

PPH $\quad .526$

HASS HG $\quad 14.07$

ETHANOL

PPH

HASS MG
$1 \mathrm{~A}$

\section{COLD TRANSIENTT}

( 0-140 SEC.)

\subsection{7}

34.97

12.043

453.40

.085

4.08

.107

5.20

.062

3.10

.000

.00

.000

.00

.000

.00

.000

.00

.526

47.692

1877.87
TEST TA4-E85-36HRC

DATE 12/ 1/95 RON

DYNO 2 BAG CART 2

ACTOAL ROAD LOAD $6.80 \mathrm{EP}$ ( $5.07 \mathrm{~kW})$

TEST WETEHT 3500 LBS ( 1587 KG)
ETHANOL 85\% 표-2154-F FUEL DENSITY $6.480 \mathrm{LB} / \mathrm{GAL}$

$\begin{array}{llllllllll}\text { B } .132 & \text { C } & .600 & 0 & 0.268 & \& & .000\end{array}$

NOX HOMIDITY C.F. .964

DRY BULB TERPERATORE $73.0^{\circ} \mathrm{F}\left(22.8^{\circ} \mathrm{C}\right)$ 3

COLD TRANSIENT STABILIZED $\quad$ HOT TRANSIENT

(140- 505 SEC.)

(505-1372 SEC.)

( 0- 505 SEC.)

BACKGROOND

.039

.028

.006

.112

5.46

2.09

.007

.481

.009

.011

.52

.000

.000

.00

.000

.00

.000

.00

.003

.48

11.51

.000

.000

.000

.000

.00

.00

.00

.000

.00

.000

.000

.00

.000

.000

.000

.000

.00

.000

.000

.00

.000

.00

.000

.000

.000

.000

.00

.013

.035

.011

.023

1.09

.046

.028

4-BAG COKPOSITE RESOLTS

FORMALDEFYDE MG/MI

ACETALDEHYDE MG/MI

ACROLEIN MG/MI

ACETONE $\quad \mathrm{GG} / \mathrm{MI}$

PROPIONALD. HG/MI
3.311

28.842

.235

1.863

.178
63.09

.032

1.10

2.77

\begin{abstract}
CROTONALD. MG/MI
ISOBOTYR+MER MG/MI

BENZALDEHYDE MG/MI

HEXANALDEFYDE HG/HI

METHANOL MG/MI

ETHANOL MG/MI
\end{abstract}

.000

.000

.000

.000

.987

111.852 


\section{REPORT DOCUMENTATION PAGE}

Form Approved OMB NO. 0704-0188

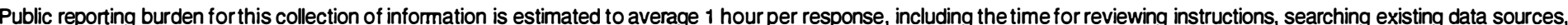

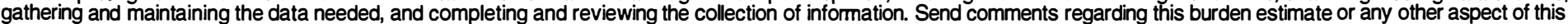

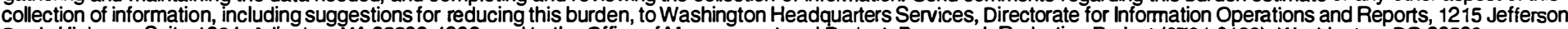

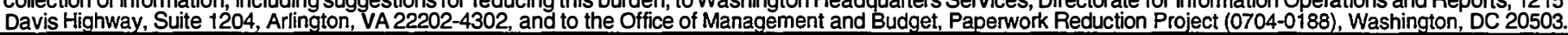
1. AGENCY USE ONLY (Leave blank)
2. REPORT DATE
3. REPORT TYPE AND DATES COVERED
April 1998
Subcontract report

4. TITLE AND SUBTITLE

Development of a Dedicated Ethanol Ultra-Low-Emissions Vehicle (ULEV): Phase 3 Report

6. AUTHOR(S)

L. Dodge, T. Callahan, D. Leone, D. Naegeli, K. Shouse, L. Smith, and K. Whitney

7. PERFORMING ORGANIZATION NAME(S) AND ADDRESS(ES)

Southwest Research Institute

6220 Culebra Road

San Antonio, TX 78238-5166

\section{SPONSORING/MONITORING AGENCY NAME(S) AND ADDRESS(ES)}

National Renewable Energy Laboratory

1617 Cole Boulevard

Golden, CO 80401-3393

\section{SUPPLEMENTARY NOTES}

\section{2a. DISTRIBUTION/AVAILABILITY STATEMENT}

National Technical Information Service

U.S. Department of Commerce

5285 Port Royal Road

Springfield, VA 22161

\section{FUNDING NUMBERS}

(C) YAW-3-12243-01

(TA) FU702130

\section{ABSTRACT (Maximum 200 words)}

The objective of the 3.5-year project discussed in this report was to develop a commercially competitive vehicle powered by ethanol (or an ethanol blend) that can meet California's ultra-low-emissions vehicle (ULEV) standards and equivalent corporate average fuel economy (CAFE) energy efficiency for a light-duty passenger car application. This particular report summarizes the third phase of the project, which lasted 12 months. Emissions tests were conducted with advanced aftertreatment devices on one of the two, almost identical, test vehicles, a 1993 Ford Taurus flexible-fuel vehicle. The report also covers tests on the engine removed from the second Taurus vehicle. This engine was modified for an increased compression ratio, fitted with air-assist injectors, and included an advanced engine control system with modelbased control.

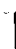

\section{SUBJECT TERMS}

Alternative fuels, ultra-low-emissions vehicles (ULEVs), emissions

1
8. PERFORMING ORGANIZATION REPORT NUMBER

10. SPONSORING/MONITORING AGENCY REPORT NUMBER

NRELSR-540-24225 12b. DISTRIBUTION CODE

UC-1504

\section{SECURITY CLASSIFICATION OF THIS PAGE}

\section{SECURITY CLASSIFICATION} OF REPORT

\section{SECURITY CLASSIFICATION} OF ABSTRACT
15. NUMBER OF PAGES

45

16. PRICE CODE

-

20. LIMITATION OF ABSTRACT
Standard Form 298 (Rev. 2-89) Prescribed by ANSI Std. Z39-18 298-102 